\title{
SIMULAÇÃO DE ESCOAMENTO EM MICROBACIA HIDROGRÁFICA UTILIZANDO SISTEMAS DE INFORMAÇÕES GEOGRÁFICAS E DE MODELAGEM HIDROLÓGICA
}

\section{EDER JOAO POZZEBON}

Engenheiro Agrônomo

Orientador: Prof. Dr. DECIO EUGENIO CRUCIANI

Tese apresentada à Escola Superior de
Agricultura "Luiz de Queiroz",
Universidade de São Paulo, para
obtenção do título de Doutor em
Agronomia, Área de Concentração:
Irrigação e Drenagem.

PIRACICABA

Estado de São Paulo - Brasil

Junho 2000 
Dados Internacionais de Catalogação na Publicação (CIP)

DIVISÃO DE BIBLIOTECA E DOCUMENTAÇÃO - Campus "Luiz de Queiroz"/USP

Pozzebon, Eder João

Simulação de escoamento em microbacia hidrográfica utilizando sistemas de informações geográficas e de modelagem hidrológica / Eder João Pozzebon. - -

Piracicaba, 2000.

234 p. : il.

Tese (doutorado) - Escola Superior de Agricultura Luiz de Queiroz, 2000.

Bibliografia.

1. Escoamento 2. Hidrologia 3. Manejo ambiental 4. Microbacia hidrográfica 5. Modelo matemático 6. SIG (Sistema de computador) 7. Simulação I. Título

CDD 551.483 
A toda a minha família, especialmente aos meus pais Fidélix e Lirba,

Dedico 


\section{AGRADECIMENTOS}

À Escola Superior de Agricultura "Luiz de Queiroz" - USP pela oportunidade de realização do curso.

Ao Conselho Nacional de Desenvolvimento Científico e Tecnológico - CNPq pela concessão da bolsa de estudos.

Ao Prof. Dr. Décio Eugênio Cruciani pela orientação, confiança e entusiasmo diante do tema.

Ao Prof. Dr. Carlos Alberto Vetorazzi pelas sugestões e atenção.

Ao Prof. Dr. Rubens Duarte Coelho pelas sugestões.

Ao Departamento de Ciências Florestais e a Estação Experimental de Itatinga pela cessão de dados básicos referentes a Microbacia do Tinga. Nesse sentido agradeço especialmente ao professor Dr. Valter de Paula Lima.

À pesquisadora científica do IPEF $\operatorname{Dr}^{\mathrm{a}}{ }^{\text {. }}$ Maria José Brito Zakia pela sua colaboração e disponibilidade.

À doutoranda Carla Daniela Câmara pela valiosa ajuda relacionada ao processamento dos dados de precipitação e vazão.

Ao Francisco José de Oliveira Parise pela sua intensa colaboração e disponibilidade em todas as fases do trabalho, sempre com um espírito de colaboração e amizade. Da mesma forma agradeço a Magali Suemi Tanaka, especialmente, pela sua colaboração na fase final.

A todos as pessoas que, com amizade e colaboração, permitiram que tarefas dificeis fossem transformadas em experiências agradáveis. Dessa forma, agradeço ao Amador, Cristina, Diniz, Gláucia, Manuel, Ronalton, Rinaldo, Sebastião, Vanoli e todos os outros colegas da ESALQ.

À minha namorada, Márcia, pelo apoio durante o tempo de dedicação ao curso. 


\section{SUMÁRIO}

Página

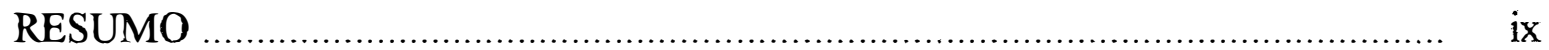

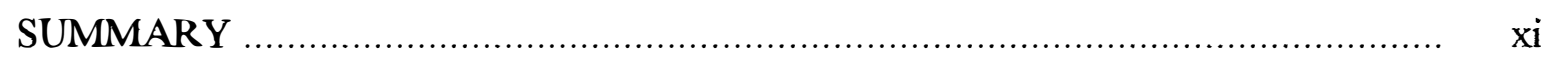

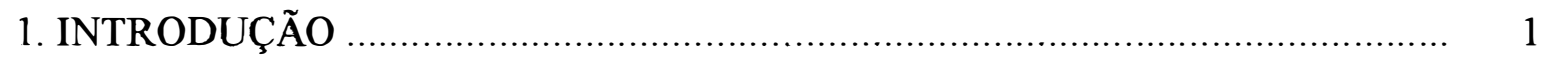

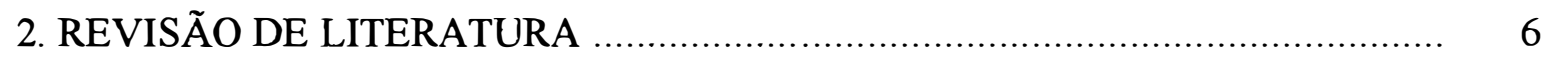

2.1 Hidrologia de bacias hidrográficas e o escoamento ...................................... 6

2.2 Efeitos hidrológicos de mudanças na ocupação das bacias ............................... 14

2.3 Modelagem hidrológica de bacias hidrográficas .................................... 24

2.3.1 Modelos de transformação da chuva em escoamento ................................. 28

2.3.1.1 Modelo do SCS para transformação da chuva em escoamento ..................... 33

2.3.1.1.1 Método do Número da Curva para determinação das perdas iniciais ........... 33

2.3.1.1.1.1 Determinação do número da curva a partir de tabelas ............................ 40

2.3.1.1.1.2 Determinação do número da curva a partir de dados .............................. 46

2.3.1.1.2 Hidrógrafa Sintética Adimensional do SCS para transformação da chuva efetiva em hidrógrafas de escoamento.................................................. 47

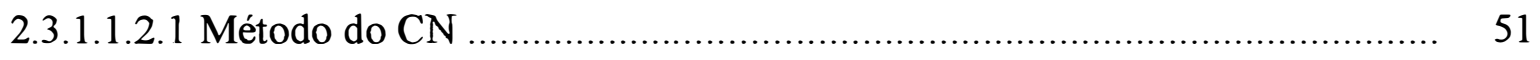

2.3.1.1.2.2 Métodos que consideram a velocidade do fluxo .............................. 52

2.3.1.2 Modelos de propagação em canais .................................................... 56

2.4 Sistemas de Informações Geográficas na modelagem hidrológica ..................... 59

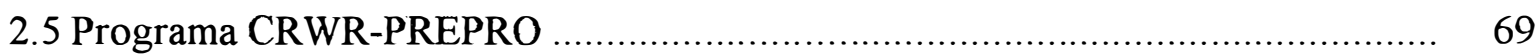

2.5.1 Análise do terreno baseada no formato grade e definição da rede ................... 71

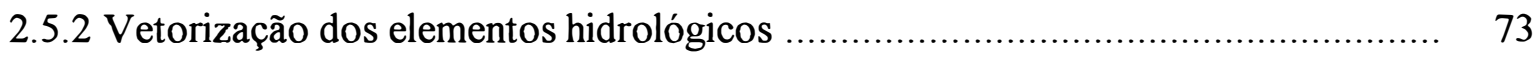

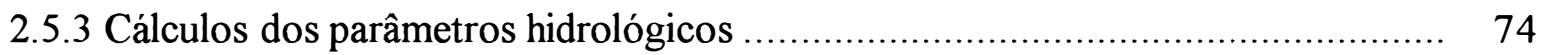

2.5.4 Isolamento de um sub-sistema hidrológico ..................................... 77

2.5.5 Análise topológica e preparação do arquivo de bacia para o HEC-HMS .......... 77 
Página

2.6 Sistema de modelagem hidrológica (Hydrologic Modeling System/HEC-HMS) ... 79

2.6.1 Calibração dos parâmetros ............................................................. 85

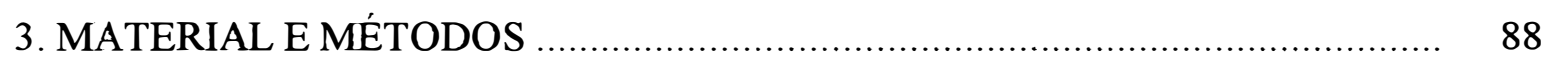

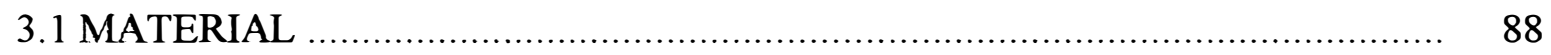

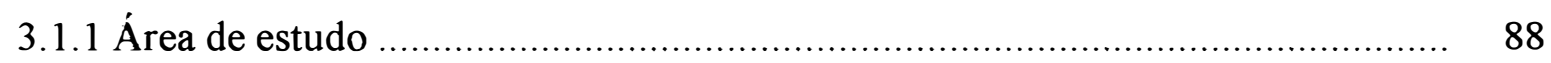

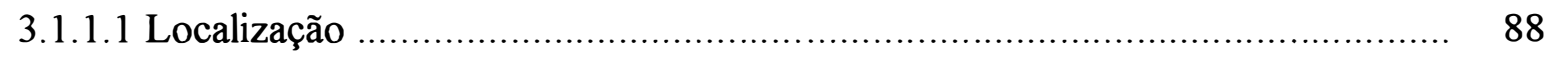

3.1.1.2 Características físicas ............................................................... 88

3.1.1.3 Clima e balanço hídrico ........................................................... 92

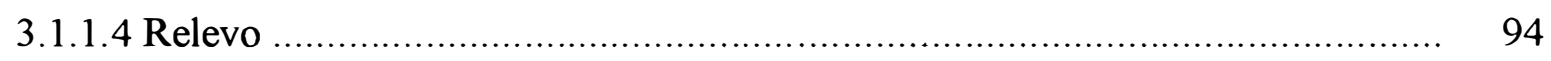

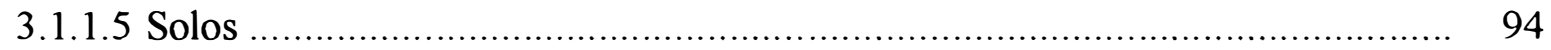

3.1.1.6 Vegetação .................................................................................. 96

3.1.2 Material utilizado como fonte de dados ............................................... 98

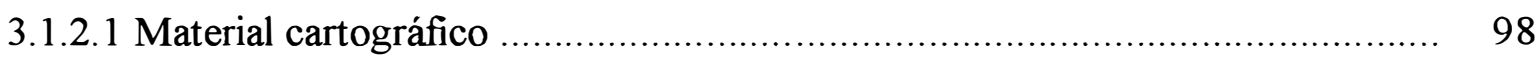

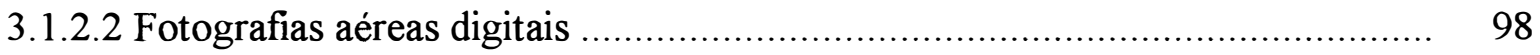

3.1.2.3 Material utilizado como fonte de dados de chuva e vazão ......................... 98

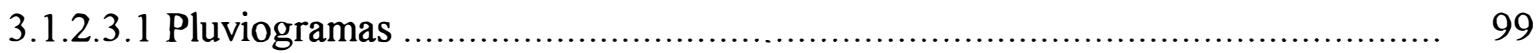

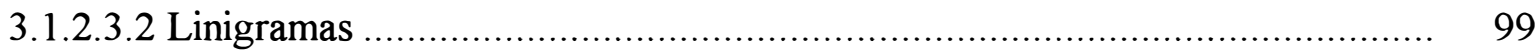

3.1.3 Material utilizado na elaboração do banco de dados e simulação do escoamento 99

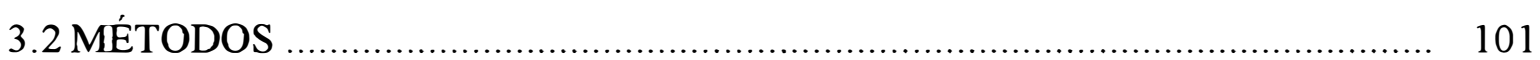

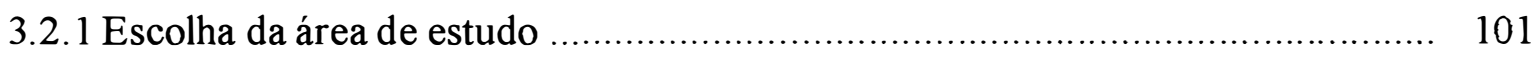

3.2.2 Elaboração do modelo digital do terreno ........................................... 103

3.2.3 Definição e conexão dos elementos hidrológicos pelo CRWR-PREPRO .......... 104

3.2.3.1 Delineamento de canais e sub-bacias ............................................... 104

3.2.3.2 Determinação do número da curva ................................................. 108

3.2.3.3 Isolamento da Microbacia do Tinga ............................................ 110

3.2.3.4 Cálculo dos parâmetros baseados no MDT e hidrológicos ....................... 110

3.2.3.4.1 Cálculo dos parâmetros baseados no MDT ..................................... 111 
Página

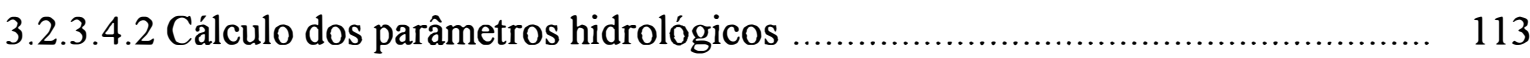

3.2.3.4.2.1 Parâmetros de canais ................................................................. 113

3.2.3.4.2.1.1 Velocidade da água nos canais ................................................... 113

3.2.3.4.2.1.1.1 Método do USDA (Upland Method)_........................................ 113

3.2.3.4.2.1.1.2 Fórmula de Manning ............................................................... 115

3.2.3.4.2.1.2 Tempo de retardamento em canais ............................................... 115

3.2.3.4.2.2 Parâmetros de bacias .................................................................. 117

3.2.3.4.2.2.1 Tempo de retardamento em sub-bacias .......................................... 117

3.2.3.4.2.2.1.1 Método do Número da Curva do SCS ......................................... 117

3.2.3.4.2.2.1.2 Método da Velocidade do SCS ................................................ 118

3.2.3.5 Elaboração do diagrama esquemático e preparação do arquivo de entrada no HEC-HMS

3.2.4 Preparação dos dados de chuva e vazão para entrada no HEC-HMS ............... 118

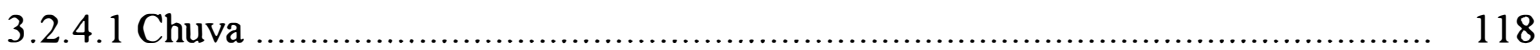

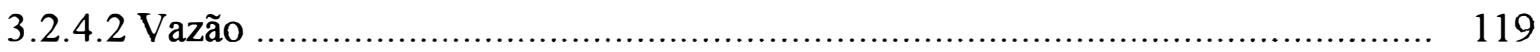

3.2.5 Simulação do escoamento com dados de chuva, vazão e ocupação atual .......... 120

3.2.5.1 Reconstrução do arquivo de bacia no HEC-HMS, entrada de dados de precipitação e especificações de controle ................................................. 120

3.2.5.1.1 Modelo de bacia ........................................................................ 120

3.2.5.1.2 Modelo de precipitação ................................................................ 121

3.2.5.1.3 Especificações de controle .......................................................... 122

3.2.5.2 Caracterização dos eventos de chuva e do escoamento direto ...................... 122

3.2.5.3 Calibração dos parâmetros hidrológicos usando-se dados de precipitaçãovazão

3.2.5.3.1 Determinação dos números da curva a partir de dados observados ............. 122

3.2.5.3.2 Calibração do $\mathrm{CN}$ e das abstrações iniciais ................................................. 123

3.2.5.4 Simulação com os parâmetros calibrados ................................................. 124

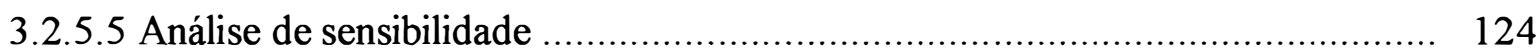


Página

3.2.6 Estabelecimento dos cenários a serem avaliados ................................... 125

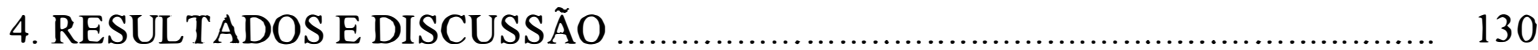

4.1 Elaboração do modelo digital do terreno ............................................. 130

4.2 Definição e conexão dos elementos hidrológicos pelo CRWR-PREPRO ............. 132

4.2.1 Delineamento de canais e sub-bacias ............................................... 132

4.2.2 Determinação do número da curva .................................................... 140

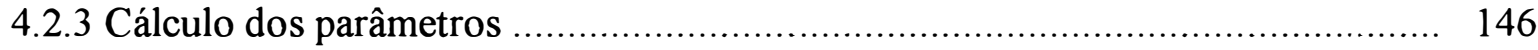

4.2.3. 1 Cálculo dos parâmetros baseados no MDT ......................................... 146

4.2.3.2 Cálculo dos parâmetros hidrológicos ........................................... 152

4.2.3.2.1 Parâmetros de canais ............................................................ 152

4.2.3.2.2 Parâmetros de bacias ............................................................. 155

4.2.4 Elaboração do diagrama esquemático e preparação do arquivo de entrada no 160 HEC-HMS

4.3 Simulação de escoamento com dados observados de chuva, vazão e ocupação 165 atual

4.3.1 Reconstrução do arquivo de bacia no HEC-HMS .................................. 148

4.3.2 Caracterização dos eventos de chuva e do escoamento direto ....................... 167

4.3.3 Calibração dos parâmetros hidrológicos usando-se dados de precipitação-vazão 173

4.3.4 Simulação do escoamento com os parâmetros calibrados ............................ 178

4.3.5 Análise de sensibilidade ........................................................... 189

4.4 Simulação do escoamento sob cenários alternativos de ocupação ..................... 192

4.4.1 Simulação do escoamento sob cenários considerando diferentes zonas de 193 declividade.

4.4.2 Simulação do escoamento sob cenários considerando parte alta e parte baixa.... 202

4.4.3 Considerações complementares 208

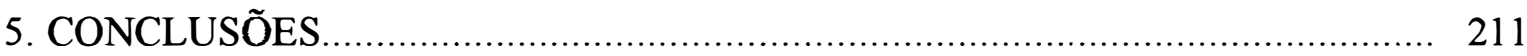

REFERÊNCIAS BIBLIOGRÁFICAS ................................................... 213 


\title{
SIMULAÇÃO DE ESCOAMENTO EM MICROBACIA HIDROGRÁFICA UTILIZANDO SISTEMAS DE INFORMAÇÕES GEOGRÁFICAS E DE MODELAGEM HIDROLÓGICA
}

\author{
Autor: EDER JOAO POZZEBON \\ Orientador: DÉCIO EUGÊNIO CRUCIANI
}

\section{RESUMO}

Com o objetivo de simular o escoamento de água em uma microbacia hidrográfica de 81,7 ha, sob diversos cenários de uso da terra, informações espacializadas foram pré-processadas por meio da extensão CRWR-PREPRO do Sistema de Informações Geográficas (SIG) ArcView. Basicamente, esse pré-processamento, realizado a partir do modelo digital do terreno (MDT), consistiu no delineamento de subbacias e canais e na determinação de uma estrutura interconectada desses elementos hidrológicos e seus parâmetros. O tamanho de célula escolhido para o MDT foi de $10 \mathrm{~m}$ x $10 \mathrm{~m}$, pois, nessa resolução, o delineamento das sub-bacias e canais foi satisfório. Para melhorar o delineamento dos canais nas áreas planas, a rede de drenagem, representada em cartas plani-altimétricas por linhas, foi digitalizada e sobreposta no MDT.

Além do MDT, foi necessária a determinação de mapas de número da curva (CN) do SCS (Serviço de Conservação de Solos dos Estados Unidos) e da velocidade da água na superficie do terreno e nos canais. Os mapas de $\mathrm{CN}$ foram determinados no SIG ArcView por meio da interseção de mapas de solos com mapas de uso da terra, associada às informações de grupo hidrológico, condição hidrológica da superficie e de umidade antecedente.

A seguir, a estrutura de bacia, criada pelo CRWR-PREPRO em formato de arquivo ASCII, foi utilizada no sistema de simulação hidrológica Hydrologic Modeling System (HEC-HMS). Aproveitando a estrutura interconectada, as simulações foram feitas com base no método do número da curva do SCS para determinação do volume de 
escoamento, com base no método da hidrógrafa unitária adimensional do SCS para transformação desse volume em hidrógrafas de cada elemento e finalmente na propagação dessas hidrógrafas em canais. Os parâmetros $\mathrm{CN}$ e abstrações iniciais, foram calibrados para a condição de toda a microbacia ocupada por floresta de eucalipto e mata ciliar ( $8 \%$ ), usando-se eventos observados de chuva e descarga.

As simulações mostraram que as mudanças na ocupação de uma floresta de eucalipto bem manejada para pastagem ou cultivos mal manejados podem aumentar de forma drástica a produção do escoamento direto e a vazão de pico. Mudanças consideráveis na forma das hidrógrafas foram conseguidas simplesmente com a inversão da posição das ocupações dentro da bacia, isto ocorreu pela desincronização dos picos de vazão. A intensidade e o padrão da distribuição temporal das chuvas em interação com a posição da ocupação dentro da microbacia também influenciaram a forma da hidrógrafa. Essas informações, bem como a metodologia empregada, por ser baseada em dados facilmente disponiveis, podem ser usadas no planejamento e manejo de microbacias hidrográficas. 


\title{
RUNNOF SIMULATION WITHIN A SMALL WATERSHED BY GIS AND HYDROLOGIC MODELING SYSTEM
}

\author{
Author: EDER JOAO POZZEBON \\ Adviser: DÉCIO EUGÊNIO CRUCIANI
}

\section{SUMMARY}

With purpose to simulate the runnof in a watershed of 81,7 ha under variate scenarios, spatial informations have been processed by CRWR-PREPRO extension of the ArcView program. Subbasins and channels of whole area were connected in a network of hydrologic elements. A digital elevation model (DEM) was necessary for data processing, thus the SCS Curve Number Method and the runnof velocity in the channels and overland flow. Soil maps, land use, hydrologic soil group and antecedent moisture conditions were analised too. The basin structure processed by the CRWR-PREPRO was introduced in the Hydrologic Modeling System (HEC-HMS). Simulations were carried out by the SCS CN Method in order to determine the volume of runoff and by the SCS Dimensionless Unit Hydrograph. By this procedure a resulting hydrograph was achieved for each scenario.

A satisfactory calibration of the modeling structure was achieved by using local field data of rains and discharges. For the DEM, pixels of $10 \mathrm{~m} \times 10 \mathrm{~m}$ were selected for best resolution. Simulations demonstrated that a change in soil occupation between Eucaliptus and row crops produces a significant change of the hydrograph shape and peak discharge. These results may be used as advisory in planning land use.

The rain pattern as temporal distribution connected with the vegetation distribution within the basin determines the hydrograph shape with high sensitivity. That information may be used as a sound orientation in watershed management. 


\section{INTRODUÇÃO}

A ocupação agrícola no Brasil tem, freqüentemente, se caracterizado por causar grandes distúrbios ambientais. Problemas como erosão do solo, assoreamento de rios, inundações, poluição, falta de água e outros estão intrinsecamente relacionados ao uso inadequado do solo. Além de afetarem a qualidade de vida da população e a sustentabilidade do sistema agrícola, esses problemas representam consideráveis perdas sconômicas.

Visando à sustentabilidade duradoura e considerando a bacia hidrográfica como uma unidade central de interesse para muitos propósitos, um manejo de bacias mais adequado é aquele em que, previamente, são instituídas normas de uso da terra. Tal medida, associada ao desenvolvimento de práticas conservacionistas, resultará no crescimento e manutenção da produtividade dos recursos naturais a longo prazo. Necessariamente, o estabelecimento dessas normas deve se fundamentar em estudos pormenorizados dos efeitos de mudanças nas bacias.

Como todas as atividades realizadas na bacia afetam de alguma forma as relações entre os demais recursos naturais e a água, o planejamento do uso de uma bacia tem que considerar os fatores hidrológicos. Por exemplo, mudanças de uso do solo, que afetam a capacidade de infiltração, a condutividade hidráulica e a capacidade de retenção de água do solo, obrigatoriamente alteram o volume de água escoado. Fica claro, então, que é imprescindível avaliar as conseqüências hidrológicas de ações a serem efetuadas na bacia, tais como a remoção da cobertura vegetal nativa com eventual substituição por culturas ou pastagens e a mudança de sistema do preparo do solo convencional, baseado em arado e grade, para um sistema mais sustentável, como o plantio direto. 
Apesar das relações de causa e efeito entre uso do solo, eventos de chuva e produção de escoamento ainda não estarem totalmente elucidadas, já existem conhecimentos suficientes para estabelecer modelos de simulação e, dessa forma, inferir sobre efeitos das mudanças. Daí, seria possível, definir normas orientadas para o uso adequado do solo, bem como auxiliar no planejamento de ocupação, nos projetos de recuperação de áreas degradadas e na conservação do meio ambiente.

A resposta hidrológica das bacias, variável conforme diferentes ocupações, pode ser avaliada pelo uso de modelos materiais. Neste caso, podem ser usadas as chamadas bacias experimentais, em estudos em uma única bacia ou em bacias pareadas. No entanto, a obtenção experimental de todas as combinações de práticas de manejo, culturas, precipitações e demais fatores, necessários para as avaliações, na prática é impossível. Mesmo para casos simples, apresentam aplicabilidade limitada, e seus custos são proibitivos. Em seu lugar, são utilizados modelos hidrológicos matemáticos, assim chamados por serem abstrações matemáticas que tentam representar as propriedades do sistema. Como esses modelos são simplificações abstraídas da complexidade do mundo real, precisam ser aplicados com critério para que representem os fenômenos de forma a satisfazerem os objetivos aos quais se destinam. Quando isso ocorre eles são uma valiosa ferramenta, pois permitem simular cenários altemativos ou idealizados, nunca antes testados experimentalmente. Os modelos, por serem transcritos para linguagem computacional, também são denominados modelos computacionais.

A determinação do escoamento direto (superficial e sub-superficial) é um aspecto fundamental para estudos referentes ao manejo de bacias, porque é um bom parâmetro de avaliação, quando o interesse for estudar o efeito de ações tomadas em uma microbacia. Tal afirmação é justificada, especialmente, pelo fato do escoamento direto estar altamente associado a problemas de erosão do solo. Para a modelagem do processo transformação da chuva em descarga de bacias, há uma grande variedade de modelos computacionais. Entre tantas classificações, podem ser agrupados em empíricos, conceituais ou teóricos (baseados nos processos fisicos). Podem também ser determinísticos ou probabilísticos, lineares ou não lineares, variantes ou invariantes no tempo, contínuos ou discretos e analíticos ou numéricos. Alguns simulam a partir de 
eventos de chuva, outros continuamente, requerem informações globais (concentradas) ou distribuídas.

Os modelos hidrológicos distribuídos com base nos processos fisicos têm sido construídos sob duas concep̧̧ões. A primeira considera a bacia como um conjunto de reservatórios interconectados, simulando a propagação por meio de várias expressões de descarga e modelos conceituais. Como exemplo, a infiltração determinada pelo Método Green Ampt e o Método da Hidrógrafa Unitária Geomorfológica. A segunda concepção, além de considerar a bacia como um conjunto de volumes de controle, usa, para simular a propagação, um conjunto de equações diferenciais para conservação da massa e momento e modelos que procuram descrever os fenômenos - tais como a equação de Darcy, as equações de Saint-Venant e Manning e as equações para fluxo superficial e em canais abertos. Como exemplo da primeira concepção, é possível citar o Stanford Watershed Model, SLURP e TOPMODEL. Para a segunda, o SHE, IHDM, KINEROS, THALES, HYDROTEL. O Hydrologic Modeling System (HEC-HMS), apesar de ser enquadrado na primeira, pode simular alguns processos por métodos enquadrados na segunda.

Os modelos distribuídos, por comportarem informações espacializadas, são mais exeqüiveis para simular a realidade. Afinal, as propriedades que têm influência nos processos de transformação da chuva em vazão são dotadas de variabilidade espacial. A aplicação desses tipos de modelos tem sido facilitada pelo advento do sensoriamento remoto, dos modelos digitais do terreno (MDT) e dos Sistemas de Informações Geográficas (SIG). Já, os modelos que representam os processos hidrológicos por parâmetros globais, apresentam a vantagem de simplificar a modelagem e diminuir a necessidade de dados. No entanto, certamente há perdas de precisão. Ademais, é possível adotar os modelos semi-distribuídos, onde alguns parâmetros de maior influência são tratados espacialmente, e outros, menos importantes, de forma global. Ganha-se precisão, sem torná-los demasiadamente complexos e com necessidade menor de dados. A manipulação de informações espacializadas pode ser feita pelos SIG's, que apresentam um grande potencial para simulação de fenômenos hidrológicos, como o escoamento. Apesar desse potencial, os SIG's atualmente 
disponíveis não são capazes de realizar as simulações e análises sofisticadas, pois trabalham melhor dados estáticos e discretos. Como os modelos hidrológicos envolvem processos dinâmicos e contínuos, para efetuar as simulações é necessária sua integração com os SIG's.

Assim, com o surgimento de SIG's abertos, o seu uso é possivel como pré-processadores de dados de entrada em modelos e como pós-processadores para melhor apresentação dos resultados de saída. A tendência é que, com o aumento da funcionalidade, os SIG's se tomem um ambiente adequado para a integração de todas as fases do processo de modelagem, ou seja, formação do banco de dados, processamento, análise e visualização dos resultados, sempre numa forma amigável ao usuário. Cabe mencionar que a formação do banco de dados é uma tarefa cara e demorada, portanto, deve ser levada em conta no momento da escolha do modelo.

O Center for Research in Water Resourses (CRWR) da Universidade do Texas, Austin, desenvolveu um pré-processador de dados de entrada para o modelo Hydrologic Modeling System (HEC-HMS). O CRWR-PREPRO é uma sintese de várias aplicações de SIG e modelagem hidrológica desenvolvidas recentemente. Tais avanços possibilitam a determinação dos parâmetros físicos para o HEC-HMS com maior facilidade, tendo a vantagem de ser automática e permitir resultados reproduziveis.

O CRWR-PREPRO cria um arquivo de bacia, em formato ASCI, a partir de planos de informações de SIG. Ele armazena informações hidrológicas, topográficas e topológicas, que serão automaticamente transformadas numa rede esquemática de subbacias e trechos de canais dentro do HEC-HMS. Para cada um desses elementos são calculados parâmetros hidrológicos. Cabe ressaltar que o CRWR-PREPRO não estima parâmetros para todos os modelos suportados pelo HEC-HMS.

O Hydrologic Modeling System (HEC-HMS), que foi desenvolvido pelo Hydrologic Engineering Center (HEC) do U.S. Army Corps of Engineers (USACE), é o sucessor do HEC-1. Embora, esteja em sua versão 2, lançada em 2000, o software já vinha sendo utilizado anteriormente nas versões $1.1,1.0$ e beta. O HEC-HMS é um programa muito flexivel, que permite ao usuário escolher entre diferentes modelos de determinação das perdas, modelos de transformação da chuva efetiva em hidrógrafas, 
bem como diversos modelos de propagação dessas hidrógrafas em canais. Podem ser escolhidos também diversos modelos para a simulação do escoamento básico.

Motivado pela necessidade de entender os efeitos da ocupação de uma bacia na sua resposta hidrológica, esse trabalho teve como objetivo básico desenvolver simulações do processo chuva-escoamento em uma microbacia, para variados cenários alternativos de ocupação do solo e para diferentes padrões de chuva aplicando o sistema de modelagem hidrológica HEC-HMS, associado ao pré-processador de dados em SIG CRWR-PREPRO. Visou, ademais, explorar a possibilidade de determinação de ocupações mais adequadas conforme fins específicos de atividade agrícola e conservação hidrológica. Nas simulações, foram usados modelos suportados pelo HECHMS. Para a determinação do volume de escoamento direto, aplicou-se o Modelo do Número da Curva $(\mathrm{CN})$ do SCS. Para a transformação desse volume em hidrógrafas de descarga, recorreu-se à Hidrógrafa Adimensional do SCS. Para a propagação das hidrógrafas na rede de drenagem abaixo, foi usado um modelo de fluxo em canais chamado de retardamento puro. Estes modelos são classificados como empíricos, concentrados, de parâmetros ajustados e para simulação de eventos de precipitação.

A partir desses objetivos, algumas hipóteses puderam ser formuladas como desdobramento:

1) A produção de escoamento (pico de descarga e volume) é afetada pelo modelo de distribuição temporal da chuva e isso deve influenciar na melhor ocupação do solo da bacia.

2) A disposição das ocupações na microbacia promove mudanças na forma da hidrógrafa, permitindo a escolha daquelas mais adequadas para cada caso.

3) As simulações realizadas com informações espacializadas são mais indicadas, quando comparadas com aquelas feitas com informações concentradas (globais).

4) O programa HMS tem precisão suficiente e necessária para que se possa estabelecer cenários futuros de ocupação de uma microbacia, com a determinação de qual é a mais adequada. 


\section{REVISÃO DE LITERATURA}

\subsection{Hidrologia de bacias hidrográficas e o escoamento}

O ciclo hidrológico, ao ser estudado em sua fase terrestre, tem como elemento fundamental as bacias hidrográficas. Nesse meio, ocorrem processos que podem ser esquematizados de forma simplificada como apresentado na Figura 1. É possível, então, considerar a bacia hidrográfica um sistema onde a precipitação é a entrada e o escoamento, a saída.

A diversidade dos processos que estão envolvidos na hidrologia de bacias hidrográficas possibilitaram o surgimento de várias linhas conceituais. Mediondo \& Tucci (1997), enumeraram alguns dos mais destacados processos de geração do escoamento em bacias, incluindo os que foram descritos ao longo do último século (Tabela 1). Segundo Kobiyama et al. (1998), o atual estágio conceitual da geração de escoamento admite, numa visão distribuída, a possibilidade de coexistir diferentes mecanismos atuando em distintas partes da bacia, com abrangências espaciais dinâmicas. Ademais, independente da abordagem adotada para o estudo da geração de escoamento, seja a hortoniana, a dos processos internos, a hewlett-dunniano e outras, recentemente é perceptível uma significativa mudança de enfoque a favor de uma integração dos processos de forma interdisciplinar e sistêmica.

O escoamento pode ocorrer sob três formas. O superficial é aquela parcela da precipitação que, durante ou após um evento de chuva, flui através da rede de drenagem. Tanto pode ser a água que não infiltrou, como a emergente do solo. Já, o subsuperficial é o volume de água que movimenta-se nas camadas ocupadas pelas raízes. 


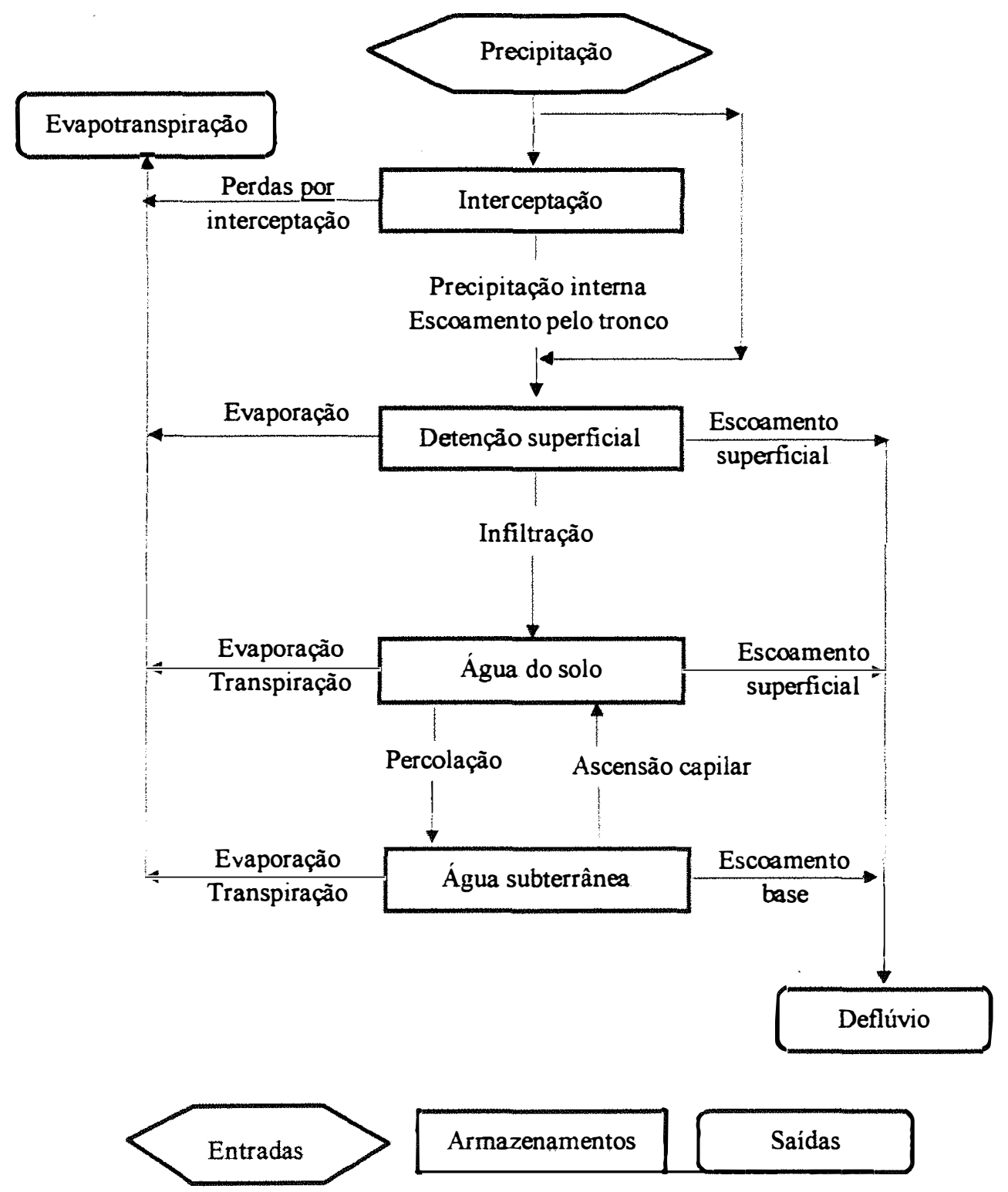

Figura 1 - Representação esquemática dos processos hidrológicos quantitativos em uma bacia (adaptado por Lima, 1993, a partir de Walling, 1980). 
Tabela 1 - Processos de escoamento numa bacia e respectivas linhas conceituais de pesquisa.

\begin{tabular}{ll}
\hline Processos & Linha de pesquisa \\
\hline Escoamento superficial excedente da infiltração & Horton (1933) \\
Escoamentos internos & Hewlett \& Hibbert (1967) \\
& Tsukamoto (1961, 1963) \\
i) Efeito pistão & Ward (1984) \\
ii) Escoamento de retorno & Dunne (1978), Ward (1984) \\
iii) Fluxo de macroporos & Beven \& Germann (1982) \\
iii-1) longitudinais ('piping') & Jones (1971) \\
$\quad$ iii-1-1) gradientes do potencial & Jones (1986) \\
$\quad$ iii-1-2) por interconexão & Dunne \& Black (1970) \\
iii-2) Condutos verticais & Germann (1986) \\
iv) Intumescência da camada saturada & Sklash \& Farlvoden (1979) \\
Escoamento superficial por saturação do solo & Dunne (1978, 1983) \\
Escoamento pela integração dos processos & Kirkby (1988), Grayson et al. \\
& (1992), Wheater et al. (1993)
\end{tabular}

Fonte: Kobiyama et al. (1998)

Está relacionado à ocorrência de fatores como a presença de camadas de impedimento, camadas compactadas em áreas agrícolas (pé-de-arado), a porosidade do solo e a permeabilidade das camadas mais superiores do solo. Por fim, o fluxo subterrâneo é resultante da contribuição do aqüifero.

Ainda, o escoamento pode ser classificado conforme as características de infiltração, transmissão e exfiltração da água no solo. Assim, o fluxo superficial é hortoniano, quando a intensidade de precipitação excede a taxa de infiltração do solo. Comporta-se de acordo com os conceitos da teoria de Horton (1933), primeiro autor a propor o termo infilltração ao processo de entrada e transmissão de água no solo. É mais 
importante em áreas agrícolas com baixa capacidade de infïltração, áreas desérticas e semi-áridas. Cabe mencionar que este tipo de fluxo é determinante para modelar os processos de erosão.

O fluxo superficial hortoniano pode ser direto, quando a intensidade da chuva excede a capacidade de infilltração do solo e atrasado, quando a excede após certo período de tempo. Para a modelagem do fluxo atrasado é necessário representar de modo perfeito o processo de infiltração. Mesmo conseguindo tal feito, persistiriam dois problemas a serem resolvidos (Moore \& Grayson,1991). Um deles envolve a obtenção dos valores de campo para os parâmetros relevantes e o outro a influência da variabilidade espacial da infiltração no escoamento superficial.

Segundo Troendle (1985), o fluxo superficial pode ser decorrente da precipitação na rede de drenagem. Também, de áreas adjacentes que tornam-se saturadas durante os eventos e de áreas potencialmente impermeáveis, tais como estradas, afloramentos rochosos, áreas de empréstimo, entre outros, que comunicam-se diretamente com as áreas saturadas da rede de drenagem. As áreas florestais, raramente, apresentam superficies impermeáveis dotadas de extensão relativamente constante. Em função disso, é justificável a atribuiçăo de valores constantes para estas áreas nas simulações.

A saturação da superfície é favorecida quando existem camadas de impedimento à infiltração e movimentação da água no perfil do solo, de forma que durante eventos de chuva, o solo torna-se rapidamente saturado, com a conseqüente formação de um outro tipo de fluxo superficial chamado de superficial saturado.

No caso do fluxo subsuperfïcial, ele pode ser de chuva ou de saturação. $O$ de chuva é o fluxo laminar que se propaga através dos poros da camada subsuperficial do solo, conforme as menores declividades. Portanto, depende da condutividade hidráulica do solo. Quando esse fluxo converge para determinadas áreas e a capacidade do solo em transmiti-lo é excedida, ocorre a saturação, formando o fluxo saturado. Ele pode chegar à superficie, num processo de exfiltração, a partir daí fluir por essa superficie e/ou infiltrar-se novamente no solo. Nesse processo, conhecido também como escoamento de retomo, fluxo de retorno, ou efeito pistão, cada incremento de 
precipitação à montante implica num deslocamento da água retida à jusante. Se o solo estiver saturado, uma porção equivalente da água que penetra no solo da água aflora. Ao passo que num solo mais seco, ocorre redução grande, mas não linear, do volume que aflora. Coelho Neto (1995) afirmou que o fluxo subsuperficial é predominante em áreas com alta capacidade de infiltração, onde a existência de escoamento superficial é menor, particularmente em regiões úmidas ou florestas.

Já, o fluxo de macroporos é aquele presente nos caminhos preferenciais da água no solo. É caracterizado por respostas mais rápidas e podem ser formados pelas raizes, fissuras, rachaduras e fauna do solo.

Todos os tipos de fluxo juntos, ou seja, o escoamento total, segundo Vilella \& Mattos (1975), sofrem a influência de fatores que facilitam ou prejudicam sua ocorrência. Esses fatores podem ser de natureza climática, relacionados à precipitação, ou de natureza fisiográfica, relacionados às características da bacia.

Com relação aos fatores que influenciam a ocorrência do escoamento, é pertinente afirmar que áreas próximas aos cursos d'água são as que produzem mais fluxo. Afimal, elas recebem contribuição das outras partes da bacia e permanecem continuamente úmidas. Então, quando chove ou já estão saturadas ou saturam-se rapidamente, favorecendo o escoamento. Em épocas chuvosas, observa-se a expansão dessas áreas saturadas, motivo pelo qual são chamadas de áreas variáveis de contribuição (variable source area) ou afluência. As teorias acima foram desenvolvidas na década de 60. Segundo Kobiyama et al. (1998), foi a partir dos trabalhos de engenheiros florestais, referenciando os de Hewlett \& Hibbert (1967), Tsukamoto (1963) e Weyman (1970), que surgiram evidências de que nas partes mais altas das bacias toda a precipitação se infiltrava, aumentando a umidade até o ponto de saturação. A partir daí, a umidade excedente é transmitida para áreas à jusante. Para esses autores, o escoamento direto rápido ocorre somente nas áreas saturadas, principalmente à jusante, próximo à rede de drenagem. Essas áreas saturadas são alimentadas pela chuva ou pelo fluxo subsuperficial de áreas à montante. Além do mais, são variáveis, contraindo-se ou 
expandido-se conforme a precipitação e a contribuição de áreas à montante. Um outro aspecto da teoria é que a chuva absorvida pela bacia é transformada em escoamento subterrâneo, que sai da bacia mais lentamente.

As áreas saturadas, segundo Dunne (1978), são de tamanho variável e muito dinâmicas para cada evento. Uma porção significativa da água é escoada quando um estado próximo à saturação é atingido. $\mathrm{O}$ aumento do potencial de pressão com a profundidade, nos lugares com pequena declividade, facilita a rápida saturação das camadas superfíciais, em decorrência da água que infiltra ou do escoamento subsuperficial, proveniente de áreas acima.

Lima (1989) considerou que as áreas variáveis de contribuição ao fluxo são as mais sensiveis das bacias, uma vez que são as responsáveis pela geração do escoamento direto. Portanto, nos programas de recuperação de matas ciliares, um mapeamento dessas áreas seria muito importante. É cabível acrescentar que indicações da área variável podem ser obtidas pela análise dos hidrogramas de escoamento gerados por uma chuva isolada.

Para estudos do escoamento em bacias, geralmente recorre-se às hidrógrafas, onde os comportamentos do escoamento são melhor visualizados. Tratamse de gráficos que relacionam a vazão ao tempo, em resposta a uma precipitação sobre a bacia. Dependendo da escala de tempo usada, a hidrógrafa pode representar períodos de anos, meses, dias ou apenas um evento de chuva. Por exemplo, a mostrada na Figura 2 é uma hidrógrafa típica decorrente de um evento de chuva. Esta hidrógrafa pode ser separada em componentes.

Sob uma perspectiva genérica, a forma adquirida por esse tipo de gráfico, conforme Tucci (1993), depende da interação de vários fatores, tais como uso da terra, relevo, características edafológicas do solo, umidade do solo antecedente à precipitação, intensidade, duração e distribuição da precipitação sobre a bacia e obras construídas pelo homem. Segundo Hewlett (1981), em terrenos íngremes com solos rasos (menos de 1 m), sob chuvas fortes, são produzidos rápidos picos de vazão, estando florestados ou não. 


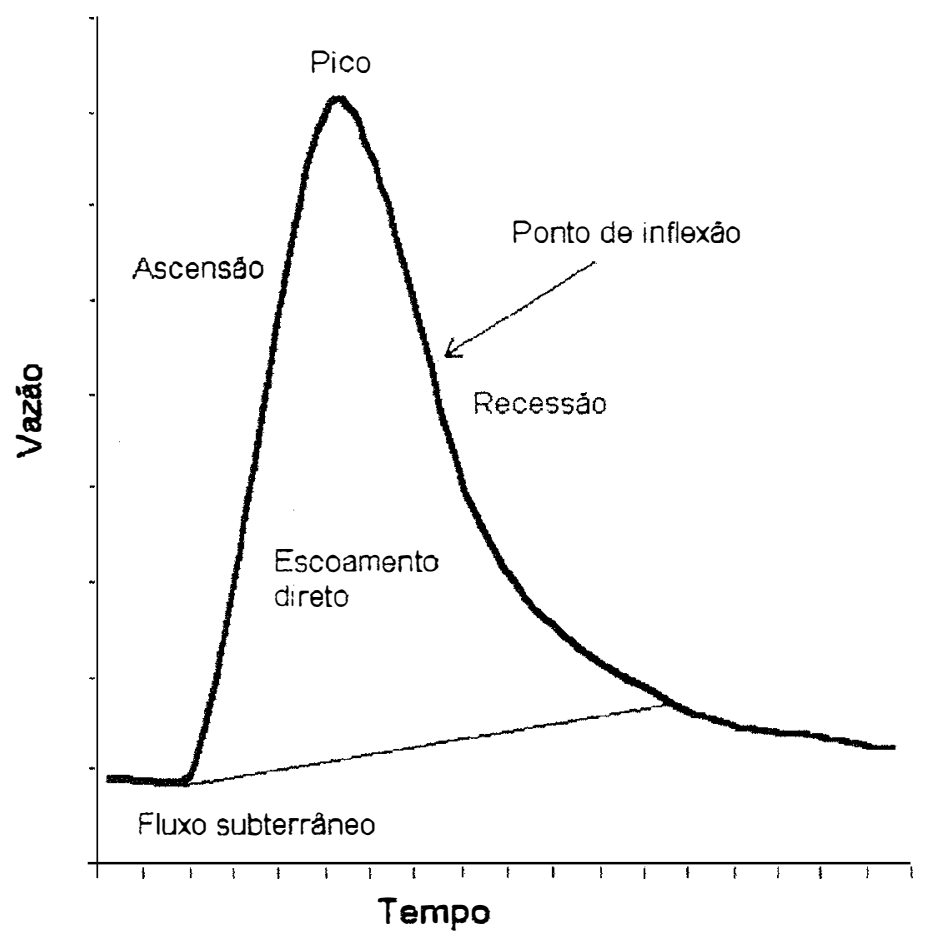

Figura 2 - Hidrógrafa típica com a definição de termos usados na sua descrição.

A parte inicial da hidrógrafa (antes da ascensão) é determinada pelas condições antecedentes, da distribuição da intensidade da chuva, do comprimento hidraúlico da bacia, da declividade do terreno e das condiçòes hidrológicas do solo na porção mais próxima à saída da bacia. Por sua vez, a parte ascendente está sujeita aosmesmos fatores, com a diferença de que se considera toda bacia. Ao passo que a parte da recessão começa quando o fluxo superficial decresce e surge a descarga proveniente da drenagem da água armazenada em canais e áreas planas (ASCE, 1996). Nesta mudança de predomínio dos fluxos superficial e subsuperficial, em hidrógrafas que apresentem forma regular é possivel a identificação do ponto de inflexão. Daí em diante, a recessão decresce exponencialmente até o fluxo básico, onde somente a descarga subterrânea contribui. 
É pertinente elucidar que a recessão da hidrógrafa, especialmente em suas partes mais baixas, representa o fluxo lateral, o fluxo interno na camada superficial do solo e fluxo lateral armazenado nas margens do curso d'água durante os eventos. Esse último decorre da elevação nível d'água do curso.

As porções inicial, ascensão e parte superior da recessão são estimadas, geralmente, recorrendo-se aos procedimentos da hidrógrafa unitária. Já, o restante da recessão é calculado por métodos empíricos ou modelos de fluxo subterrâneo numéricos ou analíticos.

Ainda, com relação à forma da hidrógrafa, pode-se afirmar que as características hidráulicas de uma bacia têm dois efeitos básicos. O primeiro efeito é devido ao tamanho, forma, contribuição hidráulica - o comprimento médio dos caminhos seguidos pela água na superfície - declividade e padrão da bacia. Tais características influenciam no tempo de fluxo superficial, fluxo nos canais, detenção e armazenamento do escoamento em feições superficiais. O segundo efeito decorre da infiltração e detenção na superficie ou outras feições superficiais, interceptação e evapotranspiração pelas plantas e evaporação da superficie de solos. Esses efeitos alteram a estimativa da água de precipitação perdida e escoada para fora da bacia.

Por exemplo, em pequenas bacias, o escoamento ocorre, predominantemente, sobre a superfície do solo, mas também através de drenos com perdas hidráulicas maiores e maior declividade. Já em bacias de grande porte, o processo predominante é o escoamento da água por um canal bem definido, de menor declividade, mas com perdas de carga bem menores (Tucci, 1993).

No estudo de bacias, as hidrógrafas são classificadas em naturais, quando medidas; sintéticas, obtidas pelo uso de parâmetros de bacia e características das chuvas para a simulação de hidrógrafas naturais; unitárias, naturais ou sintéticas, que são a resposta de uma unidade de precipitação efetiva ocorrendo uniformemente sobre toda a bacia em um tempo especificado e, finalmente, adimensionais, que são representações de hidrógrafas pelo uso de taxas de tempo e picos de vazão como unidades (USDA, 1972). 


\subsection{Efeitos hidrológicos de mudanças na ocupação de bacias}

Em seu processo de desenvolvimento, o homem realiza diversos tipos de intervençào na superficie da terra, provocando alterações inevitáveis. Todas atividades que mudam a cobertura vegetal fatalmente influenciam a quantidade e qualidade da água produzida pela bacias hidrográficas. Aliada à cobertura vegetal, a produçào de água também depende em grande parte das caracteristicas do solo, clima e porcentagem da bacia que sofre mudanças. A intensidade dessas mudanças, muitas vezes, afeta de tal forma as caracteristicas da produçào de água, que acaba promovendo catástrofes como inundações, deslizamentos, assoreamento de rios, perda da qualidade biológica e química da água. Por sua vez, tudo isso nào apenas compromete muito a qualidade de vida da populaçào, como também representa perdas econômicas consideráveis.

A despeito do conhecimento adquirido nesses casos extremos, ainda persistem dúvidas referentes ao mecanismo produçào de água e ocupação da superfície do solo e às implicações hidrológicas das mudanças extensivas da cobertura vegetal e seus efeitos a longo prazo. Nesse sentido, Brooks et al. (1991) examinaram quais seriam os efeitos reais ou antecipados da remoçào de florestas sobre o volume e distribuiçào da precipitaçào; até que ponto a produção de água poderia ser manejada através da alteraçào da cobertura vegetal; se a vegetação poderia ser usada para complementar os objetivos de gerenciamento da água e em que extensão os padrões sazonais de descargas seriam alterados pela mudança da cobertura vegetal.

Segundo os mesmos autores, estudos internacionais têm demostrado que a produçào anual de água muda conforme o tipo ou a quantidade de cobertura vegetal. Assim, aumentos na produçào de água ocorrem quando as florestas são cortadas ou raleadas ou a vegetaçào é transformada de espécies com sistema radicular profundo para sistema radicular superfícial ou as espécies com alta capacidade de interceptaçào são substituídas pelas de menor capacidade. Por exemplo, Pilgrim et al. (1982) citados por Brooks et al (1991) relataram que, na Austrália, áreas cobertas com Pinus consomem mais água do que as com eucalipto. Já, Bosch \& Hewlett (1982) revisaram a relaçào entre o aumento na produçào de água e reduções na cobertura vegetal. Os autores 
concluíram que a redução de $10 \%$ da cobertura vegetal de coníferas e eucalipto, florestas decíduas e vegetação arbustiva implicou numa média de aumento de produção de água de $40 \mathrm{~mm}, 25 \mathrm{~mm}$ e $10 \mathrm{~mm}$, respectivamente. Na Austrália, as diferenças anuais entre as duas espécies foram estimadas em 35-100 mm/ano. Em resumo, pode-se afirmar que a redução da cobertura vegetal de florestas promove aumentos da vazão média. Por outro lado, a implantação de florestas diminui a mesma. Quando o desmatamento for menor do que $20 \%$, as constataçòes de mudanças na vazão são dificeis.

Um exemplo de uso de simulação é apresentado a seguir, onde o efeito do corte de uma floresta nas hidrógrafas, foi simulado por Ardis (1973), citado por Jackson (1982), para duas bacias florestadas, utilizando um modelo hidrológico. Os parâmetros do modelo foram mudados para refletir as mudanças do corte da floresta. A Figura 3 apresenta os resultados das simulações para um mesmo evento em uma das bacias, considerando-se o corte de 5\%,50\% e 100\% da floresta. A simulação mostrou que com a redução da floresta, ocorriam maiores picos de vazão e uma fase de recessão da hidrógrafa mais rápida. Deve-se atentar para o fato de que este estudo considerou apenas um evento isolado, onde a importância da parcela evapotranspirada é menor.

Em geral, mudanças de uso da terra que reduzem a evapotranspiração aumentam a produção de água. O processo de evapotranspiração é responsável pelo consumo de grande parte da água que chega na forma de precipitação. Assim, a redução da evapotranspiração pode ser usada para aumentar a produção de água de uma bacia. Segundo Tucci \& Clarke (1998), a retirada da floresta ocasiona um volume evaporado menor, além de promover menor variabilidade da umidade nas camadas mais profundas do solo. Afinal, a floresta apresenta capacidade de retirar água de profundidades superiores a 3,6 m. Já, a vegetação rasteira retira a maior parte da água das camadas menos profundas, em torno de $20 \mathrm{~cm}$.

No entanto, Câmara (1999), estudando na Microbacia do Tinga o efeito do corte raso, encontrou resultados diferentes dos comentados acima. Pela análise da curva de dupla massa entre o total anual de precipitação e o deflúvio, para o período entre setembro de 1991 e agosto de 1998, a autora não verificou mudanças na correlação entre a produção de água e a retirada da cobertura florestal. A autora avaliou que a 


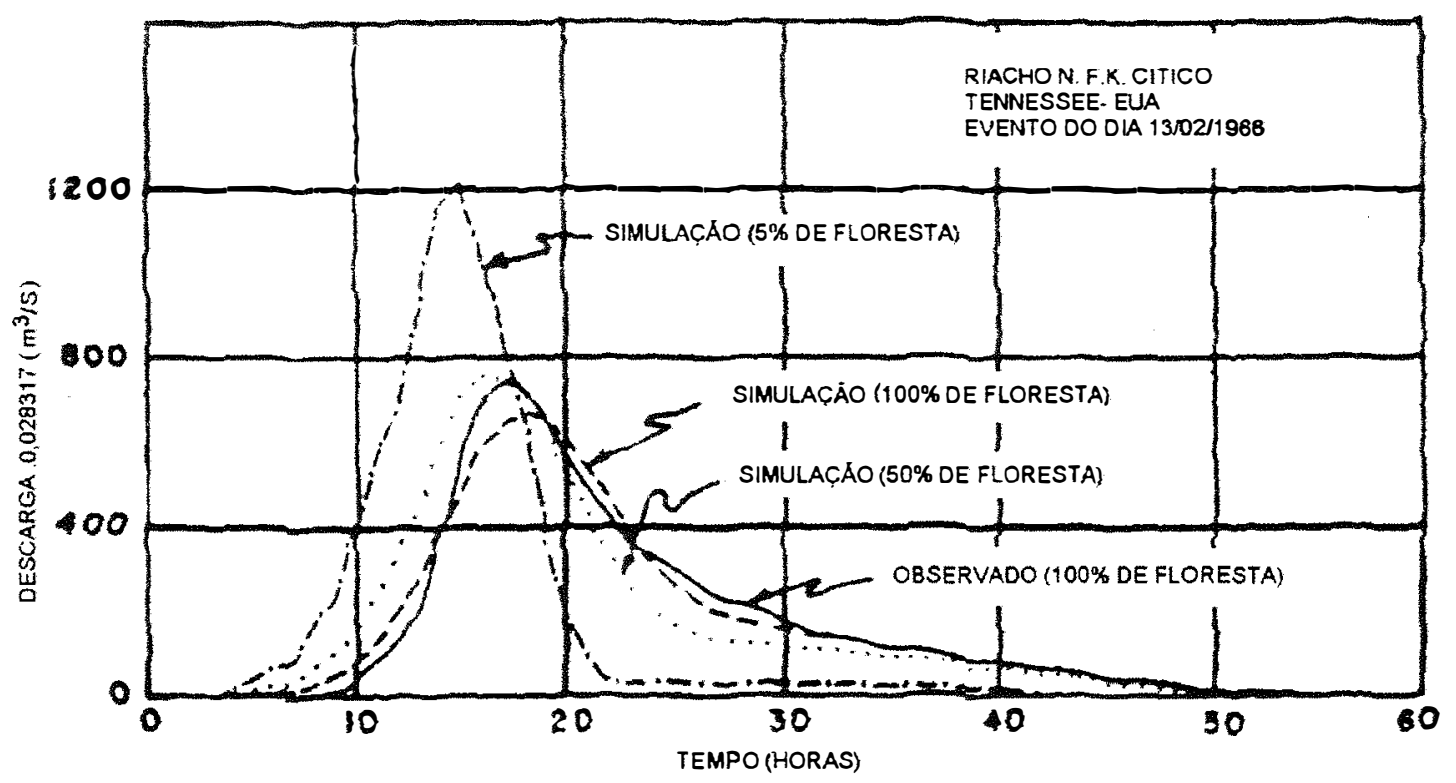

Fonte: Jackson (1982).

Figura 3 - Efeito simulado do corte de floresta na bacia do riacho North Fork Citico Tennessee-EUA, para o evento do dia 13/02/66.

evapotranspiração era de $67 \%$ da precipitação média anual antes do corte raso e $66 \%$ após o corte. Ainda, concluiu que o efeito do corte sobre a produção de água da microbacia foi inferior ao esperado, pois durante o primeiro ano após o corte raso o aumento no deflúvio foi de apenas 1\%. Ainda, Cicco \& Arcova (1998), comparando os fatores de resposta (escoamento direto/precipitação) de 15 microbacias dos E.U.A. e 4 do Brasil, verificaram que a Microbacia do Tinga foi a que apresentou o menor valor, ou seja, foi a microbacia que apresentou a menor proporção da chuva sendo ransformada em escoamento direto. Hewlett (1981) afirmou que o uso do solo tem menos efeito nas descargas do que a profundidade do solo, a textura e a presença de camadas diferenciadas no perfil do solo. Estas propriedades variam conforme a fisiografia do local.

O estado de umidade do perfil do solo é um dos fatores que influencia o volume de escoamento. Em florestas, por apresentarem maior transpiração e maior profundidade de ação das raizes, a depleção da água do solo ocorre mais rapidamente. 
Um exemplo disso foi apresentado por Bruijnzeel (1996) para uma floresta na Costa Rica, onde a depleção da umidade do solo foi muito maior, quando comparado às áreas de clareiras.

Outra função da cobertura vegetal, especialmente em florestas, é interceptar parcialmente a precipitação. A água retida pela parte aérea, posterionnente, é perdida para a atmosfera por evaporação. Como essa água não atinge a superfície do solo, é considerada uma perda na contabilização do escoamento. Além disso, o processo de evapotranspiração diminui, uma vez que a água retida nas folhas o desfavorece. Muitos pesquisadores constataram tal fenòmeno (Rutter, 1968 e Steiner et al., 1983). Dessa forma, assim como não chega água na superficie do solo, também não sai, contrabalançando a quantidade produzida.

$\mathrm{Na}$ literatura, existem resultados contraditórios quanto à capacidade de interceptação pelas coberturas vegetais, mesmo sob ambientes semelhantes. Vários fatores contribuem para isso. Coelho Neto (1995) apontou as características das chuvas, da vegetação - como tipo, forma e densidade como os mais importantes. Clegg (1963), citado pelo autor, obteve o valor extremo de $57 \%$ para $3300 \mathrm{~mm}$ de chuvas anuais numa floresta secundária de Porto Rico. Já, o menor valor observado foi de 5\% para uma precipitação anual de $3800 \mathrm{~mm}$, em uma floresta pré-montanhosa na Costa Rica (McColl, 1970, citado por Coelho Neto, 1995). No Brasil, Coelho Neto et al. (1986) e Miranda (1992) encontrarain $17 \%$ e $24 \%$, respectivamente. O ambiente de estudo foi a Floresta secundária da Tijuca, RJ, relevo montanhoso e precipitação média anual. Lima (1993), revisando na literatura as perdas percentuais por interceptação da precipitação incidente, encontrou valores para florestas de eucalipto - em diversas condições - entre $24 \%$ e 5,3\%, com uma média de 15,7\%. Dos 17 trabalhos enumerados, os maiores valores foram para as florestas adultas e os menores para as com menos de 6 anos. Entretanto, como o próprio autor recomendou, esses valores devem ser considerados apenas como uma primeira aproximação.

Considerando-se um evento isolado, uma chuva de $5 \mathrm{~mm}$ será evaporada diretamente das copas das árvores em sua totalidade. Essa quantidade será quase toda perdida se a chuva for de $100 \mathrm{~mm}$. No entanto, a porcentagem interceptada, nesse caso, 
será bem menor (Lima, 1986). Para eventos de chuva individuais, a interceptaçào tende a diminuir com os eventos ou chuvas mais intensos.

A média anual de interceptação é um bom indicador da quantidade de água produzida. No entanto, ao longo do ano podem ocorrer grandes variações, principalmente devido à alternância das condições climáticas - mais úmidas ou secas - e às características das chuvas. Em períodos úmidos, a interceptação porcentual da chuva é menor. Miranda (1992) observou que a Floresta da Tijuca intercepta toda água proveniente de chuvas com intensidade até $10 \mathrm{~mm}$. Já para chuvas mais intensas, a interceptação foi insignificante. Conclui-se dai que sua interferência nos picos de escoamento da hidrógrafa correspondente é pequena para eventos de chuvas de maior magnitude.

Outro fator importante relacionado à produção de água e cobertura vegetal é a presença da serrapilheira. Trata-se de uma camada de materiais orgânicos que caem da vegetação, localizados na camada superior do solo. É constituída de duas partes, a superior que contém materiais nào decompostos e a inferior com materiais em decomposição. A inferior permite o desenvolvimento de raizes finas, que ao se entrelaçarem formam um manto. Além de proteger o solo contra erosão e melhorar as características físicas e químicas dos solos, essa parte inferior tem uma importante função de armazenamento de água. Coelho Neto (1987) demonstrou que a água não retida pela serrapilheira pode fluir descontinuamente tanto pela parte superior, como no interior da malha de raizes. Depois, é transferida para os horizontes minerais.

No que conceme o vinculo entre os padrões sazonais de produção de água e cobertura vegetal, Deus (1991) observou que, durante o periodo de estiagem, três chuvas intensas seqüenciais $(500 \mathrm{~mm} / \mathrm{h})$ não foram suficientes para gerar escoamento superficial. Cada uma dessas chuvas foram simuladas com três horas de duração e intervalo de uma hora. Uma parcela significativa de água foi armazenada pela vegetação - área de gramíneas do Médio Vale do Paraíba do Sul - que, nessa época, estava muito seca (capacidade de retenção de água em tomo de 500\% em relação a seu peso seco). Ao passo que Dunne \& Leopold (1978) concluíram que o armazenamento de parte das chuvas tende a aumentar no período de máximo crescimento da vegetação. 
Lamentavelmente, poucos estudos são desenvolvidos nas regiões ropicais, caracterizando os efeitos das mudanças na cobertura vegetal sobre a produção de água. Isso seria particularmente necessário, levando em conta a imensa diversidade de condições notada nessas regiões. Para Brooks et al. (1991), tal carência provoca estranheza, face a propalada influência das florestas tropicais sobre o clima e as precipitações regionais. Portanto, muitas pesquisas complexas e abrangentes deveriam ser realizadas visando o entendimento e quantificação dessa influência. Por fim, concluem que questões relacionadas às mudanças na cobertura vegetal em florestas tropicais e suas implicações regionais e globais continuam mais como conjecturas, do que fatos.

No intuito de elucidar aspectos da produção de água em regiões tropicais, Gilmour et al. (1982), citados por Brooks et al. (1991), apresentaram um estudo no qual uma floresta úmida da Austrália foi derrubada e limpa para implantação de pastagem. Durante dois anos, esta área apresentou $10 \%$ de aumento na produção de água. Comparações semanais indicaram que, conforme ocorria o deflorestamento e o desenvolvimento de pastagens, as descargas mínimas aumentaram de 14 para 60\%. Esta resposta hidrológica foi semelhante à encontrada nas regiões temperadas.

As práticas silviculturais têm pouco impacto sobre a capacidade de infiltração, desde que o piso seja mantido intacto (Lima, 1986). O grande impacto ocorre quando uma floresta é transformada em culturas anuais. Afinal, apenas com o desmatamento, existe a tendência de que as condições originais sejam reestabelecidas. Segundo Tucci \& Clarke (1998), num primeiro momento, a vazão aumenta em conseqüência da retirada da floresta. Posteriormente, com o crescimento da cobertura vegetal, a vazão tende a voltar aos valores anteriores.

Cabe recordar que o pisoteio dos animais provoca mudanças nas características físicas do solo, ocasionando, dessa forma, alterações nas características hidrológicas das bacias. No entanto, diferentes condições e diversos graus de pisoteio induzem resultados diferentes. Schneider et al. (1978) encontraram uma relação de 1:40,9 entre o tempo de infiltração sem e com pisoteio numa floresta nativa. O estudo foi realizado numa área de latossolo profundo do nordeste do Rio Grande do Sul, sob 
pisoteio constante do gado (lotação de 0,3 a 0,7 animais/ha). $O$ aumento da compactação, decorrente do pisoteio, provocou a modificação da estrutura do solo e a redução da infiltração, maior escoamento superficial e erosão. Além disso, observou-se a redução do endo-humus, como conseqüência do arraste do solo superficial, diminuindo a fertilidade do solo. Ademais, foi constatada a destruição das raizes superficiais autotróficas e micotróficas.

Também, Baggio \& Schereiner (1988) constataram diferenças na densidade aparente do solo graças à introdução do pastoreio em florestas de Pinus. Os resultados mostraram que a densidade decresceu de $0,135 \mathrm{~g} / \mathrm{cm}^{3}$ para $0,12 \mathrm{~g} / \mathrm{cm}^{3}$, para $0,11 \mathrm{~g} / \mathrm{cm}^{3}$ e para $0,095 \mathrm{~g} / \mathrm{cm}^{3}$ nos quatro anos após a introdução do gado bovino. Thompson (1968), observando a penetrabilidade e a densidade aparente do solo durante 10 anos, não encontrou diferenças entre duas áreas, uma pastoreada e outra sem pastoreio. Por outro lado, Stoeckeler (1959) e Linnartz et al. (1966) verificaram aumento da densidade aparente em solos submetidos ao pisoteio por gado bovino.

Outra propriedade, a infiltração da água no solo, também é comprometida por determinadas intervenções. Mudanças nas características da superfície e da permeabilidade do solo alteram o movimento descendente da água através do perfil do solo, conseqüentemente, a descarga de uma bacia, o armazenamento de água pelo solo e a recarga dos lençóis.

Diversos trabalhos intemacionais mostraram a influência da cobertura florestal sobre a capacidade de infiltração dos solos. Arend (1942), citado por Lima \& Zakia (1998), comparou a capacidade de infiltração para diferentes condições do piso florestal. Para o piso florestal intacto a capacidade de infiltração foi de $59,9 \mathrm{~mm} / \mathrm{h}$, - para piso removido mecanicamente, $49,3 \mathrm{~mm} / \mathrm{h}$ - para piso queimado anualmente, $40,1 \mathrm{~mm} / \mathrm{h}$ e para pastagem degradada, $24,1 \mathrm{~mm} / \mathrm{h}$. No Brasil, a despeito do número reduzido de trabalhos, alguns podem ser mencionados. Valente et al. (1979) mediram a velocidade de infiltração básica em solos latossolos vermelho-amarelo cobertos por Pinus e Bombax. Os autores encontraram valores de $115,5 \mathrm{~mm} / \mathrm{h}$ e $84,7 \mathrm{~mm} / \mathrm{h}$, respectivamente para os dois tipos de cobertura vegetal. Ao passo que Carmo (1976), ao utilizar infiltrômetro de anéis, mediu a velocidade de infiltração básica como sendo $400 \mathrm{~mm} / \mathrm{h}$ 
em floresta de eucalipto em Viçosa (MG). Observe-se que as variações nos valores de infiltraçào encontrados na literatura podem ser justificadas pela aplicaçào de diversas metodologias de medida. Afinal, infiltrômetros de anéis, simuladores de chuva e gotejamento apresentam sensibilidades diferentes para caracteristicas diversas do solo.

As práticas agricolas e a cobertura também modificam muito a habilidade do solo em absorver água. Apenas uma passagem de trator já é suficiente para reduzir a macroporosidade pela metade e a capacidade de infiltraçào em 80\% (Selby,1993). A compactaçào pelas máquinas ou por animais pode ser tào grande que a infitraçào chega a apresentar valores muito menores do que as área florestadas.

$\mathrm{Na}$ transformação de florestas naturais para agricultura é inevitável que aconteçam desequilibrios. O modo de preparar o solo da maneira convencional, ou seja, com o uso intenso de arações e gradagens, provoca erosào e, logicamente, rendimentos decrescentes, comprometendo a sustentabilidade.

Em busca da maior sustentabilidade do sistema agricola foram feitas várias tentativas, chamadas de preparo conservacionista do solo, que tem como objetivo a reduçào da intensidade do preparo do solo, a manutençào de uma superfície mais rugosa, com o máximo de resíduos na superficie. Com o decorrer dos anos, a decomposiçào dos residuos melhora as condições do solo. Surgiram, assim, os cultivos reduzido e mínimo e o plantio direto.

O coeficiente de rugosidade de Manning (n), que numa situaçào de solo desnudo e recém gradeado é de aproximadamente 0,03, passa, segundo Chaves (1997), para 0,05 no plantio direto. Apenas esse aumento de $\mathrm{n}$ é responsável por uma redução de cerca de $40 \%$ na velocidade da enxurrada, com uma reduçào proporcional de sua energia cisalhante, responsável pela formaçào dos sulcos.

Com relaçào à cobertura vegetal, Roth (1984), estudando um latossolo do Paraná sob plantio direto, concluiu que quanto maior a cobertura do solo, menor o escoamento superficial. Para solos com cobertura de até $50 \%$, as porcentagens da precipitaçào escoadas superficialmente permaneceram entre $20 \%$ e $5 \%$. Ao passo que 
para cultivos sob preparo convencional, em rotações de cultura com milho e solo com menos de $10 \%$ de cobertura vegetal, os valores ficaram entre 30 e $50 \%$ da precipitação. Muitos resultados na literatura mostram as vantagens do plantio direto.

É pertinente mencionar que no plantio direto o solo permanece obrigatoriamente o ano todo sob cobertura vegetal. Portanto, esse tipo de uso ao longo dos anos, acarreta a melhoria de várias características do solo. Entre elas, a estabilidade dos agregados, que é um fator fundamental para que não ocorra o selamento superficial, com a conseqüente redução da capacidade de infiltração e o aumento do escoamento superficial. Sidiras et al. (1982) citado por Derpsch et al. (1991) constataram que, usando plantio direto, na camada $0-10 \mathrm{~cm}$ de profundidade, $67 \%$ dos agregados (da classe $52 \mathrm{~mm}$ a $5,66 \mathrm{~mm}$ ) do solo permanecem estáveis em água. Já, no preparo convencional apenas $3 \%$. Os autores ainda recordaram que quanto maior a estabilidade dos agregados, menor o escoamento superficial.

Ademais, a presença constante de uma camada de vegetal sobre o solo, beneficia o desenvolvimento de sua fauna. Conforme Prevedello et al. (1998), já é comprovada a importância das minhocas para a incorporação de matéria orgânica nas camadas mais profundas de solos florestais e pastoris, com pH acima de 4,5. Ainda, a rede de galerias produzida pelas minhocas, que se deslocam até a superficie em busca de alimentos, melhora a porosidade do solo. Por sua vez, a maior porosidade favorece a aeração do solo, a infiltração e redistribuição de água. Como essas galerias funcionam como caminho preferencial da água, elas aumentam muito a capacidade de infiltração do solo. Com a maior infiltração, ocorre menor escoamento superficial. Para completar, os caminhos preferenciais em macroporos produzem respostas mais rápidas quanto a redistribuição da água no perfil. Kobiyama (1994) estudou a influência da minhoca sobre a movimentação da água no solo.

Aliado a ação de microrganismos, Eltz et al. (1989) observaram a formação de canais pelo apodrecimento das raizes no plantio direto contínuo. Além dos beneficios mencionados anteriormente esses canais propiciam, durante maior tempo, condiçòes mais uniformes de infiltraçào, resultando em maior velocidade final de infiltração. 
Lal (1974), avaliando a infiltração em solo franco-arenoso após um ano da transformação de uma floresta em cultivo de milho e em solo desnudo, descobriu reduções de $40 \%$ e $73 \%$ na capacidade de infiltração, respectivamente.

Segundo Connolly (1998), uma estrutura pobre do solo, ou seja, baixa agregação e porosidade, é considerada a maior limitação à infiltração, redistribuição e armazenamento de água no solo. Os efeitos de diferentes culturas e tipos de cultivos já foram largamente comprovados pela pesquisa. Entre outros, que o cultivo pode reduzir a estabilidade dos agregados, aumentar o selamento e reduzir a condutividade hidraúlica na camada superficial. A compactação por máquinas reduz a porosidade, a condutividade hidraúlica e a capacidade de retenção de água a valores bem baixos. $\mathrm{O}$ aumento do escoamento decorrente da redução de infiltração provoca erosão. Solos desnudos ficam susceptíveis a danos pelo impacto da gotas das chuvas, com a quebra dos agregados e formação de uma fina camada compactada na superficie, podendo reduzir em 2000 vezes a condutividade hidraúlica de um solo.

Investigações indicaram que ocorre um significativo incremento no pico de descarga em decorrência da urbanização de uma bacia. Tais incrementos são, geralmente, atribuídos à construção de sistemas coletores de água que conduzem-na mais rapidamente a um mesmo ponto, aumentando a vazão. $O$ grau de impermeabilização devido à urbanização varia desde aproximadamente $20 \%$ para o caso de baixas densidades de residências para cerca de $90 \%$ em áreas comerciais e de negócios (USDA, 1972).

As mudanças na capacidade de infiltração do solo e nos outros fatores relacionados à produção de água podem ser observadas e medidas diretamente no campo. No entanto, a gama de fatores relacionados à produção de água e as combinações das mudanças é infinita. Tal dificuldade pode ser minimizada recorrendo-se à elaboração de modelos, usando os dados mais facilmente disponíveis. 


\subsection{Modelagem hidrológica de bacias hidrográficas}

Os modelos hidrológicos de bacias hidrográficas são, segundo Ponce (1989), conjuntos de abstrações matemáticas das fases relevantes do ciclo hidrológico, formuladas com o propósito de simular a transformação da chuva em escoamento. Em princípio, as técnicas de modelagem são aplicáveis em bacias pequenas, médias ou grandes. Entretanto, na prática, seu uso limita-se à análise de bacias que podem ser descritas segundo às variações temporais e espaciais.

Woolhiser \& Brakensiek (1982) consideraram que as abstrações restituem parte do universo, estudada por um modelo de estrutura simples. Os autores agrupam os modelos em duas categorias: os materiais e os formais. Os modelos de bacias materiais são os simuladores de chuva e as chamadas bacias experimentais. São caros e de pouca aplicabilidade. Por outro lado, os modelos formais são facilmente disponíveis e mais flexíveis. Por isso, são preferidos na solução de problemas de bacias hidrográficas. Um modelo formal é uma abstração matemática de uma situação idealizada, que preserva as propriedades estruturais importantes do protótipo. Como são invariavelmente matemáticos, são conhecidos, também, como modelos matemáticos. Ao serem usados em computadores, tornam-se modelos computacionais.

A grande vantagem do uso de simulações é o seu baixo custo, pois, enquanto os custos de execução de pesquisas de campo tornam-se cada vez mais elevados, os relativos à aquisição de computadores mais velozes e equipamentos de informática, estão cada vez menores. Entretanto, a despeito das vantagens da simulação, as pesquisas de campo continuam necessárias (Pessoa et al., 1997).

Em razão da existência de uma grande variedade de tipos de modelos matemáticos com diferentes nomes e muitas classificações, baseadas nas estruturas, objetivos e complexidade, Flemming (1975) sugeriu a separação em três classes: determinísticos, estatísticos e de otimização (Figura 4A). Chow et al.(1988) propôs a separação em duas classes, determinísticos e estocásticos. (Figura 4B). 


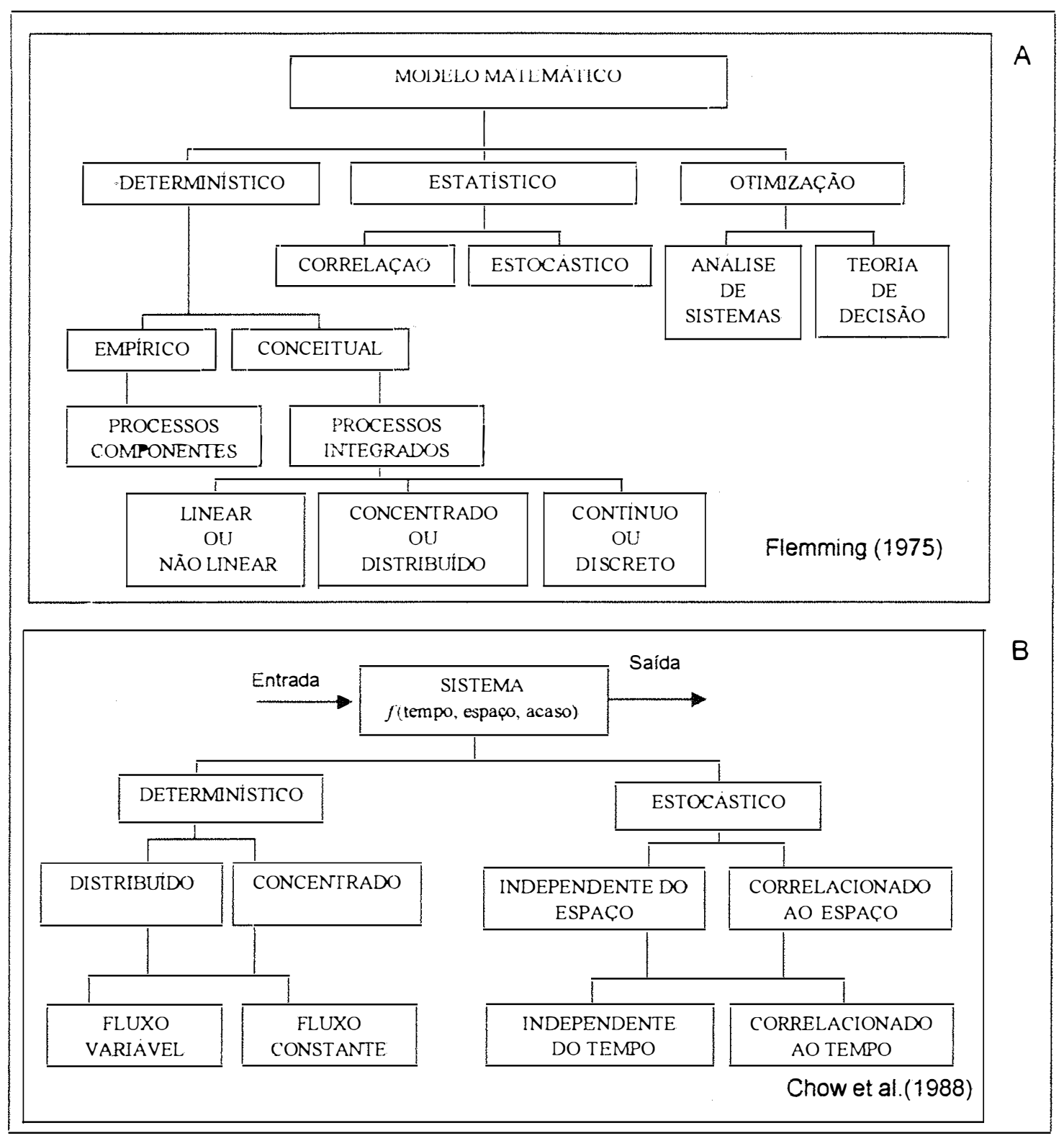

Figura 4 - Classificação dos modelos hidrológicos.

Ponce (1989) agrupou os modelos matemáticos em 3 tipos: teóricos, conceituais e empiricos. Os teóricos e empiricos apresentam significados contrários. Já, os conceituais situam-se em posição intermediária. Especificamente para a modelagem de bacias, reconheceu quatro principais tipos: determinísticos (baseado em leis fisicas), 
probabilísticos (apresentam componentes aleatórios), conceituais (os processos físicos são considerados de uma forma prática) e paramétricos (baseados em dados medidos ou em experiências anteriores, com os parâmetros medidos ou ajustados).

A classificação de Chow et al. (1988), segundo Maidment (1993b), advém do fato de que os fenômenos hidrológicos variam nas 3 dimensões ( $\mathrm{x}, \mathrm{y}$ e $\mathrm{z}$ ), no tempo e são aleatórios ou dotados de incerteza. Afinal, baseiam-se na precipitação e englobam propriedades do fluxo que ainda não são dominadas, especialmente do fluxo subsuperficial. Então, podem ser consideradas cinco fontes de variação na modelagem hidrológica: o tempo, as 3 dimensões e o acaso. Considerando a classificação, o autor acrescentou que o modelo mais simples é o determinístico (não aleatório), concentrado ou global (onde os processos são considerados espacialmente uniformes) e, modelo de fluxo constante (invariável no tempo). Um exemplo típico para aplicação desse tipo de modelo é o fluxo uniforme e constante num canal, para o qual a mecânica envolvida já é bem entendida e modelada.

Os modelos determinísticos, também conhecidos como não probabilísticos, não permitem que as variáveis sejam aleatórias. As suas características operacionais devem ser relações exatas (Pessoa et al., 1997). Nesse tipo de modelo, contanto que as entradas sejam as mesmas, as saídas serão sempre exatamente iguais. Contrariamente, os modelos estocásticos possuem pelo menos uma de suas características operacionais dada por uma função de probabilidade. Descrevem fenômenos aleatórios, por isso são mais complexos.

A distinção entre modelos conceituais e empíricos está baseada no conhecimento sobre o qual o modelo é construido. Os modelos conceituais são baseados em processos que acionam as entradas produzindo as saídas. Essas representações dos processos são simplificadas, dando-se mais importância a alguns parâmetros conceituais chaves. Os empíricos são construídos apenas pela observação de entradas e saídas, sem levar em conta os processos. Segundo Pessoa et al. (1997), os modelos empíricos descrevem os fenômenos por equações matemáticas, que representam os dados experimentais. Contrariamente, os modelos conceituais apresentam, de forma objetiva, clara e ordenada, as considerações pertinentes a um problema em estudo. Permitem uma 
visão holística do problema, relacionando as várias áreas do conhecimento envolvidas na sua descrição. Quanto aos modelos empíricos, deve-se ter cuidado na aplicação para condições diferentes daquelas em que os dados foram obtidos. Os modelos baseados nos processos físicos, na literatura, também são chamados de mecanísticos.

Os modelos distribuídos são aqueles que levam em consideração explicitamente as variações das características e processos no espaço geográfico. Ao passo que os modelos concentrados (ou globais) ignoram ou consideram condições médias (HEC-USACE, 2000).

Por outro lado, modelos mais complicados são os que envolvem processos dinâmicos, isto é, que englobam variáveis em mais dimensões (espacial e temporal). Esses modelos baseados em processos dinâmicos, para Sá et al. (1993), podem ser melhor estruturados se a bacia hidrográfica for subdividida em células, formando uma grade. Ainda, por representarem com maior precisão as variações espaciais dos parâmetros e variáveis do sistema, produzem uma melhor compreensão das interações hidrológicas.

Entre os componentes dos modelos alguns merecem comentários. As variáveis são suas próprias quantidades fisicas, por exemplo, vazão, área de contribuição e velocidade (Ponce, 1989). Já, os parâmetros são valores que adequam o modelo para condições específicas (HEC-USACE, 2000). Sendo assim, os parâmetros são quantidades que controlam o comportamento das variáveis (Ponce, 1989).

No preparo para a aplicação dos modelos, os mesmos devem passar por algumas fases. A calibração é a fase em que os valores dos parâmetros são manipulados, numa tentativa de se obter o ajuste entre dados simulados e observados, considerando-se uma situação particular. No caso da modelagem de bacias hidrográficas, essa etapa consiste no uso de dados de precipitação e vazão para o formecimento de parâmetros que proporcionam o melhor ajuste entre os dados observados e simulados. Na fase de validação dos parâmetros dos modelos, esses são avaliados quanto a sua capacidade de simulação com dados diferentes daqueles usados na fase de calibração. 


\subsubsection{Modelos de transformação da chuva em escoamento}

Ao se modelar a transformação da chuva em escoamento, a hidrógrafa unitária tem sido usada como um conceito chave. Proposta pela primeira vez por Le Roy K. Shermam em 1932 e, mais tarde, aperfeiçoada por outros pesquisadores, a hidrógrafa unitária é a resposta da microbacia a uma lâmina unitária de excesso de chuva, distribuída uniformemente sobre a bacia a uma taxa constante num dado período de tempo (Pilgrim \& Cordery, 1993).

A hidrógrafa unitária apresenta a suposição simplificadora de considerar a resposta da rede de drenagem como um sistema concentrado (global), não levando em conta a distribuição espacial dos parâmetros. O padrão do escoamento superficial é dependente apenas da duração e independente dos padrões temporais do excesso de chuva. Assim, é assumido que não existe variação temporal do fenômeno de produção de escoamento. As ordenadas das hidrógrafas de escoamento são consideradas em proporção linear ao total de chuva efetiva. Essa suposição permite a aplicação dos princípios de proporcionalidade e superposição, sendo a bacia de drenagem tratada como um sistema linear com equilíbrio dinâmico e propriedades espacialmente invariantes. A superposição possibilita a obtenção de hidrógrafas para eventos de chuvas complexos, ou seja, uma vez conseguida a determinação da hidrógrafa instantânea, é possível construir uma hidrógrafa para montantes de chuva efetiva discretizados em períodos. Assim, pode-se elaborar uma hidrógrafa correspondente a uma chuva efetiva de qualquer duração. A abordagem do hidrograma unitário convencional assume que o escoamento direto é produzido por um fluxo de superficie hortoniano através da bacia (USDA, 1972, Chow et al., 1988, Cruciani, 1989, Maidment, 1993a).

Caso não fossem assumidas estas hipóteses simplificadoras com o comportamento da bacia considerado não linear e com propriedades que variam espacialmente, as análises seriam bem mais complexas. 
Segundo Brooks et al. (1991), o Método da Hidrógrafa Unitária é simplesmente um modelo "caixa-preta", que, empiricamente, relaciona a vazão de saída para uma dada duração de precipitação. Não são considerados os vários processos envolvidos no fluxo de água através da bacia.

Para bacias não instrumentadas, é possivel estimar hidrógrafas unitárias sintéticas pelo relacionamento dos parâmetros de uma hidrógrafa unitária sintética com as características físicas da bacia de drenagem. Por meio dessas relações, viabiliza-se o desenvolvimento de hidrógrafas para outras bacias e condições diferentes das originalmente utilizadas, sem o uso de dados de precipitação e vazão. Entretanto, esses relacionamentos, por serem empíricos, não apresentam aplicação universal. Nesse sentido, várias hidrógrafas unitárias sintéticas foram desenvolvidas, porém, somente algumas apresentam uso difundido. Segundo Chow et al. (1988), as hidrógrafas sintéticas são enquadradas em três categorias. As que relacionam características da hidrógrafa unitária às da bacia, como exemplo a de Snyder. As que são baseadas em uma hidrógrafa adimensional, como a do SCS. E, finalmente, as que são fundamentadas em uma representação semi-distribuída do armazenamento na bacia, tal como a hidrógrafa de Clark e Clark modificada.

Entre os modelos de hidrógrafa sintéticas mais aplicados estão os de Snyder, Clark, Nash e a hidrógrafa unitária do U.S. Soil Concervation Service. Os modelos de Snyder e o do SCS apresentam muitas semelhanças. Porém, ambos são diferentes, tanto do modelo de Clark, como o de Nash. Esses dois últimos são similares, pois ambos envolvem a propagação do excesso de chuva por armazenamentos, numa tentativa de representar estes efeitos na bacia (Pilgrim \& Cordery, 1993 e HEC-USACE, 2000).

No modelo de Snyder (1938), foram estabelecidas relações entre algumas das características da hidrógrafa unitária como pico de vazão, tempo de retardamento, tempo-base e tempo que leva para atingir $50 \%$ e $75 \%$ do pico.

Clark (1945) propôs uma hidrógrafa unitária como resultado de uma combinação de um processo de propagação (routing) de translação pura, seguido por um processo de armazenamento puro. A etapa de translação da água (movimento da chuva 
efetiva desde sua origem até a saída da bacia) baseia-se no diagrama tempo-área, embora não haja desenvolvimento de uma análise espacialmente distribuída. Já, a etapa de armazenamento (redução da vazão na saída, em decorrência de armazenamentos temporários na bacia) corresponde à propagação da resposta da translação através de um reservatório linear único, localizado na saída da microbacia. Segundo Olivera et al. (1996), o tempo de retenção do reservatório é selecionado para reproduzir a fase de recessão das hidrógrafas observadas. Observa-se, ademais, que o tempo de percurso atual de uma partícula de água, conforme essa abordagem, é o tempo de percurso dado pelo diagrama tempo-área mais o tempo de retenção do reservatório. Em tempo, o diagrama tempo-área é um gráfico que mostra a distribuição temporal das contribuições das áreas da bacia, discretizadas em isócronas.

Alguns anos mais tarde, Nash (1957) sugeriu a hidrógrafa unitária como uma equação com distribuição gama, isto é, a resposta de uma bacia como uma cascata de reservatórios lineares em série como um modelo de hidrógrafa unitária. Para cada um desses reservatórios, relaciona-se o volume de água armazenado à vazão. Tal proposta, segundo Oliveira et al. (1996), não permitiu modelar a bacia por ela mesma e representou apenas uma técnica de ajuste, baseada no primeiro e segundo momentos das hidrógrafas calculadas e observadas.

A hidrógrafa unitária é considerada um modelo global (concentrado), pois transforma diretamente a chuva em escoamento, sem explicitamente representar a distribuição interna do fluxo dentro da bacia. Para Maidment (1993a), uma questão que vem à tona é como os SIGs podem ser usados para construir uma hidrógrafa unitária que reflita melhor o fluxo espacialmente distribuído dentro de uma bacia. Portanto, considerar a variabilidade espacial da bacia é uma tentativa plausivel no sentido de abrandar as suposições da hidrógrafa unitária. Muitas pesquisas relacionadas a esses tópicos foram realizadas recentemente, gerando considerável volume de artigos encontrados na literatura.

Por exemplo, Pilgrim (1976) mediu o tempo de percurso de partículas marcadas com traçadores de escoamento entre a entrada e saída de uma bacia de 0,39 $\mathrm{km}^{2}$, próxima à Sidney (Austrália). Uma de suas conclusões foi que os tempos de 
percursos e as velocidades médias, em fluxos médios a altos, tornam-se quase constantes, indicando um comportamento quase linear nessa faixa de fluxos. Finalmente, Pilgrim (1976) mostrou que decompor a área como uma propriedade dos sistemas de propagaçào lineares foi uma descoberta importante para inserir a variabilidade espacial nesse tipo de estudo.

Outra tentativa importante foi feita por Rodrigues-Iturbe \& Valdez (1979). Os autores buscaram unir características geomorfológicas de uma microbacia lançando mào das leis empíricas de Horton. A geomorfologia do sistema é descrita pelos comprimentos dos cursos de água, sua classificação e áreas correspondentes. Nesse caso, a hidrógrafa unitária instantânea é definida como uma função da densidade de probabilidade do tempo que uma gota de chuva escolhida ao acaso leva para alcançar a saída da bacia. Esse tempo é a soma dos tempos gastos para uma gota de chuva passar de uma ordem de canal para outra. O tempo gasto em cada ordem de canal é uma variável aleatória, com uma funçào de densidade de probabilidade exponencial, cujo parâmetro depende da razào do comprimento de Horton, velocidade média do fluxo no canal e um fator de escala. Segundo Pilgrim \& Cordery (1993), até 1993 o modelo não estava sendo aplicado na prática.

Uma abordagem interessante para modelar as respostas rápida e lenta de uma bacia é apresentada por Littlewood \& Jakeman (1992, 1994). No modelo, a microbacia é idealizada como dois sistemas de armazenamentos lineares, em paralelo, representando os sistemas superficial e subsuperficial. O sistema superficial é mais rápido e afeta, principalmente, a ascensão da hidrógrafa resultante. Já, o sistema subsuperficial é lento e determina a recessào da hidrógrafa.

Maidment (1993a) usou um SIG para o desenvolvimento de uma hidrógrafa unitária espacialmente distribuída. Foram utilizados uma grade de direção do fluxo, elaborada a partir de um MDT, e uma correspondente grade da velocidade do fluxo espacializada sobre a superficie, a partir da qual foi construído um diagrama tempo-área. É importante assinalar que a velocidade é um vetor especificado por magnitude e direção e a grade de direçào de fluxo especifica apenas a direção. A grade de velocidade foi determinada por meio do uso de uma funçào de velocidade na forma 
de $\mathrm{V}=\mathrm{a} \mathrm{S}^{\mathrm{b}}$, onde $\mathrm{S}$ é a declividade da superficie do solo e a e b são coeficientes relacionados ao uso do solos, baseados em procedimentos do SCS. Para a determinação do diagrama tempo-área, recorreu-se às informações de cada célula quanto à direção, velocidade e rota de fluxo de cada célula até a saída. Assim, foi possível a criação de uma grade de tempo de percurso, onde o valor em cada célula é o tempo gasto pela água para fluir até a saída da bacia. Ainda, na elaboração do diagrama tempo-área, as células foram classificadas em zonas com diferentes tempos de percurso, que são chamadas de isócronas. Dessa forma, um mapa de isócronas foi criado e o diagrama tempo-área determinado pela plotagem das áreas de drenagem fluindo para a saída, contra as zonas de tempos de percurso correspondentes.

No trabalho acima, evidencia-se que as suposições da hidrógrafa unitária de tempo de base constante e linearidade da resposta chuva-escoamento são eqüivalentes a assumir que, indiferentemente do montante da chuva, o fluxo da água no terreno sempre segue a mesma trajetória com o mesmo tempo de percurso médio, ou seja, que a velocidade do escoamento no campo é espacialmente variável, mas invariável no tempo e volume de descarga.

Um desafio que se apresenta para a hidrologia, com a emergência dos SIG's, é a determinação de como usá-los de uma forma conveniente, tanto pela sua ligação aos modelos hidrológicos, quanto para repensar a modelagem hidrológica em termos espaciais, para que possam ser criados melhores modelos hidrológicos (Maidment, 1993a).

Independente da multiplicidade de abordagens e modelos existentes, um dos mais utilizados para determinação da hidrógrafa foi desenvolvido pelo Serviço de Conservação do Solo (Soil Consevation Service - SCS) do Departamento de Agricultura dos Estados Unidos (United States Department of Agriculture - USDA). O Modelo do SCS, segundo Dugger (1997), consiste de um conjunto de equações que governam o deslocamento do volume de água escoada pela superfície do solo. Os poucos parâmetros necessários são o volume de precipitação, a condição de umidade antecedente, perdas iniciais e algumas informações gerais sobre as características do solo e uso da terra. A partir da determinação do volume de escoamento direto, é feita a transformação em 
hidrógrafas usando-se a hidrógrafa unitária sintética adimensional do SCS ou a hidrógrafa triangular do SCS. Já, para a propagaçào da água pelos canais, sào usados os modelos de Muskingum, Muskingum-Cunge ou do retardamento puro.

\subsubsection{Modelo do SCS para transformação da chuva em escoamento}

\subsection{Método do Número da Curva para determinação das perdas iniciais}

Os primeiros desenvolvimentos foram iniciados entre 1944 e 1954, com o desenvolvimento do Hydrology Guide, guia para ser usado no planejamento de bacias dos EUA. Posteriormente, esse guia transformou-se no Hydrology Section 4 do National Engineering Handbook. Nessa época, foi criada a Equaçào do Número da Curva de Escoamento do SCS. Os trabalhos iniciais se basearam em Sherman (1949), que foi um dos primeiros a propor a plotagem do escoamento direto versus a chuva. Posteriormente, Mockus (1949) propôs um procedimento para estimativa do escoamento baseado em parâmetros de bacias. A partir de 1954, hidrologistas do SCS e outras instituições iniciaram debates e análises de dados de bacias sobre a importância das abstrações iniciais, que culminou, em 1959, na sua inclusào. A partir dai, a equação evoluiu para a apresentação atual. Atualmente, o Método do SCS tem sido chamado também de Método do NRCS (Natural Resourses Conservation Service).

O Método do Número da Curva do SCS, segundo Pilgrim \& Cordery (1993), é muito utilizado na estimativa do escoamento em pequenas e médias bacias rurais com poucos dados disponiveis. Embora em menor extensào, também é o método aplicado nas bacias urbanas. Nos Estados Unidos, tem substituido em grau significativo o Método Racional, graças à difusão de suas bases de dados e a maneira como são levadas em conta as caracteristicas fisicas da bacia. Originalmente, esse método foi desenvolvido com o propósito de obter dados estimados de volume e pico de descarga para serem aplicados em projetos de conservação do solo e controle de inundações. Segundo USDA (1972), a equação do método foi desenvolvida para ser usada principalmente em pequenas bacias onde somente existiam dados de bacia e precipitação diária. Ela foi desenvolvida para dados totais diários de precipitação, sem 
levar em conta a distribuição no tempo. Entretanto, o método é usado para estimativa do escoamento direto a partir de chuvas de um dia, ou menos. Do momento em que foi lançado até agora, muitas modificações foram feitas.

Os procedimentos aqui descritos são baseados principalmente em USDA (1972, 1973, 1986,1997), em Chow et al. (1988), Ponce (1989). O Método do Número da Curva do SCS, é um método para o cálculo da abstração hidrológica. A parcela da precipitação, que não é escoada, é um parâmetro de abstração chamado de número da curva de escoamento, número de escoamento ou $\mathrm{CN}$ (Curve Number).

$\mathrm{O}$ método fundamenta-se, principalmente, em testes de infiltração, medidas de precipitação e escoamento em pequenas parcelas. O SCS obteve, por meio de plotagem, curvas que relacionam a precipitação com o escoamento de muitas bacias. No sentido de padronizar essas curvas, foram definidos números adimensionais, os CN's. Ainda, o método se baseia na hipótese de que tanto para o escoamento, como para as abstrações, a razão entre o atual e o potencial é a mesma, ou seja, o método entende que há proporcionalidade entre a retenção e o escoamento, conforme segue:

$$
\frac{\mathrm{F}_{\mathrm{a}}=\mathrm{P}-\mathrm{Q}}{\mathrm{S}}=\frac{\mathrm{Q}}{\mathrm{P}}
$$

onde P é o escoamento potencial (total de precipitação) e Q o escoamento atual, também chamado de precipitação efetiva ou volume de escoamento direto, com $\mathrm{P} \geq \mathrm{Q}$. A retenção atual após o começo do escoamento é $\mathrm{P}-\mathrm{Q}$, também pode ser chamada de abstração contínua $\left(F_{a}\right)$. A retenção potencial (ou potencial máximo de retenção) é $S$, com $\mathrm{S} \geq \mathrm{P}-\mathrm{Q}$. Essa conjetura dá suporte aos conceitos do Método do Número da Curva. Segundo Tucci (1993), a relação tem o seguinte significado:

$$
\frac{\text { volume infiltrado }}{\text { capacidade máxima }}=\frac{\text { precipitação efetiva }}{\text { precipitação total }}
$$


Pelo princípio da continuidade,

$$
P=Q+I_{a}+F_{a}
$$

onde: P é o escoamento potencial (total de precipitação); Q o escoamento atual; $I_{a}$ são as abstrações iniciais e $F_{a}$ as abstrações contínuas. A abstração inicial engloba, principalmente, processos que ocorrem antes do escoamento começar, como a interceptação, infiltração e armazenamento superficial. Combinando as Equações 1 e 3 com a simplificação da retirada das abstrações iniciais $\left(\mathrm{I}_{a}\right)$, do potencial de escoamento (P) e resolvendo para o escoamento $Q$ fica:

$$
\begin{aligned}
& \frac{P-I_{a}-Q}{S}=\frac{Q}{P-I_{a}} \\
& Q=\frac{\left(P-I_{a}\right)^{2}}{P-I_{a}+S}
\end{aligned}
$$

A Equação 5 é a equação básica para o cálculo da lâmina de escoamento. Cabe recordar que o escoamento é fisicamente sujeito a restrição $P \geq I_{a}$, ou seja, 0 resultado da diferença entre o potencial de escoamento e a abstração inicial não pode ser negativo.

Para simplificar essa equação, a abstração inicial é relacionada a um potencial máximo de retenção, supondo empiricamente que a abstração inicial é $1 / 5$ do potencial máximo de armazenamento para uma determinada bacia. Esta relaçào foi obtida pelo SCS fundamentada em dados de chuva-escoamento de pequenas bacias experimentais. Assim:

$$
I_{a}=0,2 . S
$$


O coeficiente 0,2 tem sido submetido a extensivos exames. Springer et al. (1980), citado por Ponce (1989), avaliaram pequenas bacias úmidas e semi-áridas e encontraram coeficientes de abstração inicial variando de 0 a 0,26 . Contudo, 0,2 é o coeficiente reconhecido como padrão pelo SCS. Esse coeficiente de abstração inicial pode ser considerado um parâmetro adicional no Método do $\mathrm{CN}$ na pesquisa, particularmente, quando for assegurado por dados de campo. Em geral, a abstração inicial é relacionada à retenção potencial por meio de um parâmetro $\mathrm{k}$ de abstração:

$$
\mathrm{I}_{\mathrm{a}}=\mathrm{k} . \mathrm{S}
$$

Assim, a equação reduz-se para:

$$
\mathrm{Q}=\frac{(\mathrm{P}-0,2 \cdot \mathrm{S})^{2}}{\mathrm{P}+0,8 \cdot \mathrm{S}}
$$

sujeita à restrição de $\mathrm{P} \geq 0,2 \mathrm{~S}$. Sendo $\mathrm{Q}, \mathrm{P}$ e $\mathrm{S}$ expressos em unidades de lâminas.

Cabe ressaltar que os CN's também servem para generalizar a aplicabilidade da equação a vários tipos de bacias. Além disso, os CN's descrevem as características da superfície e o armazenamento associado. Ainda, o uso desse número adimensional justifica-se na extrema variabilidade da máxima retenção encontrada nas bacias. O CN varia de 0 a 100 . O valor 0 é encontrado em áreas totalmente permeáveis, onde o potencial de armazenamento é elevado e não ocorre escoamento. Já, o valor 100 é aplicado a áreas totalmente impermeáveis, sem armazenamento ou outras perdas, como por exemplo os corpos de água ou as áreas saturadas. Nesse caso, o escoamento da chuva é total.

$\mathrm{O}$ valor de $\mathrm{CN}$ varia conforme as características da bacia, o grupo hidrológico do solo, o uso da terra, o manejo do solo, a condição da superfície e da umidade antecedente. Para bacias menores que $26 \mathrm{~km}^{2}$ a precisão do valor de $\mathrm{CN}$ é dada pela estimativa da porcentagem de cada grupo de solo e uso da terra. 
Para a condição de umidade antecedente AMC II , que é a padrão, a relação entre o armazenamento $\mathrm{S}$ (em mm e polegadas ) e o número da curva $\mathrm{CN}$ é dado pela Equação 9.

$$
S=\left\{\begin{array}{c}
\frac{25400}{\mathrm{CN}}-254(\mathrm{~mm}) \\
\frac{1000}{\mathrm{CN}}-10 \text { (polegadas) }
\end{array}\right\}
$$

Uma vez especificadas as caracteristicas do terreno, tipo de solo e umidade antecedente, o escoamento direto pode ser calculado a partir do evento de chuva que cai sobre a área. Conforme Ponce (1989), a partir da Equação 9, a Equação 8 pode ser expressa em termos de $\mathrm{CN}$ (Equação 10). Nessa equação, $\mathrm{P}$ e $\mathrm{Q}$ são dados em $\mathrm{cm}$, contanto que se considere o fator de tranformação $\mathrm{R}=2,54$.

$$
\mathrm{Q}=\frac{\mathrm{R} \cdot\left[\mathrm{CN}\left(\frac{\mathrm{P}}{\mathrm{R}}+2\right)-200\right]^{2}}{\mathrm{CN} \cdot\left[\mathrm{CN}\left(\frac{\mathrm{P}}{\mathrm{R}}-8\right)+800\right]} \text {, para } \mathrm{P} \geq \mathrm{R}\left[\left(\frac{200}{\mathrm{CN}}-2\right)\right]
$$

Para a inclusão da variável abstração inicial, a equação é rescrita como Equação 11.

$$
\mathrm{Q}=\frac{\mathrm{R}\left[C N\left(\frac{\mathrm{P}}{\mathrm{R}}+10 \mathrm{~K}\right)-1000 . \mathrm{K}\right]^{2}}{\mathrm{CN}\left\{\mathrm{CN}\left[\frac{\mathrm{P}}{\mathrm{R}}-10(1-\mathrm{K})\right]+1000(1-\mathrm{K})\right\}} \text { para } \mathrm{P} \geq \mathrm{R}\left[\left(\frac{1000 \mathrm{~K}}{\mathrm{CN}}-10 \mathrm{~K}\right)\right]
$$

O Método do SCS foi desenvolvido com dados de pequenas bacias agricolas no meio-oeste americano, de forma que sua aplicação fora daquele ambiente é incerta. $O$ valor padrão para as abstrações iniciais $(0,2 . S)$ não depende das características da chuva ou de tempos. Por conseguinte, se usado com chuvas de projeto, esses valores serão sempre os mesmos. A intensidade da chuva não é considerada, ou seja, a mesma 
chuva efetiva é calculada para, por exemplo, $50 \mathrm{~mm}$ de precipitação em uma hora ou um dia. Ainda, Hewlett (1981) afirmou que o Método do SCS superestima o pico para áreas florestadas num fator de 2 ou mais, enquanto pequenos eventos podem ser estimados como 0 , devido à falsa suposição de abstrações iniciais.

Apesar das críticas, a literatura é vasta quanto à aplicação do Método do Número da Curva do SCS. Entre outros, Ponce \& Hawkins (1996) citam as principais vantagens do Método Número da Curva do SCS: simplicidade, previsibilidade e estabilidade.

O determinação dos valores do número da curva do SCS tem sido tradicionalmente aplicado na forma composta para bacias com diversos tipos de solos e usos do solo. Neste caso é calculado a média ponderada dos valores de $\mathrm{CN}$ para uma bacia inteira ou em sub-bacias. Dessa forma são reduzidas as necessidades de cálculos, com economia de tempo. Entretanto; com a proliferação de computadores com alta performance e dos sistemas de informações geográficas, tornou-se possível o uso de valores $\mathrm{CN}$ distribuídos para a aplicação do método. Para comparar os resultados de lâminas de escoamento feitas com valores de $\mathrm{CN}$ compostos e distribuídos Grove et al. (1998) idealizaram simulações que apresentaram lâminas de escoamento em torno $100 \%$ maiores quando foram usados valores de $\mathrm{CN}$ distribuídos. A causa de diferenças tão grandes foi atribuída ao fato de que os valores de $\mathrm{CN}$ e a produção de escoamento apresentam uma relação curvilinear. As maiores diferenças foram quando as precipitações eram baixas, as faixas de valores de $\mathrm{CN}$ eram grandes ou os valores de $\mathrm{CN}$ eram baixos. Em função dos resultados, os autores recomendam que seja feito o uso de $\mathrm{CN}$ distribuídos, especialmente quando forem estudados os efeitos de urbanização que apresentarem valores bem diferentes dentro de uma mesma área. Em estudos hidrológicos de longa duração em que forem usados dados diários de chuva, e em pequenos projetos que usam como critério chuvas com pequenos tempos de retorno.

Wood \& Blackburn (1984), ao medir o escoamento em 1660 parcelas experimentais nos Estados de Nevada, Texas e Novo México (EUA), concluíram que a condição de umidade antecedente exerce o maior efeito sobre o escoamento. Ainda, a 
umidade antecedente teve maior efeito e os resultados foram melhores para solos desnudos ou com vegetação rala.

Hawkins \& Cate (1998) estudaram os efeitos secundários (aqueles que poderiam influenciar a geração do escoamento, além do efeito principal que é o montante de chuva) sobre o escoamento direto, usando 1830 eventos em 25 pequenas bacias com chuvas efetivas maiores do que 1 polegada $(25,4 \mathrm{~mm})$. Uma variação da função do numero da curva foi usada como base para resposta primária da profundidade da chuva. Os resultados mostraram que a profundidade da chuva foi responsável pela maior parte da variância no escoamento direto. Os efeitos secundários, em geral, foram dispersos e inconsistentes, nem sempre de acordo com a razão hidrológica. $\mathrm{O}$ efeito secundário mais pronunciado foi a condição antecedente de umidade, que foi avaliada como o total de chuvas nos 5 dias antecedentes ao evento analisado (positivo em $44 \%$ dos casos). A distribuição temporal e intensidade da chuva apresentaram efeitos dispersos.

Quanto aos efeitos secundários, Ramser (1927), Ragan \& Duru (1972) Agiralioglu \& Singh (1981) e Singh \& Agiralioglu (1982), não encontraram correlação significativa entre a umidade antecedente - representada pelo total de chuva nas 48 horas antecedentes - e a produção de escoamento e também entre a intensidade da chuva e o escoarnento.

Amorim \& Leopoldo (1996) concluíram que o modelo do SCS não se ajustou às condições da Bacia do Córrego Paraíso (São Manuel-SP), quanto às condições de precipitação e armazenamento. Com uma área de $3,26 \mathrm{~km}^{2}$ em latossolo vermelhoamarelo, a bacia é coberta principalmente por pastagem (58\%), culturas e florestas. Os autores explicaram que o modelo não foi satisfatório para dimensionar o processo para valores de precipitação abaixo de 19,7 mm (precipitação crítica encontrada pelo método). Naquela situação, os autores observaram que os resultados não condiziam com a realidade, pois todos os eventos com menos de 19,7 mm de chuva produziram escoamento. Argumentaram que as características físicas e climáticas, cobertura vegetal e o tipo de manejo empregado na bacia não eram semelhantes às dos EUA, onde o modelo foi desenvolvido e seus coeficientes empíricos ajustados. 
Hawkins (1973) obteve, a partir de dados de bacias florestadas de pequeno tamanho nos E.U.A., um estranho ajuste empírico entre os valores de $\mathrm{CN}$ observados e o volume de precipitação. Em Hawkins (1979), o mesmo autor testou a hipótese de que tal comportamento decorreria das áreas saturadas aproximadamente impermeáveis. Concluiu que a determinação de um $\mathrm{CN}$ constante e independente do tamanho das chuvas não é adequado para todas as situações. O autor observou que em alguns eventos, ocorriam áreas constantes, saturadas e impermeáveis, por exemplo, a área dos canais, e outras com maior capacidade de infiltração. Entretanto, nos eventos extremos em intensidade ou a bacia em condições de umidade alta ou ambos, ocorriam outros processos.

Segundo Steenhuiss et al. (1995), o modelo do SCS está diretamente fundamentado nos princípios das áreas parciais e pode prever a área de contribuição com menos incômodo que o método de Boughton (1987). Boughton (1987) descreveu um modelo para determinação das proporções de áreas saturadas de uma bacia que contribuem ao fluxo superficial em diferentes eventos e num mesmo evento pela análise de dados observados de precipitação e vazão.

Cabe reforçar que o Método do $\mathrm{CN}$ foi elaborado a partir de eventos de chuva-escoamento de 24 horas, seu uso limita-se à determinação da lâmina de escoamento e não leva em conta as variações espaciais da intensidade de chuva. A distribuição temporal da chuva pode ser introduzida num estágio mais avançado, durante a geração da hidrógrafa, por meio da convolução da hidrógrafa unitária (Ponce, 1989).

\subsection{Determinação do número da curva a partir de tabelas}

As condições antecedentes de umidade são chamadas de $\mathrm{AMC}$ (Antecedent Moisture Conditions). Podem ser AMC I, AMC II e AMC III e dependem do volume de chuva nos 5 dias precedentes ao evento a ser simulado (Tabela 2). 
Tabela 2 - Condição de umidade antecedente em função da precipitação total nos cinco dias antecedentes, considerando a estação do ano.

\begin{tabular}{lrr}
\hline Condição de & Dormência & Estação de crescimento \\
\cline { 2 - 3 } Umidade antecedente. & Total de chuva nos 5 dias antecedentes $(\mathrm{cm})$ & \\
I & Menos de 1,3 & Menos de 3,6 \\
II & 1,3 à 2,8 & 3,6 à 5,3 \\
III & Mais de 2,8 & Mais de 5,3 \\
\hline
\end{tabular}

Fonte:USDA(1972)

Os CN's para as diversas condições de superficie e umidade antecedente, para áreas rurais e urbanas estão disponiveis em tabelas do SCS para regiões e vegetações típicas dos E.U.A. Na Tabela 3, é feita a determinação dos valores de $\mathrm{CN}$, conforme as diversas condições, segundo Setzer e Porto (1979). Os valores de CN apresentados na Tabela 3 são válidos para a condição de umidade antecedente AMC II. Para serem aplicados às outras duas condições, existem tabelas de correção. Hawkins et al. (1985) correlacionaram os valores de potencial máximo de retenção (S) para as condições de AMC I e III com o potencial para a condição AMC II e encontraram, com uma boa aproximação, a razão de 2,3 para $\mathrm{S}_{\mathrm{I}} / \mathrm{S}_{\amalg}$ e $\mathrm{S}_{\mathrm{I}} / \mathrm{S}_{\text {III. }}$. A partir dessa relação as seguintes expressões foram desenvolvidas para o cálculo dos CN's para as condições AMC I e AMC III.

$$
\begin{aligned}
& \mathrm{CN}(\mathrm{I})=\frac{4,2 \mathrm{CN}(\mathrm{II})}{10-0,058 \mathrm{CN}(\mathrm{II})} \\
& \mathrm{CN}(\mathrm{III})=\frac{23 \mathrm{CN}(\mathrm{II})}{10+0,13 \mathrm{CN}(\mathrm{II})}
\end{aligned}
$$


Tabela 3 - Valores dos parâmetros $\mathrm{CN}$ para bacias rurais na condiçào antecedente de umidade do solo II (Setzer \& Porto, 1979).

\begin{tabular}{|c|c|c|c|c|c|c|c|}
\hline \multirow{2}{*}{$\begin{array}{l}\text { Cobertura vegetal ou } \\
\text { tipo de uso do solo }\end{array}$} & \multirow{2}{*}{$\begin{array}{c}\text { Condição da } \\
\text { superfície }\end{array}$} & \multirow{2}{*}{$\begin{array}{l}\text { Situação } \\
\text { hidrológica } \\
\end{array}$} & \multicolumn{5}{|c|}{ Grupo hidrológicodo solo } \\
\hline & & & A & B & $\mathrm{C}$ & D & $E$ \\
\hline $\begin{array}{l}\text { Solo arado quase, } \\
\text { sem cobertura }\end{array}$ & $\begin{array}{l}\text { SR } \\
\text { SR }\end{array}$ & $\begin{array}{l}\text { Boas } \\
\text { Boas }\end{array}$ & $\begin{array}{l}65 \\
65\end{array}$ & $\begin{array}{l}80 \\
78\end{array}$ & $\begin{array}{l}88 \\
86\end{array}$ & $\begin{array}{l}92 \\
90\end{array}$ & $\begin{array}{l}95 \\
92\end{array}$ \\
\hline $\begin{array}{l}\text { Cultivos de ciclo curto } \\
\text { e arações freqüêntes }\end{array}$ & $\begin{array}{l}\text { SR } \\
\text { SR } \\
C \\
C \\
C-T \\
C-T\end{array}$ & $\begin{array}{l}\text { Más } \\
\text { Boas } \\
\text { Más } \\
\text { Boas } \\
\text { Más } \\
\text { Boas }\end{array}$ & $\begin{array}{l}60 \\
52 \\
56 \\
48 \\
52 \\
45\end{array}$ & $\begin{array}{l}72 \\
66 \\
65 \\
60 \\
62 \\
55\end{array}$ & $\begin{array}{l}81 \\
75 \\
78 \\
72 \\
74 \\
67\end{array}$ & $\begin{array}{l}87 \\
82 \\
84 \\
78 \\
80 \\
75\end{array}$ & $\begin{array}{l}90 \\
86 \\
87 \\
82 \\
84 \\
80\end{array}$ \\
\hline $\begin{array}{l}\text { Cultivos de ciclo médio } \\
\text { arações anuais }\end{array}$ & $\begin{array}{l}\text { SR } \\
\text { SR } \\
C \\
C \\
T \\
T\end{array}$ & $\begin{array}{l}\text { Más } \\
\text { Boas } \\
\text { Más } \\
\text { Boas } \\
\text { Más } \\
\text { Boas }\end{array}$ & $\begin{array}{l}58 \\
54 \\
55 \\
50 \\
52 \\
48\end{array}$ & $\begin{array}{l}65 \\
62 \\
64 \\
60 \\
62 \\
55\end{array}$ & $\begin{array}{l}73 \\
70 \\
72 \\
67 \\
70 \\
65\end{array}$ & $\begin{array}{l}82 \\
79 \\
78 \\
75 \\
77 \\
73\end{array}$ & $\begin{array}{l}88 \\
85 \\
84 \\
83 \\
82 \\
80\end{array}$ \\
\hline $\begin{array}{l}\text { Semeação densa ou } \\
\text { a lanço; cobertura curta } \\
\text { mas densa, como } \\
\text { a das leguminosas e } \\
\text { dos pastos em rodizio }\end{array}$ & $\begin{array}{l}\text { SR } \\
\text { SR } \\
C \\
C \\
T \\
T\end{array}$ & $\begin{array}{l}\text { Más } \\
\text { Boas } \\
\text { Más } \\
\text { Boas } \\
\text { Más } \\
\text { Boas }\end{array}$ & $\begin{array}{l}56 \\
50 \\
54 \\
48 \\
50 \\
45\end{array}$ & $\begin{array}{l}64 \\
58 \\
60 \\
56 \\
58 \\
52\end{array}$ & $\begin{array}{l}72 \\
66 \\
69 \\
64 \\
65 \\
60\end{array}$ & $\begin{array}{l}80 \\
76 \\
76 \\
72 \\
75 \\
70\end{array}$ & $\begin{array}{l}86 \\
82 \\
83 \\
80 \\
80 \\
76\end{array}$ \\
\hline $\begin{array}{l}\text { Pastagem velha com } \\
\text { arbustos }\end{array}$ & $\begin{array}{l}C \\
C \\
C\end{array}$ & $\begin{array}{l}\text { Más } \\
\text { Boas } \\
\text { Más } \\
\text { Boas } \\
\text { Más } \\
\text { Boas }\end{array}$ & $\begin{array}{l}65 \\
60 \\
56 \\
55 \\
42 \\
50\end{array}$ & $\begin{array}{l}70 \\
66 \\
62 \\
62 \\
59 \\
56\end{array}$ & $\begin{array}{l}78 \\
75 \\
72 \\
70 \\
67 \\
64\end{array}$ & $\begin{array}{l}85 \\
82 \\
79 \\
78 \\
75 \\
72\end{array}$ & $\begin{array}{l}90 \\
87 \\
84 \\
86 \\
82 \\
79\end{array}$ \\
\hline Reflorestamento & $\begin{array}{c}\text { SR } \\
\text { SR } \\
C \\
C\end{array}$ & $\begin{array}{l}\text { Más } \\
\text { Boas } \\
\text { Más } \\
\text { Boas }\end{array}$ & $\begin{array}{l}35 \\
30 \\
30 \\
25\end{array}$ & $\begin{array}{l}50 \\
42 \\
45 \\
36\end{array}$ & $\begin{array}{l}62 \\
55 \\
57 \\
52\end{array}$ & $\begin{array}{l}74 \\
68 \\
69 \\
64\end{array}$ & $\begin{array}{l}83 \\
78 \\
80 \\
75\end{array}$ \\
\hline $\begin{array}{l}\text { Mata } \\
\text { capoeira velha }\end{array}$ & & $\begin{array}{l}\text { Más } \\
\text { Boas }\end{array}$ & $\begin{array}{l}32 \\
18\end{array}$ & $\begin{array}{l}40 \\
25\end{array}$ & $\begin{array}{l}55 \\
42\end{array}$ & $\begin{array}{l}67 \\
58\end{array}$ & $\begin{array}{l}76 \\
70\end{array}$ \\
\hline $\begin{array}{l}\text { Gramados } \\
\text { tratados }\end{array}$ & & $\begin{array}{l}\text { Más } \\
\text { Boas }\end{array}$ & $\begin{array}{l}65 \\
59\end{array}$ & $\begin{array}{l}72 \\
67\end{array}$ & $\begin{array}{l}78 \\
74\end{array}$ & $\begin{array}{l}84 \\
81\end{array}$ & $\begin{array}{l}88 \\
86\end{array}$ \\
\hline $\begin{array}{l}\text { Estradas de } \\
\text { terra }\end{array}$ & & $\begin{array}{l}\text { Más } \\
\text { Boas }\end{array}$ & $\begin{array}{l}80 \\
74 \\
\end{array}$ & $\begin{array}{l}85 \\
80 \\
\end{array}$ & $\begin{array}{l}90 \\
86 \\
\end{array}$ & $\begin{array}{l}93 \\
90\end{array}$ & $\begin{array}{l}95 \\
92 \\
\end{array}$ \\
\hline
\end{tabular}

Notas: $S R=$ sulcos retos; $T$ =terraceamento; $C=$ cultivo em contorno, paralelamente às curvas de nivel.

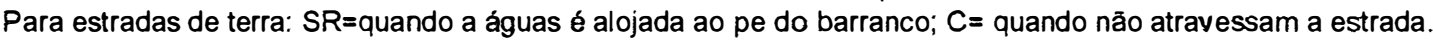

Fonte: Setzer \& Porto (1979). 
Os CN's apresentados na Tabela 3 foram tabulados pelo SCS em função do tipo de solo e uso da terra e foram definidos cinco grupos de solos conforme a divisão de Setzer \& Porto (1979). Segundo Genovez (1991), esses autores basearam-se em estudos pedológicos ocorrentes em todas as formações geológicas do Estado de São Paulo e em fotografias aéreas e, aproveitando as idéias do SCS, dividiram os solos em cinco grupos hidrológicos conforme a descrição a seguir:

"A-Solos arenosos com baixo teor de argila total, inferior a $8 \%$, não há rocha nem camadas argilosas e nem mesmo densificadas até a profundidade de $1,5 \mathrm{~m}$. O teor de humus é muito baixo, não atingindo $1 \%$. Com potencial mínimo de escoamento superficial. Alta taxa de infiltração.

B-Solos arenosos menos profundos que os do grupo A e com maior teor de argila total, porém ainda inferior a $15 \%$. No caso de terras roxas, este limite pode subir a $20 \%$ graças a maior porosidade. Os dois teores de humus podem subir, respectivamente, a $1,2 \%$ e $15 \%$. Não pode haver pedras e nem camadas argilosas até 1,5 m, mas é quase sempre presente camada mais densificada que a camada superficial. Taxa de infiltração superior à média.

C-Solos barrentos com teor total de argila de 20\% a $30 \%$, mas sem camadas argilosas impermeáveis ou contendo pedras até a profundidade de 1,2 $\mathrm{m}$. No caso de terras roxas, estes dois limites máximos podem ser de $40 \%$ e $1,5 \mathrm{~m}$. Nota-se a cerca de $60 \mathrm{~cm}$ de profundidade camada mais densificada que no grupo B, mas ainda longe das condições de impermeabilidade.

D-Solos argilosos (30\%-40\% de argila total) e ainda com a camada densificada a uns $50 \mathrm{~cm}$ de profundidade. Ou solos arenosos como B, mas com camada argilosa quase impermeável ou horizonte de seixos rolados. Alto potencial de escoamento superficial.

E-Solos barrentos como $\mathrm{C}$, mas com camadas argilosa impermeável ou com pedras. Ou sem tal camada, mas o teor total de argila supera $40 \%$. No caso de terras roxas, este teor pode subir a $60 \%$ (no caso D, $45 \%$ ). O mais alto potencial de escoamento superficial" (Genovez ,1991, p.53-54). 
Pelo SCS (USDA, 1972 e 1986), os solos são classificados em quatro grupos hidrológicos (A, B, C e D) para indicar a taxa mínima de infiltração, obtida quando os solos estiverem desnudos e após prolongado umedecimento. A taxa de infiltração, que é a taxa na qual a água penetra a superficie do solo, é controlada pelas condições da superficie. Os grupos hidrológicos dos solos também indicam a taxa de transmissão, ou seja, a taxa em que a água se movimenta no perfil do solo. Os quatro grupos hidrológicos foram definidos pelo SCS conforne discriminado na Tabela 4 (USDA, 1986).

Tabela 4 - Tabela de grupos hidrológicos.

\begin{tabular}{|l|l|}
\hline Grupos & Caracterização \\
\hline A & $\begin{array}{l}\text { Solos arenosos profundos com pouca argila e silte. } \\
\text { Bem drenados. } \\
\text { Apresentam altas taxas de infiltração mesmo quando úmidos. } \\
\text { Apresentam altas taxas de transmissão da água. } \\
\text { Produzem baixo escorrimento superficial. } \\
\text { Taxa de infiltração: } 7,6 \text { - 11,4 mm/hora*. }\end{array}$ \\
\hline B & $\begin{array}{l}\text { Solos com texturas finas a moderadamente grosseira. } \\
\text { Moderadamente profundos a profundos. } \\
\text { Bem drenados a moderadamente drenados. } \\
\text { Apresentam taxas de infiltração moderada quando úmidos. } \\
\text { Apresentam taxas moderadas de transmissão da água. } \\
\text { Taxa de infiltração: 3,8 - 7,6 mm/hora*. }\end{array}$ \\
\hline C & $\begin{array}{l}\text { Solos com texturas moderadamente finas a finas. } \\
\text { Solos com baixa infiltração quando úmidos. } \\
\text { Solos com camada de impedimento que impede movimento da água. } \\
\text { Apresentam baixas taxas de transmissão da água. } \\
\text { Taxa de infiltração: 1,3 - 3,8 mm/hora*. }\end{array}$ \\
\hline D & $\begin{array}{l}\text { Solos com argilas expansivas e pouco profundos. } \\
\text { Solos com camadas de argilas próximo a superficie ou na superficie. } \\
\text { Solos superficiais sobre materiais impermeáveis ou quase impermeáveis. } \\
\text { Apresentam taxas muito baixas de infiltração quando úmidos. } \\
\text { Apresentam taxas moderadas de transmissão da água. } \\
\text { Alto potencial de produção de escoamento superficial } \\
\text { Taxa de infiltração: 0 - 1,3 mm/hora* }\end{array}$ \\
\hline
\end{tabular}

*Segundo Skaggs \& Khaleel(1982) 
Lombardi Neto et al. (1989) fizeram uma associação de classes de solos com os grupos hidrológicos, baseados no Levantamento e Reconhecimento de Solos do Estado de São Paulo (BRASI, 1960). Por meio da associação (Tabela 5), é possível a obtenção direta dos grupos hidrológicos do solo que ocupam a bacia.

Tabela 5 - Agrupamento de solos segundo suas qualidades, características e resistência à erosão (Lombardi Neto et al., 1989).

\begin{tabular}{|c|c|c|c|c|c|c|c|}
\hline \multirow[b]{2}{*}{ Grupo } & \multirow[b]{2}{*}{$\begin{array}{c}\text { Resistência } \\
\text { à erosão }\end{array}$} & \multicolumn{3}{|c|}{ Principais características } & \multirow[b]{2}{*}{$\begin{array}{c}\text { Razảo }_{\text {textural }}^{(2)} \\
\text { tex }^{\text {Rex }}\end{array}$} & \multirow[b]{2}{*}{ Exemplos $^{(3)}$} & \multirow[b]{2}{*}{ Índice } \\
\hline & & Profundidade ${ }^{(1)}$ & Permeabilidade ${ }^{(1)}$ & Textura ${ }^{(1)}$ & & & \\
\hline A & alta & $\begin{array}{l}\text { muito profundo } \\
(>2 \mathrm{~m}) \\
\text { profundo } \\
(1 \text { a } 2 \mathrm{~m})\end{array}$ & $\begin{array}{l}\text { rápida/rápida } \\
\text { moderada/rápida }\end{array}$ & $\begin{array}{c}\text { média/média } \\
\text { m.argilosa/m.argilosa } \\
\text { argilosa/argilosa }\end{array}$ & $<1,2$ & $\begin{array}{l}\text { LR, LE, LV, } \\
\text { LVr, LVt, LH, } \\
\text { LEa e LVa }\end{array}$ & 1,25 \\
\hline B & moderada & $\begin{array}{l}\text { profundo } \\
(1 \text { a } 2 \mathrm{~m})\end{array}$ & $\begin{array}{c}\text { rápida/rápida } \\
\text { rápida/moderada } \\
\text { moderada/moderada }\end{array}$ & $\begin{array}{l}\text { arenosa/arenosa } \\
\text { arenosa/média } \\
\text { arenosa/argilosa } \\
\text { média/argilosa } \\
\text { argilosa/m.argilosa }\end{array}$ & 1,2 a 1,5 & $\begin{array}{l}\text { LJ, LVP, PV. } \\
\text { PVL, PIn, TE, } \\
\text { PVIs, R, RPV- } \\
\text { RLV, Lea } \\
\quad \text { LVa }\end{array}$ & 1,1 \\
\hline C & baixa & $\begin{array}{c}\text { profundo } \\
(1 \text { a } 2 \mathrm{~m}) \\
\text { moderadamente prof. } \\
(0,5 \mathrm{a} 1 \mathrm{~m})\end{array}$ & $\begin{array}{l}\text { lenta/rápida } \\
\text { lenta/moderada } \\
\text { rápida/moderada }\end{array}$ & $\begin{array}{l}\text { arenosa/média }^{(4)} \\
\text { média/argilosa } \\
\text { arenosa/argilosa }^{(4)} \\
\text { arenosa/m.argilosa }\end{array}$ & $>1,5$ & $\begin{array}{l}\text { Pml, PVp, } \\
\text { PVls, Pce } \\
\text { M }\end{array}$ & 0,9 \\
\hline D & muito baixa & $\begin{array}{c}\text { moderadam. prof. } \\
(0,5 \text { a } 1 \mathrm{~m}) \\
\text { raso } \\
(0,25 \text { a } 0,5 \mathrm{~m})\end{array}$ & $\begin{array}{l}\text { rápida, moderada } \\
\text { ou lenta sobre lenta }\end{array}$ & muito variável & $\begin{array}{c}\text { muito L } \\
\text { variável }\end{array}$ & $\begin{array}{l}\text { Li-b, Li-ag, gr, } \\
\text { Li-fi, Li-ac e } \\
\text { PVp (rasos) }\end{array}$ & 0,75 \\
\hline \multicolumn{8}{|c|}{$\begin{array}{l}\text { (1) Segundo Lepsch et al (1983). } \\
\text { (2) Média da porcentagem de argila do horizonte B (excluindo B3) sobre a média de todo o horizonte A } \\
\text { (3) Abreviaçzes segundo Brasil (1960). } \\
\text { (4) Somente com a mudança textural abrupta entre os horizontes A e B. } \\
\text { (5) Somente aqueles com horizonte A arenoso. }\end{array}$} \\
\hline
\end{tabular}




\subsection{Determinação do número da curva a partir de dados}

Apesar da disponibilidade de tabelas de valores de $\mathrm{CN}$ para variadas condições, quando existirem dados medidos de eventos de chuva e escoamento, os mesmos podem ser usados para determinações do número da curva. A determinação precisa de $\mathrm{CN}$ a partir de tabelas é dificil, sendo que a estimativa para áreas agricolas apresenta maior probabilidade de sucesso do que para bacias florestadas. (Hawkins, 1993). Segundo o USDA (1986), a determinação dos CN feita a partir de dados observados é mais confiável. Existem vários métodos, entre os quais o Método Gráfico e Estatistico (USDA, 1986) e o de Hawkins (1993).

O Método Gráfico é aplicado da seguinte maneira: plota-se a precipitação e vazão no gráfico da solução numérica da Equação do SCS (Equação 8). A seguir, determina-se a curva média que divide estes pontos ao meio. Para a determinação do número da curva, é feita a interpolação entre as duas curvas com as curvas de números inteiros mais próximos à mesma.

Para o Método Estatístico são calculados os valores de $\mathrm{S}$ e CN. O cálculo pode ser realizado pela Equação 13, que é um rearranjamento algébrico da Equação 8 para S.

$$
S=5\left[P+2 \cdot Q-\left(4 Q^{2}+5 P Q\right)^{1 / 2}\right]
$$

onde: P é a precipitação; Q o escoamento direto e existe a condição de $0<\mathrm{Q}<\mathrm{P}$. Para cada par de valores de $\mathrm{P}$ e $\mathrm{Q}$ é calculado de $\mathrm{S}$. Nessa equação, para $\mathrm{P}=\mathrm{Q}, \mathrm{S}=0$. O valor de $\mathrm{CN}$ é calculado usando-se a Equação 9.

Posteriormente, o logaritmo de cada valor de S (base 10 ou naturais) é calculado, assim como a média e o desvio padrão dos dados transformados são determinados. A média dos logaritmos de uma variável com distribuição lognormal é a média da variável original. Dessa forma, o antilogaritmo do resultado do desvio padrão 
calculado fornece a média do valor de $\mathrm{S}$. Então, com esse valor de $\mathrm{S}$, calcula-se o $\mathrm{CN}$. Tanto o Método Gráfico como o Estatístico são descritos em detalhes e com exemplos em USDA (1986).

Righetto (1998), ao descrever os procedimentos do SCS, fez algumas recomendações. Em nível regional, valores experimentais de precipitação e escoamento devem ser levantados com a finalidade de permitir ajustes do CN. Para tanto, a maior tormenta observada deve ser considerada. Ainda, os valores de $\mathrm{S}$ e $\mathrm{CN}$ devem ser calculados e ser verificado se P>0,46. Caso contrario, o par de valores não é adequado para a realização da determinação. Em seguida, tomar a segunda maior tormenta observada, e se $\mathrm{P}>0,46$, calcular $\mathrm{CN}$ pela média dos dois eventos considerados. Sucessivamente, são introduzidas novas observações a medida que vão sendo coletadas.

O Método de Hawkins (1993) usa eventos de precipitação e escoamento direto. Para cada par de precipitação e escoamento direto, é feita a determinação de S e $\mathrm{CN}$ seguindo as Equações 13 e 9, respectivamente. A partir das relações observadas entre $\mathrm{CN}$ e precipitação, é feito o enquadramento em 3 categorias conforme o comportamento. O comportamento complacent apresenta um valor de $\mathrm{CN}$ que declina contianuamente sem apresentar um valor constante. Os comportamentos padrão (fluxo superficial e subsuperficial rápido) e violento definem um $\mathrm{CN}$ constante com o aumento da precipitação, o que permite uma determinação assintótica do valor do $\mathrm{CN}$. Contudo, o caso complacente não leva a uma definição segura do $\mathrm{CN}$. Neste caso o autor recomenda outras metodologias de determinação do escoamento superficial.

\subsection{Hidrógrafa Sintética Adimensional do SCS para transformação da chuva efetiva em hidrógrafas de escoamento.}

A Hidrógrafa Unitária Adimensional do SCS, desenvolvida por Victor Mockus em 1950 e descrita pelo USDA em 1972, é amplamente utilizada para transformação da chuva em escoamento. Trata-se do resultado da análise de um grande número de hidrógrafas unitárias naturais dos Estados Unidos, com vários tamanhos e 

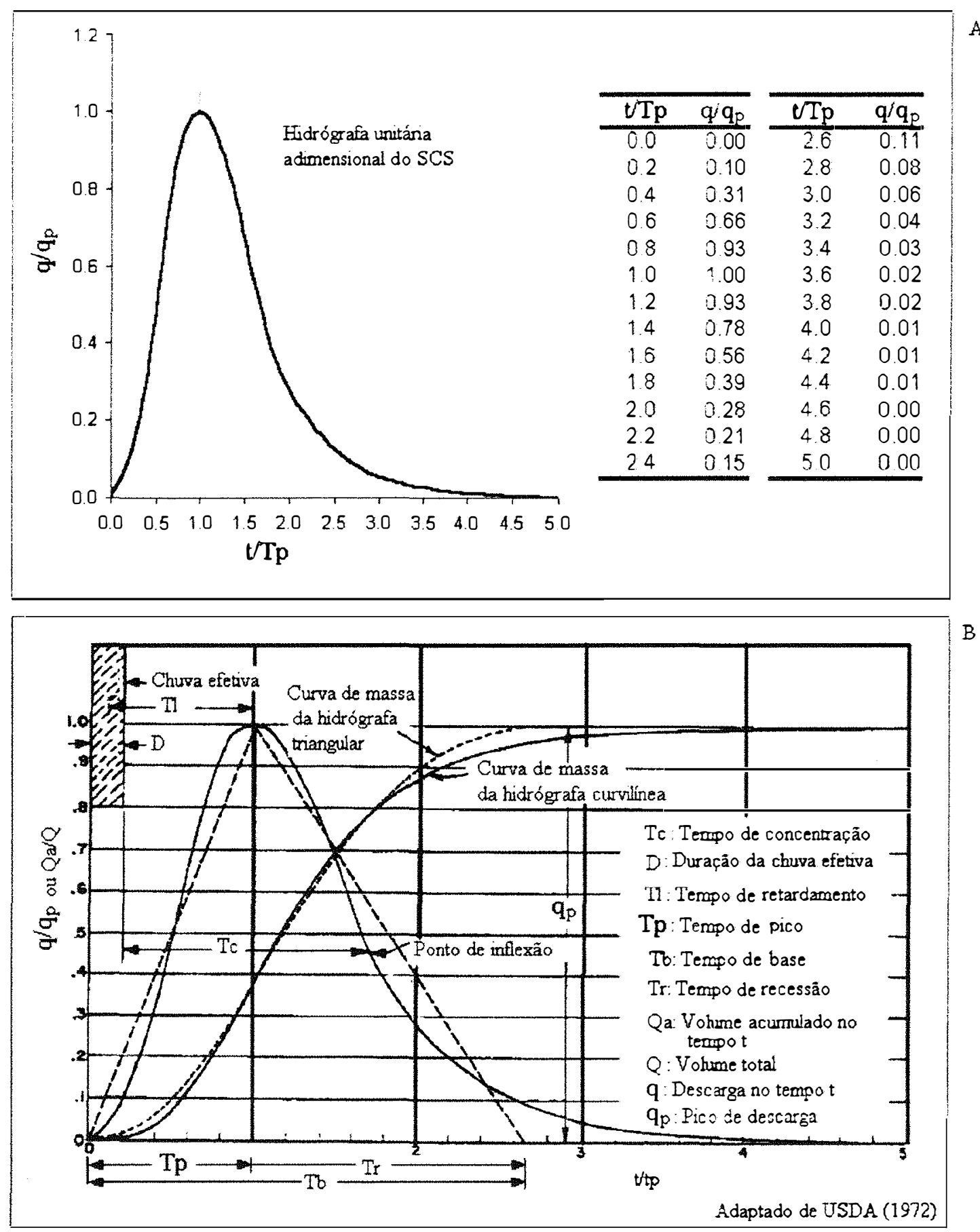

Figura 5 - Hidrógrafa Sintética Adimensional do SCS, na forma gráfica e tabular (A), comparação entre a forma triangular e curvilínea e interpretação dos parâmetros (B). 
diversos locais. O método tem sido aplicado a bacias de tamanho médio. A Hidrógrafa Unitária Adimensional do SCS (Figura 5 A e B) expressa uma deternninada vazão como uma taxa entre vazão/vazão de pico (Q/Qp) e o tempo como uma taxa entre tempo/tempo de pico ( $\mathrm{t} / \mathrm{tp})$ e confere um formato padrão de hidrógrafa unitária. Juntamente com ela, os tempos de retardamento e de concentração são os fundamentos do Método do SCS para transformar a chuva em escoamento.

A Hidrógrafa Adimensional do SCS apresenta o ponto de inflexão, a aproximadamente 1,7 vezes o tempo de pico, e o tempo de pico é 0,2 vezes o tempobase. Ela perfaz 37,5\% do volume total no ramo ascendente. Essa hidrógrafa curvilínea também pode ser representada por um triângulo, com as mesmas unidades de tempo e descarga (Figura 5B). Para uma precipitação de $1 \mathrm{~cm}$ sobre a área, pesquisas do SCS mostraram que o pico de vazão pode ser expresso pela Equação 14:

$$
q_{p}=C \frac{A}{T_{p}}
$$

onde: $\mathrm{q}_{p}$ é o pico de vazão $\left(\mathrm{m}^{3} / \mathrm{s}\right)$; A é a área da bacia $\left(\mathrm{km}^{2}\right), T_{p}$ é o tempo do pico (horas) e C uma constante de conversão (2,08 no SI). O detalhamento de como foi obtido o valor 2,08 pode ser encontrado em USDA (1972) ou em Genovez (1991). O tempo de pico, que também é conhecido como o tempo de ascensão, está relacionado pela equação:

$$
\mathrm{T}_{\mathrm{p}}=\frac{\Delta \mathrm{t}}{2}+\mathrm{t}_{1}
$$

onde: o $\Delta t$ expressa o intervalo dos cálculos ou a duração da chuva efetiva (D) e $t_{1}$ é o tempo de retardamento da bacia.

Para uma adequada definição das ordenadas no ramo ascendente, os intervalos de tempos $(\Delta t)$ usados nos cálculos não deverão ser maiores do que $29 \%$ do tempo de retardamento (HEC-USACE, 1998a). 
O tempo de retardamento é um parâmetro importante na transformação da precipitação efetiva em hidrógrafas, pois, quando esse é fornecido pela Equação 15 , encontra-se o tempo de pico da hidrógrafa unitária $\left(\mathrm{T}_{\mathrm{p}}\right)$, e pela Equação 14 é determinado o pico de vazão $\left(q_{p}\right)$. Com esses valores e com as taxas $t / T_{p}$ e $q / q_{p} d a$ hidrógrafa adimensional e por multiplicação, pode ser feita a determinação da hidrógrafa, para dado evento de precipitação efetiva.

Apesar de constar na literatura diferentes definições - Singh (1988) enumerou nove - no Método do SCS, tempo de retardamento significa a diferença de tempo entre o centróide da chuva efetiva e o pico do escoamento direto. Ou seja, por essa definição, o seu cálculo demanda apenas dados de precipitação e descarga.

O tempo de retardamento da bacia, na verdade, nada mais é que o tempo de concentração ponderado. Cabe recordar que o tempo de concentração é o maior tempo que uma gota de chuva leva para chegar à saída da bacia. O tempo de retardamento também pode ser escrito como:

$$
t_{1}=\frac{\sum_{i=1}^{N} A \cdot Q_{i} \cdot t_{i}}{\sum_{i=1}^{N} A_{i} \cdot Q_{i}}
$$

onde: $A_{i}$ é o i-ésimo incremento da área da bacia; $Q_{i}$ é a chuva efetiva da área da bacia $\mathrm{Ai} ; \mathrm{t}_{\mathrm{i}} \mathrm{o}$ tempo de percurso a partir do centro de $\mathrm{A}_{i}$ até o local em consideração e $\mathrm{N}$ o número de área incrementais pelo qual a bacia é dividida para a estimativa do tempo de retardamento.

Pesquisadores têm dividido diferentemente o tempo de retardamento. $\mathrm{O}$ USDA (1986) considera que o tempo de retardamento $\left(\mathrm{t}_{\mathrm{t}}\right.$ ) está relacionado ao tempo de concentração $\left(t_{c}\right)$ por $t_{1}=0,6$.tc. Essa relação é válida para condições naturais médias, com distribuição do escoamento aproximadamente uniforme sobre a bacia. Quando as condições não forem uniformes, a bacia pode ser dividida em segmentos menores até que o escoamento seja quase uniforme e a equação anterior possa ser aplicada. 
Simas (1996) estudando 168 pequenas bacias dos EUA, em 50.000 eventos de chuvas verificou que o tempo de retardamento varia consideravelmente. No entanto, é mais estável para eventos de chuvas maiores. Afinal, nesses tipos de eventos, as condições de equilibrio dinâmico se aproximam.

$\mathrm{Na}$ aplicação do Método do SCS, a estimativa do tempo de retardamento, pode ser determinado por calibração, quando existirem dados de precipitação e vazão para as bacias. No caso de bacias sem dados, existe a sugestão do SCS de que o tempo de retardamento seja calculado por métodos que o relacionem com o tempo de concentração da bacia, através da relação empírica $\mathrm{Tl}=0,6 \mathrm{Tc}$. $\mathrm{Na}$ análise de hidrógrafas o tempo de concentração é o tempo entre o final da chuva efetiva e a ocorrência do ponto de inflexão (Figura 5B), onde a fase de recessão inicia. Entretanto quando não existirem hidrógrafas, para a determinação existem várias metodologias que podem ser usadas, algumas baseadas nos processos físicos e outras empíricas. Assim, entre tantos métodos podem ser usados o Método da Velocidade ou o Método do Número da Curva. Porém pode ser uma boa prática, considerar vários métodos e escolher o que melhor se adapta às características de uma dada bacia (USDA, 1972, Ponce, 1989).

\subsection{Método do $\mathrm{CN}$}

Em ASCE (1996) recomenda-se o Método do Número da Curva para a determinação do tempo de retardamento para bacias densamente florestadas, com canais declivosos, bacias com grande fluxo subsuperficial e intemo, cobertas por pastagens, para superficies do terreno suaves e superficies pavimentadas. O cálculo do tempo de retardamento pode ser feito pela equação:

$$
t_{1}=\frac{L^{0,8} \cdot(2540-22,86 \cdot C N)^{0,7}}{14,104 \cdot \mathrm{CN}^{0,7} \cdot \mathrm{Y}^{0,7}}
$$


onde: $t_{1}$ é o tempo de retardamento (lag) em horas; $L$, o comprimento do principal curso $(\mathrm{m})$; $\mathrm{CN}$, o número da curva e $\mathrm{Y}$, a declividade média $(\mathrm{m} / \mathrm{m})$. O valor de $\mathrm{CN}$ representa o valor médio para a bacia e é restrito ao intervalo de 50 a 95 (Ponce, 1989).

A equação pode ser usada para bacias com área de drenagem entre 0,4 ha e 810 ha. O tempo de concentração deve estar entre 0,1 horas e menos do que 10 horas, ao passo que o comprimento da trajetória do fluxo entre $61 \mathrm{~m}$ e $7900 \mathrm{~m}$. Essas restrições foram desenvolvidas com base nas bacias que foram utilizadas para desenvolver a equação. No entanto, recentes evidências sugerem que o método possa ser estendido para bacias maiores do que $16 \mathrm{~km}^{2}$, desde que a escolha do $\mathrm{CN}$ seja feita com cautela.

\subsection{Métodos que consideram a velocidade do fluxo}

O tempo de concentração pode ser considerado um parâmetro parcialmente baseado nos processos físicos. Ele é estimado como uma soma dos tempos de percursos nos canais, nos segmentos laminares do fluxo sobre o terreno e nos segmentos rasos de canais, estradas e sarjetas (HEC-USACE, 2000). Assim, o curso principal é dividido em extensões, a velocidade média (V) é calculada e o tempo de percurso ( $\mathrm{t}$ ) determinado para o comprimento do trecho (L) por $\mathrm{t}=\mathrm{L} / \mathrm{V}$. A soma do tempo de percurso para todas as extensões é o tempo de concentração da bacia.

O tempo de retardamento é estimado a partir do tempo de concentração da bacia, usando-se a relação $0,6 \mathrm{Tc}$. Entretanto, a experiência do SCS tem mostrado que essa taxa é típica de bacias de tamanho médio. Segundo Ponce (1989), o Método da Velocidade é indicado para bacias com $\mathrm{CN}$ fora do intervalo 50 a 95 ou maiores do que $8 \mathrm{~km}^{2}$. Para o USDA (1972), o método é recomendado para áreas onde o escoamento superficial é predominante. Ele também pode resultar em tempos de concentração muito curtos em áreas onde os fluxos internos e subterrâneos forem os predominantes.

Para essas determinações, o ponto critico é a estimação da velocidade da água em cada um dos segmentos. Conforme Chow et al. (1988), o fluxo superficial é um processo complicado porque varia no tempo e no espaço tridimensional. O fluxo superficial acontece como uma fina camada distribuida no terreno. No entanto, esse 
fluxo persiste apenas por alguma distância, por aproximadamente 30 metros, formando canais tortuosos. A seguir, concentra-se gradualmente com a fusão do fluxo em uma rede de drenagem, que pode ser identificada mesmo fora de eventos de chuvas.

O fluxo superficial da água é governado pelo princípio da continuidade e momento. A aplicação desses princípios para um fluxo tridimensional variável é possivel somente se forem assumidas situações simplificadas, que possibilitem considerar o fluxo de forma unidimensional ou bidimensional. Como o fluxo aumenta unidimensionalmente, ou seja, a profundidade do fluxo aumenta conforme a água desce à jusante, fica fácil entender que a resistência ao fluxo decorrente da superficie e canais diminui de montante à jusante. Para levar em conta essas características do fluxo laminar, Maidment et al. (1996a) propuseram a Equação 18 para calcular modificações da velocidade conforme o fluxo se desloca à jusante.

$$
\mathrm{v}=\mathrm{v}_{\mathrm{m}} \frac{\mathrm{S}^{\mathrm{b}} \mathrm{A}^{\mathrm{c}}}{\left[\mathrm{S}^{\mathrm{b}} \mathrm{A}^{\mathrm{c}}\right]_{\mathrm{m}}}
$$

onde: $v$ é a velocidade superficial do fluxo $(\mathrm{m} / \mathrm{s}) ; \mathrm{v}_{\mathrm{m}}$ a velocidade média da área inteira da bacia; $\mathrm{S}$ a declividade da superfície do solo; $\mathrm{A}$ a área de drenagem à montante; $\left[S^{b} A^{c}\right]_{m}$ a média de $S^{b} A^{c}$ de toda a área da bacia e b e c são constantes. $O$ termo $A^{c}$ reflete implicitamente o raio hidráulico, conforme fluxo se desloca a jusante. $O$ termo $\frac{\mathrm{S}^{\mathrm{b}} \mathrm{A}^{\mathrm{c}}}{\left[\mathrm{S}^{\mathrm{b}} \mathrm{A}^{\mathrm{c}}\right]_{n}^{-}}$modifica a velocidade média $\left(\mathrm{v}_{\mathrm{m}}\right)$ para refletir mudanças locais quanto à declividade e área de drenagem. Como os cálculos da velocidade podem variar muito ou mesmo serem nulos, graças às variações na declividade, devem ser estabelecidos limites [ $V_{\text {mirima }}<v<V_{\text {máxima] }}$. A Equação 19 é adequada para ser aplicada em Sistemas de Informaçōes Geográficas juntamente com informações provenientes de MDT.

Para o cálculo da velocidade na superficie do terreno, o USDA (1972) apresentou o nomograma do Upland Method (Figura 6). A partir dele, podem ser retiradas as velocidades para vários tipos de ocupações, levando em conta também a declividade do trecho considerado. A velocidade na superficie do terreno varia muito 


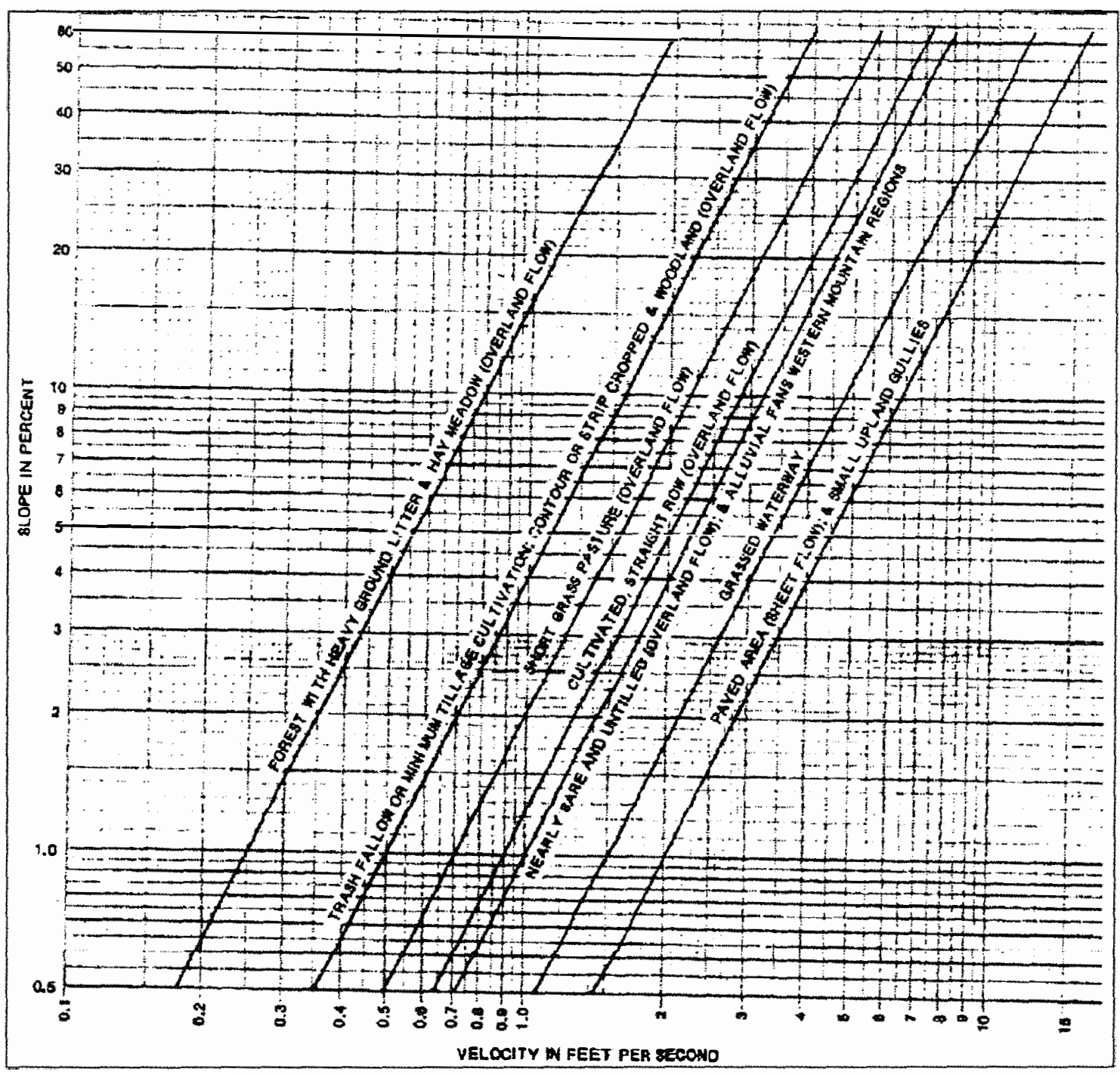

Figura 6 - Nomograma para estimativa das velocidades do fluxo (USDA,1972).

com o tipo de ocupação (Figura 6). Os fluxos considerados para aplicação desta metodologia são aqueles sobre a superficie do terreno, ou em canais gramados, sobre áreas pavimentadas e em pequenas ravinas com fluxo concentrado pouco profundo.

Os segmentos do escoamento mais remotos, que compõem o tempo de concentração, ocorrem em maior proporção, formando lâminas sobre a superficie do terreno e definindo canais. Eles são, segundo o USDA (1972), importantes apenas em 
bacias de pequeno tamanho, uma vez que a concentração do fluxo ocorre a menos de uma centena de metros de sua origem. Assim, a aplicação do Upland Method deverá ser feita em bacias pequenas ou em sub-bacias de bacias maiores, onde é impossível o levantamento topográfico das seções transversais dos canais e outros detalhes hidráulicos.

O tempo de percurso do fluxo sobre superficies planas e com comprimento do fluxo menores que $100 \mathrm{~m}$ pode ser calculado por uma solução aproximada das equações da onda cinemática (Equação 19). Esta equação foi desenvolvida pelo SCS e revisada em USDA (1986).

$$
\mathrm{t}=\frac{0,007(\mathrm{~nL})^{0,8}}{\left(\mathrm{P}_{2}\right)^{0.5} \mathrm{~S}^{0,4}}
$$

onde: $\mathrm{t}$ é o tempo de percurso (horas) ou tempo de concentração se for considerada a bacia inteira, $n$ é o coeficiente de rugosidade de Manning, $L$ é o comprimento do fluxo (ft), $\mathrm{P}_{2}$ é uma chuva de 24 horas de duração e tempo de retorno de 2 anos (polegadas) e $\mathrm{S}$ a declividade do terreno ( $\mathrm{ft} / \mathrm{ft}$ ). Os valores dos coeficientes de rugosidade de Manning (n) para fluxo laminar foram compilados por Engman (1986).

As simplificações desta solução cinemática de Manning são baseadas no fato de que o fluxo é raso e uniforme e está em equilíbrio. A intensidade da chuva efetiva é constante e com duração de 24 horas. A importância da infiltração sobre o tempo de percurso é pequena.

O fluxo raso se concentra após $100 \mathrm{~m}$. A velocidade para o fluxo, nessas condições, pode ser calculado como $\mathrm{V}=16,1345 . \mathrm{S}^{0,5}$ para superficies permeáveis e $\mathrm{V}=20,3282 \mathrm{~S}^{0,5}$ para superficies pavimentadas - $\mathrm{V}$ é a velocidade em $\mathrm{ft} / \mathrm{s}$ e $\mathrm{S}$, a declividade em ft/ft (HEC-HMS, 2000). Segundo USDA (1986), essas duas equações são baseadas na solução da Equação de Manning para os coeficientes de rugosidade e raios hidráulicos correspondentes, para as duas situações. 
Para o fluxo concentrado em canais, a velocidade deve ser calculada conforme técnicas de análise de canais. Nesse caso, é possível recorrer-se à Equação de Manning (Equação 20).

$$
\mathrm{V}=\frac{1}{\mathrm{n}} \mathrm{R}^{2 / 3} \mathrm{~S}^{12}
$$

onde: o R é o raio hidraúlico ( $\mathrm{m}$ ); $\mathrm{S}$ a declividade da linha de energia, sendo considerada como a declividade do fundo do canal $(\mathrm{m} / \mathrm{m}) ; \mathrm{n}$ um fator de friç̧ão e $\mathrm{v}$ a velocidade $(\mathrm{m} / \mathrm{s})$. Na literatura, existem diversos trabalhos com tabelas de valores dos coeficientes $\mathrm{n}$ para várias situações. Para canais, Chow (1959) apresentou uma chave ilustrada com fotografias e descrições para determinação de coeficientes de rugosidade $n$ para condições típicas.

Quando for considerado um fluxo laminar sobre o terreno, é possível adotar um valor de $\mathrm{R}$ de $\mathrm{D} / 100$, onde $\mathrm{D}$ é a profundidade do fluxo em $\mathrm{cm}$. $\mathrm{O}$ raio hidráulico $(\mathrm{R})$ é definido como uma razão entre a área da seção transversal e o perímetro molhado.

\subsubsection{Modelos de propagação em canais}

Pelos métodos anteriores, é determinada a quantidade da chuva que transformou-se em escoamento direto, e o retardamento que a mesmo sofre até atingir a saída de sub-bacias. Mas antes de atingir a saída da bacia, o fluxo de água passa por canais. Este processo é chamado de propagação (routing) de canais e inclui a combinação de uma vazão à montante como entrada para prever a vazão em determinado ponto do trecho de canal à jusante. A propagação em canais emprega modelos matemáticos para prever a mudança quanto ao montante, velocidade e forma da onda de cheia nos cursos de água. Existem muitos métodos, o Método da Onda Cinemática, Método de Puls Modificado, Muskingum e o Retardamento Puro. Um dos mais usados é o Método Muskingum, que foi, segundo Tucci (1993), desenvolvido por 
McCarthy em 1939 e aplicado no Rio Muskingum. O método se baseia na equação da continuidade e na equação do armazenamento. Uma das grandes vantagens desse método é que ele é capaz de modelar a relação entre descarga e armazenamento (Chow et al., 1988).

O Método Muskingum usa o volume de água armazenada nos canais como soma de um prisma e uma cunha, como mostrado na Figura 7. O prisma representa o armazenamento através de uma seção constante ao longo do comprimento de canal. A cunha representa um volume adicional de água não contida pelo prisma, ou a onda causada pela entrada da água na seção do canal (Dugger, 1997).

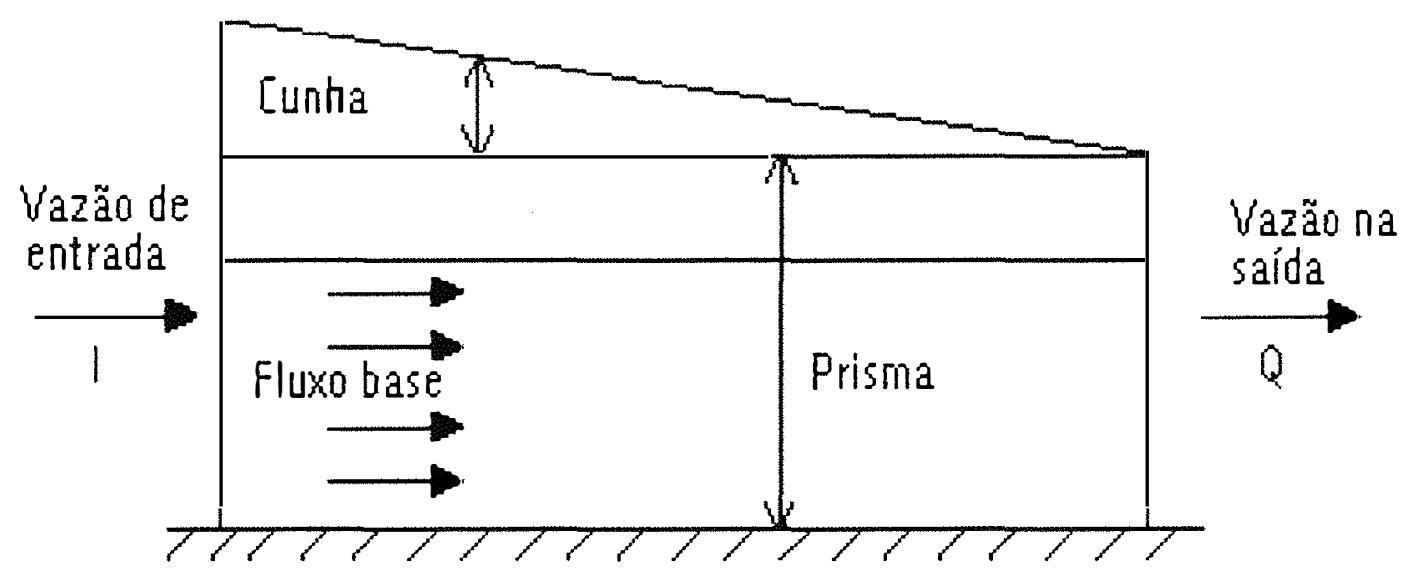

Figura 7 - Armazenamentos em prisma e cunha no Método de Muskingum (adaptado de Dugger, 1997).

Assumindo velocidade constante, existe uma taxa constante entre a vazão e a secção transversal. Isso significa que a vazão é diretamente dependente do volume armazenado no prisma, multiplicado por um fator $\mathrm{K}$ (armazenamento no prisma $=\mathrm{K} . \mathrm{Q}$ ). 
O armazenamento no prisma é dependente do comprimento do trecho e área da seç̧ào transversal. $\mathrm{O}$ fator $\mathrm{K}$ significa o tempo de percurso da onda através do trecho de canal sendo modelado. O volume armazenado na cunha depende de ondas adicionais de àgua, ou seja, a diferença de vazào entre a entrada e a saida (1-Q). Assim, o armazenamento total pode ser derivado, segundo Chow et al. (1988), como:

$$
S=K[X I+(1-X) Q]
$$

onde: $X$ é um fator de ponderaçào variando de a 0,5 , dependendo da forma da cunha. Ele representa a habilidade do trecho de canal em reter a água.

Para um reservatório, ou armazenamento total, o fator de ponderaçào é minimo $(X=0)$, significando que nào existe cunha enquanto nào houver saida de água. Já, o máximo fator de ponderaçào $(X=0,5)$ significa translaçào pura, ou seja, sem efeitos de armazenamentos. Normalmente em rios, o valor de $X$ situa-se entre 0 e 0,3 . A equaçào acima é repetida de incrementos de tempos para determinar a mudança do armazenamento no tempo e, por conseguinte, na vazào.

Dentre os modelos para a determinaçào da propagaçào em canais, um dos mais simples foi desenvolvido por Tatum (1940), citado por Fread (1985). O retardamento é definido como uma diferença de tempo entre a vazào de entrada e saida dentro de um trecho de propagaçào. Este método, chamado de tempos de retardamento médios sucessivos, assume que num trecho de canal considerado, a média das ordenadas das hidrógrafas de saida e entrada apresentam valores aproximadamente constantes.

No Método do Retardamento Puro aplicado no HEC-HMS (HECUSACE, 2000), o fluxo nào é atenuado, de modo que a forma da hidrógrafa nào é modificada. Na aplicaçào desse método, a hidrógrafa de entrada no canal é retardada em determinado tempo e é a mesma hidrógrafa da saida (Equaçào 22). Segundo Pilgrim \& Cordery (1993), é um método bastante aplicado em drenagem urbana.

$$
Q\left(t+t_{l}\right)=I(t)
$$


onde: $\mathrm{t}_{1}$ é o tempo de percurso no canal; I a vazão de entrada no tempo inicial t e $\mathrm{Q}$ a vazão de saida.

De acordo com o HEC-USACE (2000), é um caso especial de outros métodos, pois se os parâmetros desses métodos não forem cuidadosamente escolhidos, a resposta pode ser a mesma que a obtida pelo Método do Retardamento Puro. Por exemplo, se no Método de Muskingum forem usados $X=0,5$ e $K=\Delta t$, a hidrógrafa de saida será idêntica à calculada pelo Método do Retardamento Puro atrasada por K.

O tempo de retardamento em canais pode ser estimado de hidrógrafas observadas pela diferença de tempo entre os centróides das hidrógrafas de entrada e saida do trecho considerado. Para este fim, também podem ser usados os tempos de pico.

\subsection{Sistemas de Informações Geográficas na modelagem hidrológica}

Os Sistemas de Informações Geográficas (SIG’s) surgiram no início da década de $60 \mathrm{e}$, desde então, seu desempenho tem evoluido progressivamente. Nos últimos quinze anos, com o surgimento dos computadores pessoais (PC's), foram bastante difundidos. Burrough (1986) definiu os SIG's como um poderoso conjunto de ferramentas que coletam, armazenam, recuperam, transformam e permitem a visualização de dados espacializados. Ao passo que, para Maguire (1991), um SIG é muito mais dificil de ser definido do que imaginado.

Já, para Câmara (1993), os SIG's destacam-se por permitir combinar diversas informações recorrendo a algoritmos que geram mapas derivados; consultar, recuperar, visualizar e desenhar o conteúdo dos bancos de dados geocodificados e integrar, num único banco de dados, as infornações espaciais provenientes de várias fontes. Cada variável é arquivada em um formato digital, geograficamente referenciado, chamado plano de informação, que pode ser a topografia, os tipos de solos ou o tipo de ocupação da área. Segundo Sá et al. (1993), os SIG’s também possibilitam a ocorrência de interação entre os atributos da base geográfica, que são vitais para a compreensão e o gerenciamento de atividades. 
Geralmente, os arquivos dos planos de informação encontram-se num formato de grade (raster). A abordagem em grade consiste na subdivisão do terreno em células quadradas idênticas, arranjadas em linhas e colunas. Também podem estar no formato de redes irregulares triangulares (TIN). Os triângulos são formados pela uniāo de uma série de pontos representativos, irregularmente distribuidos.

Os SIG's têm inúmeras aplicaçòes como o monitoramento e a análise ambiental, o planejamento do uso da terra, o manejo florestal e outros recursos naturais, o uso em projetos de engenharia, entre outros. Hoje, existe também um grande potencial de aplicação em hidrologia, especificamente na modelagem do escoamento. Como os SIG's apresentam a capacidade de manipular dados espacializados, muitas informaçòes importantes podem ser incorporadas aos modelos, visando uma estimativa mais realista do escoamento. Atualmente, tal qualidade viabiliza, segundo Pessoa (1993), prever o volume e o pico de escoamento para diferentes formas de uso da terra. Além de propiciar um indicativo de qual é o uso mais adequado, essas informaçòes ainda são utilizadas, por exemplo, no dimensionamento de obras como vertedouros de barragens, pontes, bueiros, na determinação de volume a ser armazenado por uma barragem durante um determinado período, etc.

No entanto, os SIG's, conforme Sui \& Maggio (1999), ainda são deficientes na capacidade de modelagem e análises sofisticadas. Muitas pesquisas, especialmente nos últimos 10 anos, tem objetivado desenvolver essas capacidades. Um desses esforços é a integração de SIG com modelos hidrológicos, possibilitando a ligaçào entre análise espacial e modelagem hidrológica.

A considerável potencialidade de aplicação dos SIG's na modelagem hidrológica foi sustentada por Musik (1988). Afinal, eles permitem a simulação do comportamento de microbacias para diversas combinaçòes de parâmetros. Esses parâmetros são definidos em termos de tipo do solo, precipitação, topografia e uso da terra. Segundo o mesmo autor, quaisquer mudanças no uso da terra, ou em outro parâmetro, podem ser investigadas de forma que os tomadores de decisão tenham subsídios para avaliar seu impacto sobre as descargas e a qualidade da água. Ainda, 
Vieira \& Emerich (1992) afirmaram que as informações extraídas de imagem de satélite, modelos digitais do terreno e cruzamentos de plano de informaçào, integradas num único banco de dados, são essenciais para o estudo de bacias hidrográficas.

$\mathrm{Na}$ tentativa de considerar a variabilidade espacial do terreno na modelagem, os pesquisadores têm recorrido a um ou outro dos seguintes caminhos: dividir o sistema hidrológico em subsistemas e aplicar modelos globais para cada um deles ou desenvolver interfaces usuário-SIG, para gerar arquivos de entrada para outros modelos globais e apresentar os resultados na forma de um mapa. Ambos os casos podem ser vistos como uma evoluçào em relaçào aos modelos tradicionais, completamente globais. Contudo, não é possivel afirmar que esses tipos de soluçào confiram aos dados um tratamento espacialmente distribuido. Ou seja, entre os dois tipos existem aqueles que nào podem ser considerados puramente globais, nem inteiramente espacialmente distribuídos. Por exemplo, uma tentativa anterior aos SIG's para incorporar atributos espaciais foi a do modelo HEC-1. Tào bem conhecido como um modelo global, permite ao usuário subdividir a microbacia em sub-bacias menores e roteia suas respostas correspondentes para a saida da microbacia.

La Barbera et al. (1993) comentaram que, quando orientados para a modelagem hidrológica, os SIG's incluem procedimentos automáticos implementados para o delineamento dos canais, sua identificaçào hierárquica e cálculo de parâmetros geomorfológicos. Tais parâmetros estão relacionados, principalmente, à descrição topográfica da paisagem por meio de uma caracterizaçào distribuida da altitude, uso da terra, tipo e cobertura do solo. As informações extraídas de fontes cartográficas podem ser constantemente atualizadas pela análise de imagens de satélite. Essas idéias motivaram os autores a projetar um modelo distribuido de chuva-escoamento para simulação de enchente na bacia de Amo, Itália. O modelo, desenvolvido numa estrutura de um SIG hidrologicamente orientado, foi embasado na capacidade desse SIG manipular dados distribuídos e na análise de dados temporais de precipitaçào, obtidos simultaneamente por satélite e uma rede de coleta de dados de precipitação. O modelo 
reproduziu bem o comportamento hidrológico das bacias estudadas. Os autores recomendaram cautela quanto ao procedimento de derivar a precipitaçào a partir de dados de satélite, devido aos problemas de adequabilidade de escala.

Para descrever os atributos do terreno espacialmente distribuidos, os SIG's elaboram os chamados modelos digitais do terreno (MD's'). Apesar dos MDT's terem sido introduzidos nos anos 50 , a sua aplicaçào potencial nào foi feita antes dos anos 80, quando tornaram-se mais disponíveis. Com o advento dos MDT's, as análises e procedimentos hidrológicos, segundo Smith \& Brilly (1992), também puderam ser baseados em estrutura de SIG. Os pacotes comercialmente disponiveis, rotineiramente, oferecem opçòes para muitos tipos de processamentos de MDT. As análises incluem passos para o delineamento de bacia, obtenção de declividades, interpolaçòes provenientes de pontos ou contornos, operaçòes de filtragem e estimativas de corte e aterro. Ademais, os MDT's proporcionaram a melhoria dos modelos hidrológicos (Wang \& Yin, 1998).

Outros pesquisadores têm desenvolvido suas próprias metodologias de processamento, montando-as dentro de "caixas de ferramentas" de análises. Essas incluem procedimentos para análise de células em grade e em redes irregulares triangulares (TIN) do MDT. Recentemente, os TIN's têm recebido significativa atenção, enquanto os MDT's continuam a ser populares por serem facilmente acoplados a estruturas de sensoriamento remoto.

Jensen \& Domingue (1988) apresentaram uma detalhada descrição dos procedimentos e análises a serem aplicados aos MDT's. A detecção de depressões e seu preenchimento, computação da direção do fluxo e atribuição de valores de acumulação de fluxo sào procedimentos usados para criar conjuntos de dados que favorecem melhores análises (Figura 8A). Usando esse conjunto de dados, operaçòes como a determinação das ligaçòes entre as bacias e o delineamento da bacia e sub-bacias puderam ser feitas. Além do mais, os algoritmos foram testados em grandes bacias e foram encontrados resultados com boa concordância entre a estrutura topográfica da área e aquela obtida pelos autores. 

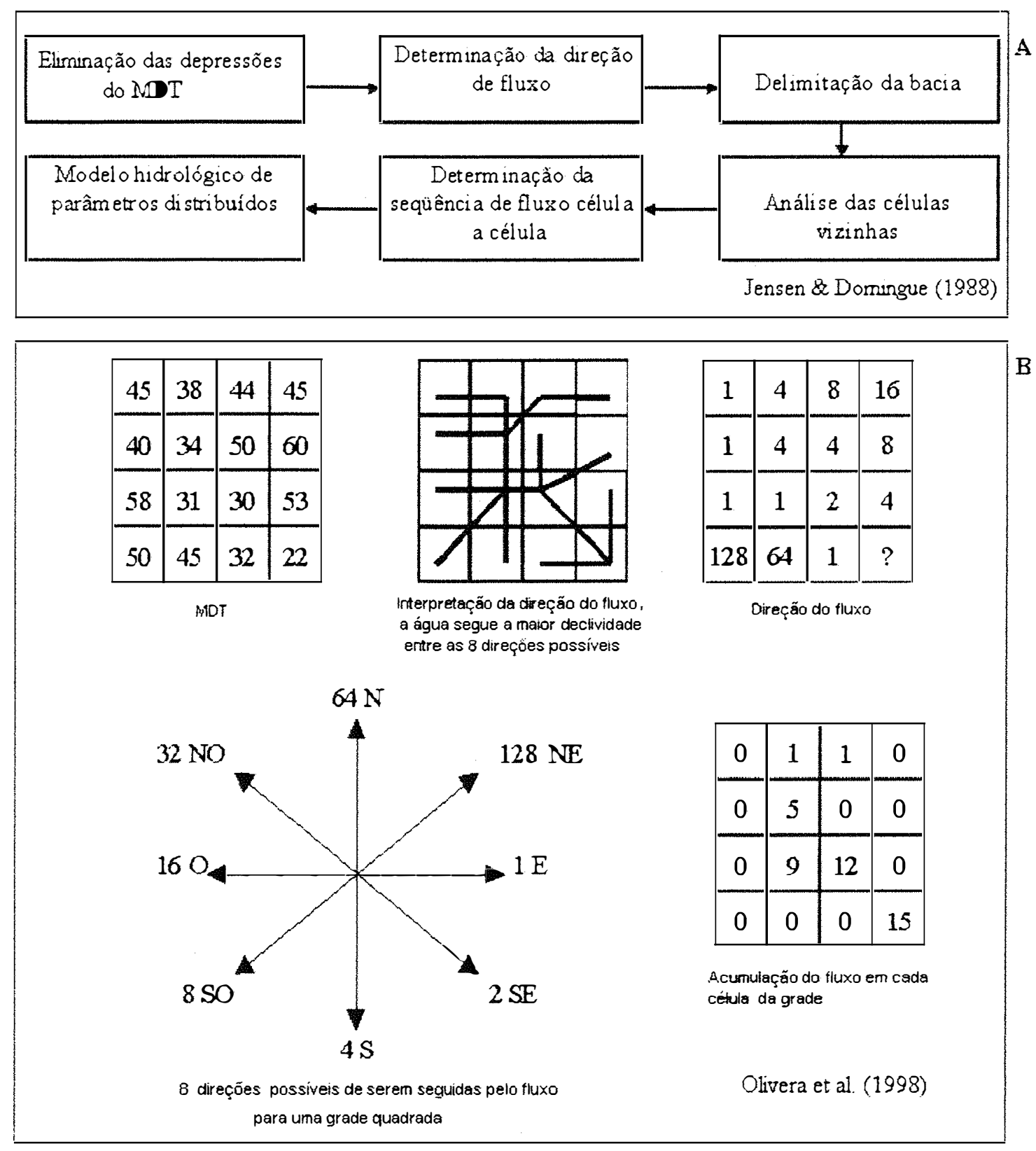

Figura 8 - Funções de análise do terreno em SIG em formato grade, para propósitos hidrológicos, segundo Jensen \& Dorningue (1988) e Olivera et al. (1998). 
Os sistemas em grade sào ideais para o modelamento do fluxo, por que o mesmo é guiado somente pela topografia, nào é sujeito a variáveis que dependem do tempo. Ainda, sào os mais adequados ao modelamento hidrológico, principalmente, porque já existe um entendimento maduro a respeito dessa tecnologia. Assim, osconjuntos de programas computacionais incluem funçòes hidrológicas como partes de sua capacidades, que permitem a determinaçào da direçào de fluxo, área de drenagem, o delineamento de redes de canais e bacias a partir de modelos digitais do terreno. Por exemplo, as funçòes hidrológicas, disponiveis nos conjuntos de programas GRID e GRASS, pennitem determinar a direçào de fluxo e a área de drenagem em qualquer local, redes de canais, delineamento de microbacias, etc (Maidment, 1993b).

Olivera et al. (1998) também consideraram o formato grade em ambiente SIG muito adequado para a modelagem hidrológica, principalmente, por esse sistema já estar sendo usado há alguns anos e, portanto, ser conhecido profundamente. Tal conhecimento consolidado, acrescentaram os autores, permitiu o desenvolvimento de algoritmos eficientes e úteis para análise dos terrenos (Figura 8B).

Os procedimentos apresentados nas Figura 8A e 8B sào baseados em Jensen \& Domingue (1988), que elaboraram um esquema de grade para delinear limites de bacias e redes de canais. Esse esquema utiliza dados do modelo digital do terreno para atribuir uma direçào de fluxo a cada uma das células da grade, no sentido da maior declividade em relaçào às oito vizinhas (D8), ou seja, cada célula da bacia é conectada à vizinha mais baixa. O fluxo de contribuiçào das células ao ponto de escoamento pode ser contabilizado e sua soma representa a área de contribuiçào. As células que nào contribuem definem os limites da área de drenagem. As células com um fluxo de acumulaçào em excesso, acima de um limite estabelecido, sào classificadas como células da rede de canais.

Estudos prévios mostraram a limitaçào dos algoritmos que se baseiam na suposiçào de que a água segue uma das oito direçòes possíveis. Entre outros Wolock \& McCabe (1995), indicaram que a água pode seguir múltiplas direçòes a partir de um ponto. Também, a direçào da declividade pode seguir para duas das oito direçòes possiveis. Assim, alguns algoritmos alocam a direçào do fluxo em múltiplas células 
adjacentes de acordo com a direção do fluxo (Quinn et al., 1991). Nesse estudo, a sensibilidade do algoritmo para geração do fluxo sob diferentes tamanhos de célula também foi estudada.

Com relação à definição da direção do fluxo pelo procedimento D8, ESRI (1994), identificou problemas na busca pela célula mais declivosa entre as oito ao redor, quando duas delas tinham o mesmo valor. Essa situação é mais usual quando são utilizados tamanhos de grade muito pequenos para a resolução espacial dos dados originais no processo de interpolação.

Tarboton (1997) estudando vários métodos de direcionamento do fluxo observou a formação de traços retilíneos e alinhados com as linhas da grade, quando o Método D8 foi aplicado em um MDT de alta resolução, grade de $2 \mathrm{~m}$, indicando que o fluxo tinha a tendência de ser influenciado pelo alinhamento da grade. Concluiu que isso acontece porque esse método não consegue resolver com precisão o problema de direcionamento do fluxo. Quando foi utilizada uma resolução de $30 \mathrm{~m}$, os traços retilíneos foram menores. $O$ autor também verificou que conforme a resolução aumentava, ocorriam maiores diferenças entre os métodos.

Resultados de sensibilidade do modelo à resolução espacial dos dados foram apontados por Vieux (1993) que discutiu como o tamanho da célula da grade afeta a medida de declividade do terreno e o comprimento do fluxo, conseqüentemente, o escoamento. Vieux \& Needham (1993) concluíram que um tamanho da célula maior acarreta comprimentos de canais mais curtos.

Wang \& Yin (1998) elaboraram MDT's a partir de cartas nas escalas 1:24.000 e 1:250.000 e compararam as redes de drenagem e parâmetros produzidos. As melhores estimativas foram alcançadas na escala 1:24.000. Para a rede delineada a partir de 1:250.000, os autores encontraram problemas decorrentes da reduzida resolução espacial. Nessa escala, as estimativas de parâmetros que consideram o gradiente de altitude (entre eles o direcionamento do fluxo) foram subestimadas devido à generalização das variações do terreno, uma vez que os cálculos envolveram os valores de altitude de células vizinhas. Porém, para parâmetros geométricos e topológicos, tais como comprimento de canais e razão de bifurcação, as estimativas foram razoáveis. Os 
autores concluíram que os dois fatores que mais afetam a precisào da rede de drenagem extraida de MDT's sào a escala e a densidade da rede. Por fim, os autores comentaram também que existem poucos estudos sobre qual faixa de escalas os MDT's podem ser usados satisfatoriamente para derivar parâmetros da rede de drenagem.

Garbrecht \& Martz (1993) extrairam parâmetros de rede a partir de MDT's de uma pequena bacia de $84 \mathrm{~km}^{2}$. A comparaçào entre os parâmetros extraídos dos MDT's e os extraidos diretamente de cartas com escala 1:24000 demonstrou que as diferenças entre eles nào passaram de 5\%. Estudando o efeito da resoluçào dos MDT's sobre parâmetros extraídos, Garbrecht \& Martz (1994) encontraram que a sensibilidade ao tamanho da grade varia entre os diversos parâmetros extraidos.

Ao se quantificar a variabilidade espacial das caracteristicas das bacias, essas sào discretizadas em unidades elementares. As respostas hidrológicas de cada unidade sào computadas conforme uma seqüência de tempo e espaço. Esse tratamento é muito adequado para investigar o efeito de mudanças no uso da terra sobre a produçào de escoamento, o transporte de poluentes (Young et al. 1989), bem como a modelagem da transferência de sedimentos de bacias hidrográficas.

Uma das funções essenciais para certos tipos de modelos é a conectividade de seqüência célula a célula. Para computar o fluxo superficial, utiliza-se uma aproximaçào cinemática ou uma cascata de reservatorios, sendo os cálculos procedidos segundo a correta seqüência hidrológica. Antes que a transformaçào da chuva em escoamento de uma célula seja feita, todos os fluxos que ocorrem acima dessa célula deverào ser analisados. Quando as bacias sào pequenas, ou o tamanho e formato das células sào grandes, a conectividade das células pode ser feita a mào. Contudo, no caso oposto, ao se examinar uma bacia grande ou com um número elevado de células, um procedimento automático é necessário, tal como foi desenvolvido por Hellwegger (1997) e Hellwegger \& Maidment (1999).

Vários outros trabalhos utilizaram os SIG's na modelagem do escoamento. É possivel citar, por exemplo, Stuebe \& Johnson (1990) que aplicaram SIG em todas as fases da modelagem, incluindo o delineamento e propagaçào do escoamento. Comparando-o com os métodos convencionais, concluiram que o SIG 
demonstrou ser vantajoso em relação aos métodos manuais. Isso é particularmente válido quando as bacias em estudo forem numerosas ou grandes, o escoanento for modelado repetitivamente, forem explorados cenários alternativos de uso da área ou já existir um banco de dados para a área em estudo.

Musik \& Pomeroy (1990) desenvolveram um SIG orientado à hidrologia, que utilizava dados no formato em grade (raster) de uso da área, tipo de solo, curvaschave, número da curva $(\mathrm{CN})$, hidrógrafas unitárias regionais adimensionais e relaçōes de tempo de retardamento regionais. O sistema foi usado para previsão de curvas de freqüência de inundação para bacias.

As mudanças de uso na Bacia de Sarca di Campiglio (Norte da Itália) foram definidas e quantificadas por Cazorzi \& Fontana (1994). Quatro mapas de uso da terra, elaborados a partir de fotografias aéreas digitalizadas, tomadas em diferentes anos foram empregados. Os dados foram avaliados por um SIG e mapas hidrológicos do número da curva $(\mathrm{CN})$ foram obtidos pela combinação de mapas de uso da terra, tipos de solos e litologia. Além do mais, um modelo distribuído de fluxo direto foi estabelecido como um módulo do SIG. O módulo simulou o excesso de precipitação para curtos espaços de tempo para cada célula da grade (raster) usando o $\mathrm{CN}$ do local. Esses excessos foram transformados em descargas, que foram atrasadas conforme um mapa de tempo de contribuiçăo, derivado de uma rede sintética de canais. O modelo foi calibrado com valores experimentais de precipitação-escoamento, aplicados para ajustar tabelas de $\mathrm{CN}$. Ainda, o modelo foi testado por meio da simulação direta de inundaçòes registradas. Precipitaçòes críticas, com diferentes tempos de retornos, foram utilizadas para quantificar as mudanças decorrentes de alterações de uso da terra.

Já, Drayton et al. (1992) apresentaram um modelo de chuva-escoamento desenvolvido com base em uma grade de células retangular. O escoamento de cada célula foi estimado empiricamente e propagado através da rede de drenagem até os cursos principais. Informaçòes de cobertura do solo, em cada célula de $50 \mathrm{~m} \times 50 \mathrm{~m}$, foram obtidas por sensoriamento remoto. Ao passo que valores de parâmetros de topografia para cada célula foram derivados de um MDT. A manipulação dos dados pelo SIG adotado forneceu para cada célula uma estimativa do escoamento calculado pelo 
$\mathrm{CN}$ estimado. Tomando como base o MDT, foram definidos para cada célula a trajetória do escoamento, posteriormente, propagado célula por célula até o curso principal. A partir daí, recorreu-se a uma análise hidráulica convencional até a saída. $\mathrm{O}$ modelo foi testado com dados obtidos de dois locars de West Wales, que passaram por profundas mudanças graças à retirada da cobertura florestal.

Musik (1992) apresentou um SIG desenvolvido para previsào de hidrógrafas de inundaçào em bacias nào instrumentadas. O procedimento adotado foi embasado no Método $\mathrm{CN}$ do SCS para a determinaçào das abstrações iniciais e no Método da Hidrógrafa Unitária Adimensional Regional para a determinação da hidrógrafa unitária sintética da bacia. Os dados de tipo e cobertura do solo, uso da terra, precipitação, escoamento, $\mathrm{CN}$, hidrograma adimensional regional e as relações de tempo de retardamento foram armazenados no formato em grade. O sistema foi testado em bacias nas Montanhas Rochosas em Alberta, no Canadá.

Por sua vez, Kamieli (1991) descreveu a aplicaçào de um SIG a um modelo de chuva-escoamento semi-distribuído considerando a umidade do solo e a desuniformidade da entrada de dados de chuva espacialmente. O modelo incluiu inúmeras variáveis e parâmetros, cada um derivado de uma fonte diferente e dotado de variabilidade espacial.

Chieng \& Luo (1993) juntaram um SIG com o Método Racional para a estimativa do pico de escoamento. O SIG demonstrou ser aplicável em todas as fases da modelagem hidrológica. As informações que, anteriormente, nào eram utilizadas ou derivadas, puderam ser incluídas. A extensào e melhoria do Método Racional Convencional foi conseqüência da obtençào de valores mais realistas para o tempo de concentraçào; do exame de outras condiçōes como a movimentaçào e desuniformidade de intensidade de chuvas, em vez de assumir que ocorriam chuvas estacionárias e uniformes em toda a bacia e da melhor estimativa do coeficiente de escoamento, pela possibilidade de levar em consideraçào o padrào de uso da área, sob diferentes condiçōes topográficas e de solos. 
Maidment et al. (1996b) apresentaram o delineamento da microbacia do rio Niger baseado num MDT com células de $1 \mathrm{~km}$. Nesse delineamento, um curso de água foi identificado no MDT quando área de drenagem a montante excedia $10.000 \mathrm{~km}^{2}$. Os limites das sub-bacias foram delineados a partir de suas saidas, correspondentes a cada junção de canais, produzindo uma rede de drenagem com um único canal ou curso de água para cada sub-bacia. Para evitar longos trechos entre junções, saídas foram colocadas em canais longos a cada $250 \mathrm{~km}$. Um total de 167 canais com suas áreas de drenagem correspondentes foram assim determinados. Antes do delineamento das microbacias, o MDT foi alterado para incorporar a bacia do lago Chade, localizada no nordeste da bacia do Niger. Uma vez que o processo delineamento padrão consiste em preencher as depressões do terreno, um ponto de sangramento na parte baixa da bacia do lago Chade foi escolhido para evitar o preenchimento total da bacia e fazer o fluxo superfícial percorrer necessariamente na direção da bacia do Niger.

Apesar de muitas das aplicações dos SIG's na hidrologia terem alcançado significativos progressos em qualidade e eficiência na análise do manejo dos recursos hídricos, o longo prazo necessário para a obtenção dos dados ainda limita consideravelmente o uso dos modelos hidrológicos.

\subsection{Programa CRWR-PREPRO}

Os sistemas de informações geográficas podem colaborar muito para ajudar a modelagem hidrológica de bacias hidrográficas, pois, segundo Dugger (1997), o maior problema na modelagem hidrológica é a incorporação de todos os parâmetros necessários a um modelo compreensivo da superfície do terreno e da rede de drenagem. O SIG permite que vários parâmetros sejam especificados para uma dada unidade hidrológica, seja ela canais ou bacias, e que atributos sejam associados a esses elementos de forma espacializada. A partir daí, podem ser realizadas cálculos em cada unidade individual e os resultados ligados aos de outros elementos para criar um esquema geral de movimentação da água sobre a superficie do terreno e através da rede de drenagem. 
O SIG ArcView e sua extensão para análise espacial (Spatial Analyst) já fornecem ferramentas para o delineamento de canais e bacias realizado a partir de modelos digitais do terreno. No entanto, apesar desse SIG e sua extensão permitirem a execução das tarefas anteriormente citadas, eles geram um tipo de arquivo num formato ainda incompativel com os modelos hidrológicos.

Para eliminar esse obstáculo, foi desenvolvido por Hellwegger (1997) o programa HEC-PREPRO, que toma as informaçòes do ArcView e as resume num arquivo com formato que possa ser lido pelo modelo HEC-HMS. Assim, as informaçòes como os limites das bacias e sub-bacias, seus trechos de canais interconectados, formando uma rede de drenagem esquemática, e seus atributos podem ser transferidos para o HEC-HMS. Cabe ressaltar que a transferência dessas informaçòes, por levarem em conta caracteristicas distribuídas espacialmente, seria muito trabalhosa, caso nào houvesse um programa pré-processador como o HEC-PREPRO, especialmente em bacias extensas.

Inicialmente, foram lançadas as versòes 1 e 2 e, posteriormente, seu nome mudou para CRWR-PREPRO, por ter sido desenvolvido, com a ajuda de outras organizaçòes, pelo Center for Research In Water Resourses (CRWR) da Universidade do Tëxas, localizado em Austin, E.U.A. (Olivera et al. 1998, Olivera \& Maidment. 1999).

O CRWR-PREPRO é uma sintese de várias aplicacões dos Sistemas de Informaçōes Geográficas e modelagem hidrológica que foram desenvolvidos recentemente. Foi elaborado em linguagem Avenue e trabalha em ambiente ArcView na forma de menus.

Olivera et al. (1998) deixaram claro que o menu principal consta de funções que sào executadas seqüencialmente até a obtenção do arquivo de bacia, ou melhor, de entrada para o HEC-HMS. É oportuno informar que, além do HEC-HMS. está prevista a capacidade de pré-processar dados para uma grande variedade de pacotes de modelagem. 
As funçòes, segundo Olivera et al. (1998), são divididas em 5 etapas:

1. Análise do terreno baseada no formato raster e definiçào da rede;

2. Vetorizaçào dos elementos hidrológicos;

3. Cálculo dos parâmetros dos elementos hidrológicos;

4. Isolamento de um sub-sistema hidrológico e

5. Análise topológica e preparação do arquivo de bacia para o HEC-HMS.

\subsubsection{Análise do terreno baseada no formato grade e definição da rede}

A análise topográfica necessária para a detenninação do sistema hidrológico baseia-se no MDT. Pelo processamento da função de direcionamento de fluxo, uma única célula à jusante - na direção descendente mais declivosa - é definida para cada célula do terreno, de tal forma que um único caminho de cada uma delas até a saída da bacia é determinado. Esse processo produz uma rede de células, com a forma de uma árvore, que representa os caminhos do sistema de fluxo da microbacia. Contudo, como a direção de fluxo não pode ser determinada para as células que estão abaixo de suas vizinhas circundantes, um processo de preenchimento de falsas depressòes do terreno é necessário, antes de processar a funçào de direcionamento de fluxo. Na maioria dos casos, a existência de depressòes no MDT é explicada por erros numéricos introduzidos no processo de interpolação. O preenchimento das depressões consiste no aumento do valor das células, onde ocorre depressào, ao nível da área circundante, de modo que a água seja capaz de fluir para fora da área.

Uma vez preenchidas as depressōes e conhecidas as direções de fluxo, a área de drenagem - em unidades de célula - é calculada pelo procedimento de acumnlação de fluxo. A funçào de acumulação de fluxo conta o número de células localizadas a sua jusante (a célula em si nào é incluída) e, quando multiplicado pela área da célula, resulta na área de drenagem.

A rede de canais e bacias é determinada de forma que exista um único segmento de canal para cada bacia que é modelada. As células do MDT que formam os canais sào definidas como a uniào de dois conjuntos de células. O primeiro conjunto 
identifica os canais com a maior área de drenagem, mas não necessariamente com o maior fluxo, porque esse depende de outras variáveis que não são relacionadas exclusivamente à topografia. O segundo conjunto é definido interativamente pelo usuário conforme uma seleção de um certo ponto no mapa, que resulta numa escolha automática de toda célula à jusante. Essa ferramenta foi incluída no HEC-PREPRO, ou na versão atual CRWR-PREPRO, porque observou-se que, sob circunstâncias específicas, os usuários estão interessados em determinados canais, que poderiam ter uma área pequena de drenagem (acumulação de fluxo baixa). Para incluir esses canais, usando o critério do limite (threshold), seria necessário diminuir seu valor para o sistema inteiro, definindo, dessa forma, desnecessariamente uma rede de canais muito mais densa.

O valor threshold representa a mínima área de drenagem acina necessária para a manutenção de um canal. Diferentes valores irão resultar em uma rede de drenagem com valores totais de comprimentos de canais também diversos. $\mathrm{O}$ problema é que esse é um ponto crucial do processo, uma vez que envolve necessariamente uma escolha e segundo Montgomery \& Foufoula-Georgeou (1993), geralmente, essa escolha é arbitrária. Outros estudos mostraram que a escolha desse limite pode afetar a precisão da estimativa de vários parâmetros de drenagem (Quinn et al.,1995; Da Ros \& Borga, 1997; Gandolfi \& Bischetti, 1997).

As saidas das sub-bacias são também definidas como a união de dois conjuntos de células. O primeiro conjunto, baseado na rede de canais, é formado por todas as células localizadas bem próximas à jusante das junções. Conseqüentemente, numa junção, duas células de saída são identificadas, uma para cada um dos ramos à jusante. A saída do sistema é também identificada como uma saida. O segundo é definido interativamente pelo usuário, também pela escolha de qualquer célula na rede de canais, tais como aquelas associadas a estações medidoras ou outros pontos de controle de vazào. Uma vez definidas as saídas das sub-bacias, um único código de identificação é conferido para cada segmento de canal, conectando sua célula inicial com a saída da sub-bacia ou duas saídas de sub-bacias. 
A funçào de delineamento de bacias é utilizada para delinear as áreas cuja água drena para cada saida de sub-bacia. Uma relaçào um para um entre segmentos de canal e sub-bacias é mantida, uma vez que um único segmento tem sido identificado para cada saida de sub-bacia.

\subsubsection{Vetorização dos elementos hidrológicos}

Depois que os segmentos de canal e suas áreas de drenagem correspondentes foram delineados no formato grade, ativa-se o processo de vetorizaçào utilizando funções de conversào de grade para vetorial, incluídas na extensào Análise Espacial (Spatial Analyst) do Arc View. Esse processo consiste na criaçào de um arquivo de linhas de canais e um arquivo de poligonos de sub-bacias, ambos no formato vetorial. O que justifica essa vetorizaçào é que o número de elementos hidrológicos (canais e subbacias) no sistema é, geralmente, pequeno, quando comparado ao número de células e o processamento e a modelagem adicionais sào mais rápidos no formato vetorial.

Seguindo a conversào de grade para vetorial, os passos do processamento vetorial sào incluidos para preservar a relaçào de um para um entre as linhas de canais e poligonos de sub-bacias e para determinar a conectividade entre polígonos. Quando se vetoriza sub-bacias, é importante verificar que cada uma delas seja representada por um único poligono. Tal fato é um problema comum, quando a representaçào da sub-bacia no formato grade inclui um conjunto de células "suspensas" (dangling - um grupo de células interconectadas a esse conjunto de células somente por um lado). Afinal, a tranformaçào do formato grade para o vetorial agrupa as células de poligono discretos com um mesmo valor e um lado comum. Nesse caso, ao conjunto de células "suspensas" é atribuido um código de identificaçào diferente. Dessa forma, cria-se um segundo poligono para a mesma sub-bacia. Um programa tem sido incluído para unir (merge) todos os poligonos (algumas vezes mais que dois), que correspondem à mesma subbacia, num único poligono. O CRWR-PREPRO, também identifica, para cada poligono 
de sub-bacia, todos os polígonos de sub-bacias localizados a seu montante e unindo-os de tal forma que eles possam ser facilmente recuperados quando uma microbacia for delineada a partir de um ponto.

\subsubsection{Cálculos dos parâmetros hidrológicos}

Os parâmetros calculados em cada sub-bacia pelo CRWR-PREPRO, são: área, comprimento e declividade da rota de fluxo mais longa, $\mathrm{CN}$ médio e tempo de retardamento. Uma vez que o modelo do SCS exige somente os parâmetros área de cada sub-bacia e tempo de retardamento para o cálculo da hidrógrafa unitária adimensional, o CRWR-PREPRO é capaz de gerar todas as informações necessárias para o roteamento do fluxo em cada sub-bacia.

A área de cada sub-bacia é calculada automaticamente no processo de vetorização dos polígonos. A rota de fluxo mais longa é identificada como o conjunto de células da sub-bacia em que a soma entre o comprimento da rota do fluxo para baixo até a saída da bacia e o comprimento da rota do fluxo acima até a divisa da sub-bacia seja máxima (Smith, 1995). A declividade da rota mais longa é determinada como a queda de elevação entre dois pontos arbitrariamente definidos da rota de fluxo, dividida por suas distâncias ao longo do canal.

A média do número da curva do SCS é calculada como a média do mesmo dentro de cada sub-bacia. O tempo de retardamento é calculado pela fórmula do número da curva do SCS (Chow et al., 1988). Essa equação foi desenvolvida pelo SCS a partir de dados de bacias agrícolas e assume que o tempo de concentração da bacia seja igual a 1,67 vezes o tempo de retardamento. O HEC-PREPRO também apresenta a possibilidade de cálculo pelo Método da Velocidade. 


$$
\mathrm{t}_{1}=\left\{\begin{array}{l}
\frac{\mathrm{L}_{w}^{0.8}\left[\frac{1000}{\mathrm{CN}}-9\right]^{0.7}}{31,67 \mathrm{~S}^{0.5}} ; \text { método do número da curva } \\
0,6 \sum\left[\frac{0,3048 \cdot \mathrm{L}_{\mathrm{w}}}{60 \cdot \mathrm{v}}\right] ; \text { método da velocidade }
\end{array}\right\}
$$

onde: $t_{p}$ é o tempo de retardamento da sub-bacia (minutos), significando o tempo entre o centróide do hietograma da chuva até o tempo de pico da hidrógrafa; $L_{w}$ o comprimento do percurso mais longo seguido pelo fluxo em cada sub-bacia (pés); $\mathrm{S}$ a declividade média desse maior percurso para cada sub-bacia (\%); CN o número da curva do SCS médio para a sub-bacia e $v$ é a velocidade na trajetória de percuso mais longa $(\mathrm{m} / \mathrm{s})$. Mas, como no Método da Hidrógrafa Adimensional do SCS e, conseqüentemente, no HEC-HMS, o intervalo de tempo das análises tem que satisfazer a condição de ser menor do que 0,29 vezes o tempo de retardamento da bacia (USDA, 1972 e HECUSACE, 1998a), o tempo de retardamento deve ser igual ou maior do que 3,5 vezes o intervalo de tempo de análise (Olivera \& Maidment, 1999). Assim, o tempo de retardamento é redefinido para os dois métodos como:

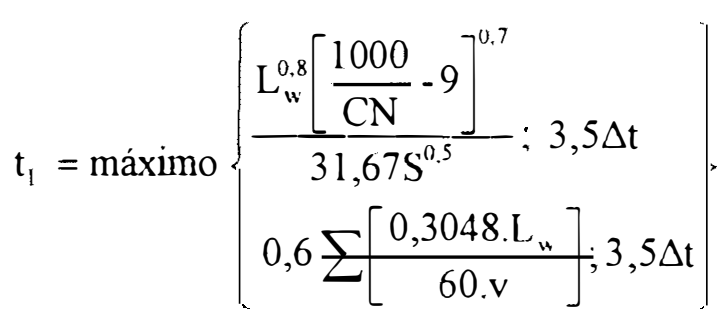

onde: $\Delta \mathrm{t}$ é o tempo do intervalo da análise. O segundo termo das equaçòes acima significa um valor mínimo para o tempo de retardamento conforme SCS (1972). Embora essa modificação atrase artificialmente o fluxo na sub-bacia, ela somente afeta as bacias muito pequenas, com tempo de retardamento menor do que 3,5 vezes o tempo de intervalo da análise (Olivera et al., 1998). Também nessas sub-bacias, o volume de escoamento produzido é pequeno quando comparado ao sistema inteiro, não afetando-o 
significativamente. Cabe ser colocado que o tempo de retardamento não afeta a conservação de massa da sub-bacia, influindo apenas nos tempos, ou seja, na forma da hidrógrafa gerada.

O comprimento do trecho de canal dentro de cada sub-bacia é calculado automaticamente no processo de vetorização dos canais. O tempo é calculado como L/v, onde $\mathrm{L}$ é o comprimento do trecho de canal e v é a velocidade do fluxo. O Método de Muskingum é usado para o roteamento em canais em todos os trechos longos o suficiente para não apresentarem problemas de instabilidade númérica. Em trechos curtos, nos quais o tempo do fluxo é menor do que o intervalo de tempo, recorre-se ao Método de Retardamento Puro. Para prevenir instabilidades numéricas, quando for usado o Método de Muskingum, os trechos de canais longos são divididos em trechos mais curtos, sempre satisfazendo a condição $2 \mathrm{Xk}<\Delta \mathrm{t}<\mathrm{k}$ (HEC-USACE, 1998a), onde $\mathrm{k}$ é o tempo do fluxo nos trechos (min) e X é um parâmetro do Método de Muskingum. Como o tempo em todos os trechos de canais é igual a $\mathrm{k}=60 \mathrm{~K} / \mathrm{n}=(\mathrm{L} / 60 \mathrm{v}) / \mathrm{n}$, onde $\mathrm{K}$ é o tempo de fluxo no trecho (horas), v é a velocidade do fluxo no trecho $(\mathrm{m} / \mathrm{s})$ e $\mathrm{n}$ é o número de trechos (sendo inteiro e maior do que zero), então:

$$
2 \mathrm{X} \frac{\mathrm{L} / 60 \mathrm{v}}{\Delta \mathrm{t}}<\mathrm{n}<\frac{\mathrm{L} / 60 \mathrm{v}}{\Delta \mathrm{t}}
$$

Entretanto, como $\mathrm{n}$ deve ser igual a no minimo $1, \mathrm{~L} / 60 \mathrm{v}$ deverá ser maior do que $\Delta t$ para satisfazer as restriçòes do Método de Muskingum. Caso essas condiçòes não sejam atendidas, o Método do Lag Puro deverá ser usado. Para determinação do número mínimo e máximo de sub-trechos, recorre-se à Equação 26:

$$
\mathrm{n}=\left\{\begin{array}{l}
\operatorname{int}\left(2 X \frac{\mathrm{L} / 60 \mathrm{v}}{\Delta \mathrm{t}}\right)+1 ; \text { número mínimo de trechos } \\
\operatorname{int}\left(\frac{\mathrm{L} / 60 \mathrm{v}}{\Delta \mathrm{t}}\right) ; \text { número máximo de trechos }
\end{array}\right\} \text {. }
$$


onde: a funçào int torna um número inteiro o argumento, porém sem arredondamento. $\mathrm{O}$ parâmetro $\mathrm{K}$ do Método de Muskingum e o tempo de retardamento para o Método do Retardamento Puro são iguais ao tempo de percurso. O K (horas) é calculado por $\mathrm{L} / 3600 \mathrm{v}$ e o tempo de retardamento (min) é calculado como $\mathrm{L} / 60 \mathrm{v}$.

\subsubsection{Isolamento de um sub-sistema hidrológico}

Uma vez concluido o pré-processamento, o usuário pode escolher isolar um sub-sistema hidrológico para modelagem posterior. Um programa incluido para isolar a área de drenagem a partir de um ponto escolhido pelo usuário define um subsistema composto de canais e bacias e cria os arquivos vetoriais correspondentes. Os parâmetros dos elementos hidrológicos - calculados como parte do pré-processamento são transferidos para as tabelas de atributos dos novos arquivos e outros parâmetros sào determinados para o polígono mais à jusante. Programas do delineador de bacias utilizam os dados do polígono de sub-bacia criados no pré-processamento para acelerar o delineamento de bacias a partir de um ponto. O CRWR-PREPRO, identifica o poligono de sub-bacia, no qual o ponto definido pelo usuário está localizado, isola-o do resto do $\mathrm{MDT}$, processa dentro do polígono o delineamento de bacia baseado no formato grade e funde todos os poligonos de sub-bacia localizados à montante.

\subsubsection{Análise topológica e preparação do arquivo de bacia para o HEC-HMS}

Depois dos arquivos vetoriais do subsistema terem sido criados, o CRWR-PREPRO è utilizado para converter as informaçòes geográficas (Figura 9A) em hidrológicas (Figura 9B) e transferi-las para o arquivo de bacia do HEC-HMS. Considerando todos os nós da rede de canais, o esquema de classificaçào de nós desenvolvido por Hellweger \& Maidment (1999) è usado para identificar junçòes e sumidouros. Junçòes e sumidouros também servem como saidas de sub-bacias no 


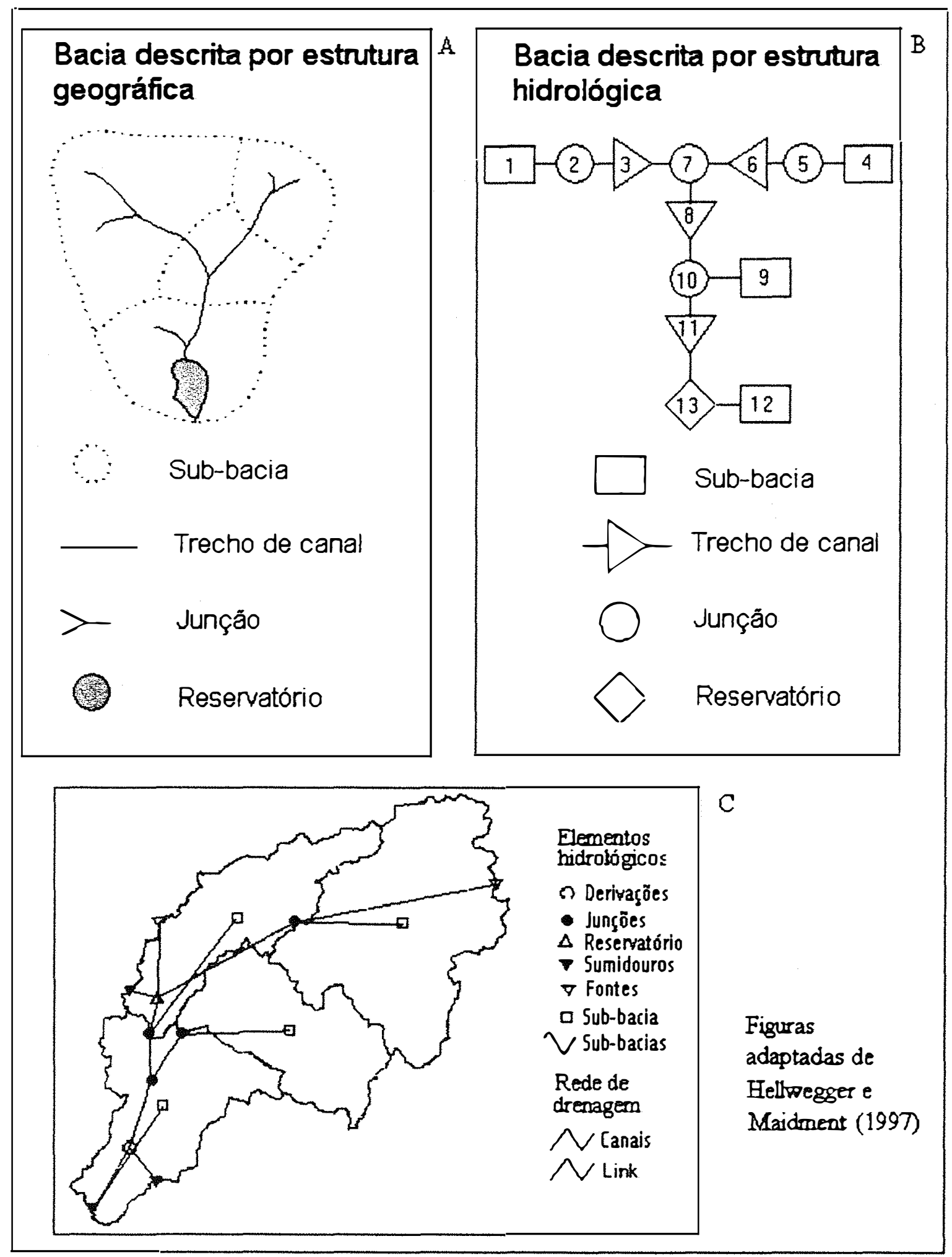

Figura 9 - Bacia descrita por estrutura de dados geográfica (A), hidrológica (B) e esquema de bacia com pontos e linhas conectados (C). 
CRWR-PREPRO, por causa do modo pelo qual os canais e sub-bacias são definidos. A conexão entre uma sub-bacia e sua saida é determinada pela proximidade do ponto de saida ao limite da sub-bacia. Os canais são identificados como elementos de canais (reach elements) dependendo dos tipos de nó no inicio e final de cada linha.

Como um passo intermediário na criação do arquivo de bacia do HEC-HMS, arquivos simbólicos de pontos e linhas são criados (Figura 9C). Campos nas tabelas de atributos desses arquivos armazenam informação a respeito da conectividade entre elementos e de seus parâmetros hidrológicos calculados. Posteriormente, informaçòes desses campos são enviadas para o arquivo de bacia do HEC-HMS.

\subsection{Sistema de modelagem hidrológica (Hydrologic Modeling System/HEC-HMS)}

O Hydrologic Modeling System (HEC-HMS) foi desenvolvido pelo Hydrologic Engineering Center (HEC) do U.S Army Corps of Engineers (USACE), como parte do projeto denominado Next Generation (NexGen) Sofware Development Project. O HEC-HMS é o sucessor do programa HEC-1 que foi lançado em 1981, dotado de interface gráfica ao usuário e com avanços quanto a suas capacidades técnicas (Peters \& Feldman, 1997). Atualmente, o programa está na versão 2, que foi lançada em 2000 (HEC-USACE, 2000). Sua primeira versão surgiu em 1998, apesar de já estar sendo testado anteriormente em sua versão experimental beta. As características de projeto internas do HEC-HMS foram descritas por Charley et al. (1995).

Segundo HEC-USACE (1998b), basicamente o HEC-HMS apresenta quatro componentes: um sistema para armazenamento e manejo de dados, especialmente para grandes conjuntos de dados variáveis no tempo; um modelo analítico para calcular o escoamento superficial e propagação dos mesmos nos canais; um sistema gráfico para ilustração dos componentes hidrológicos com características interativas e meios para apresentação e geração de relatórios das saídas do modelo.

O HEC-HMS descreve as características da bacia usando um diagrama esquemático associado a um arquivo de bacia e fornece uma grande variedade de opçòes de simulação do processo de precipitação-vazão, conforme a Tabela 6. Cabe ressaltar 
Tabela 6 - Opções de métodos para simulaçào disponiveis no HEC-HMS e classificaçào de cada modelo em categorias

\begin{tabular}{|c|c|c|}
\hline Processo & Opção de simulação & Categoria do modelo \\
\hline Perdas & $\begin{array}{l}\text { Número da Curva do SCS } \\
\text { Inicial/ Constante, } \\
\text { Deficit/constante } \\
\text { Green \& Ampt } \\
\text { SCS em grade } \\
\text { Consid. Umid do solo } \\
\text { (SMA) } \\
\text { SMA em grade }\end{array}$ & $\begin{array}{l}\text { Evento, global, empírico, parâm. ajustados } \\
\text { Evento, global, empírico, parâm. ajustados } \\
\text { Continuo, global., empirico, parâm. ajust. } \\
\text { Evento, distribuido, cmpírico, parâm. ajust. } \\
\text { Evento, distribuido, empirico, paràm. ajust } \\
\text { Continuo, global., empírico, parâm. ajust. } \\
\text { Continuo, distrib., empírico, paràm. ajust }\end{array}$ \\
\hline $\begin{array}{l}\text { Transfor- } \\
\text { maçào do } \\
\text { escomento }\end{array}$ & $\begin{array}{l}\text { Hidrógrafa Unitária do SCS } \\
\text { Hidrógrafa Unitária de Clark } \\
\text { Hidr. Unitária de Snyder } \\
\text { Método da Onda Cinemática } \\
\text { Método de Clark modificado } \\
\text { HU especificada p/ usuário }\end{array}$ & $\begin{array}{l}\text { Evento, global, empirico, parâm. ajustados } \\
\text { Evento, global, empirico, parâm. ajustados } \\
\text { Evento, global, empirico, parâm. ajustados } \\
\text { Evento, global, conceitual, parâm. medidos } \\
\text { Evento, distribuido, empirico, paràm. ajust. } \\
\text { Evento, global, empirico, parâm. ajustados }\end{array}$ \\
\hline $\begin{array}{l}\text { Propaga- } \\
\text { çào }\end{array}$ & $\begin{array}{l}\text { Método da Onda Cinemática } \\
\text { Retardamento puro } \\
\text { Método de Puls modificado } \\
\text { Muskingum } \\
\text { Mét. de Muskingum.- Cunge } \\
\text { (padrào) } \\
\text { Mét. de Muskingum.- Cunge } \\
\text { (secçào com } 8 \text { pontos) } \\
\text { Confluência } \\
\text { Bifurcação }\end{array}$ & $\begin{array}{l}\text { Evento, global, conceitual, parâm. medidos } \\
\text { Evento, global, empirico, parâm. ajustados } \\
\text { Evento, global, empirico, parâm. ajustados } \\
\text { Evento, global, empirico, parâm. ajustados } \\
\text { Evento, global, quasi-conceitual, parâm. } \\
\text { medidos } \\
\text { Evento, global, quasi-conceitual, parâm. } \\
\text { medidos } \\
\text { Continuo, conceitual, parâm. medido } \\
\text { Continuo, conceitual, parâm. medido }\end{array}$ \\
\hline Fluxo base & $\begin{array}{l}\text { Constante mensal } \\
\text { Recessão exponencial } \\
\text { Reservatório linear }\end{array}$ & $\begin{array}{l}\text { Evento, global, empírico, parâm. ajustados } \\
\text { Evento, global, empirico, parâm. ajustados } \\
\text { Evento, global, empirico, parâm. ajustados }\end{array}$ \\
\hline $\begin{array}{l}\text { Precipi- } \\
\text { Taçào }\end{array}$ & $\begin{array}{l}\text { Precip. baseada em grade } \\
\text { Média de precip. Em grade } \\
\text { Hietograma importado } \\
\text { Especificaçào de pesos para } \\
\text { Especificaçào de pesos para } \\
\text { Ponderação do peso das esta } \\
\text { Baseada na freqüència da chı } \\
\text { Chuva de projeto padrào (eas }\end{array}$ & $\begin{array}{l}\text { stações } \\
\text { stações } \\
\text { pelo inverso da distância } \\
\text { de projeto } \\
\text { US }\end{array}$ \\
\hline
\end{tabular}

Fonte-Traduzido de HEC-USACE (2000) (HEC-HMS User's Manual) 
que o HEC-HMS é um sistema de modelagem hidrológica dotado de opçōes de escolha de modelos para representar cada etapa do processo chuva-escoamento, perdas (determinação do volume de escoamento), transformação desse escoamento em hidrógrafas para cada sub-bacia (escoamento direto), determinação do escoamento básico ou propagação do escoamento pela rede de drenagem.

O HEC-HMS conceitualiza o comportamento de uma bacia como o diagrama ilustrado na Figura 10A, onde são apresentados os processos de geração do escoamento a partir da chuva, em escala consistente com a modelagem do HEC-HMS. Uma representação apropriada do sistema mostrado depende das necessidades de informaçōes do estudo. Para algumas análises, é necessário levar em conta o detalhamento do movimento e armazenamento da água através de todos os componentes. Por exemplo, na estimativa de efeitos decorrentes de mudanças no uso do solo. Neste caso, a evapotranspiração, infiltração, percolação e outros movimentos e armazenamentos deverão ser analisados considerando longos períodos. Para fazer isso, são necessários modelos detalhados que estão incluídos no HEC-HMS. Em estudos menos detalhados, a visão do HEC-HMS pode ser mais simples, de forma que somente os componentes mais importantes são levados em consideração. Assim, na Figura 10B, são apresentados os componentes necessários para a simulação do escoamento, sendo os outros componentes usados como médias ou omitidos. Dessa forma, em uma aplicação comum, o HEC-HMS omite os detalhes que levam em conta o movimento da água dentro do solo. Neste modo reducionista, o HEC-HMS inclui modelos de infiltração da superfície do solo, porém ele não modela o armazenamento e movimento da água verticalmente dentro da camada de solo. Ele combina implicitamente o fluxo próximo da superfície e superficial, modelando como escoamento direto. Ademais, não é incluído um modelo detalhado de fluxo interno ou subsuperficial, pelo contrário, representa somente a combinação dos mesmos como fluxo básico (HEC-USACE, 2000).

O HEC-HMS é um modelo orientado para eventos de precipitação, porém pode simular periodos maiores pelo Método de Perda Déficit/Constante. O programa também simula uma transformação distribuída do escoamento, que pode ser aplicada com dados de chuva no formato de grade. Ainda, para ser usado em períodos mais 

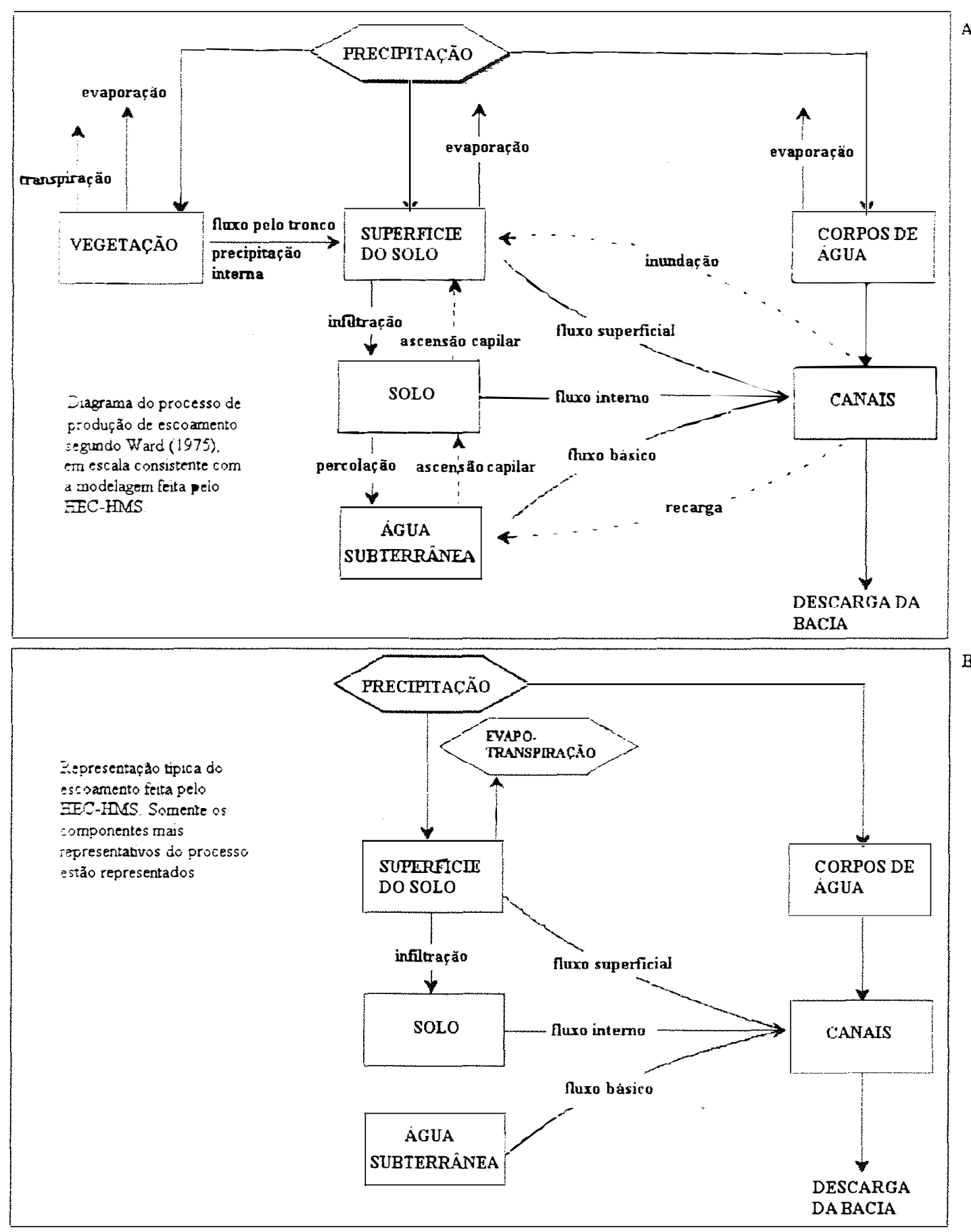

Figura 10 - Diagrama do processo de escoamento conforme Ward (1975) e uma representação típica do escoamento feita pelo HEC-HMS (HEC-USACE, 2000). 
extensos de simulaçào, aplica-se uma depleçào da umidade. $\mathrm{Na}$ versào 2, foram adicionados modelos para simulaçào contínua que levam em consideraçào a umidade do solo (SMA) e o mesmo modelo no formato de grade.

A interface gráfica do HEC-HMS tem capacidade para representaçào esquemática de uma rede de elementos hidrológicos, sub-bacias, trechos de canais e junçòes. O esquema pode ser configurado por seleçào e conexào dos elementos. Uma vez desenvolvido o esquema, podem ser solicitados menus suspensos, que permitem ter acesso a um editor para a entrada e ediçào de dados associados para cada elemento hidrológico e possibilita mostrar os resultados de uma simulaçào para aquele elemento específico. A entrada de um grande número de elementos hidrológicos é trabalhosa, se editada individualmente para cada elemento. Para a automatizaçào do processo, podem ser utilizados pré-processadores em ambiente SIG.

A estrutura básica para a simulaçào da bacia é semelhante ao do HEC-1 (Peters, 1995). Os elementos hidrológicos sào arranjados em uma rede dendrítica e os cálculos sào feitos seqüencialmente de montante para jusante. A execuçào das simulaçōes requerem as especificaçòes de três conjuntos de dados. O primeiro chamado de modelo de bacia, contém parâmetros e dados de conectividade para os elementos hidrológicos. Os tipos de elementos sào: sub-bacias, trechos de canais, junçòes, reservatórios, fontes, sumidouros e derivaçòes. O segundo conjunto, rotulado de modelo de precipitaçào, é formado por dados meteorológicos e informaçòes necessárias para processá-los. O modelo pode representar condiçōes históricas ou hipotéticas. O terceiro conjunto de dados, chamado de especificaçào de controle, indica informaçòes relacionadas ao tempo para as simulaçòes. Um projeto requer dados de cada um dos tipos de conjunto. O programa é processado com a configuração de um modelo de bacia, de precipitaçào e as especifícaçòes de controle.

Cabe mencionar que o escoamento pode ser simulado em ambos os modos, global (concentrado) ou distribuído. No modo global, a precipitaçào e as perdas sào médias espacializadas em cada sub-bacia. No modo distribuído linear, a chuva é 
especificada como uma grade. Ao passo que a perda e o excesso sào considerados separadamente para cada de uma das sub-bacia. Entào, o excesso é transformado em escoamento direto pelo Método Modificado de Clark.

No modelo de bacia, as perdas podem ser calculadas para cada evento de simulação por diferentes métodos, como o inicial/constante, o da curva numérica do SCS, o do número da curva em grade e o do Green \& Ampt. Para uma simulação contínua é possivel aplicar a funçào de perda déficit/constante, onde o usuário especifica uma capacidade de armazenamento da água no solo, que pode ser preenchida antes que o excesso venha a ocorrer. Durante os períodos sem chuvas, a capacidade de armazenamento e a preenchida pelas chuvas, sofre a depleçào de acordo com uma taxa média mensal, especificada pelo usuário. Quando a capacidade for preenchida, as perdas acontecem a una taxa constante especificada.

Ainda, no modelo de bacia, a transformação do excesso de precipitação em escoamento direto pode ser conseguida com a hidrógrafa unitária ou pelo Método da onda cinemática. A hidrógrafa unitária pode ser na forma tabular ou ser definida pelos Métodos de Clark, Snyder ou do SCS. O Método da Onda Cinemática permite a definição de dois planos de fluxo superficial retangulares. Assim, o escoamento a partir de um plano de fluxo superficial pode ser roteado através de dois canais coletores e um canal principal empregando o Método da Onda Cinemática ou o Método de MuskingumCunge. Um tratamento semi-distribuído pode ser aplicado com o Método Modificado de Clark (Peter \& Easton, 1996), que é fundamentado no Modelo Conceitual de Clark (Clark, 1945). No Método Modificado de Clark uma grade de células é sobreposta sobre a bacia e a chuva é considerada em cada uma delas. O excesso de chuva de cada célula é atrasado até a saída da bacia e roteada pelo princípio de reservatórios linear. As saídas desses reservatórios lineares são somadas e adicionadas ao fluxo base para a obtenção de uma hidrógrafa de escoamento total.

Ao passo que as opçòes de propagaçào incluem os Métodos de Muskingum-Kunge, onda cinemática, Pulso modificado e Muskingum. Os Métodos da Onda Cinemática e o Muskingum-Kunge requisitam a configuraçào de formas geométricas padrão (círculo e trapezóide) dos canais, com seç̧ões definidas em oito 
conjuntos de coordenadas X-Y e três valores de coeficientes n de Manning. Nesses métodos, o conjunto de programas computacionais tem capacidade de rotear dados de fluxo através de um reservatório de controle, no qual uma relação entre saida e entrada é requisitada.

Ainda, na modelagem de bacia, as derivações são especificadas em termos de uma relação tabular entre o fluxo de entrada e saida. Por sua vez, a hidrógrafa derivada pode ser tratada como entrada em um local à jusante na rede do sistema.

O modelo de precipitação é um conjunto de informações requeridas para definir precipitações históricas ou hipotéticas para serem usadas em conjunto com o modelo de bacia. Há muitas opções disponiveis para a especificação de precipitações históricas: utilizar precipitações baseadas em células como as requeridas pelo Método Modificado de Clark; importar precipitação previamente determinada como média espacial; especificar as estações de medição com pesos associados (polígonos de Thiessen); especificar estações de medição e sua localização e determinar pesos e local dos nós índices para serem utilizados em uma ponderação automática pelo inverso do quadrado da distância. Esse último método é usado em casos de dados ausentes, de forma que os da estação mais próxima são automaticamente adotados.

As especificações de controle englobam as datas iniciais e finais para as simulações e o tempo de intervalo para os cálculos.

\subsubsection{Calibração dos parâmetros}

Segundo a descrição de HEC-USACE (2000), o HEC-HMS possibilita a capacidade de estimar automaticamente parâmetros de bacias selecionados, quando existem dados disponiveis de precipitações e de descargas observadas. A estimativa dos parâmetros é obtida pelo ajuste automático de valores para os parâmetros selecionados, visando, para um determinado local, a maior concordância possivel entre uma hidrógrafa computada e uma observada. 
Os paràmetros selecionados para calibraçào podem estar associados a perdas, transformaçào do escoamento, fluxo base ou propagaçào para alguma sub-bacia ou algum trecho de canal à montante do local em consideraçào.

Sob o ponto de vista quantitativo, o ajuste ótimo é dado pela funçào objetivo, que é baseada no grau de variaçào entre as hidrógrafas simuladas e observadas. Caso as hidrógrafas sejam exatamente iguais, é igual a zero. A estimativa automática é feita por um procedimento de procura, objetivando a adequaçào dos parâmetros selecionados para produzir um ajuste ótimo, ou seja, minimizar o grau da funçào objetivo. Ainda, restriçōes sobre os valores dos parâmetros sào impostas para garantir que valores discrepantes nào sejam utilizados.

A Figura 11 ilustra as características básicas da metodologia de otimizaçào do HEC-HMS. A especificaçào dos valores iniciais para todos os parâmetros são requeridos no princípio da otimizaçào. A hidrógrafa é computada no mesmo local em que a hidrógrafa observada foi especificada e a valor da funçào objetivo é calculado. Esse procedimento ajusta valores para os parâmetros, otimizando-os. Assim, uma nova hidrógrafa simulada e funçào objetivo sào obtidos. Esse ciclo segue até que sejam encontradas melhorias significativas na funçào objetivo.

A funçào objetivo pode ser escolhida conforme quatro definiçōes para a medida da qualidade do ajuste de uma hidrógrafa simulada em relaçào à observada. A Função Objetivo Hec-1 (HEC-USACE, 1998a) é a padrão do HEC-HMS. Trata-se de uma funçào que pondera e dá maior peso para os desvios associados às maiores vazões. É possivel recorrer-se a funçōes objetivos mais simples como a Soma dos Quadrados dos Resíduos, que expressa a soma das diferenças dos quadrados entre as hidrógrafas simuladas e observadas. Outra possibilidade é a Soma dos Residuos Absolutos em que as diferenças entre as hidrógrafas observadas e simuladas sào somadas e, dessa forma, pesos iguais sào dados para todas as diferenças. A última é a Porcentagem de Erro no Pico de Vazào, que considera apenas o pico das hidrógrafas simuladas e observadas, sem atentar para as diferenças entre os demais tempos e volumes. 


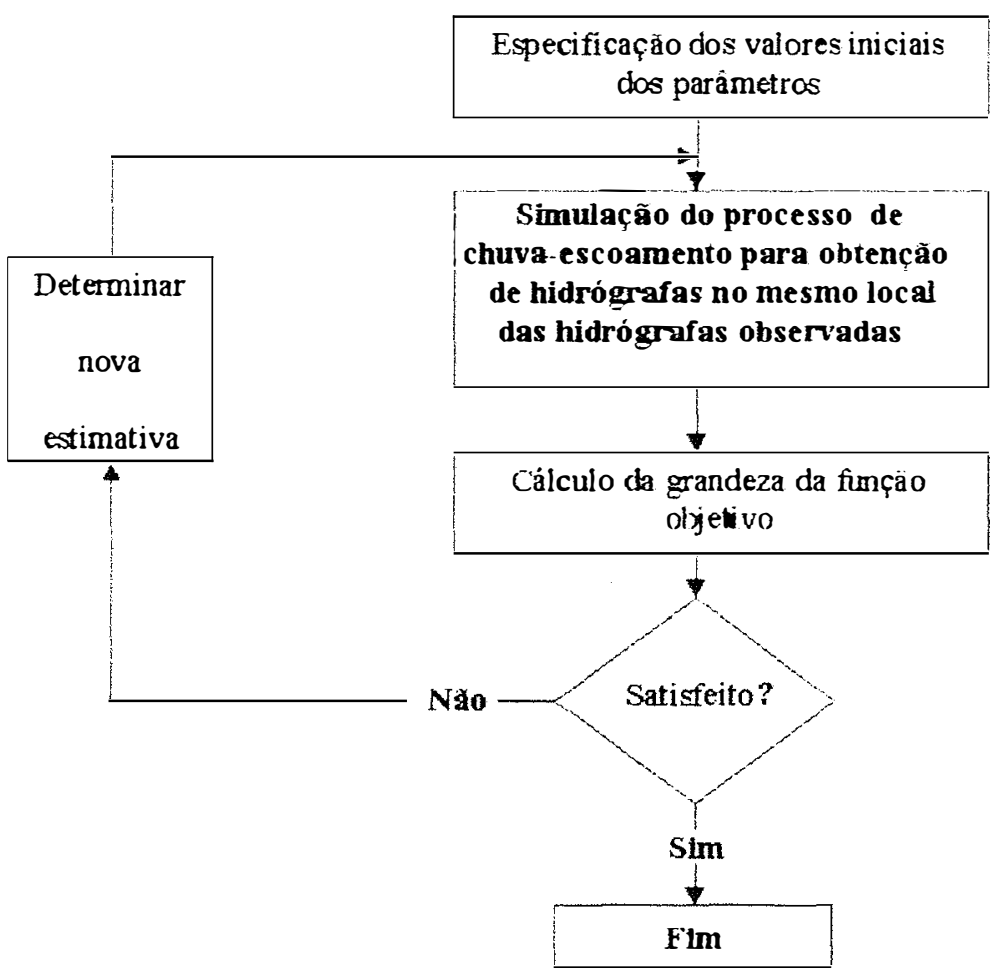

Figura 11 - Estrutura do HEC-HMS para otimização da calibração de parâmetros. 


\section{MATERIAL E MÉTODOS}

\subsection{MATERIAL}

\subsection{1 Área de estudo}

\subsubsection{Localização}

A área de estudo, denominada Microbacia do Tinga, está localizada na Estação Experimental do Departamento de Ciências Florestais da Escola Superior de Agricultura "Luiz de Queiroz" - ESALQ/USP, no Município de Itatinga. As coordenadas geográficas do local estão entre os paralelos $23^{\circ} 02^{\prime} 01^{\prime \prime}$ e $23^{\circ} 02^{\prime} 30^{\prime \prime}$ de Latitude sul e os meridianos $48^{\circ} 38^{\prime} 34^{\prime \prime}$ e $48^{\circ} 37^{\prime} 30^{\prime \prime}$ de Longitude oeste a partir de Greenwich (Figura 12).

\subsubsection{Características físicas}

A Microbacia do Tinga é uma área experimental, cujos limites se restringem à estação medidora de vazão, localizada no ponto vermelho da Figura 13. O Córrego do Tinga é um afluente do Córrego do Potreirinho que, por sua vez, faz parte da bacia do Baixo Paranapanema, na parte central do Estado de São Paulo. A declividade média da área de estudo é de $4,6 \%$, situando-se a parte mais declivosa junto aos canais e a menos, à montante. Um mapa de superficie com a delimitação da Microbacia do Tinga é apresentado na Figura 14. Já na Tabela 7, estão listadas as caracteristicas físicas da área de estudo. 


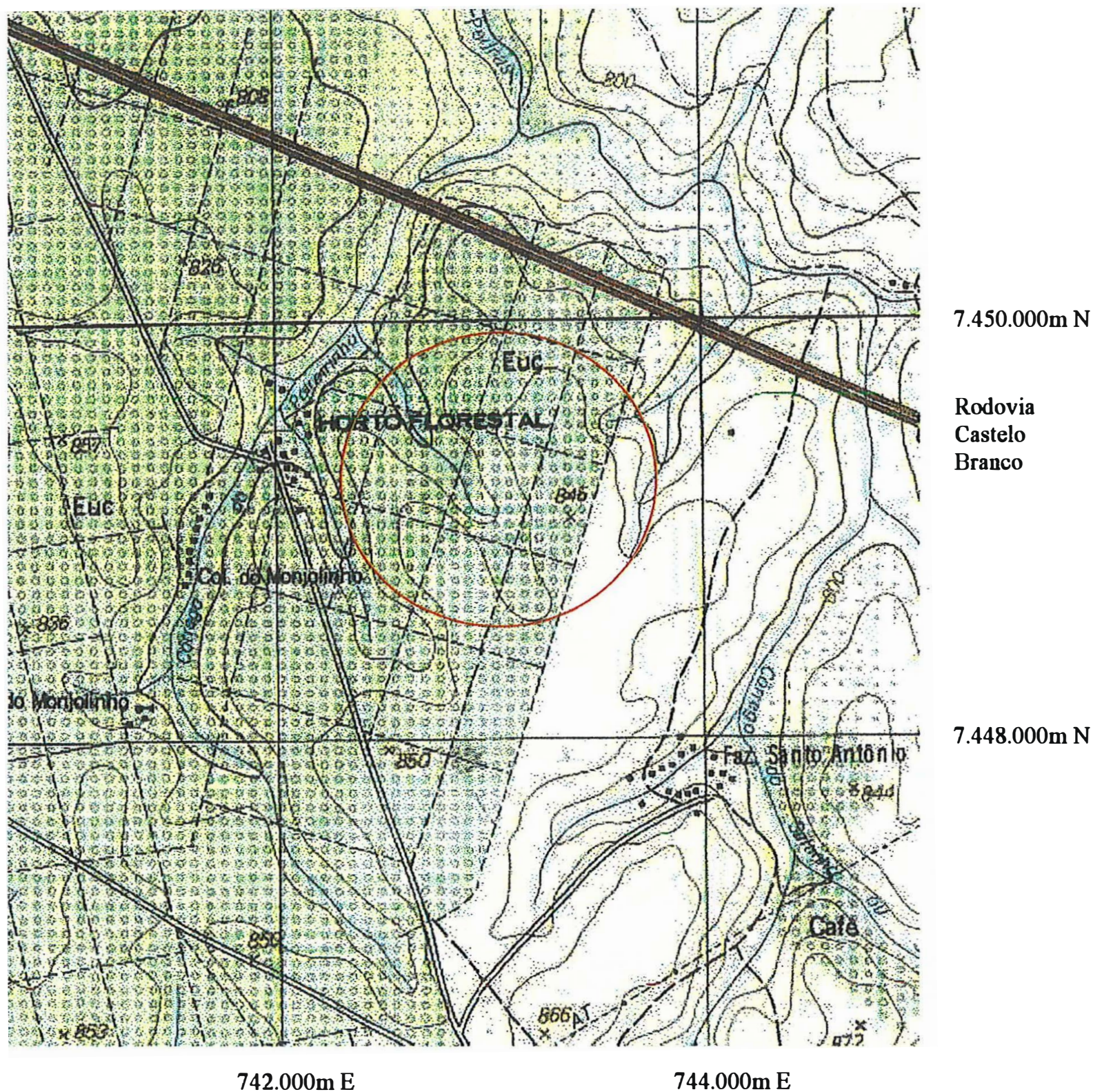

Figura 12 - Localização geográfica da área de estudo, na escala 1:50.000 (IBGE, 1973). 


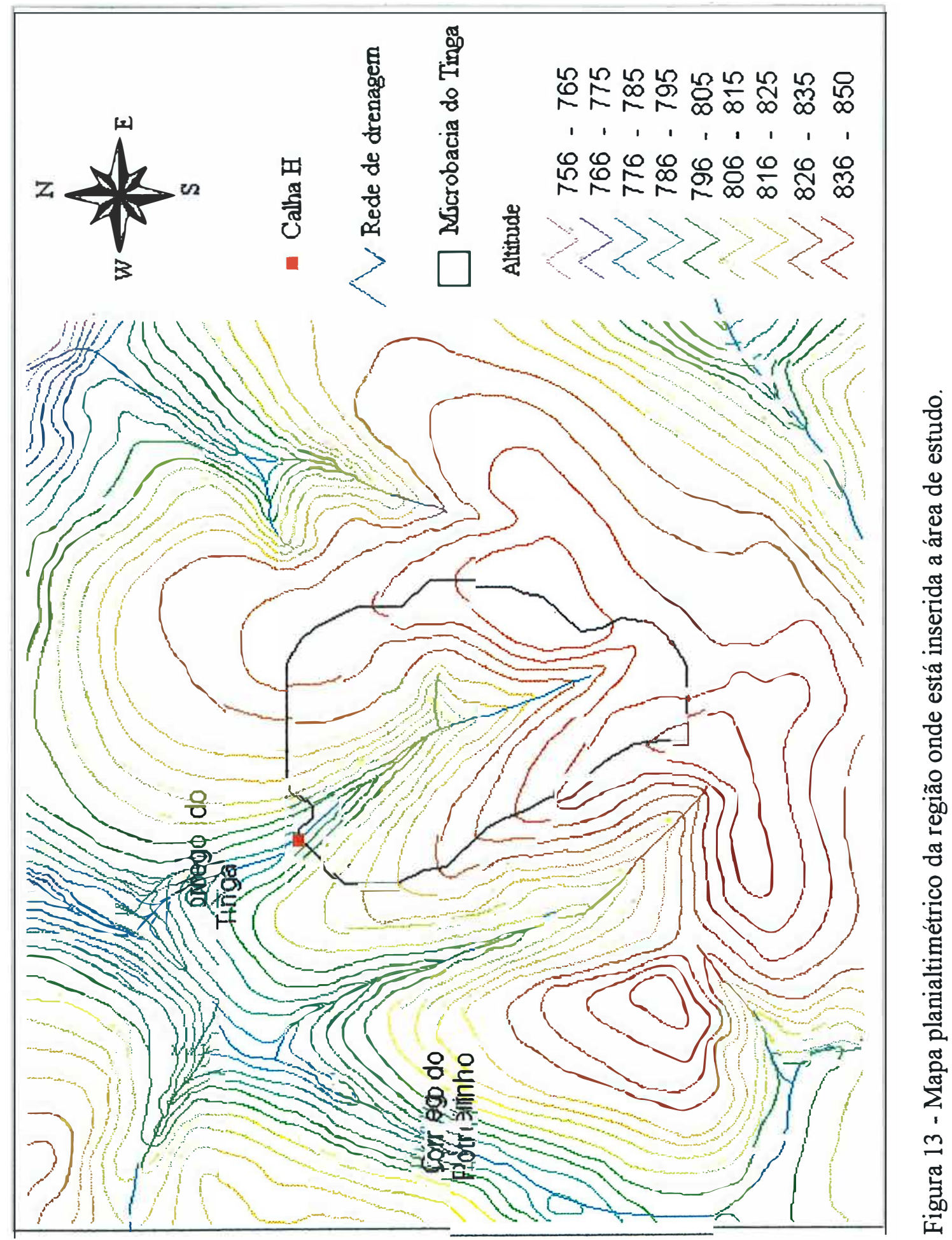



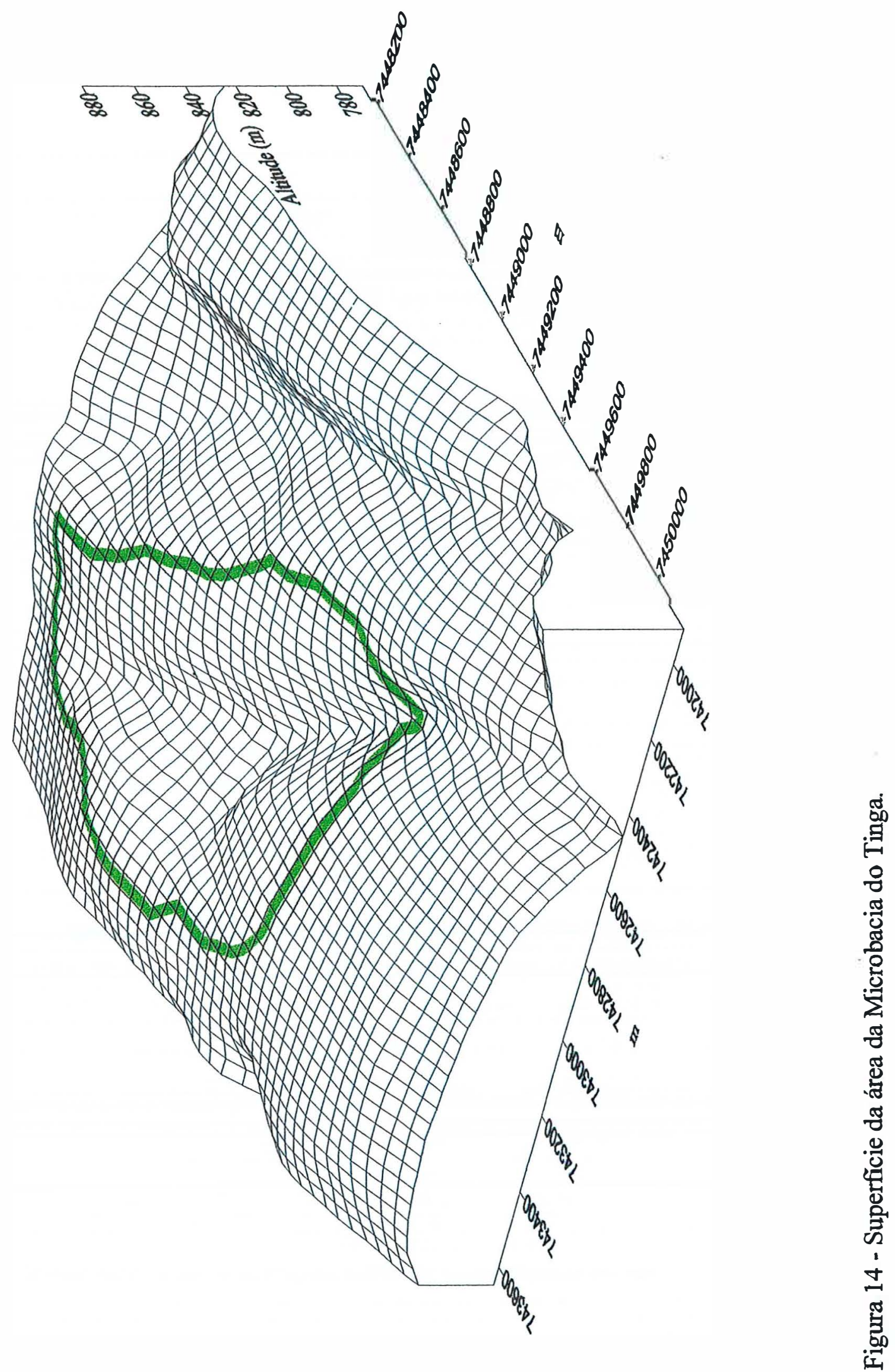
Tabela 7 - Características físicas da Microbacia do Tinga.

\begin{tabular}{lc}
\hline Área (ha) & 81,7 \\
Orientação & NO \\
Fator de forma & 0,64 \\
Densidade de drenagem & 1,6 \\
Índice de compacidade & 1,15 \\
Razão de bifurcação & 2 \\
Comprimento do canal principal (km) & 1,12 \\
Comprimento do canal secundário (km) & 0,186 \\
Perímetro (km) & 3,71 \\
Altitude máxima (m) & 852,1 \\
Altitude mínima (m) & 795,5 \\
Altitude média (m) & 830,6 \\
Altitude mediana (m) & 832,4 \\
Classificação (Strahler, 1957) & $2^{\underline{a}}$ ordem \\
Padrão de drenagem & Dentrítico \\
Declividade média da bacia (\%) & 4,6 \\
Declividade média dos canais (\%) & 4,6 \\
\hline
\end{tabular}

\subsubsection{Clima e balanço hídrico}

O clima é do tipo Cfa, segundo a classifícação de Köppen, isto é, mesotérmico úmido, sem estação seca definida. O trimestre mais chuvoso corresponde aos meses de dezembro a fevereiro e o período mais seco aos meses de maio a agosto. Nesse último, a evaporação pode exceder a precipitação (Pessotti, 1994). Na Tabela 8, estão apresentadas algumas características climáticas. As médias mensais de precipitação, escoamento e evapotranspiração, num período de 3 anos, retiradas de Lima et al (1996), são apresentados na forma gráfica (Figura 15). Observe-se que, na figura, a estimativa da 
Tabela 8. Características climáticas da Microbacia do Tinga.

\begin{tabular}{lc}
\hline Temperatura média anual $\left({ }^{\circ} \mathrm{C}\right)$ & 19,4 \\
Temperatura mínima anual $\left({ }^{\circ} \mathrm{C}\right)$ & 12,8 \\
Umidade relativa do ar média anual (\%) & 83,3 \\
Precipitação de julho, o mês mais seco (mm) & $30-60$ \\
Precipitação média anual (mm) & 1635 \\
Evapotranspiração potencial (mm/ano) & 877 \\
Precipitação - Evapotranspiração (mm/ano) & 758 \\
\hline
\end{tabular}

Fonte dos dados: Pessotti (1994)

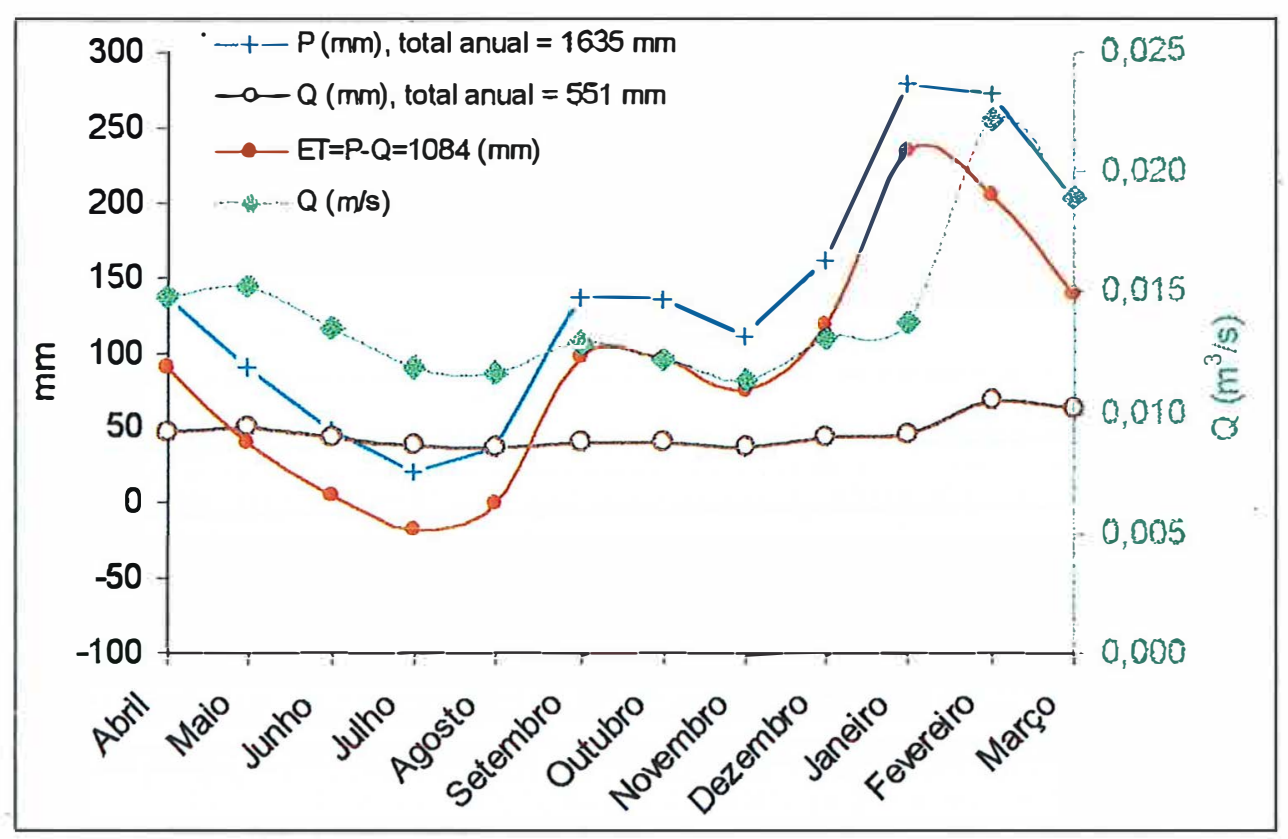

Figura 15 - Médias mensais de precipitação (P) e deflúvio (Q), com dados de 3 anos (adaptados de Lima et al., 1996). Também são apresentados a ETP e a Q $\left(\mathrm{m}^{3} / \mathrm{s}\right)$. 
evapotranspiração foi feita pelo balanço hídrico da bacia hidrográfica $(E=P-Q)$. Nos meses de julho e agosto, o balanço hídrico tem um excedente de $762 \mathrm{~mm}$ e um déficit de $3 \mathrm{~mm}$, com uma evapotranspiração potencial de $877 \mathrm{~mm}$ e uma capacidade de armazenamento de 150 mm. (Scardua, 1994 e Câmara, 1999).

\subsubsection{Relevo}

O relevo dominante na área, conforme Pessotti (1994), é o suave ondulado, composto por topos aplainados e encostas de formas retilineas ou convexas. Em menor expressão, ocorre o relevo ondulado, com declividade entre 10\% e 15\% e rampas de forma retilínea, marcado pela ausência de topos aplainados. A rede de drenagem é de baixa intensidade, com cabeceiras arredondadas, vales abertos a fechados, com planície aluvial restrita. A forma do relevo é a de degradação de planaltos dissecados. Um sistema de circulação, com estradas e carreadores, foi implantado na área sem levar em conta a topografia. Esse sistema serve como acumulador e condutor de águas da drenagem superficial (Figura 16). Segundo Pessotti (1994), nos carreadores com maior declividade havia processo erosivo, com a deposição de sedimentos na rede de drenagem.

\subsubsection{Solos}

Os solos da Microbacia do Tinga foram classificados por Pessotti (1994) em dois tipos: latossolos vermelho-escuro e vermelho-amarelo, com transições difusas e graduais entre os horizontes, porosos e com profundidades superiores a $2 \mathrm{~m}$.

Dentre esses tipos ocorrem cinco classes de solos:

a) LE1 $\rightarrow$ (latossolo vermelho-escuro, álico, A moderado, textura argilosa, relevo ondulado) e retenção de água, ao longo do perfil, que vai entre $0,61 \mathrm{~cm}$ de lâmina de água $/ \mathrm{cm}$ de solo a $0,66 \mathrm{~cm}$ de lâmina de água $/ \mathrm{cm}$ de solo, refletindo as variações no conteúdo de argila;

b) LE2 $\rightarrow$ (latossolo vermelho escuro, álico, A moderado, textura média argilosa, relevo ondulado) e retenção de água de $0,53 \mathrm{~cm}$ de lâmina de água/cm de solo; 


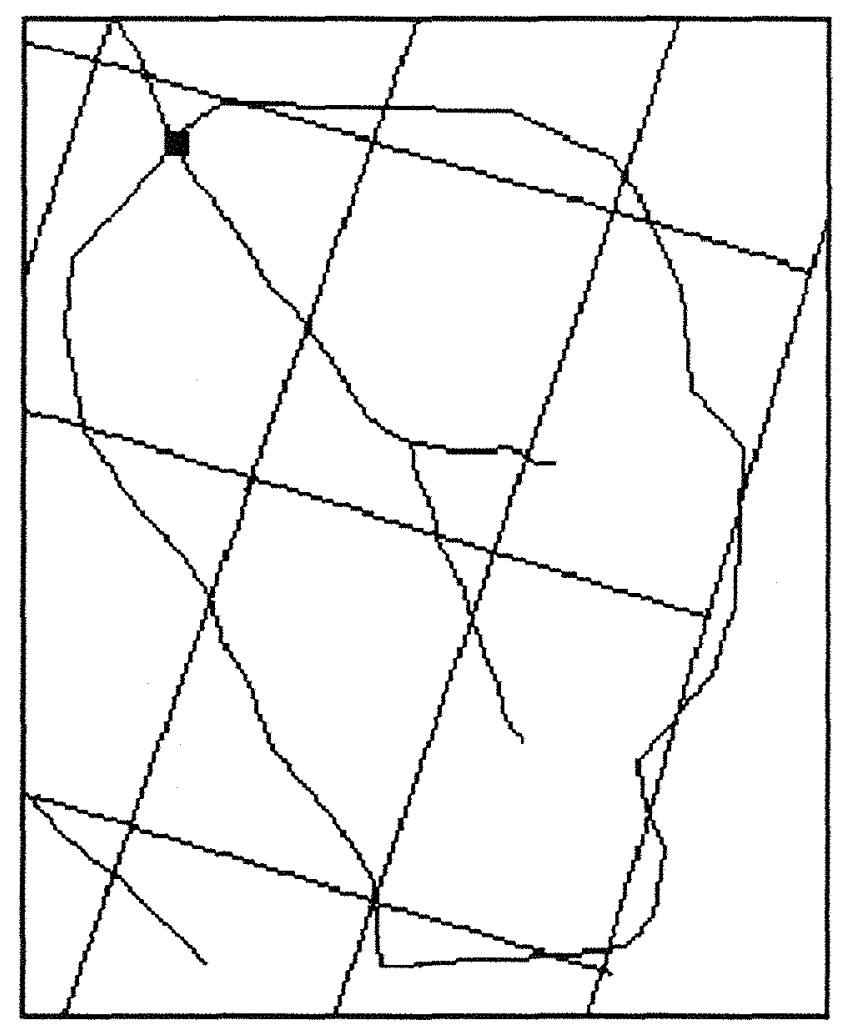

Figura 16 - Sistema de circulação com estradas e carreadores.

c) LE3 $\rightarrow$ (latossolo vermelho escuro, álico, A moderado, textura média argilosa, relevo suave ondulado) e retenção de água de $0,53 \mathrm{~cm}$ de lâmina de água $/ \mathrm{cm}$ de solo;

d) LV1 $\rightarrow$ (latossolo vermelho-amarelo, álico, A moderado, textura média argilosa, relevo suave ondulado) e retenção de água entre $0,46 \mathrm{~cm}$ de lâmina de água $/ \mathrm{cm}$ de solo e $0,49 \mathrm{~cm}$ de lâmina de água/cm de solo;

e) LV2 $\rightarrow$ (latossolo vermelho-amarelo, álico, A moderado, textura média arenosa, relevo suave ondulado) e retenção de água de $0,43 \mathrm{~cm}$ de lâmina de água $/ \mathrm{cm}$ de solo.

A porcentagem de área ocupada por esses solos é, respectivamente, $66,8 \%$ $1,6 \%, 16,3 \%, 10,4 \%$ e $4,9 \%$. Cabe esclarecer que os valores de retenção de água apresentados são de amostras de solo deformadas, submetidas à tensões entre 0,1 atm e $15 \mathrm{~atm}$. 
Observe-se que o LVl é predominante nas formas mais suavizadas do relevo, que, na área de estudo, correspondem às partes mais altas. Por outro lado, as encostas são ocupadas majoritariamente pelo LE1, que são as áreas mais baixas, próximas aos canais.

Na Tabela 9, são apresentados os perfís de LE1 e LV1 caracterizados por Pessotti (1994). Esses perfis foram escolhidos como representativos dos latossolos vermelho-escuro e vermelho-amarelo. Nota-se que a textura do latossolo vermelhoescuro (LE1) é média argilosa, com teores de argila crescentes ao longo do perfil. Já, a textura do latossolo vermelho-amarelo (LV1) é média arenosa, com horizontes apresentando consideráveis teores de areia, o que facilita a drenagem ao longo do perfil, que ocupa a parte mais alta da bacia.

\subsubsection{Vegetação}

A Microbacia do Tinga é coberta por Eucalyptus saligna Smith, dividida em talhões de $500 \mathrm{~m} \times 350 \mathrm{~m}$ por carreadores de $7 \mathrm{~m}$ de largura. Ao longo do riacho existe uma mata ciliar totalizando 7,6 ha. De acordo com Lima et al. (1996), o eucalipto foi plantado em torno de 1945. A primeira fase de produção foi voltada para lenha (1945 a 1957), a seguir, a madeira foi destinada a dormentes de estradas de ferro, com corte seletivo (1957 a 1978). A partir de então, acentuou-se a regeneração natural e a presença de vegetação de gramíneas, sendo o volume de madeira avaliado em $135 \mathrm{~m}^{3} / \mathrm{ha}$ (Lima et al. (1996). Em maio de 1997, a área sofreu um corte raso para a retirada da madeira, com exceção da mata ciliar. 
Tabela 9 - Características de um perfil da unidade de mapeamento Latossolo vermelhoescuro (LEl) e de um da unidade Latossolo vermelho-amarelo (LV1), coletadas na Microbacia do Tinga.

\begin{tabular}{|c|c|c|c|}
\hline \multirow[t]{2}{*}{ Características } & \multicolumn{2}{|c|}{$\begin{array}{c}\text { Latossolo vermelho escuro (LE1) } \\
\text { Horizontes }\end{array}$} & \multirow[b]{2}{*}{ BW2 } \\
\hline & $A$ & BW1 & \\
\hline Profundidade $(\mathrm{cm})$ & $0-24$ & $24-91$ & $91-170$ \\
\hline Areia (\%) & 62 & 58 & 51 \\
\hline Silte (\%) & 6 & 8 & 7 \\
\hline Argila (\%) & 32 & 34 & 42 \\
\hline Porosidade (\%) & 35 & 48 & 46 \\
\hline Densidade real $\left(\mathrm{g} / \mathrm{cm}^{3}\right)$ & 2,13 & 2,35 & 2,35 \\
\hline Densidade aparente $\left(\mathrm{g} / \mathrm{cm}^{3}\right)$ & 1,39 & 1,23 & 1,26 \\
\hline Matéria orgânica (\%) & 2,4 & 1,7 & 1 \\
\hline Raizes finas & Abundantes & Abundantes & Poucas \\
\hline Textura & Franco argilo arenoso & Franco argilo arenoso & Argilo aren. \\
\hline Macro e microporos & & Abundantes & Abundantes \\
\hline Relevo local & Terço médio de encosta & & \\
\hline Drenagem & Boa & & \\
\hline Erosão & Laminar severa & & \\
\hline Uso atual & Eucalipto & & \\
\hline Classificação: Latossolo & elho-Escuro álico A moder & textura argilo & \\
\hline
\end{tabular}

\begin{tabular}{|c|c|c|c|c|}
\hline \multirow[t]{2}{*}{ Características } & \multicolumn{4}{|c|}{$\begin{array}{c}\text { Latossolo vemelho amarelo (LV1) } \\
\text { Horizontes }\end{array}$} \\
\hline & A1 & $\mathrm{BA}$ & BW1 & BW2 \\
\hline Profundidade $(\mathrm{cm})$ & $0-26$ & $26-52$ & $52-108$ & $108-170+$ \\
\hline Areia (\%) & 77 & 76 & 74 & 68 \\
\hline Silte (\%) & 3 & 2 & 2 & 2 \\
\hline Argila (\%) & 20 & 22 & 24 & 30 \\
\hline Porosidade (\%) & 44 & 42 & 42 & 44 \\
\hline Densidade real $\left(\mathrm{g} / \mathrm{cm}^{3}\right)$ & 2,22 & 2,25 & 2,27 & 2,35 \\
\hline Densidade aparente $\left(\mathrm{g} / \mathrm{cm}^{3}\right)$ & 1,25 & 1,3 & 1,31 & 1,32 \\
\hline Matéria orgânica (\%) & 2,5 & 1,7 & 1,6 & 1,4 \\
\hline Raizes finas & Abundantes & & Abundantes & Poucas \\
\hline Textura & Franco arenoso & Argilo aren. & Argilo aren. & Fr. arg.aren. \\
\hline Macro e microporos & & & Abundantes & Abundantes \\
\hline Relevo local & \multicolumn{4}{|c|}{ Topo levemente inclinado } \\
\hline Drenagem & \multicolumn{4}{|l|}{ Boa } \\
\hline Erosåo & \multicolumn{4}{|l|}{ Laminar severa } \\
\hline Uso atual & \multicolumn{4}{|l|}{ Eucalipto } \\
\hline Classificaçăo: Latos & o-Amarelo álico A & erado textu & dia arenosa & \\
\hline
\end{tabular}




\subsubsection{Material utilizado como fonte de dados}

\subsubsection{Material cartográfico}

- Cartas planialtimétricas do Plano Cartográfico do Estado de São Paulo, folha Córrego do Lobo (SF-22-Z-D-II-2-NO-B), a Ribeirão das Pedras (SF-22-Z-D-II-2-NE-A), a Fazenda Toca (SF-22-Z-D-II-2-NE-C) e a Córrego Potreirinho (SF-22-Z-D-11-2-ND), Governo do Estado de São Paulo, Secretaria de Economia e Planejamento, Coordenadoria de Ação Regional, Divisão de Geografia, $1^{\text {a }}$ edição, 1979, escala 1:10.000 (SÃO PAULO, 1979);

- Carta planialtimétrica elaborada pelo Departamento de Engenharia Rural, Seção de Topografia e Geoprocessamento, Escola Superior de Agricultura "Luiz de Queiroz", ESALQ/USP, escala 1:4.000 (SÃO PAULO, 1994);

- Mapa detalhado de solos do Horto Itatinga elaborado por Consultoria em solos S/c Ltda - Consult, 1994, escala 1:10.000 (Pessotti, 1994).

\subsubsection{Fotografias aéreas digitais}

Fotografias aéreas pertencentes a Estação Experimental de ItatingaESALQ (USP), provenientes de vôo realizado no dia 24/01/1999 pela empresa Phóton Imageamento Aéreo e com escala aproximada de 1:40.000 (SÃO PAULO, 1999).

\subsubsection{Material utilizado como fonte de dados de chuva e vazão}

Os eventos de chuva e vazão analisados ocorreram entre janeiro de 1996 e fevereiro de 1998, para os dados provenientes do posto meteorológico e estação linimétrica. Para o período entre outubro de 1997 e fevereiro de 1998 foram utilizados 
dados da estação meteorólogica automática. Também, foram analisados eventos entre abril de 1991 e 1994 publicados por Scardua (1994).

\subsection{Pluviogramas}

Os dados de precipitação usados foram obtidos de diagramas de pluviógrafo com rotação semanal (Figura 17a), modelo PLG 75 (HIDROLOGIA S.A.). O aparelho estava instalado no posto meteorológico da Estação Experimental de Itatinga, a mais ou menos $1050 \mathrm{~m}$ da calha medidora de vazão. Próximo à calha, também estavam instalados dois pluviômetros.

Os dados de precipitação obtidos da estação meteorológica automática, instalada junto ao posto meteorológico, foram coletados em intervalos de 12 minutos.

\subsection{Linigramas}

Foram utilizados diagramas de linígrafo de rotação semanal (Figura 17b) instalado junto a uma calha tipo $\mathrm{H}$ de $45 \mathrm{~cm}$ de altura, localizada no ponto de descarga da microbacia.

\subsubsection{Material utilizado na elaboração do banco de dados e simulação do escoamento}

- scanner de mesa Scanjet HP 4c;

- Programa em linguagem Dbase para interpolação de séries temporais, desenvolvido pelos Eng. Florestal Silvio Frosini de B. Ferraz e $\operatorname{Dr}^{\mathrm{a}}$. Maria. J. B. Zakia do Departamento de Ciências Florestais ESALQ/USP;

- software Excel 97, desenvolvido pela Microsoft; 

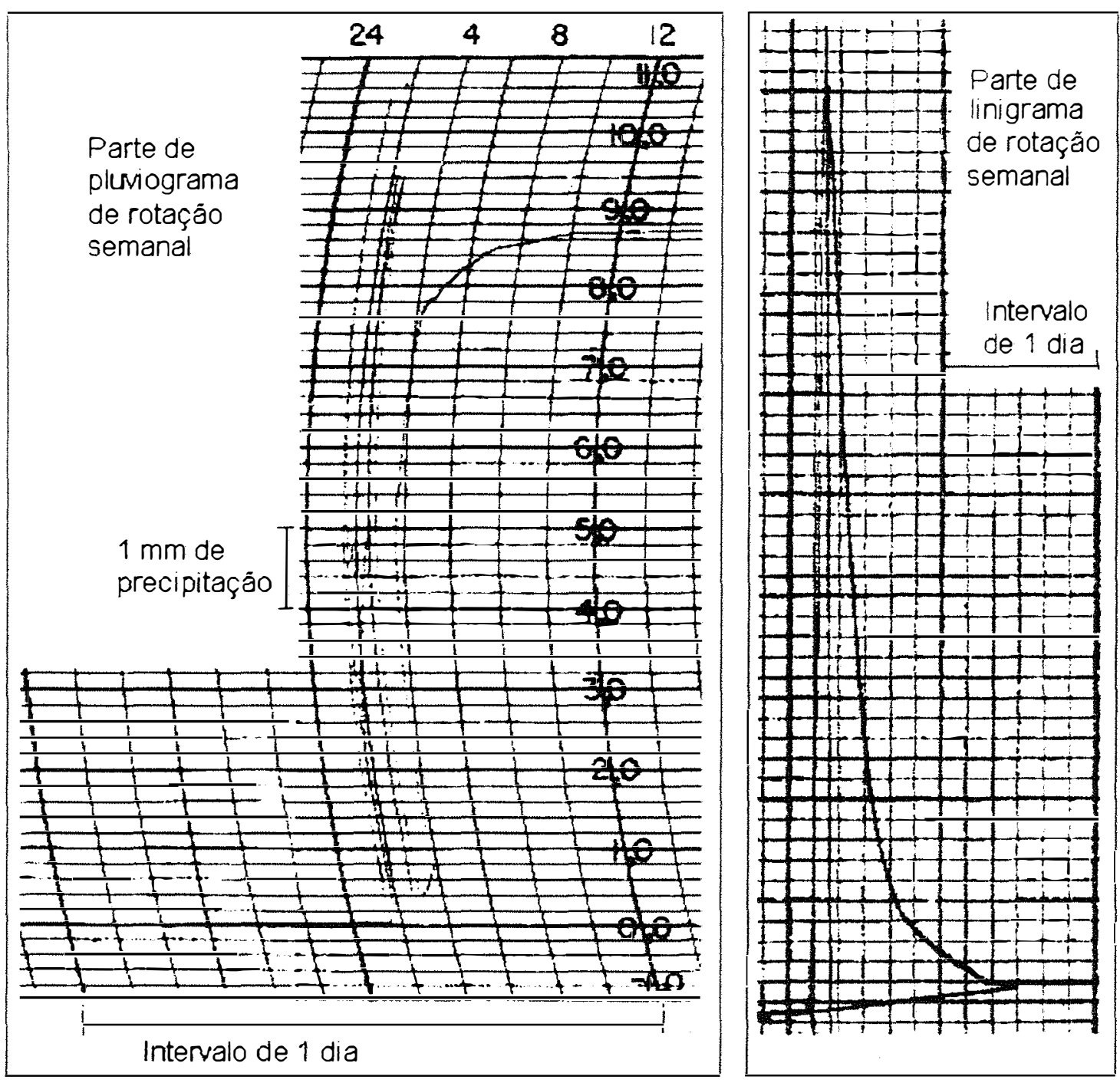

Figura 17 - Detalhes do pluviograma (a) e linigrama (b), ambos com autonomia semanal.

- software ArcView v.3.1 com a extensão Spatial Analyst v 1.1, ambos desenvolvidos pela Enviromental Systems Research Institute (ESRI), Redlands, CA;

- Extensões do ArcView e programas em linguagem Avenue, obtidos no endereço http://www.esri.com/arcscripts/:

- Extensão Screen Digitizer (zscrndig.avx), desenvolvida por Howie Sternberg (Environmental and Geographic Information Center Department of Environmental Protection State of Connecticut); 
- Extensão Image to Map Register (Register.avx), de autoria de Kenneth R. McVay (Universtiy of Houston Clear Lake) e Guenter Doerffel ;

- Extensão ImageWarp version 2.0 (imagewarp.avx), desenvolvida por Kenneth R. McVay;

- Extensão Xtools (xtoolsmh.avx), desenvolvida por Mike DeLaune (Oregon Department of Forestry). Essa extensão foi descarregada do endereço http://www.odf.state.us/sfgis/;

- software CRWR-PREPRO, desenvolvido pelo Centro de Pesquisas em Recursos Hidricos da Universidade do Texas em Austin (E.U.A.) obtido da página do CRWR (http://www.ce.utexas.edu/prof/olivera/prepro/prepro.htm). O software também é encontrado no servidor ftp.crwr.utexas.edu, diretório lpublgisclasslpreprol;

- software Hydrologic Modeling System HEC-HMS v.1.1 desenvolvido pelo Centro de Engenharia Hidrológica do Corpo de Engenheiros das Forças Armadas dos Estados Unidos (HEC-USACE). O software por ser de domínio público foi descarregado do endereço http://www.hec. usace.army.mil.

\subsection{MÉTODOS}

Em linhas gerais, a simulação do escoamento sob os diferentes cenários de ocupação da área de estudo foi obtida conforme os métodos e procedimentos ilustrados na Figura 18.

\subsubsection{Escolha da área de estudo}

O processo de escolha da área de estudo demandou um tempo considerável, uma vez que não havia uma microbacia agrícola com dados de escoamento disponiveis. Tal busca justificava-se na crença de que o método escolhido estimaria melhor as hidrógrafas nesse tipo de ocupação, conforme indicações da literatura (Ponce, 


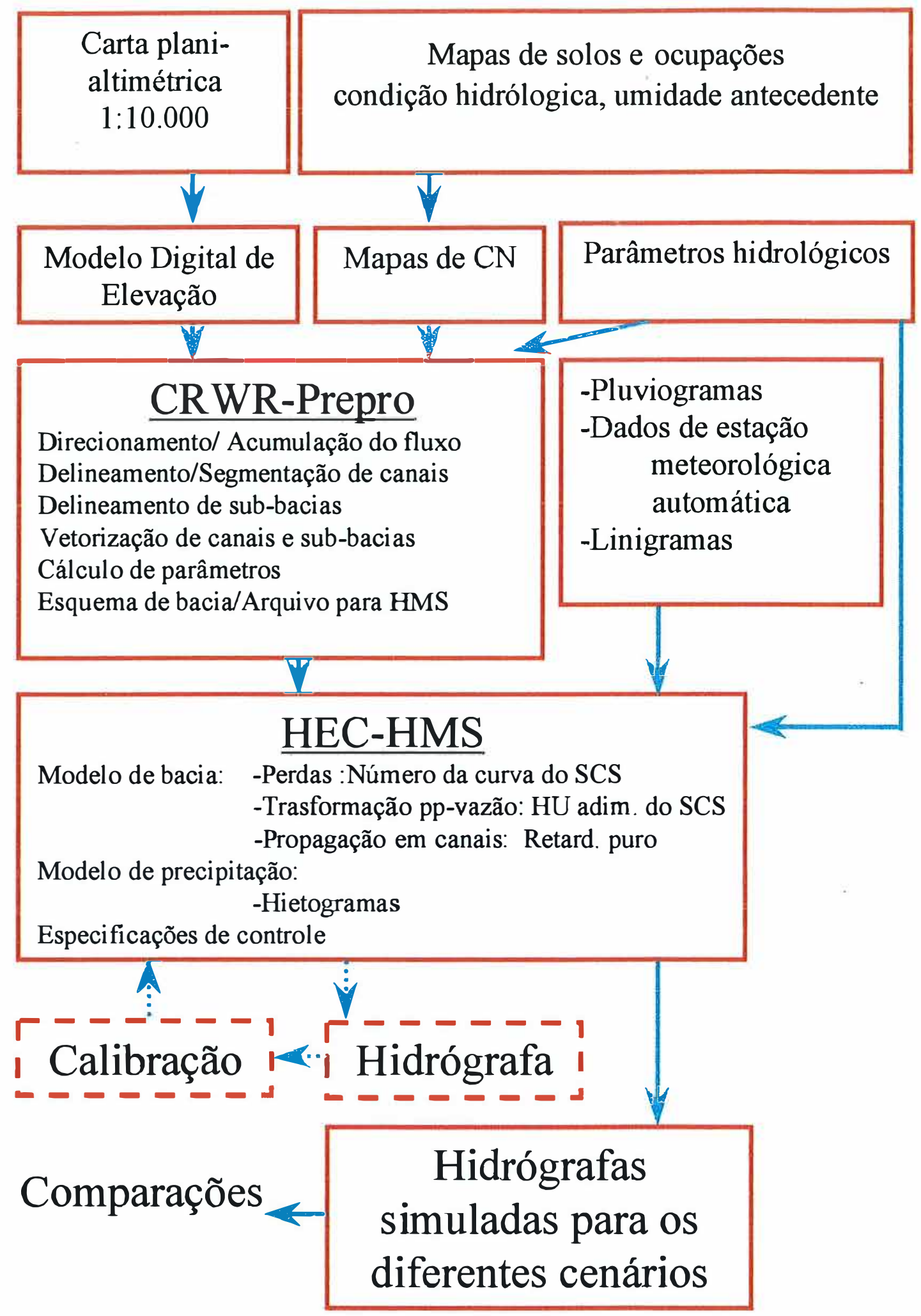

Figura 18 - Fluxograma dos principais métodos e propedimentos utilizados. 
1989, Chow et al., 1988 e Maidment et al., 1993). A solução mais viável, foi aproveitar dados da Microbacia do Tinga, gentilmente cedidos pela Estação Experimental de Itatinga/Departamento de Ciências Florestais/ESALQ/USP.

\subsubsection{Elaboraçāo do modelo digital do terreno}

O modelo digital do terreno foi obtido pela interpolação do arquivo vetorial de pontos, gerado pela digitalização em tela das cartas planialtimétricas. Essas cartas foram convertidas ao formato digital por meio do uso de um scanner. Os arquivos assim criados foram georeferenciados no software ArcView por intermédio da extensão Image to Map Register. Posteriormente, esses arquivos foram unidos e serviram de fundo para a digitalização em tela das curvas de nível, realizada por meio da extensão Screen Digitizer.

$\mathrm{O}$ arquivo vetorial de pontos, por sua vez, foi interpolado, utilizando-se a função Interpolate Grid do Spatial Analist v.1.1 que oferece quatro opções de interpolação, sendo que o método escolhido foi o Spline.

O Método Spline, além de representar de maneira satisfatória as variações de altitude da área de estudo, era o recomendado pelo manual de ajuda ao usuário da Extensão Spatial Analist como o mais adequado para interpolação de superfícies de terreno. Cabe esclarecer que as funções Splines ajustam uma superfície de curvatura mínima (suave) nos pontos considerados. Conceitualmente é o mesmo que, em desenhos, traçar uma curva entre pontos com a curva japonesa (barra flexivel que em inglês também é chamada de spline). Para representar superfícies os procedimentos de ajustes devem ser em duas dimensões. Na aplicação desse método pelo Spatial Analist, foi necessário o fornecimento de várias informações, entre outras, o número de pontos para o ajuste local e um parâmetro de função de peso, que considera, mais ou menos, os pontos mais próximos do ponto que está sendo interpolado. 
Para a escolha do tamanho da célula a ser adotado, foram feitos testes preliminares. Esses testes consistiram da interpolação do arquivo vetorial de pontos para diversos tamanhos de célula. Em cada MDT gerado foi delineada a rede de drenagem para a verificação de diferenças.

\subsubsection{Definição e conexão dos elementos hidrológicos pelo CRWR-PREPRO}

A definição e conexão dos elementos hidrólogicos pelo CRWR-PREPRO fundamentou-se nos procedimentos descritos por Olivera et. al. (1998) e Olivera et. al. (1999), autores que vêm continuamente melhorando o software, e em Hellwegger \& Maidment (1997), que iniciaram seu desenvolvimento. Para tal finalidade, seguiu-se o menu principal ilustrado na Figura 19.

\subsubsection{Delineamento de canais e sub-bacias}

Inicialmente, o MDT foi "marcado" pela rede de drenagem digitalizada das cartas planialtimétricas, recorrendo-se ao procedimento de elevação arbitrária da área (Burn Streams) fora da rede de drenagem (Figura 20). O novo MDT foi normalizado pelo procedimento de preenchimento de depressões (Fill Sinks), para evitar erros no direcionamento do fluxo. Afinal, o método considera, para direcionar o fluxo, as oito células vizinhas de cada célula avaliada (procedimento D8), optando pela de maior declividade.

O próximo passo foi calcular as direções de fluxo pelo procedimento de direcionamento de fluxo (Flow Direction) a partir do MDT preenchido. A seguir, obtevese as acumulações de fluxo pelo procedimento de acumulação de fluxo (Flow Accumulation), que direcionou cada célula do MDT e contou quantas células acima contribuíram ao fluxo em cada célula. 


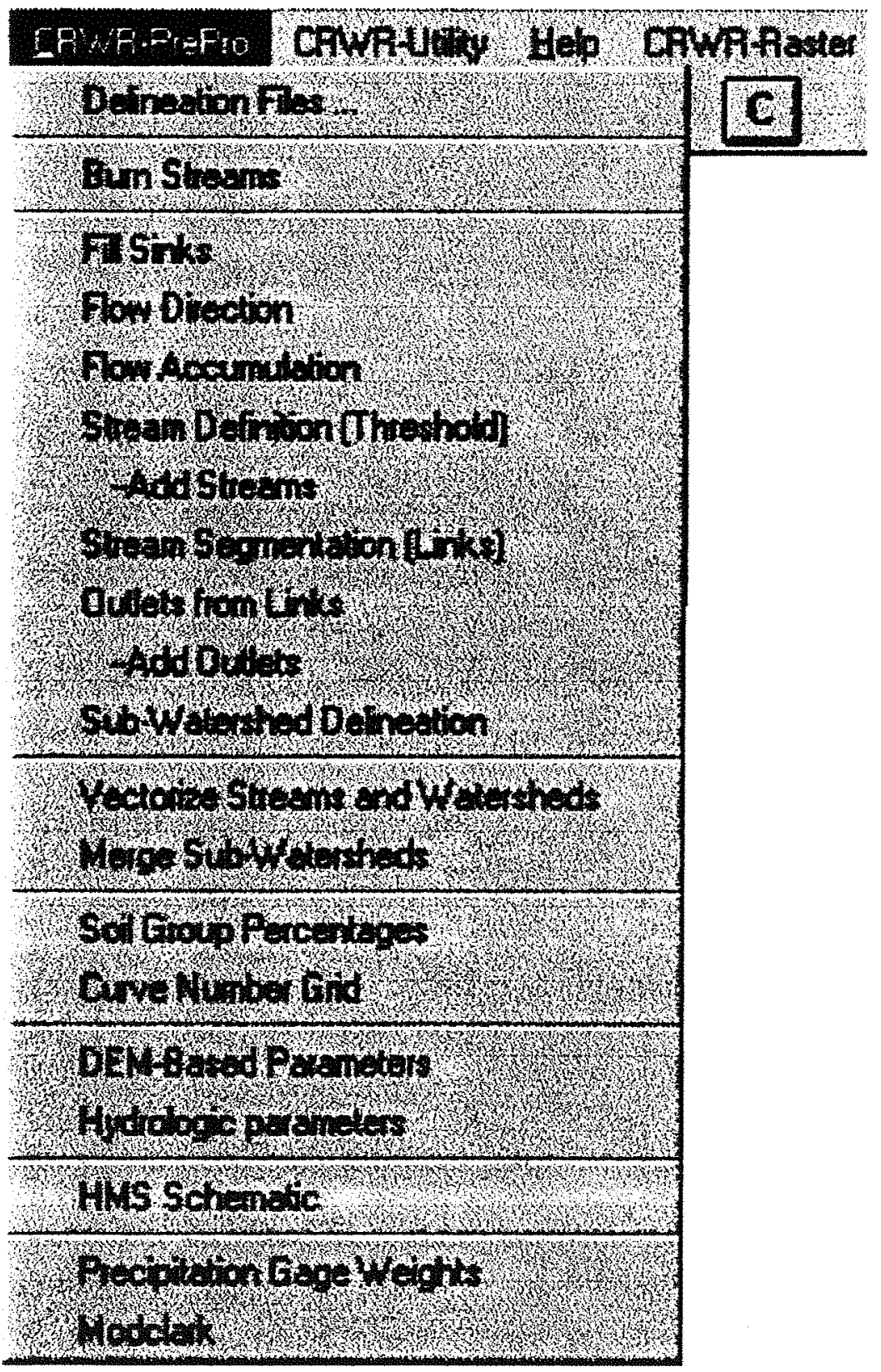

Figura 19 - Menu principal do CRWR-PREPRO, em ambiente ArcView 3.1. 


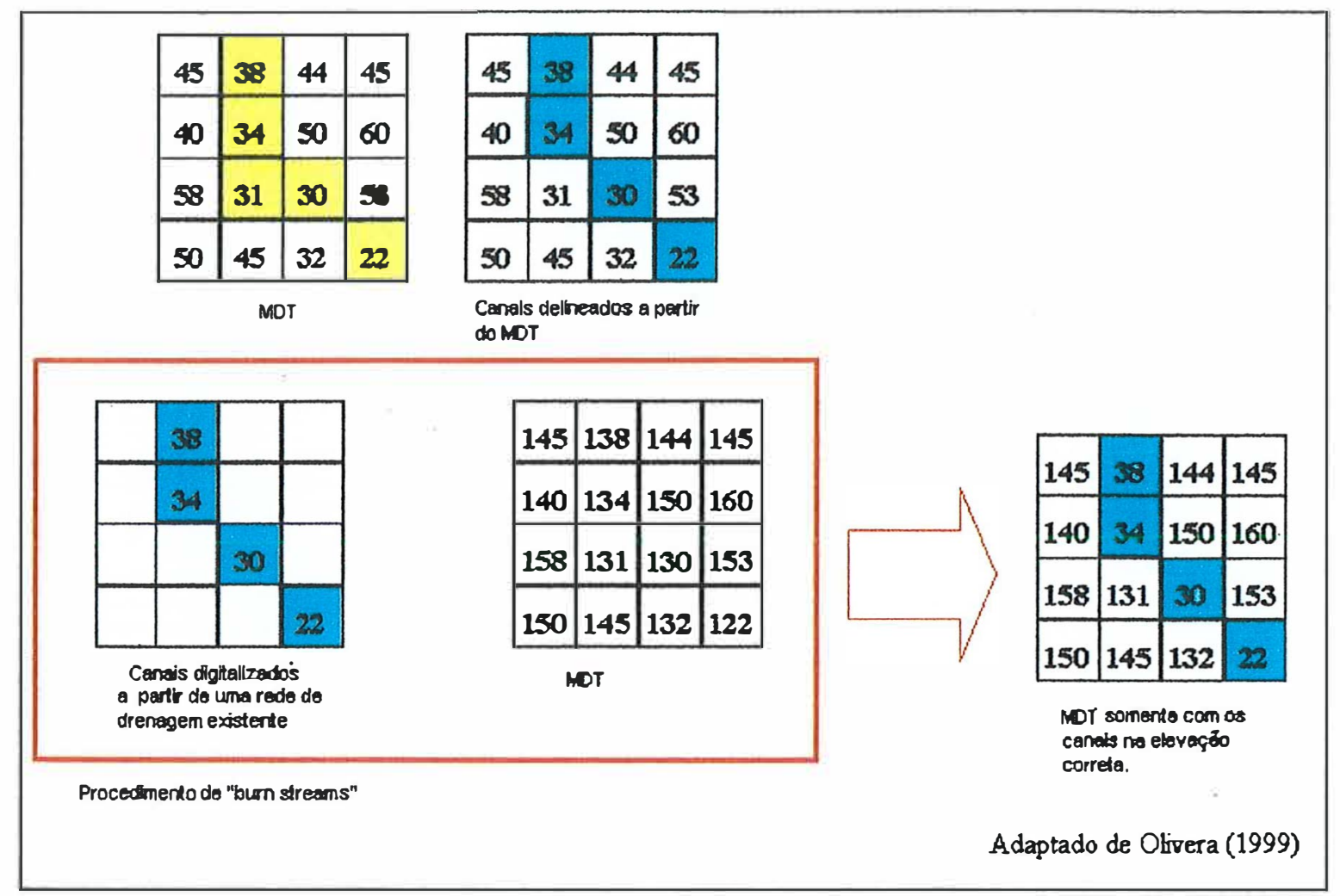

Figura 20 - Procedimento de elevação arbitrária da área não pertencente a canais.

Já, o procedimento de definição de canais (Stream Definition) determinou os canais com base no número mínimo de células que contribuiu para formar um canal (threshold). No presente estudo, foi adotado $v$ threshold de 1000 células. Por outro lado, o procedimento de adição de canais (Add Streams) não foi utilizado, pois não foi necessária a adição de canais. O procedimento segmentação de canais (Stream Segmentation) separou a rede de drenagem em cada início de canal ou na interseção de dois canais, no curso abaixo do canal ou no ponto final do sistema. Cada segmento de canal foi identificado com um número único e sua última célula classificada, ou não, como uma saída potencial da microbacia pelo procedimento de saída de bacia (Outlets from Links). 
A partir dai, foi possivel delinear as sub-bacias no formato grade (SubWatershed Delineation). Esse arquivo e o de canais, também no formato grade, foram convertidos ao formato vetorial por intermédio do procedimento de vetorização de canais e sub-bacias (Vectorize Stream and Watershed).

Como o procedimento de delineamento gerou apenas 3 sub-bacias, adicionou-se, pelo procedimento de adição de saídas (Add Outlets), 7 pontos de saída de bacias nos canais, espaçados em aproximadamente $170 \mathrm{~m}$, para que fossem formadas áreas de contribuição mais ou menos semelhantes. O primeiro foi inserido no local onde se localiza a estação medidora, portanto, fundamental para que, a partir dele, a Microbacia do Tinga pudesse ser delimitada. A divisão da área de estudo em sub-áreas menores visou à maior discretização espacial da Microbacia do Tinga, conseqüentemente, incrementando o fator de variabilidade espacial na determinação de parâmetros. Um outro motivo para efetuar essa sub-divisão foi a criação de uma rede dentritica para aplicação do modelo hidrológico HEC-HMS. Segundo Ponce (1989) uma bacia pode ser vista como um conjunto de sub-bacias menores, onde técnicas de hidrógrafas unitárias podem ser aplicadas para a representação do escoamento nas sub-bacias, aliadas a procedimentos de propagação do fluxo pela rede de drenagem em conexão.

Algumas vezes, a conversão dos dados para o formato vetorial cria polígonos "suspensos" devido a erros no processo. Esses polígonos que, na verdade, são pequenas áreas separadas dos polígonos adjacentes, são agregados aos últimos automaticamente pelo software. Já, o procedimento de junção de sub-bacias (função Merge Sub-Watersheds) junta as sub-bacias quando necessário.

O próximo passo, seguindo o menu do CRWR-PREPRO, seria a determinação do mapa de número da curva (função Curve Number Grid). No entanto, a metodologia do CRWR-PREPRO exige a confecção de uma tabela tipo look-up, que seria um procedimento trabalhoso, apenas justificado se a área a ser estudada fosse de grande tamanho ou com uma grande variedade de solos, ocupações, condições hidrológicas e tratamentos contra a erosão. Então, os mapas de número da curva usados foram construídos conforme procedimentos descrito a seguir. 


\subsubsection{Determinação do número da curva}

O mapa do número da curva foi obtido pelo cruzamento das informações de tipo de solo (Tabela 5 e mapa de solos), uso da terra (fotografias aéreas digitais Figura 21), grupo hidrólogico (Tabela 4), condição hidrológica da superfície (Tabela 3) e de umidade antecedente (Tabela 2). As duas primeiras informações provieram de mapas digitais no formato grade. Já, as demais, de tabelas.

Os limites das classes foram digitalizados em tela sobre a imagem do mapa original capturada por scanner, no caso dos solos. Para o uso da terra os limites foram digitalizados sobre as fotografias aéreas digitais. A digitalização foi feita pela extensão Screen Digitizer sobre o mapa original de solos georeferenciado. O georeferenciamento das imagens foi feito pelas extensões Image to Map Register para o caso dos mapa de solos e ImageWarp no caso das fotografias aéreas. Neste, o georeferenciamento foi feito pela retificação das imagems por pontos de controle obtidos das cartas planialtimétricas.

À tabela de atributos do mapa resultante da intersecção entre o mapa de solos e o de uso da terra (função Intersect da extensão Xtools) foram adicionados campos referentes ao grupo hidrólogico, condição hidrológica da superficie, uso da terra e número da curva correspondente. Esse arquivo foi transportado para a planilha eletrônica Excel, onde cada campo foi preenchido manualmente com dados tabelados de $\mathrm{CN}$ (Tabela 3). Tal procedimento justificou-se na maior praticidade e facilidade de trabalho no Excel, que apresenta compatibilidade com o ArcView, pois a extensão de arquivo *.dbf é aceita em ambos.

Após voltarem do Excel para o ArcView, os dados de número da curva foram utilizados para gerar o mapa correspondente no formato de grade, que é o formato exigido pelo CRWR-PREPRO. Recorreu-se para isso à função de conversão de temas vetoriais em temas no formato de grade do ArcView.

É pertinente argumentar que o procedimento de preenchimento manual dos valores de $\mathrm{CN}$ só foi possível porque a Microbacia do Tinga é pequena, conseqüentemente, com poucas combinações de grupo hidrólogico versus condição 


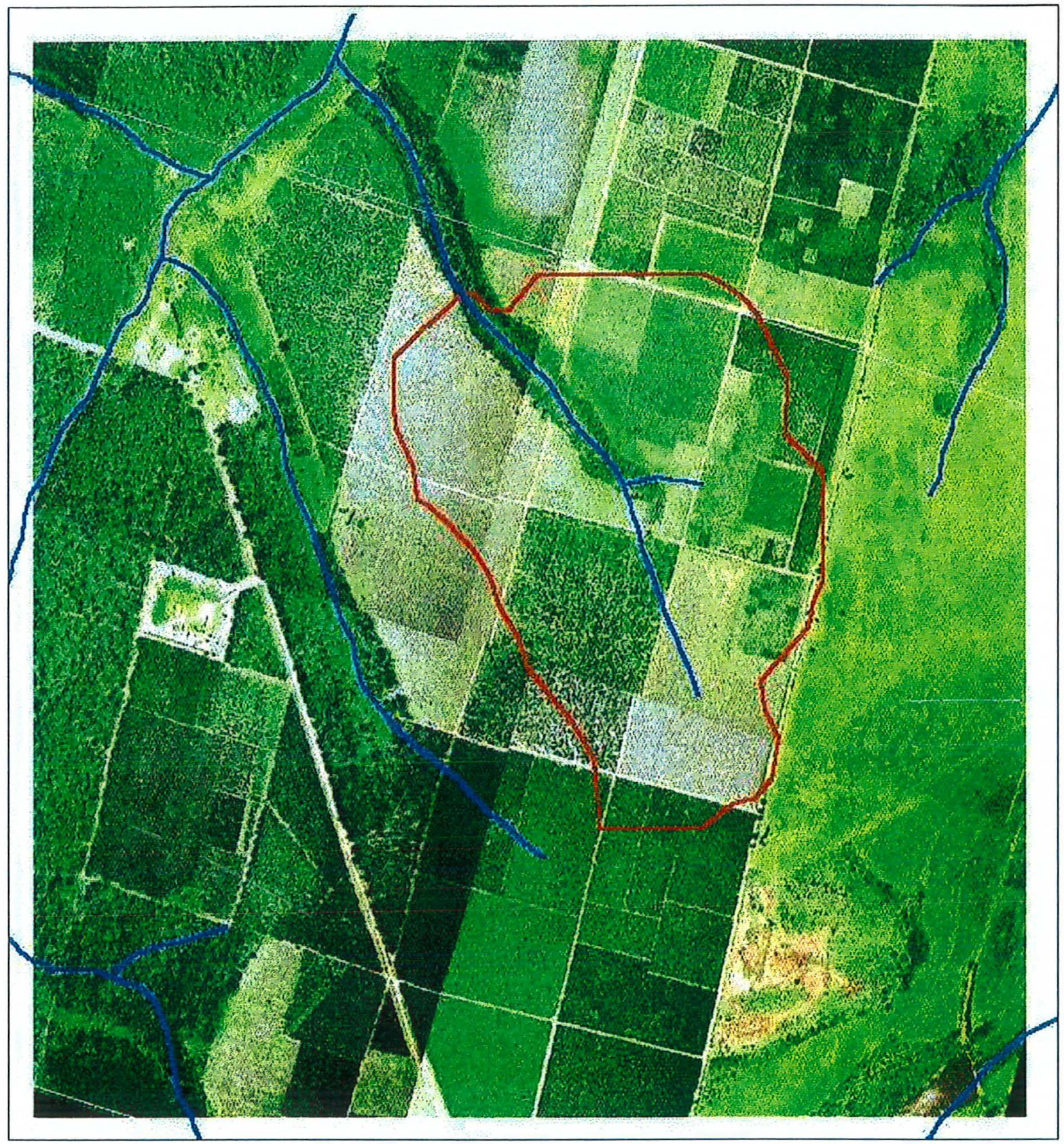

Figura 21 - Imagem áerea da Microbacia do Tinga (linha vermelha) e entorno, após o corte raso. 
hidrológica versus uso da terra. Numa situação em que o número dessas inviabilizasse a entrada manual dos dados, como por exemplo, áreas maiores ou maior número de classes, é mais indicado recorrer-se aos procedimentos automatizados do CRWR-PREPRO.

\subsubsection{Isolamento da Microbacia do Tinga}

Considerando que a área processada até aqui era maior que a Microbacia do Tinga, foi feito o isolamento desse sub-sistema. Como o HEC-HMS permite isolar áreas somente após à modelagem, a área de interesse foi selecionada e isolada no ArcView por meio do uso de procedimento específico. Toda estrutura de canais, subbacias e parâmetros, já calculados como parte do processo, foram transferidos para esse novo sistema e, desse ponto em diante, as análises foram feitas exclusivamente para a área de estudo.

\subsubsection{Cálculo dos parâmetros baseados no MDT e hidrológicos}

O cálculo dos parâmetros baseados no MDT foi efetuado pela função DEM-Based Parameters. Já, o dos parâmetros hidrológicos pela função Hydrologic parameters. Essas funções colocam automaticamente os resultados em duas tabelas de atributos (com indicação do método usado), uma caracterizando as sub-bacias e a outra os canais. Os parâmetros calculados para as sub-bacias foram: área, perímetro, comprimento e declividade do caminho mais longo seguido pela água, número da curva médio, tempo de retardamento e especificação do método de transformação da chuva em escoamento. Para canais, foram calculados o comprimento do canal principal, tempo de retardamento em canais, a velocidade da água nos canais e a especificação do método de propagação em canais. 
Como o Método do SCS exige somente os parâmetros área de cada subbacia e tempo de retardamento para o cálculo da hidrógrafa unitária adimensional, o CRWR-PREPRO foi capaz de gerar todas as informações necessárias para a propagação do fluxo em cada sub-bacia. Cabe esclarecer que a área de cada sub-bacia foi calculada automaticamente no processo de vetorização dos limites das sub-bacias.

\subsection{Cálculo dos parâmetros baseados no MDT}

O caminho mais longo seguido pela água em cada sub-bacia correspondeu ao conjunto de células da sub-bacia formado pela máxima soma entre o comprimento do fluxo de jusante à montante (FLWO) e o de montante à jusante (FLWB), ou seja, FLWO + FLWB (conforme explicado por Smith, 1995). Um esquema mostrando o procedimento de cálculo desse parâmetro é ilustrado na Figura 22, adaptado de Olivera (1998). Na determinação do caminho mais longo percorrido pela água na superfície do terreno, o CRWR-PREPRO requisitou as informações de altitude, do direcionamento do fluxo, dos temas com as saidas de bacia, dos temas com a área de estudo delimitada em formato grade e vetorial e um tema de linhas representando os canais. Por sua vez, a declividade do caminho mais longo foi determinada pelas diferenças de cota entre pontos da rota de fluxo, dividida por suas distâncias ao longo do percurso.

No cálculo do percurso $(\mathrm{P})$ entre uma célula superior e uma outra inferior, a partir do MDT, são consideradas duas situações pelo CRWR-PREPRO. A primeira é quando a direção do fluxo segue para uma das quatro células que apresentam um lado (L) em comum ao ponto sendo determinado. A outra é quando a direção do fluxo vai para uma das outras quatro células diagonais. No primeiro caso, o percurso entre uma célula e outra é tomado como sendo o próprio lado L, e no segundo caso, o percurso é tomado como $L * 2^{0,5}$. A declividade célula a célula é calculada pela subtração entre a altitude da célula superior (ACS) e altitude da célula inferior ( $\mathrm{ACI}$ ), sendo que, para o primeiro caso, a declividade é (ACS-ACI)/L e, para o segundo caso, (ACS-ACI)/L*2 $2^{0,5}$. 


\begin{tabular}{|c|c|c|c|c|c|}
\hline 90 & 910 & 900 & 900 & 900 & 891 \\
\hline 8 & & & 8 & 890 & \\
\hline & & & & 880 & 88 \\
\hline 875 & & & & 850 & 8 \\
\hline & & & 850 & & \\
\hline & & & & & \\
\hline \multicolumn{6}{|c|}{$\begin{array}{l}\text { MOT e interpretaçáo da direçá do } \\
\text { fuxo }\end{array}$} \\
\hline 0 & 0 & 0 & 0 & 0 & 0 \\
\hline 0 & 141 & 241 & 141 & 0 & 100 \\
\hline 0 & 141 & 0 & 382 & 0 & 0 \\
\hline 0 & 241 & 0 & 482 & 100 & 100 \\
\hline 0 & 141 & 382 & 0 & 623 & 0 \\
\hline 0 & 0 & 282 & 523 & 623 & 764 \\
\hline
\end{tabular}

Comprimento do muxo à montante (FLUS) até o divisor de bave

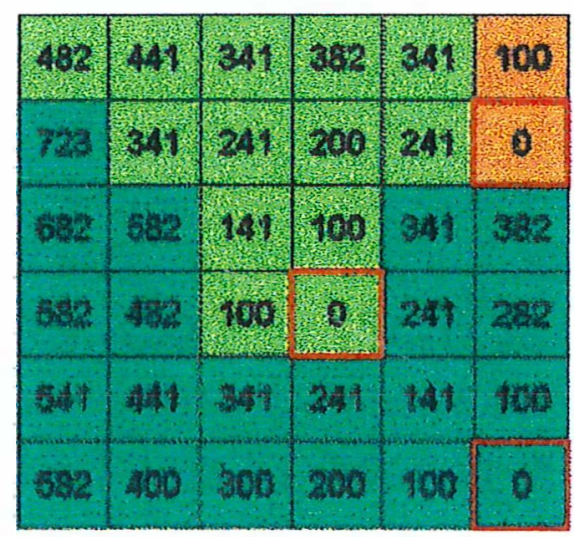

Comprimento do fluxo à jusente (FLDS) até a saída de cada sub-bacia.

\begin{tabular}{|c|c|c|c|c|c|}
\hline 784 & 723 & 823 & 684 & 623 & 100 \\
\hline 723 & 623 & 523 & 482 & 623 & 0 \\
\hline 682 & 592 & 423 & 382 & 341 & 382 \\
\hline 682 & 482 & 382 & 282 & 241 & 282 \\
\hline 641 & 441 & 341 & 241 & 141 & 100 \\
\hline 582 & 400 & 300 & 200 & 100 & 0 \\
\hline
\end{tabular}

Compiner to do muxo'a jusanto (FLDS) atóna saido

\begin{tabular}{|l|l|l|l|l|l|}
\hline 784 & 723 & 623 & 664 & 623 & 100 \\
\hline 723 & & 754 & 623 & 523 & 100 \\
\hline 682 & 723 & 423 & & 341 & 382 \\
\hline 582 & 723 & 382 & 7 & 341 & 382 \\
\hline 541 & 582 & 723 & 241 & 7 & 100 \\
\hline 582 & 400 & 582 & 723 & 723 & 7 \\
\hline
\end{tabular}

Caminho mals longo FLDS + FLUS seguido pela ácua máximo

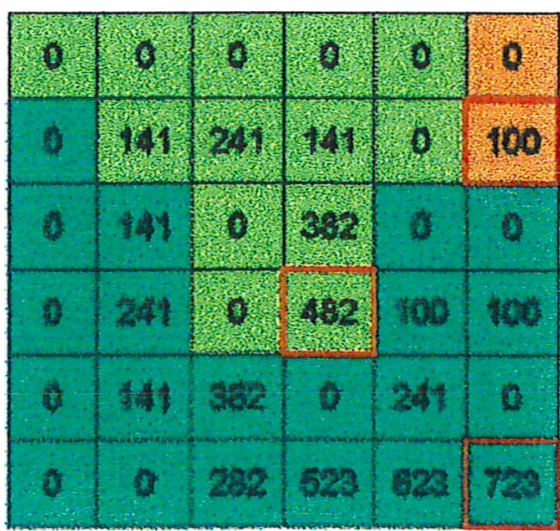

Comprimerto do fluxo a montante (FLUS) ató o clvisar de f́guas.

Adaptado de Olivera (1998)

Figura 22 - Esquema de análise digital de terrenos feita pelo CRWR-PREPRO para a determinação do maior comprimento seguido pela água na superfície do terreno. 
Cabe ressaltar que a determinação desses parâmetros foi fundamental, porque quanto maior a trajetória percorrida no terreno e menor sua declividade, maiores serão o tempo de retardamento e a oportunidade de infiltração da água no solo. Além disso, o caminho mais longo e a declividade podem ser usados para a estimativa de outros parâmetros, como por exemplo, o tempo de concentração e retardamento.

\subsection{Cálculo dos parâmetros hidrológicos}

\subsection{Parâmetros de canais}

\subsection{1 Velocidade da água nos canais}

A velocidade da água nos canais foi obtida de uma tabela de atributos criada no ArcView. A tabela foi preenchida com dados de velocidade calculada por meio do Excel segundo dois métodos: o desenvolvido pelo SCS USDA (1972), chamado de Upland Method, e a fórmula de Manning.

\subsection{1.1 Método do SCS (Upland Method)}

O Upland Method se baseia em um nomograna (Figura 6) onde pode ser determinada a velocidade do fluxo sobre o terreno, em função da declividade e das ocupações. Este nomograma foi desenvolvido baseado na solução da Equação de Manning para diferentes declividades e suposições de coeficientes $\mathrm{n}$ para as ocupações e raios hidraúlicos. Para facilitar a aplicação desse método na planilha eletrônica, dados de declividade e velocidade, para as várias ocupações, foram retirados de um nomograma estabelecido pelo SCS (Figura 6) e plotados num gráfico, conforme pode ser visualizado na Figura 23. A esses dados foram ajustadas equações do tipo $V=a S^{b}$ para cada ocupação. Onde onde V é a velocidade, $\mathrm{S}$ a declividade e a e b são coeficientés de ajuste. 


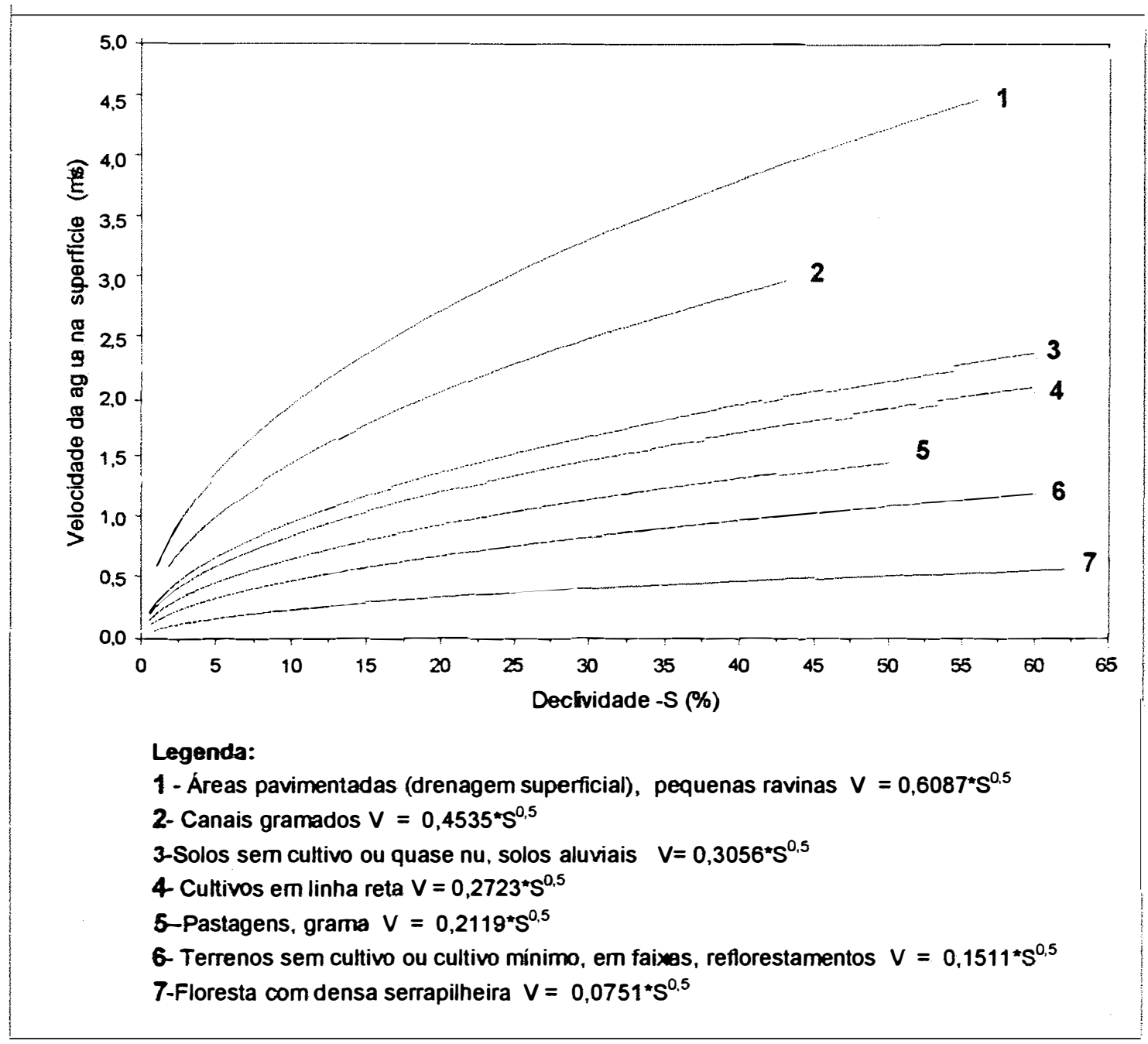

Figura 23 - Velocidade da água no terreno versus declividade, com as equações ajustadas a partir do nomograma do Upland Method (USDA, 1972).

Para o cálculo da velocidade nos canais, foi usada a equação específica para canais gramados. Já, a declividade, que também é exigida na equação, foi obtida no ArcView a partir do MDT, onde traçou-se um perfil longitudinal dos canais, cujos dados de coordenadas $\mathrm{x}$, y e $\mathrm{z}$, para cada trecho de $16 \mathrm{~m}$, foram exportados para planilha eletrônica e a declividade determinada. $\mathrm{Na}$ aplicação do método, quando a declividade era igual a zero, substituiu-se esse valor por $0,0001 \mathrm{~m} / \mathrm{m}$ para evitar velocidades muito baixas. Afinal, esse método não leva em consideração a declividade da linha de água para o cálculo da velocidade. 


\subsection{1.2 Fórmula de Manning}

A velocidade também foi calculada pela fórmula de Manning (Equação 20). Adotou-se o coeficiente de rugosidade entre 0,080 e 0,090, valores obtidos numa chave proposta por Chow (1959) para vários tipos de canais. O raio hidráulico dos canais, considerados circulares, correspondeu a $\mathrm{D} / 4$, com $\mathrm{D}$ valendo $0,5 \mathrm{~m}$ para as sub-bacias à montante, que apresentavam canais com menores dimensões e $1 \mathrm{~m}$ para as à jusante, que apresentavam canais maiores. Já, a declividade foi a mesma usada no método anterior.

\subsection{2 Tempo de retardamento em canais}

O tempo de retardamento em canais foi estimado conforme o Método de Retardamento Puro, pois os trechos eram curtos e sem armazenamentos consideráveis, seguindo a condição de $\mathrm{L} / \mathrm{V}<\Delta$ t. Como o próprio nome esclarece, nesse método a hidrógrafa é atrasada em um determinado tempo entre o início e final do trecho de canal considerado. Para sua determinação, recorreu-se ao cálculo do tempo de percurso, que lhe é eqüivalente, conforme Figura $24 \mathrm{~A}$. É pertinente informar que o comprimento do trecho de canal em cada sub-bacia foi calculado automaticamente no processo de vetorização dos canais.

Sob outras condições, seria possivel escolher outros métodos, que levassem em conta além do atraso, um efeito de armazenamento. Por exemplo, os Métodos de Muskingum ou de Muskingum-Cunge, também suportados pelo CRWRPREPRO. 

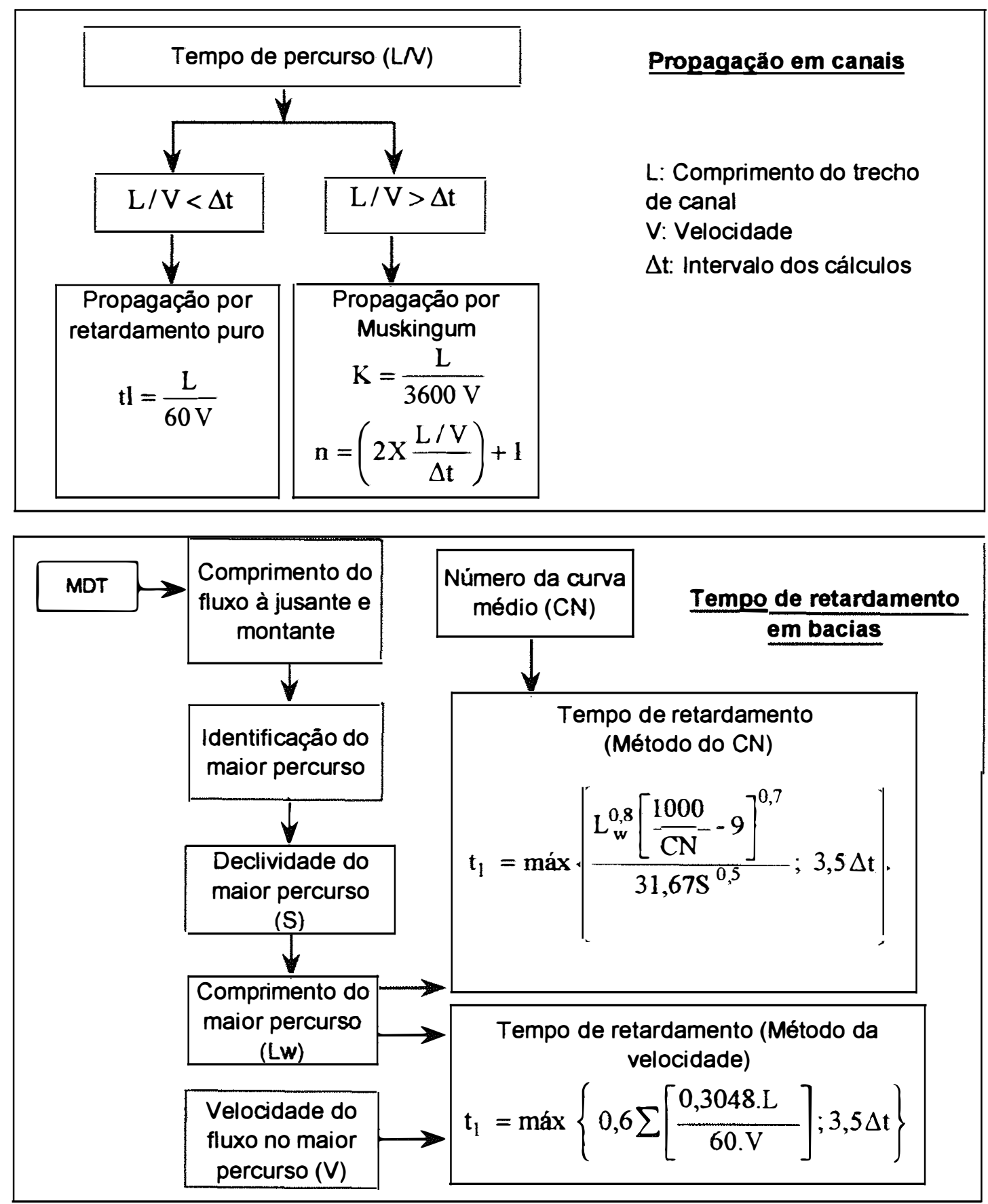

Figura 24 - Sequeência de cálculos seguidos pelo CRWR-PREPRO na determinação da propagação em canais (A) e do tempo de retardamento para bacias (B), (a figura é baseada em Olivera \& Maidment, 1999). 


\subsection{Parâmetros de bacias}

\subsection{1 Tempo de retardamento em sub-bacias}

O tempo de retardamento em bacias foi calculado pelo Método do Número da Curva do SCS e pelo Método da Velocidade, ambos desenvolvidos pelo SCS (USDA, 1972). Na Figura 24 B, é apresentado um esquema da sequeência de cálculo adotado pelo CRWR-PREPRO, para cada um dos métodos. O USDA (1972) recomenda que, para uma adequada determinação do tempo de retardamento, além da experiência do técnico, vários métodos podem ser considerados para a estimativa do tempo de retardamento. Cabe elucidar que, apesar do tempo de retardamento ter sido calculado pelos dois métodos, nas simulações foi aplicado somente o Método do Número da Curva do SCS, pois esse produziu melhores resultados.

\subsection{1.1 Método do Número da Curva do SCS}

O tempo de retardamento para cada sub-bacia foi calculado por meio do CRWR-PREPRO pela fórmula do tempo de retardamento (Equação 23 e 24) desenvolvida pelo SCS e apresentada em Chow et al.(1988). Essa equação, estimada a partir de dados de bacias agrícolas, assume o tempo de concentração da bacia como 1,67 vezes o tempo de retardamento. Ainda, exige que os parâmetros número da curva médio, comprimento e declividade do caminho mais longo já tenham sido determinados para cada sub-bacia.

Ademais, para que as hidrógrafas tenham uma forma adequada (especialmente na fase de ascensão), o intervalo de tempo das análises tem que satisfazer a condição de ser menor que 0,29 vezes o tempo de retardamento da bacia (USDA, 1972), portanto, o tempo de retardamento deve ser igual ou maior que 3,5 vezes o intervalo de tempo de análise (HEC-USACE, 1998a, Olivera et al. 1998). Assim, o tempo de retardamento foi calculado conforme apresentado na Equação 24. 


\subsection{1.2 Método da Velocidade do SCS}

O tempo de retadamento da bacia foi calculado também pelo Método da Velocidade (Figura 24 B). Apesar desse método ser uma opção do CRWR-PREPRO, os cálculos foram feitos em planilha eletrônica, pela facilidade de manuseio dos dados nesse software. O caminho seguido pela água na superfície do terreno foi subdividido em trechos conforme a ocupação, inclusive os canais. Para cada um desses trechos, foi calculada a velocidade, conforme a Figura 23, considerando-se a declividade média do trecho e a ocupação. Para o caso do trecho considerado canal, os cálculos seguiram a metodologia anteriomente descrita para canais, sendo usado o Upland Method do SCS, por ser de mais simples aplicação do que a formula de Manning. Ainda, vale lembrar que o somatório de tempo para cada um dos trechos é igual ao tempo de concentração da subbacia. Como o método considera que a razão entre o tempo de retartamento e o tempo de concentração é 6/10, aplicou-o método da velocidade seguindo as equações 23 e 24 .

\subsubsection{Elaboração do diagrama esquemático e preparação do arquivo de entrada no HEC-HMS}

Tanto para a elaboração do diagrama esquemático da microbacia, como para a preparação do arquivo de bacia ou de entrada, em formato ASCII, no HEC-HMS recorreu-se à função HMS Schematic.

\subsubsection{Preparação dos dados de chuva e vazão para entrada no HEC-HMS}

\subsubsection{Chuva}

Os dados de chuva, provenientes da estação meteorológica automática, após serem manipulados pelo software específico dessa estação, foram importados para planilha eletrônica Excel. Cabe mencionar que esses dados foram corrigidos porque apresentavam diferenças em relação aos provenientes dos pluviógrafos. Consideraram-se 
corretos os dos pluviógrafos. Portanto, os dados da estação meteorológica apenas serviram para que fosse feita a distribuição temporal dos dados, uma vez que a baixa resolução temporal dos dados dos pluviógrafos dificultava muito esse processo.

Os maiores eventos da série estudada foram selecionados, tendo-se o cuidado de excluir os que formassem hidrógrafas complexas. Após estarem separados em eventos, os dados foram linearmente interpolados para intervalos de tempo de 10 minutos, utilizando-se o programa para interpolação de séries temporais, objetivando compatibilidade com as especificações de controle do HEC-HMS.

\subsubsection{Vazão}

Para a construção das hidrógrafas de descarga, os diagramas foram capturados por meio do uso do scanner. A seguir, as imagens resultantes foram importadas para o ArcView e digitalizadas em tela como arquivo de pontos pela extensão Screen Digitizer. Posteriormente, esses pontos foram exportados para a planilha eletrônica, onde foram manipulados até a obtenção da hidrógrafa de descarga. Nas transformações, recorreu-se à equação de calibragem da calha, conforme Scardua (1994):

$$
\log Q=0,0238+2,5524(\log H)+0,254(\log H)^{2}
$$

onde: Q é a vazão $\left(\mathrm{m}^{3} / \mathrm{s}\right)$ e $\mathrm{H}$ a altura lâmina de água na calha $(\mathrm{m})$.

Após calculadas as vazões, os resultados foram interpolados para intervalos de tempo de 10 minutos. A seguir, o fluxo base foi separado do escoamento, pela aplicação do método desenvolvido por Hewlett \& Hibbert (1967). Esses autores sugeriram que, durante um evento de chuva, o fluxo base para bacias de regiões úmidas florestadas e de pequeno tamanho pode ser simulado por incrementos com gradiente constante de 0,0055 litros/s/ha/h na vazão. 


\subsubsection{Simulação do escoamento com dados de chuva, vazão e ocupação atual}

\subsubsection{Reconstrução do arquivo de bacia no HEC-HMS, entrada de dados de precipitação e especificações de controle}

Depois de preparado, o arquivo de entrada foi exportado para o HECHMS, onde tomou-se um arquivo ou diagrama esquemático de bacia. Para computar as simulações, o HEC-HMS exigiu, inicialmente, a criação do projeto onde as informações foram inseridas, processadas e os resultados apresentados. O projeto englobou os seguintes procedimentos: entrada de dados de precipitação e vazão, criação dos modelos de bacia e de precipitação, configurações das especificações de controle, procedimentos para execução das simulações, visualização dos resultados e sua impressão.

\subsection{Modelo de bacia}

Os métodos utilizados no modelo de bacia para as simulações das hidrógrafas já haviam sido formecidos ao software CRWR-PREPRO, durante o preprocessamento. Os métodos foram: Método do Número da Curva do SCS para computação das perdas iniciais, Método da Hidrógrafa Unitária Adimensional do SCS para transformação da chuva em escoamento e Método do Tempo de Retardamento puro para propagação em canais. Ainda, ao modelo de bacia foi informado que seriam feitas simulações somente para o escoamento direto e não para o básico, que voltou a ser considerado, pela soma do escoamento direto com o escoamento básico, apenas para a apresentação gráfica dos resultados. Ou seja, nas comparações e análises, considerou-se apenas o escoamento direto. 


\subsection{Modelo de precipitação}

O HEC-HMS demandou a especificação de modelos de precipitação, que, no presente estudo, foi constituido por chuvas selecionadas da série histórica analisada. Dentre as seis opsões possiveis de entrada de dados de chuva, nem todas compativeis com alguns métodos de transformação da chuva em escoamento disponiveis no HECHMS, a escolhida foi o hietograma especificado pelo usuário. Para tanto, hietogramas de todos os eventos foram digitados no módulo de edição de dados de estações medidoras do HEC-HMS. Nesse módulo, foram especificados a data, o horário inicial e final do evento e o intervalo de tempo. Na definição do modelo de precipitação, foi selecionado o mesmo hietograma para todas as sub-bacias na simulação de um evento de chuva, pois a Microbacia do Tinga possui área pequena. Dessa forma, a chuva, como principal parâmetro de entrada, foi considerada variável no tempo e uniforme no espaço. Cabe recordar que os dados de precipitação foram obtidos de apenas uma estação, localizada próximo a bacia.

Como os eventos históricos de chuvas foram usados em conjunto com os dados de descarga para a calibração do modelo, selecionou-se eventos que apresentassem diferentes padrões de distribuição temporal de chuvas - adiantados (maior intensidade no início), medianos (maior intensidade na parte intermediária) e atrasados (maior intensidade no final). Afinal, existe influência do padrão temporal das chuvas sobre a forma da hidrógrafa gerada. Por exemplo, com maiores intensidades no quarto final da chuva, segundo Tucci (1993), são gerados picos maiores. Já, caso as maiores intensidades forem no início, os picos serão menores, pois essa precipitação inicial atenderá às perdas por infiltração e depressões do terreno.

Ainda, é importante mencionar que um modelo de precipitação pode ser usado para mais de um modelo de bacia, porém, cada sub-bacia deve ter somente um hietograma associado na simulação de um evento. 


\subsection{Especificações de controle}

Nas especificações de controle, foram fornecidas as datas e os tempos de início e fim e o intervalo de tempo (passo) das simulações.

\subsubsection{Caracterização dos eventos de chuva e do escoamento direto}

Antes de passar para a fase de calibração, algumas análises procurando caracterizar os dados de chuva e escoamento direto foram feitas como uma tentativa de entender melhor a dinâmica hidrológica da área de estudo. Assim, a análise de correlação entre o escoamento direto e a precipitação antecedente objetivou verificar a significância desse efeito secundário sobre a produção do escoamento direto, além do volume total de chuva. Para os eventos estudados, determinou-se o diagrama de dispersão entre os dados de precipitação e de escoamento direto e também o fator de resposta da bacia. Ademais, uma análise preliminar do efeito do corte raso sobre a produção do escoamento direto foi realizada.

\subsubsection{Calibração dos parâmetros hidrológicos usando-se dados de precipitação- vazão}

\subsection{Determinação dos números da curva a partir de dados observados}

O uso de dados observados de precipitação e escoamento direto, conforme o USDA (1997), é a melhor maneira para o estabelecimento de números da curva mais confiáveis. Os valores determinados dessa forma são superiores aos obtidos de tabelas. Para sua determinação, podem ser usados vários métodos, por exemplo, métodos estatísticos e gráficos. Nesse trabalho, inicialmente, o planejamento era fazer a determinação do número da curva conforme a metodologia do USDA (1997), ou seja, a plotagem de valores da precipitação versus escoamento direto em um gráfico com as 
soluções numéricas da Equação de escoamento direto do SCS. Posteriormente, a nuvem de pontos seria dividida ao meio por intermédio de uma curva. Essa curva, depois de ser interpolada com as curvas laterais, representaria o número da curva médio. Entretanto, os valores de escoamento ficaram abaixo da zona de determinação segura, com exceção do maior evento (104 mm). Afinal, os eventos de chuva analisados não foram grandes, a série de dados analisados foi curta ( 2 anos) e a área de estudo possui características de alta permeabilidade. Para que o emprego dessa metodologia resultasse satisfatória seriam necessários eventos maiores de chuvas.

Também foi feita uma tentativa de determinação do valor de $\mathrm{CN}$ aplicando-se a metodologia de Hawkins (1973). Entretanto, o comportamento apresentado pela Microbacia do Tinga (pelo menos na faixa de valores de precipitaçãoescoamento usados) não permitiu a determinação segura do valor de $\mathrm{CN}$. Afinal, não foi possivel a determinação assintótica do valor do $\mathrm{CN}$, por este apresentar tendência de declínio com o aumento da precipitação, sem apresentar valores aproximadamente constantes, como seria o desejável.

Então, para uma determinação mais segura, realizou-se um processo de calibração dos parâmetros que influenciavam o volume de escoamento direto, o número da curva $(\mathrm{CN})$ e as abstrações iniciais.

\subsection{Calibração do CN e das abstrações iniciais}

Como mencionado anteriormente no item 2.6.1 da revisão bibliográfica, o HEC-HMS apresenta recursos de estimação automática de valores para os parâmetros selecionados, usando técnicas de otimização matemática, quando existirem dados observados de precipitações e vazões disponíveis. Assim, um ajuste ótimo entre uma hidrógrafa simulada e a observada é produzido e, nessa situação, são determinados os valores dos parâmetros.

Entretanto, por causa de problemas nas execuções, ao invés da calibração automática recorreu-se à manual. Nesse sentido, aplicou-se ajustes de parâmetros por tentativa e erro. Esse método, segundo Pilgrim \& Cordery (1993), geralmente, apresenta 
precisão suficiente, pois pennite examinar ou avaliar os efeitos da mudança nos valores dos parâmetros. Os parâmetros calibrados manualmente foram: o valor do número da curva e as abstrações iniciais. Essas calibrações foram feitas usando-se eventos de chuva e descarga. Para as comparações entre hidrógrafas simuladas e observadas, recorreu-se a um índice de comparação de hidrógrafas, desenvolvido por MacCuen \& Snyder (1975). Esse índice é um coeficiente de correlação que leva em consideração o tamanho e a forma da hidrógrafa. Assim, valores próximos a 1 indicam maior similaridade e valores próximos a zero indicam dissimilaridade.

\subsubsection{Simulação com os parâmetros calibrados}

Os dados de ocupação da bacia, compreendendo dois períodos, um com floresta de eucalipto e mata ciliar e outro com o corte raso do eucalipto e mata ciliar, foram utilizados para as calibrações dos parâmetros. Em razão da produção de escoamento não ter mudado antes e após o corte raso, a ocupação da área de estudo foi considerada eucalipto nos dois períodos.

\subsubsection{Análise de sensibilidade}

Uma análise de sensibilidade foi feita com o intuito de verificar a mudança nos resultados pela alteração dos parâmetros que necessitavam de julgamento. Os parâmetros submetidos à análise foram o tempo de retardamento, o $\mathrm{CN}$ e as abstrações iniciais.

A análise da variação do tempo de retardamento em função do $\mathrm{CN}$ foi feita por intermédio de um gráfico. Esse gráfico foi construído plotando-se os resultados de tempo de retardamento calculado pelo Método do $\mathrm{CN}$ utilizando-se o caminho mais longo seguido pela água (L), sua declividade (\%) e o $\mathrm{CN}$ para as diversas sub-bacias. 
Já, o pico de vazão e o volume de escoamento direto para o evento de chuva do dia 22/01/97 em função do $\mathrm{CN}$ e das abstrações iniciais foram analisados por um gráfico de isolinhas. Os resultados de pico de vazão e volume de escoamento, foram obtidos por simulações processadas no HEC-HMS, e posteriormente foi construido o gráfico de isolinhas.

\subsubsection{Estabelecimento dos cenários a serem avaliados}

As simulações foram efetuadas visando avaliar cenários futuros de ocupação da Microbacia do Tinga sob eventos de chuva significativos.

Como a bacia é dividida em duas zonas bem definidas de declividade, conforme a Figura 25, decidiu-se simular o escoamento nessas duas zonas, cada uma com a metade da área da microbacia, ou seja 40,8 ha. A primeira apresenta declividade média de $6,6 \%$ e está localizada mais próxima dos canais e a outra $2,4 \%$, situada na parte mais distante. $\mathrm{Na}$ área mais declivosa, o solo predominante é LE1, que apresenta maiores teores de argila e menores de areia, quando comparado com os solos LV1 e LV2, predominantes na zona menos declivosa (Tabela 9).

Para essas duas zonas de declividade, foram simulados os seguintes cenários: eucalipto em toda a área, eucalipto na parte mais declivosa e solo cultivado na menos declivosa, solo cultivado na parte menos declivosa e eucalipto na mais declivosa, eucalipto na parte mais declivosa e plantio direto na menos declivosa e plantio direto na mais declivosa e eucalipto na menos declivosa. Esses cenários estão esquematizados na Figura 26.

Também, simulações foram feitas considerando-se o recorte sub-bacias da parte mais alta versus as da parte mais baixa. Assim, outros tipos de cenários foram estabelecidos: toda a bacia coberta com eucalipto, pastagem degradada em toda a bacia e alternância entre eucalipto e pastagem nessas duas partes. Um esquema de como foram feitas as simulações está na Figura 27. 


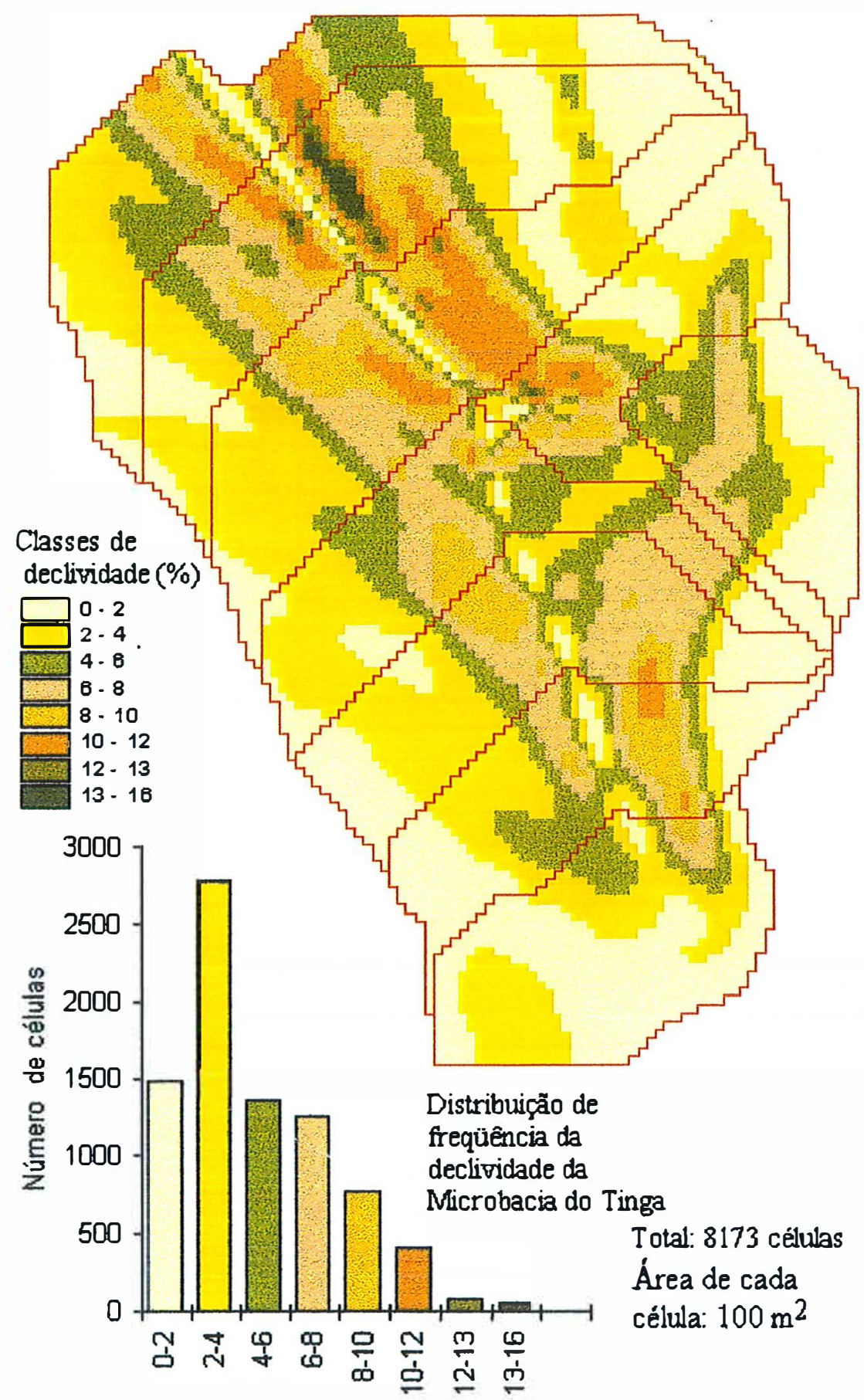

Intervalo das classes de declividade (\%)

Figura 25 - Declividade e distribuição das classes de declividade da Microbacia do Tinga. 

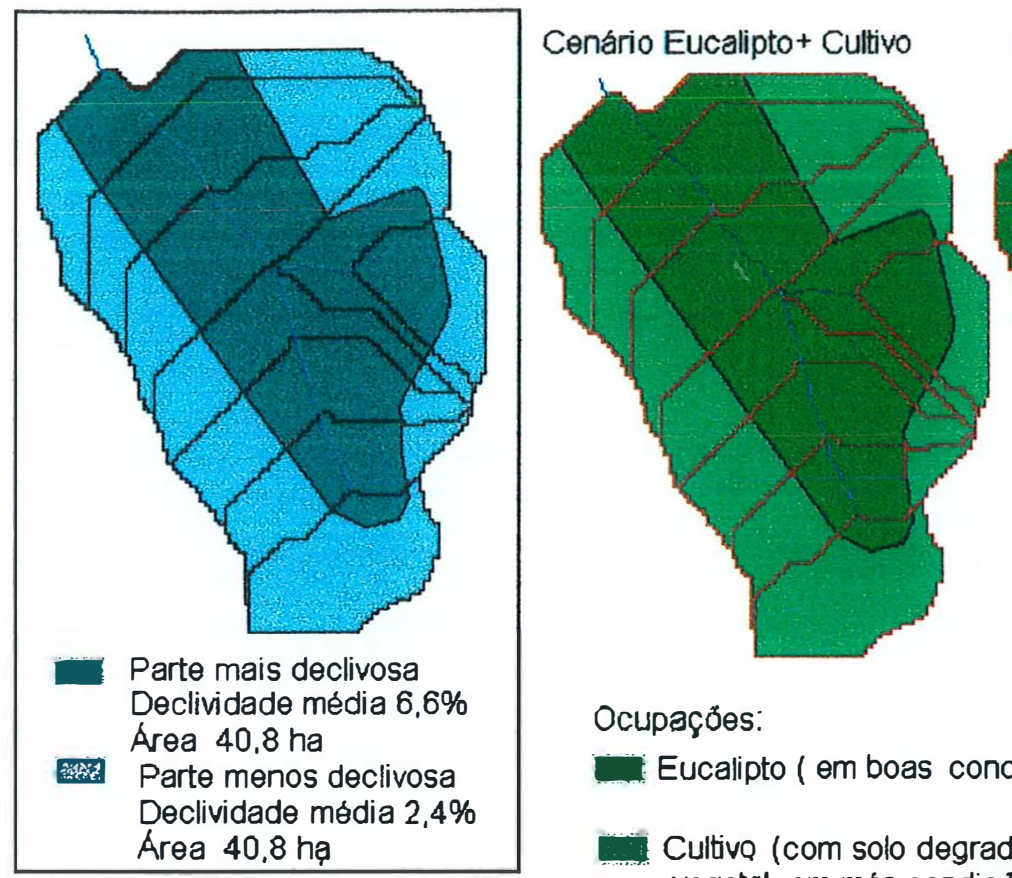

Cenário Cultivo+Eucalipto

Ocupaçöes:

Eucalipto ( em boas condicठ̋es)

Cultivo (com solo degradado e sem cobertura vegetâl, em más condiçỏes)

$\square$ Plantio direto (em boas condiçőes)

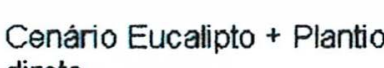
direto
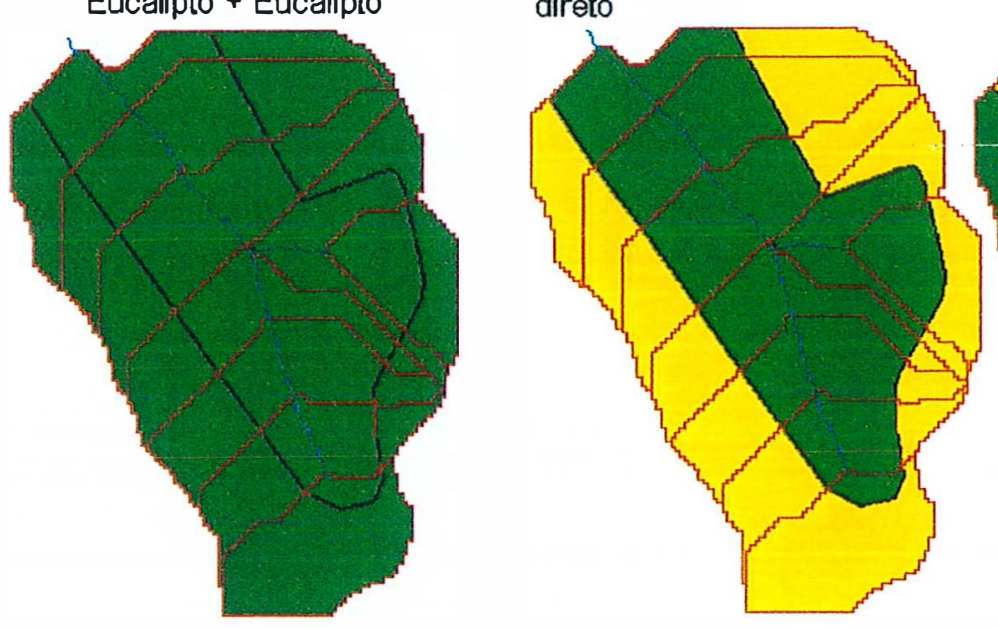

Cenário Plantio direto + Eucalipto

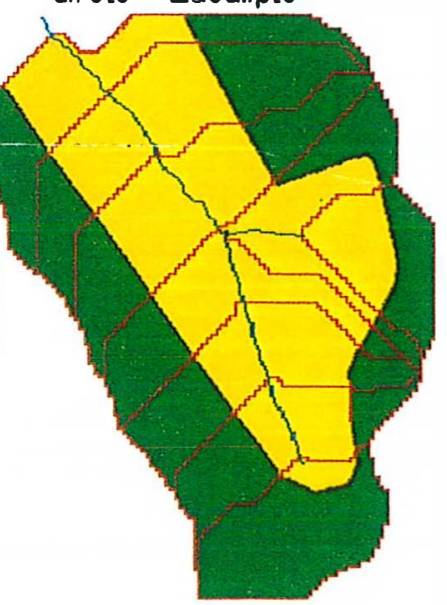

Figura 26 - Distribuição de ocupações na área de estudo para os diferentes cenários a serem simulados, considerando-se a alternância de ocupação entre a parte mais declivosa e a parte menos declivosa. 


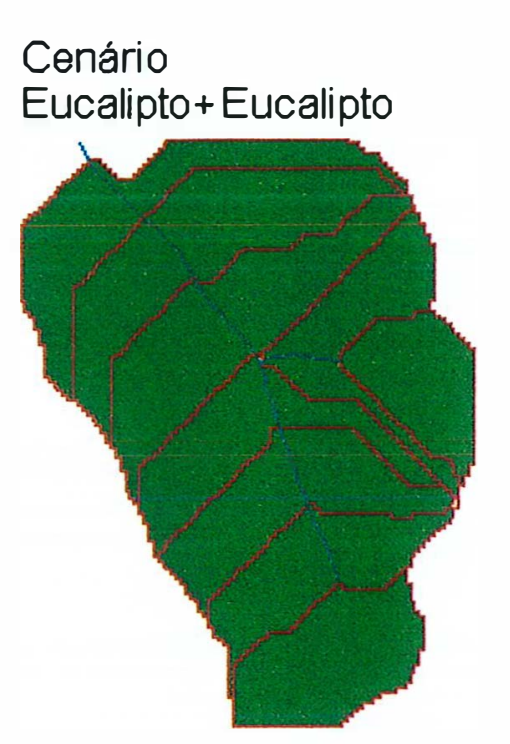

\section{Cenário \\ Pastagem +Pastagem}

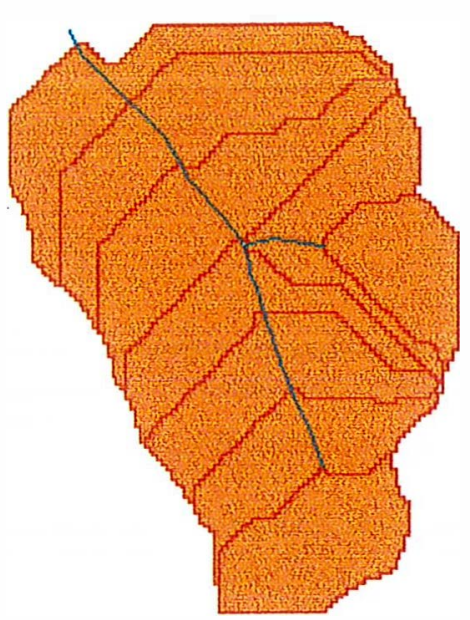

Cenário

Cenário

Eucalipto + Pastagem

Pastagem + Eucalipto
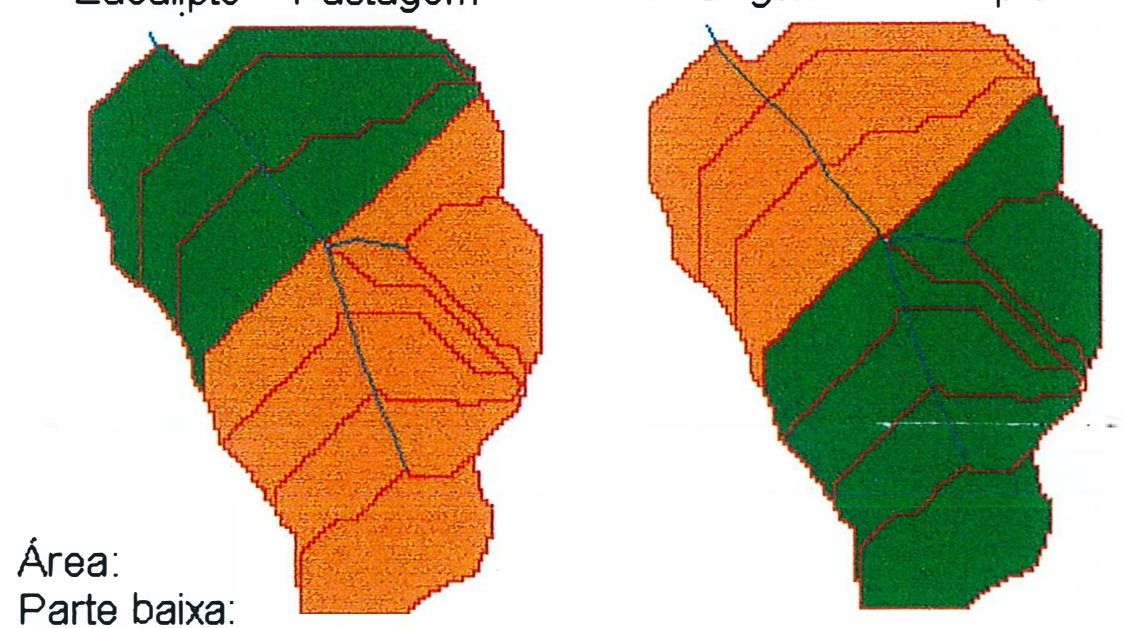

34,9 ha $(42,7 \%)$

Parte alta:

Eucalipto ( em boas condicões)

46,8 ha $(57,3 \%)$

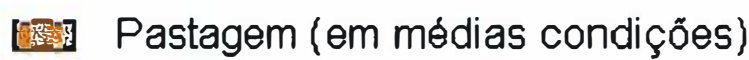

Figura 27 - Distribuição de ocupações na área de estudo para os diferentes cenários a serem simulados, considerando-se a alternância de ocupação entre a parte mais baixa e a parte mais alta da microbacia. 
Os CNs para a ocupação eucalipto foram definidos na fase de calibração, ao passo que para as outras ocupações eles foram baseados nas Tabelas 3; 4 e 5. Para o preparo convencional ou solo cultivado, foi usado o valor 65 , correspondente a solo arado, quase sem cobertura vegetal na superficie. Para pastagem, foi determinado o valor 60, eqüivalente à pastagem velha com arbustos e condição da superficie em situação hidrológica de infiltração média.

Já, a determinação do valor de $\mathrm{CN}$ para o plantio direto foi mais difícil, pois o mesmo não está especificado claramente nas tabelas. Em tabelas mais "recentes", como a do USDA (1986), existem recomendações que consideram a porcentagem da área coberta com resíduos vegetais. Entretanto, preferiu-se utilizar as indicações aproximadas de Setzer \& Porto (1979) que apresentaram uma tentativa de avaliação do escoamento superficial para o Estado de São Paulo (Tabela 3). Na tabela, para a situação de solo pertencente ao grupo hidrológico A, com cobertura por semeadura ou a lanço, curta e densa, com defesa contra erosão feita por terraços e condição hidrológica da superfície considerada boa quanto a infiltração, o valor de $\mathrm{CN}$ apresentado foi de 45. Esta foi a condição da tabela mais parecida com o plantio direto. Uma outra recomendação do valor do CN para plantio direto foi obtida em Chaves (1997), que, em simulações com esse tipo de uso, especificou um valor de 45. Assim, levando em conta essas considerações e as condicões geomorfológicas e de solos da Microbacia do Tinga, que favorecem a maior permeabilidade, foi atribuído um $\mathrm{CN}$ de 40 para o plantio 


\section{RESULTADOS E DISCUSSÃO}

\subsection{Elaboração do modelo digital do terreno}

O modelo digital do terreno da área de estudo é apresentado na Figura 28. Nela, observa-se que a altitude varia de $749 \mathrm{~m}$ a $853 \mathrm{~m}$. Cabe mencionar que, para evitar problemas no processo de interpolação, a área englobada, 1045 ha, é maior que o tamanho da Microbacia do Tinga.

O processo de construção do MDT foi muito criterioso, afinal, ele foi a base para a determinação de muitos parâmetros. Estudos recentes têm mostrado que a precisão dos parâmetros extraídos a partir de MDT's são comparáveis àqueles obtidos por métodos manuais, porém, com uma grande economia de tempo.

Após serem testados vários tamanhos de célula, decidiu-se pelo de $10 \mathrm{~m} \mathrm{x}$ $10 \mathrm{~m}$. O processo de escolha da resolução buscou o menor tamanho de célula possível para representar a superficie do terreno com precisão e, com isso, minimizar a probabilidade de problemas posteriores. Por ter sido adotado essa resolução, o MDT forneceu detalhes suficientes para que as características topográficas do terreno, a movimentação da água pelo solo e os padrões de drenagem fossem estudados.

É pertinente comentar que os tamanhos de célula menores que $10 \mathrm{~m} \times 10$ $m$ provocaram problemas na definição da rede de drenagem, com a formação frequaente de canais paralelos. A princípio, isso pareceu ser decorrente da resolução da carta, que não é a mais indicada para representar a superfície com maior detalhamento. Ou seja, o tamanho das células tem que corresponder à resolução dos MDT's em diferentes escalas. Ainda, a interpolação com tamanhos de célula menores que $10 \mathrm{~m} \times 10 \mathrm{~m}$ apenas os 


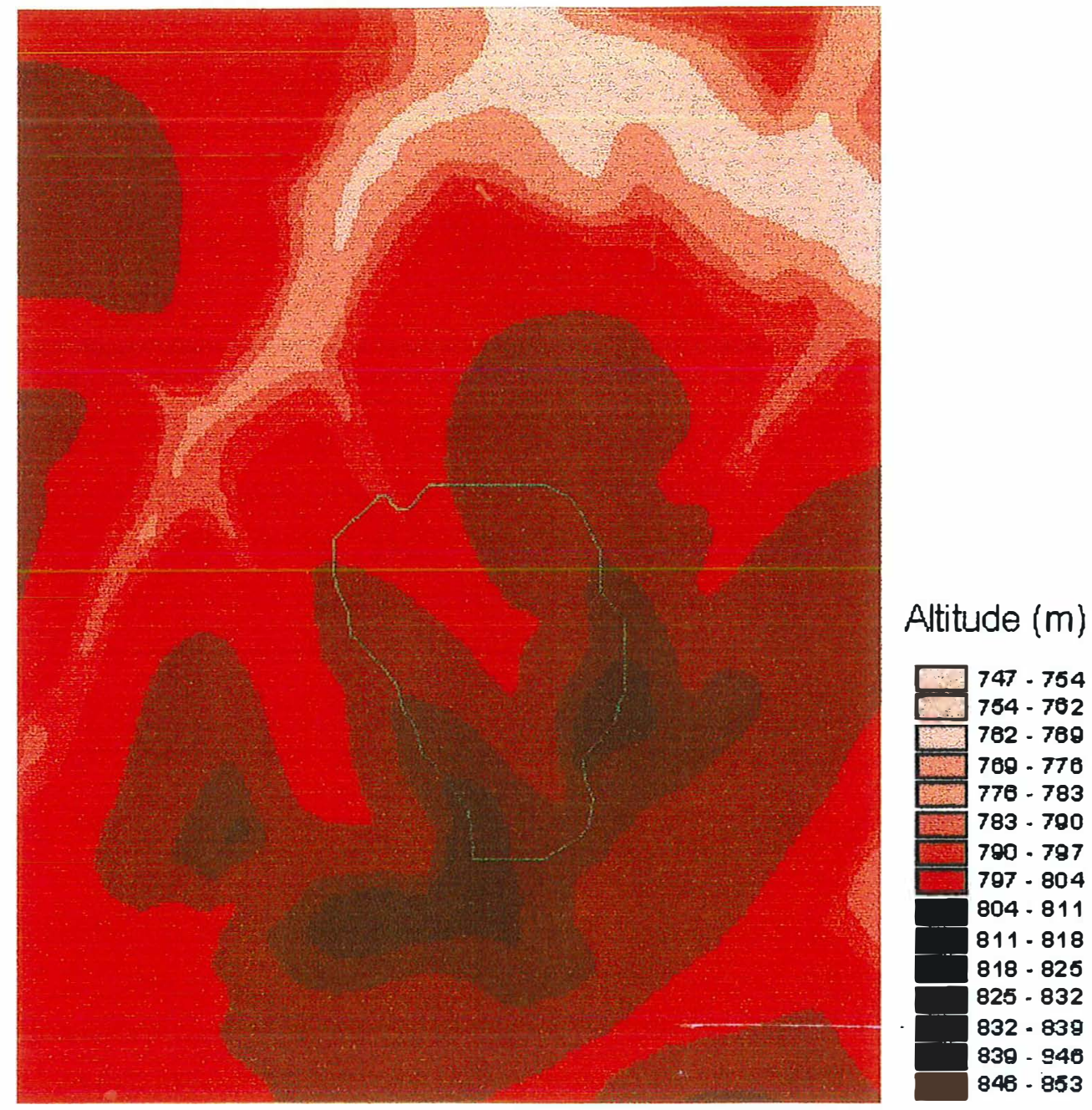

Figura 28 - Modelo digital do terreno, com as cores indicando as faixas de altitude em metros.

subdividiram e os valores de altitude continuaram praticamente os mesmos. Tal constatação foi, principalmente, válida para as áreas planas, onde a variação de altitude entre os pontos amostrados foi pequena.

A opção pelo detalhamento para definição da rede de drenagem é corroborada por outros autores. Por exemplo, Wang \& Yin (1998), Garbrecht \& Martz (1993) e Garbrecht \& Martz (1994). Vale recordar que em ESRI (1994) afirma-se que é necessário haver equilibrio entre o nível de detalhamento dos dados originais e do MDT. 
Outro ponto considerado no processo de seleção do tamanho das células foi o tamanho do arquivo gerado. Constatou-se que ele aumentou exponencialmente, tomando a velocidade de processamento lenta demais para computadores pessoais. Assim, por exemplo, arquivos com 10 milhões de células de $1 \mathrm{~m} \times 1 \mathrm{~m}$ teve um processamento bastante lento em computador com velocidade de $100 \mathrm{Mhz}$. Ademais, a literatura recomenda que, em estudos de pequenas bacias, seja adotado um tamanho de célula entre $10 \mathrm{~m}$ e $30 \mathrm{~m}$.

\subsection{Definição e conexão dos elementos hidrológicos pelo CRWR-PREPRO}

\subsubsection{Delineamento de canais e sub-bacias}

A elevação arbitrária para separar as células pertencentes aos canais da área restante é apresentada na Figura 29. Nela, é possível perceber que os canais permaneceram com as elevações originais, no entanto, o resto foi elevado em $1000 \mathrm{~m}$. Cabe ressaltar que esse novo MDT é uma superfície artificial e tal procedimento não é obrigatório. No presente estudo, justificou-se esse tratamento em razão da disponibilidade de material cartográfico representando de forma exata a rede de drenagem. Afinal, o delineamento de canais a partir do MDT é falho nas áreas planas.

Uma ilustração do procedimento de preenchimento das depressões (Fill Sinks) é mostrada na Figura 30, onde nota-se a eliminação de áreas isoladas pela sua elevação até o nível de suas células vizinhas. É pertinente recordar que as ocorrências naturais como lagos e reservatórios não devem ser submetidas a esse processo. Neste caso, eles devem ser identificados como polígonos nos temas de cobertura hidrológica. O CRWR-PREPRO apresenta algoritmos para a identificação desse tipo de ocorrência.

A direção que o fluxo irá tomar, determinada pelo procedimento de direcionamento de fluxo está representada na Figura 31. A soma das informações contidas na legenda e seu gráfico permite denotar que, na Microbacia do Tinga, o fluxo concentra-se, principalmente, em duas direções, a 16 e a 128. Ademais, essa figura já dá um indicativo da definição dos divisores de água. 


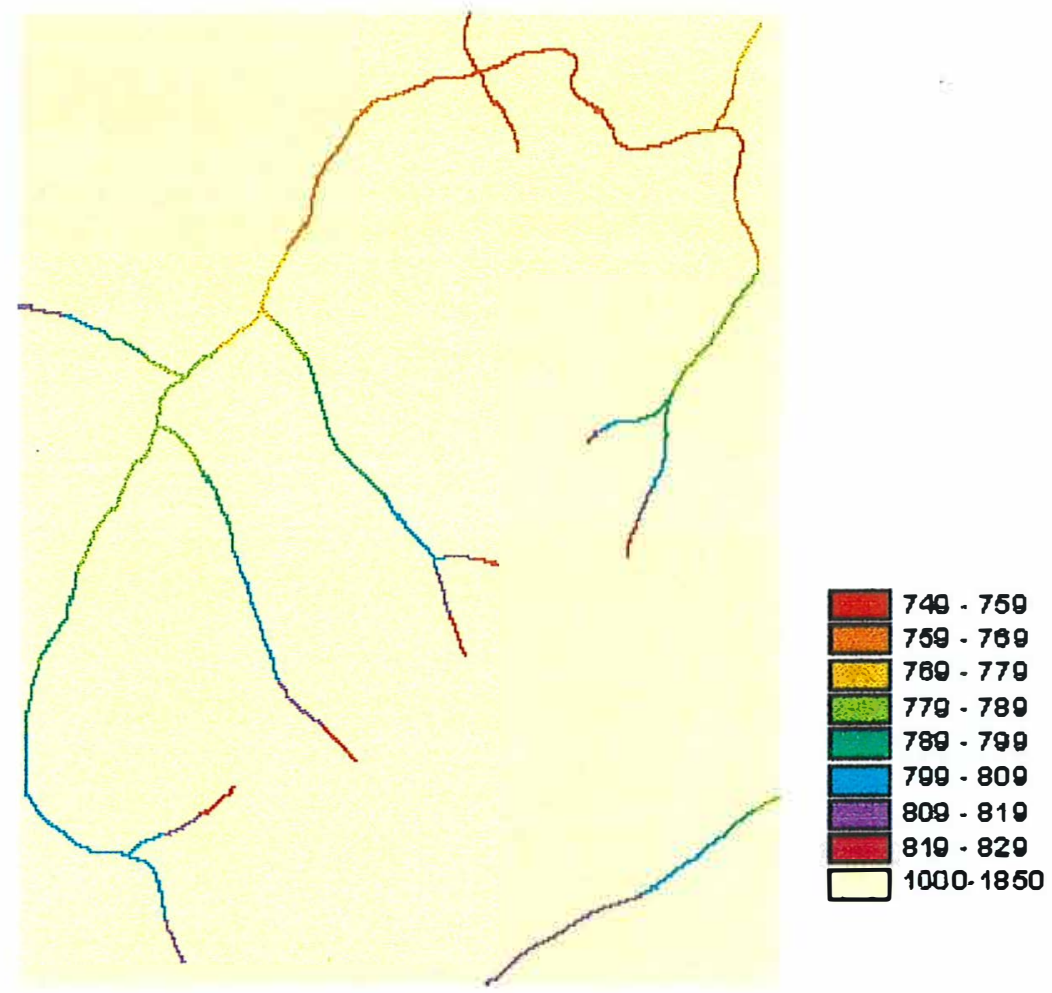

Figura 29 - Modelo digital de terreno, após o Burn Streams. As cores indicam a altitude em metros, no caso dos canais. Para o restante da área, uma elevação arbitrária.
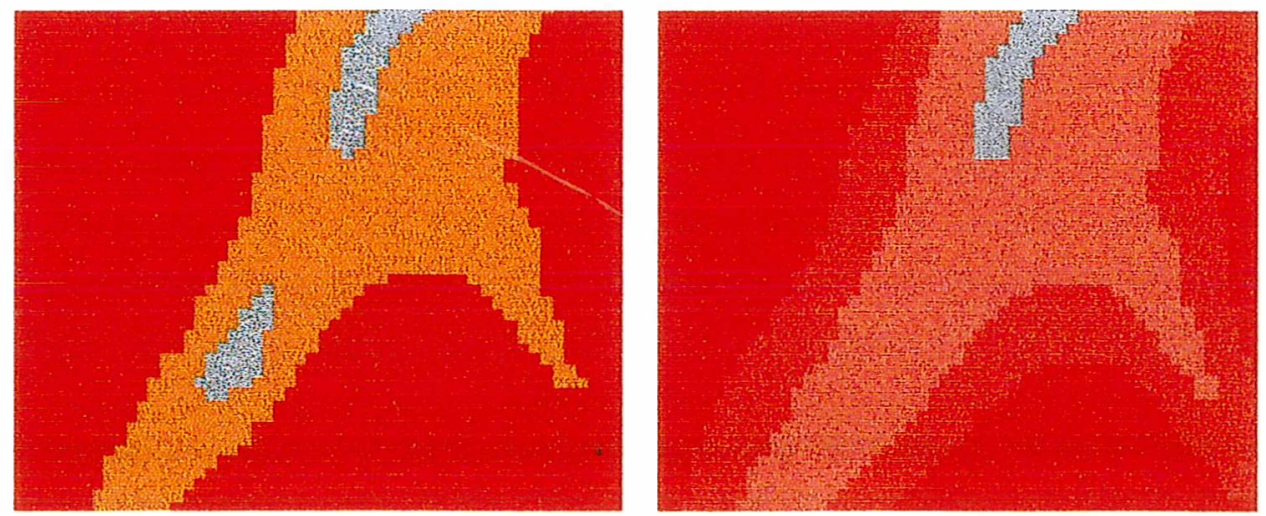

Figura 30 - Parte do modelo digital do terreno, antes e após o preenchimento de depressões. 


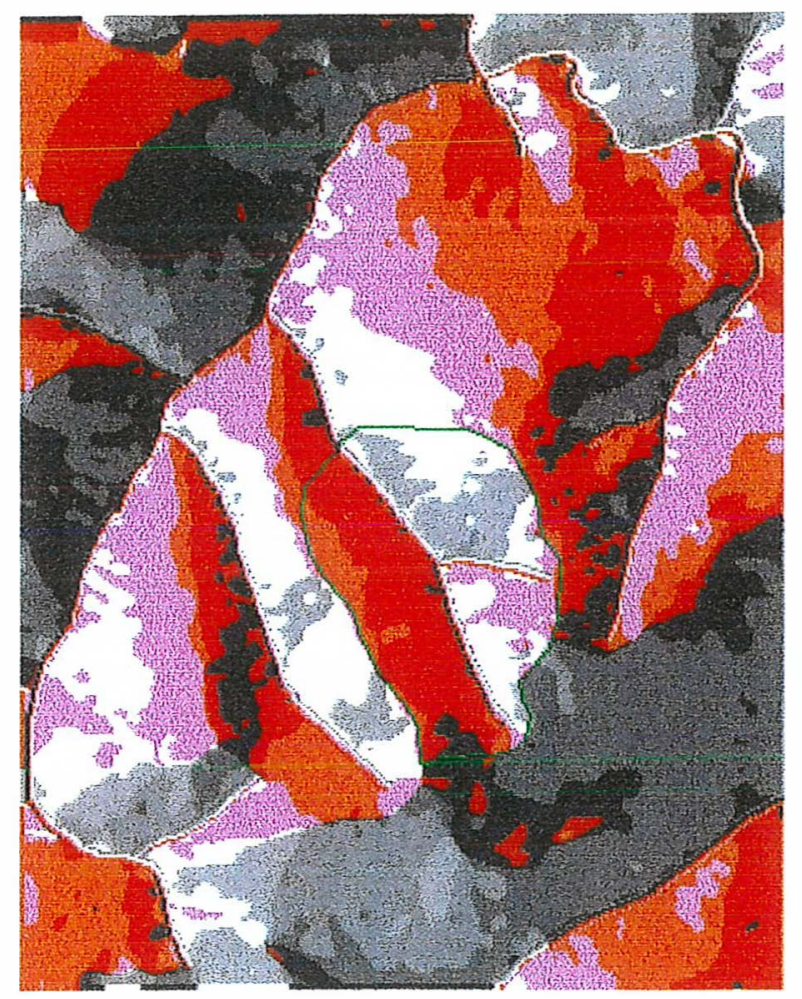

\begin{tabular}{|l|l|l|}
\hline 32 & 64 & 128 \\
\hline 16 & 34 & 1 \\
\hline 8 & 4 & 2 \\
\hline
\end{tabular}

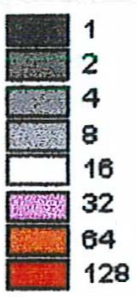

Figura 31 - Direção de fluxo da água na superficie do terreno. Cada número correspondente a cor indica uma direção, entre as oito possíveis.

Cabe discutir que a pressuposição de que a água segue uma das oito direções possíveis (D8) não é necessariamente verdadeira, uma vez que a água pode seguir outras direções. Vários estudos demonstraram isso. Entre eles, Wolock \& McCabe (1995) provaram que o fluxo a partir de um ponto pode tomar múltiplas direções. Nesse sentido, ESRI (1994) explicou que direções de fluxo indefinidas podem ocorrer quando todas as células adjacentes são mais altas ou as declividades dessas células apresentam um mesmo valor. Para Wang \& Yin (1998), tanto o algoritmo D8, quanto as tentativas de melhorá-lo apresentam limitações, principalmente, por não conseguir direcionar o fluxo em áreas planas, com depressões ou em platôs. A despeito dessas limitações, recorrer-se à simplificação do D8 justifica-se na sua maior eficiência computacional para células com formato quadrado. 
Ao aplicar o procedimento de acumulação de fluxo, obteve-se a Figura 32 onde está representado o número de células à montante que contribuem com o fluxo. Pela legenda, pode-se verificar que a cor branca engloba a maior parte das células, ou seja, aquelas com menos células à montante. Por outro lado, os tons vermelhos mais intensos representam um número de células maior contribuindo. $\mathrm{O}$ fluxo acumulado, a partir de um determinado número, torna-se o local de passagem de um canal. Além disso, pela multiplicação da área de uma célula pelo número de células drenando, obtémse a área de drenagem. Por exemplo, a célula que recebe água de 500 células, na verdade, recebe água de 5 ha à montante. Portanto, a área de uma microbacia é o número de células à montante contribuindo ao ponto de saída da mesma multiplicado pela área de cada célula. No caso da Microbacia do Tinga, 8.170 células contribuem para a célula do ponto de saída da microbacia, onde está localizado a estação medidora.

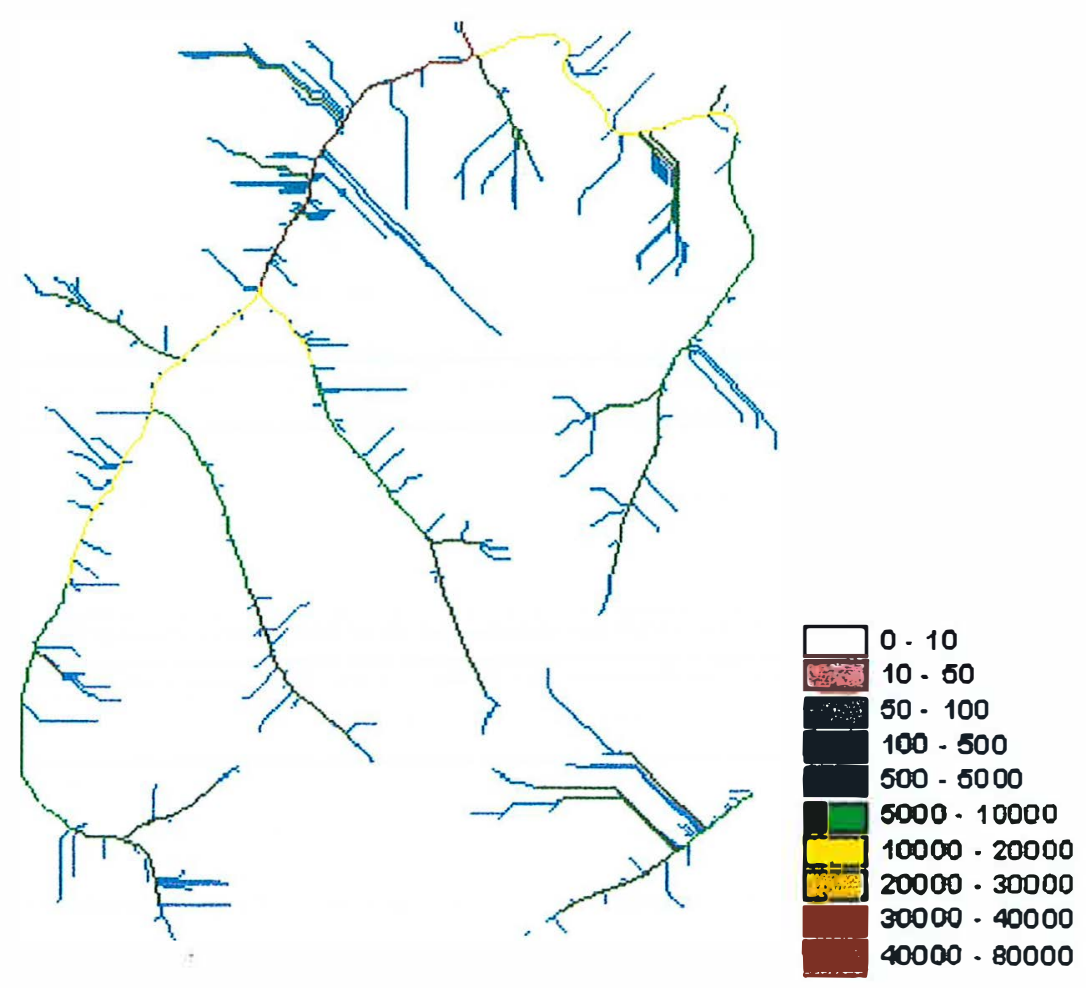

Figura 32 - Acumulação do fluxo, onde as cores indicam a quantidade de células à montante drenando para cada célula. 
No procedimento definição de canais (Stream definition), foi determinada a área ou o número mínimo de células contribuintes (threshold) para que uma célula específica fosse considerada como parte de um canal. Esse é um ponto crucial da modelagem, uma vez que envolve necessariamente uma escolha e, segundo Montgomery \& Foufoula-Georgeou (1993), geralmente, essa escolha é arbitrária. Na área de estudo, foram testados os valores de 100 células (1ha), 500 células (5ha), 1000 células (10 ha) e 2500 células ( 25 ha). Na Figura 33, são mostrados os resultados do delineamento para cada um desses valores. Como a rede de drenagem delineada a partir do valor de 10 ha (1000 células) é mais compatível com a digitalizada das cartas, escolheu-se esse valor para a separação de células de canais e de superficie. Valores muito baixos, como o de 1 ha (100 células), resultaram numa rede de canais demasiadamente intensa, onde muitos canais efềmeros seriam considerados como perenes. Em contrapartida, os mais altos estabeleceram uma rede de drenagem muito pobre. Ademais, o valor selecionado dependeu ainda do detalhamento pretendido para 0 delineamento da rede de drenagem e a delimitação das sub-bacias. Cabe ressaltar que a escolha de um valor inadequado afetaria negativamente a determinação dos parâmetros, principalmente aqueles relacionados ao comprimento dos canais.

A despeito do delineamento ter sido considerado satisfatório, alguns problemas surgiram nas áreas mais planas, prontamente contornados pelo uso do procedimento Burn Streams. Além disso, o aparecimento de canais retilíneos e paralelos foi um indicativo de que a escala das cartas mostrou-se insuficiente para intensificar a rede. Naturalmente, esses canais não se formam tão retilineamente, em especial nas áreas mais altas, onde apareceram com maior freqüência. Nessas áreas, os canais (efềmeros) tendem a ser mais tortuosos. Tarboton (1997) também encontrou traços retilineos, alinhados com as linhas da grade, quando aplicou o método D8 (8 direções) em um MDT de alta resolução com tamanho de célula de $2 \mathrm{~m}$. Quando foi usada uma resolução de $30 \mathrm{~m}$, os traços retilineos foram menores.

Nesse trabalho, a presença indesejável dos canais retilineos e paralelos foi eliminada, pois o processamento restante considerou um valor de 1000 células. Caso persistissem, tomar-se-iam um problema, pois causariam a delimitação de duas sub- 


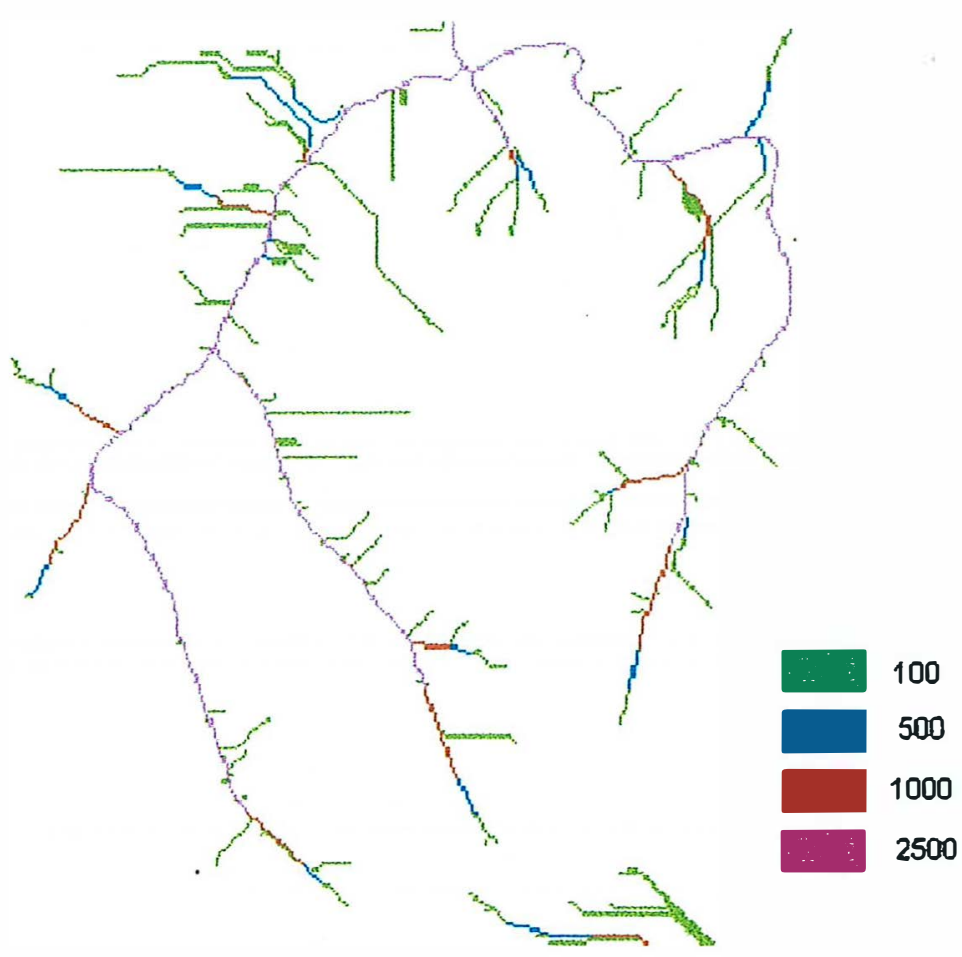

Figura 33 - Rede de drenagem formada pela definição do valor limite de 100, 500, 1000 e 2500 células drenantes, respectivamente correspondentes às áreas de 1, 5, 10 e 25 hectares.

bacias em vez de uma. Vários estudos demonstraram que a escolha de diferentes valores de threshold afetam a precisão das estimativas dos parâmetros de drenagem (DaRos \& Borga, 1997, Gandolfi \& Bischetti, 1997, Quinn et al., 1995).

A separação dos cariais em trechos pode ser visualizada na Figura 34. Percebe-se que cada um deles apresenta uma cor diferente. Para cada trecho de canal, foi delimitada uma sub-bacia, em função de seu ponto de saída. Por sua vez, cada sub-bacia foi considerada uma unidade ou elemento hidrológico para facilitar a manipulação das informações no computador. Na Figura 35A são mostradas as sub-bacias delimitadas para a área de estudo e entorno. A Microbacia do Tinga foi dividida automaticamente em três sub-bacias. Os limites das sub-bacias nas margens da imagem não estão corretos, 


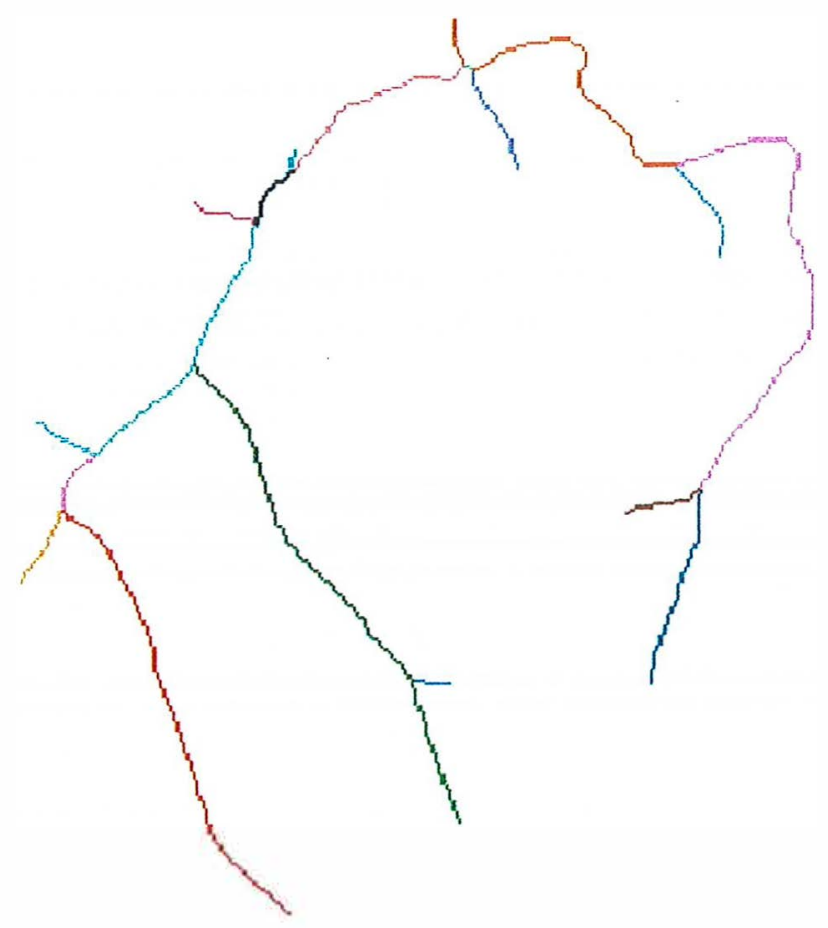

Figura 34 - Divisão dos canais em segmentos para a área da Microbacia do Tinga e entorno.
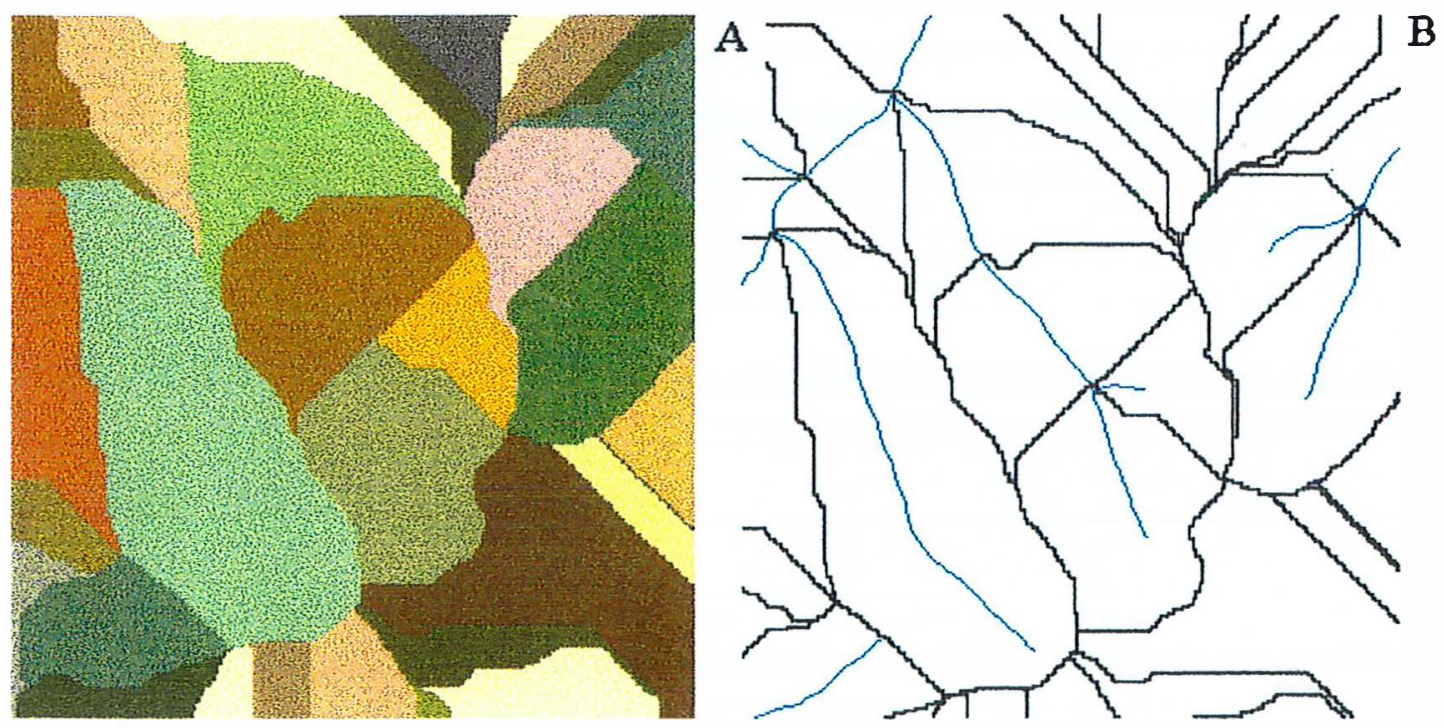

Figura 35 - Delineamento das sub-bacias para cada segmento de canal (A) e vetorização das sub-bacias e canais para áreas próximas ao Córrego do Tinga (B). 
pois a direção de fluxo dessas áreas apontou para fora da imagem. Esse mapa possui uma tabela de atributos onde foram identificadas cada sub-bacia e seu respectivo númerode células.

A Figura 35B é o produto do processo de vetorização das imagens representadas na figura ao lado e na Figura 34. A partir desse momento, cada segmento de canal e sub-bacia é melhor caracterizado pelos seus atributos, tais como área e comprimento, em forma de tabelas.

Além da adição do ponto de medição hidrológica, como ponto de saída, outros foram acrescentados ao córrego do Tinga, objetivando sua maior segmentação (Figura 36) e para formar mais sub-bacias. Esse maior número de sub-bacias visou criar zonas homogêneas de menor tamanho e, assim, ampliar as possibilidades de simulações hidrológicas com maior precisão.

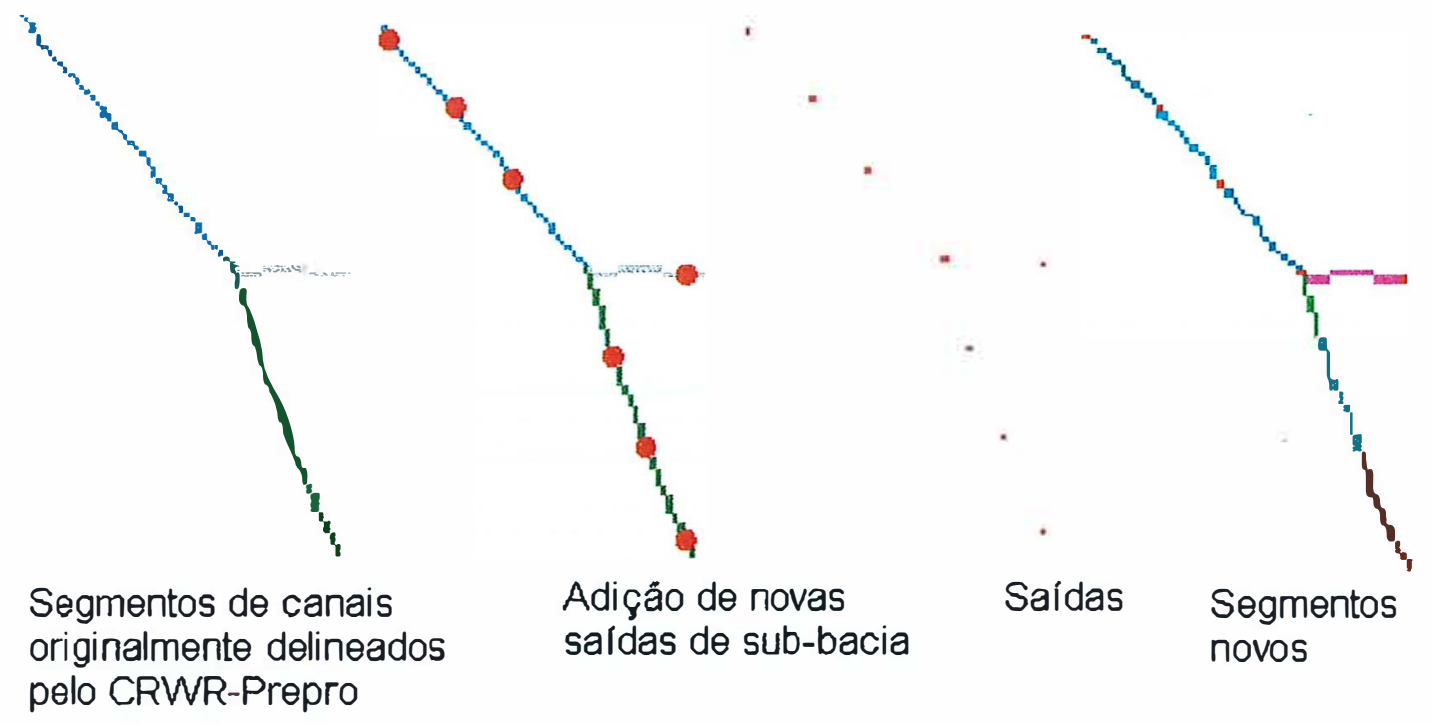

Figura 36 - Divisão dos canais em segmentos.

A adição desses pontos demandou a repetição dos procedimentos de delineamento de canais e sub-bacias e vetorização. A nova subdivisão é apresentada na Figura 37. 

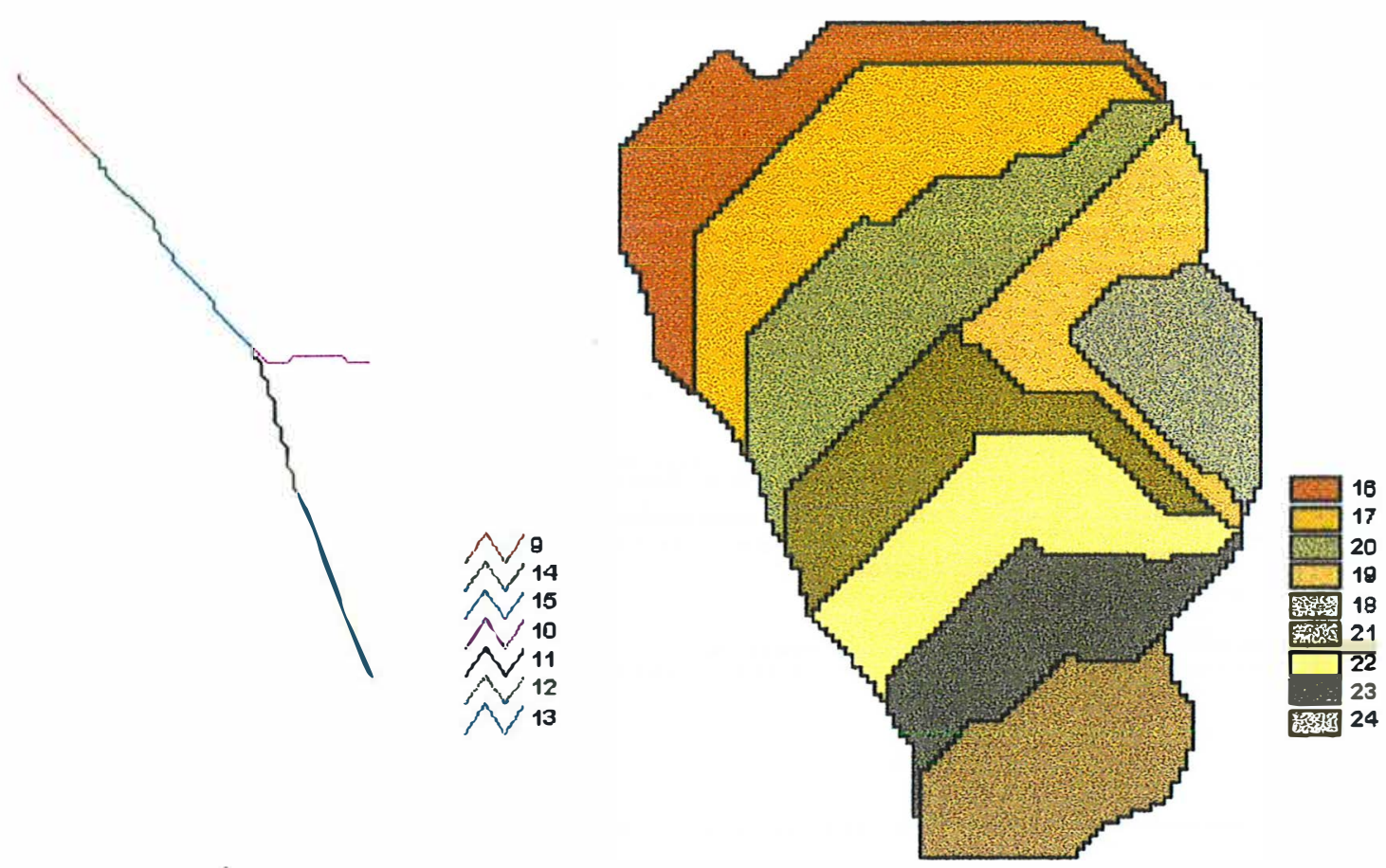

Figura 37 - Subdivisão dos canais em segmentos. Em cada um deles foi delineada uma sub-bacia. Cada elemento apresenta identificador específico.

\subsubsection{Determinação do número da curva}

Conforme explicitado na metodologia, para obter o mapa do número da curva propriamente dito, foram tratados os dados necessários para sua determinação. Assim, a Figura 38 mostra as classes de solos que ocorrem na Microbacia do Tinga. Ao passo que os dados de área e perímetro encontram-se na Tabela 10. A classe predominante é de latossolo vermelho-escuro (LE1), que ocorre em 66,8\% da área. Esse tipo de solo pertence ao mesmo grupo hidrológico que os demais encontrados na área de estudo quanto à permeabilidade e capacidade de infiltração, sendo enquadrados por Lombardi Neto et al. (1988) no grupo hidrológico A. Os solos deste grupo apresentam baixo potencial de produção de escoamento, mesmo quando úmidos. Isto foi observado na microbacia estudada, onde as condições antecedentes de umidade aparentemente não influenciaram de forma sistemática a produção de escoamento. 


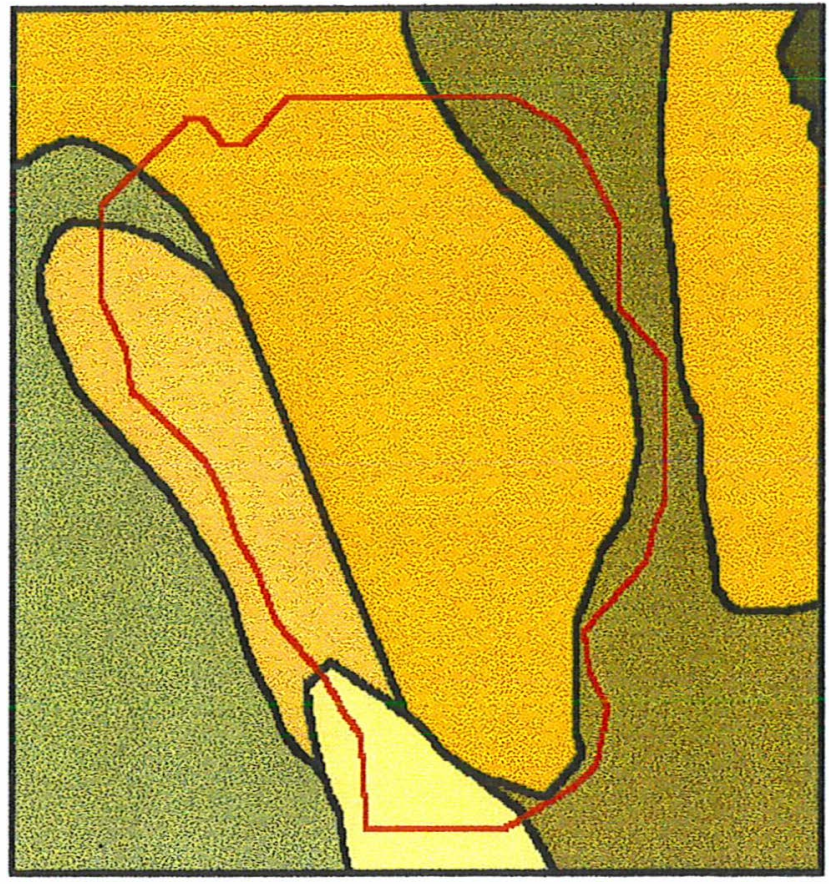

Classes

de solos

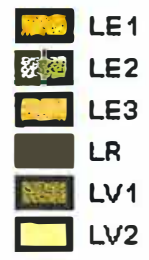

Figura 38 - Mapa de solos da Microbacia do Tinga e entorno (LE1, LE2 e LE3 latossolos vermelho-escuro, LV1 e LV2 - latossolos vermelho-amarelo e LR latossolo roxo).

Tabela 10 - Área, perímetro e porcentagem dos polígonos da Microbacia do Tinga.

\begin{tabular}{cccccc}
\hline $\begin{array}{c}\text { Polígono } \\
(\mathrm{ID})\end{array}$ & SOLOS & $\begin{array}{c}\text { ÁREA } \\
\left(\mathrm{m}^{2}\right)\end{array}$ & $\begin{array}{c}\text { ÁREA } \\
(\mathrm{ha})\end{array}$ & $(\%)$ & $\begin{array}{c}\text { PERÍMETRO } \\
(\mathrm{m})\end{array}$ \\
\hline & & & & & \\
8 & LE1 & 547086,30 & 54,71 & 66,8 & 3279,45 \\
9 & LV1 & 85337,22 & 8,53 & 10,4 & 3217,74 \\
10 & LE3 & 134116,89 & 13,41 & 16,3 & 2115,47 \\
13 & LV2 & 39201,37 & 3,92 & 4,9 & 997,76 \\
18 & LE2 & 13449,57 & 1,34 & 1,6 & 629,71 \\
\hline
\end{tabular}

Afinal, esses solos apresentam consideráveis teores de areia e alta taxa floculação das argilas, que favorecem a permeabilidade (Tabela 9). A ausência de camadas de impedimento e a grande profundidade contribuem para a manutenção de altas taxas de infiltração. A alta condutividade faz com que a água infiltrada seja 
rapidamente conduzida para camadas mais profundas, com isso as caracteristicas superficiais tendem rapidamente a voltar às condições iniciais.

Já, o mapa de uso da terra é apresentado na Figura 39. A Tabela 11 contém dados de área, perimetro e porcentagem dos diferente tipos de ocupação da Microbacia do Tinga. Com exceção da mata ciliar $(9,1 \%)$, uma pequena área de eucalipto $(2,8 \%)$, carreadores $(2,3 \%)$ e pasto ( $1 \%)$, toda a área de estudo está ocupada por eucalipto em corte raso $(85,2 \%)$.
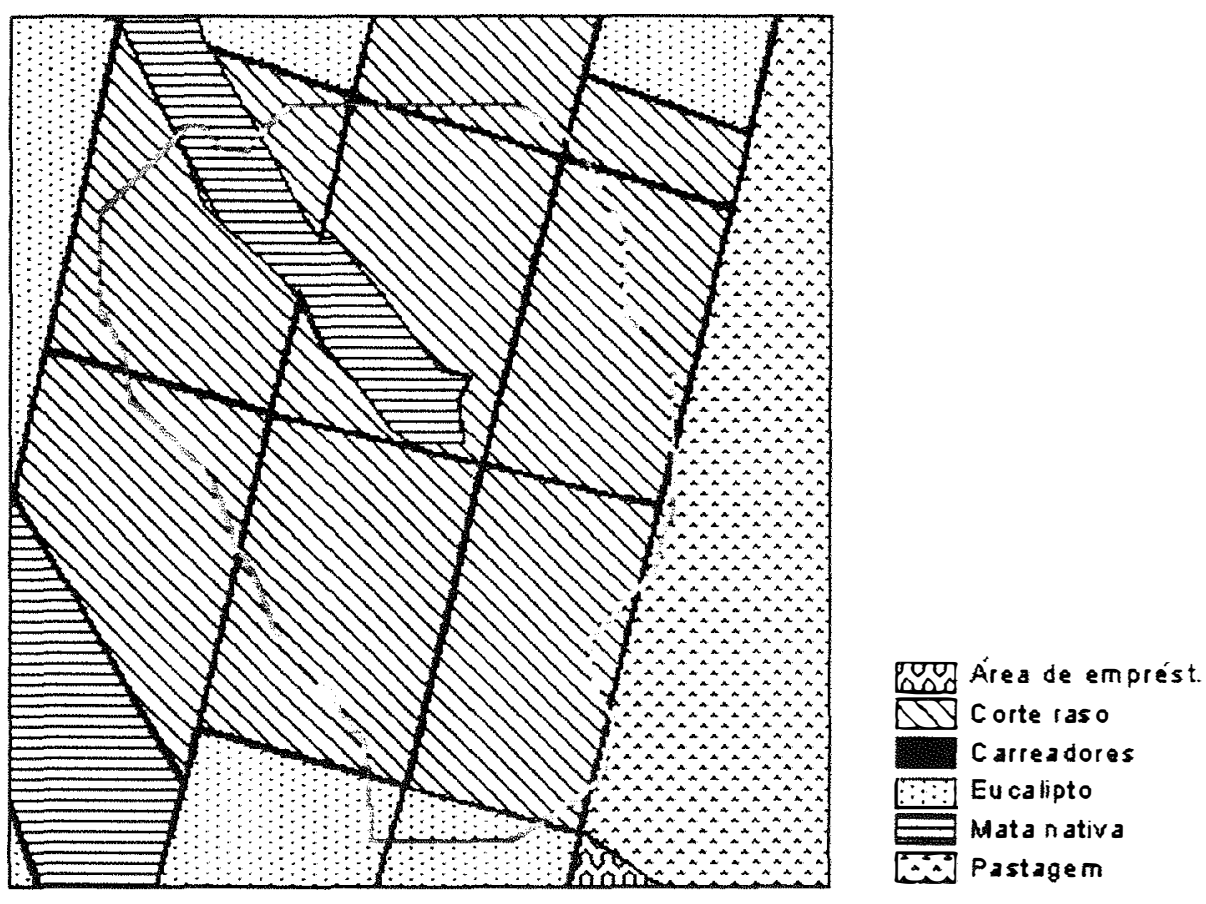

Figura 39 - Mapa de uso da terra da área da Microbacia do Tinga e entorno.

O mapa resultante da interseção entre os mapas de solos e de uso da terra é o da Figura 40. A Tabela 12 explicita os mesmos tipos de dados das duas tabelas antecedentes.

A condição hidrológica adotada na obtenção do mapa do número da curva foi considerada boa para toda a bacia, com exceção da pequena área de pasto. Da mesma forma, como mencionado anteriormente, os solos foram enquadrados no mesmo grupo 
Tabela 11 - Dados de área, perímetro e porcentagem dos diferente tipos de ocupação da Microbacia do Tinga.

\begin{tabular}{cccccc}
\hline Poligono (ID) & OCUPAÇĀO & $\begin{array}{c}\text { AREA } \\
\left(\mathrm{m}^{2}\right)\end{array}$ & $\begin{array}{c}\text { PERIMETRO } \\
(\mathrm{m})\end{array}$ & $\%$ & $\begin{array}{c}\text { ÁREA } \\
(\mathrm{ha})\end{array}$ \\
\hline 3 & Carreadores & 23036,31 & 7729,77 & 3 & 2,30 \\
2 & Pastagem & 4834,74 & 772,00 & 1 & 0,48 \\
12 & Corte raso & 11023,53 & 647,62 & 1 & 1,10 \\
13 & Corte raso & 923,66 & 142,61 & 0 & 0,09 \\
14 & Corte raso & 108196,51 & 1490,26 & 13 & 10,82 \\
15 & Corte raso & 147242,74 & 2659,17 & 18 & 14,72 \\
17 & Mata nativa & 76179,90 & 1596,31 & 9 & 7,62 \\
18 & Corte raso & 17445,15 & 590,26 & 2 & 1,75 \\
19 & Corte raso & 94128,86 & 1242,67 & 11 & 9,41 \\
20 & Corte raso & 157655,02 & 1702,75 & 19 & 15,77 \\
21 & Corte raso & 147826,58 & 1646,15 & 18 & 14,78 \\
22 & Corte raso & 27079,77 & 841,05 & 3 & 2,71 \\
27 & Eucalipto & 19455,71 & 702,15 & 2 & 1,95 \\
\hline
\end{tabular}

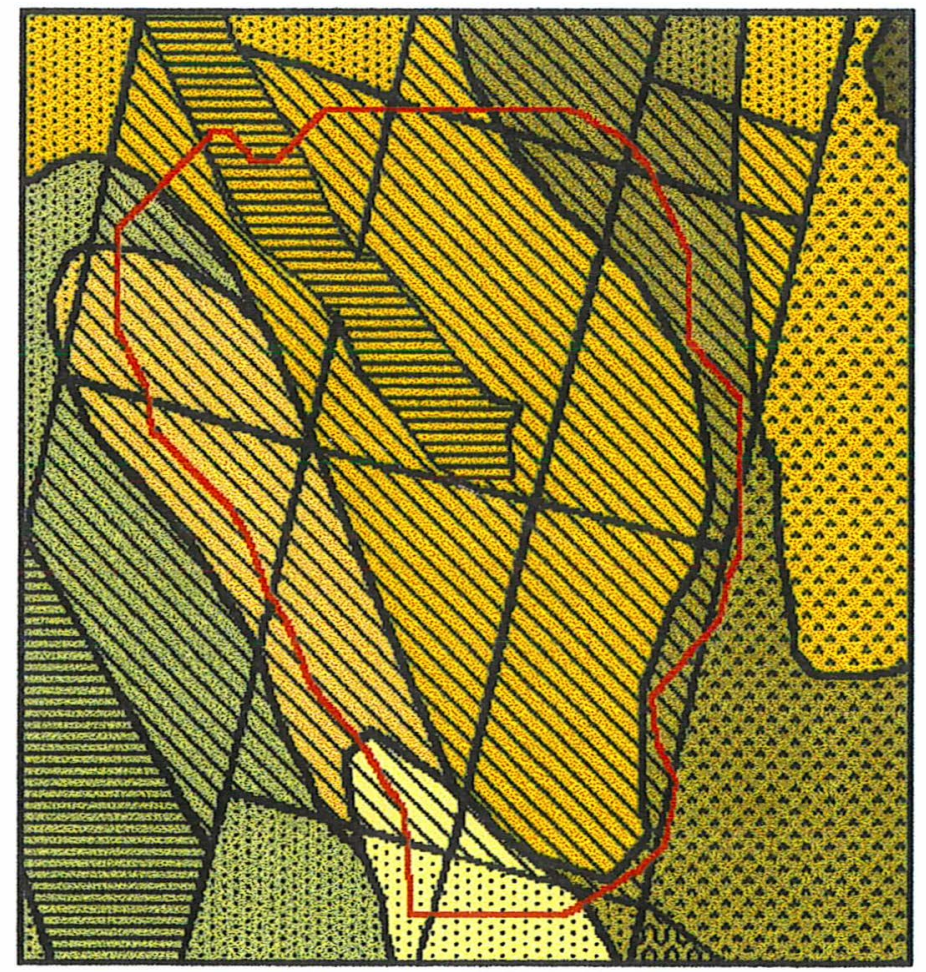

Classes de solos

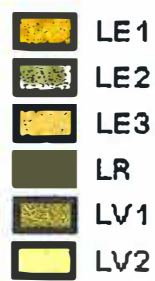

Uso do solo एण्ण Área de emprést.

\begin{tabular}{l}
\hline Corte raso \\
carreadores \\
$\therefore:$ Eucalipto \\
Mata nativa \\
Mastagem
\end{tabular}

Figura 40 - Resultado da interseção do mapa de solos com o de uso da terra. 
Tabela 12 - Dados de área, perímetro e porcentagem dos tipos de ocupação nos diferentes solos da Microbacia do Tinga.

\begin{tabular}{lccccc}
\hline Ocupação & Solos & $\begin{array}{c}\text { Área } \\
\left(\mathrm{m}^{2}\right)\end{array}$ & Hectares & $\%$ & Perimetro $(\mathrm{m})$ \\
\hline Carreadores & LE1 & 12306,0 & 1,231 & 1,48 & 4093,952 \\
Corte raso & LE1 & 1530,6 & 0,153 & 0,18 & 246,840 \\
Corte raso & LE1 & 75208,1 & 7,521 & 9,02 & 1183,967 \\
Corte raso & LE1 & 135232,6 & 13,523 & 16,21 & 2573,609 \\
Mata nativa & LE1 & 76179,9 & 7,618 & 9,13 & 1596,308 \\
Corte raso & LE1 & 17445,2 & 1,745 & 2,09 & 590,264 \\
Corte raso & LE1 & 30104,0 & 3,010 & 3,61 & 1059,551 \\
Corte raso & LE1 & 129274,7 & 12,927 & 15,50 & 1552,844 \\
Corte raso & LE1 & 78964,5 & 7,896 & 9,46 & 1385,249 \\
Carreadores & LV1 & 5168,6 & 0,517 & 0,62 & 1802,361 \\
Pastagem & LV1 & 4834,7 & 0,483 & 0,58 & 771,998 \\
Corte raso & LV1 & 9580,1 & 0,958 & 1,15 & 484,821 \\
Corte raso & LV1 & 923,7 & 0,092 & 0,11 & 142,605 \\
Corte raso & LV1 & 33282,4 & 3,328 & 3,99 & 1327,613 \\
Corte raso & LV1 & 12287,7 & 1,229 & 1,47 & 520,850 \\
Corte raso & LV1 & 20689,8 & 2,069 & 2,48 & 1448,392 \\
Eucalipto & LV1 & 336,3 & 0,034 & 0,04 & 95,135 \\
Carreadores & LE3 & 3171,1 & 0,317 & 0,38 & 1049,302 \\
Corte raso & LE3 & 112,9 & 0,011 & 0,01 & 52,623 \\
Corte raso & LE3 & 50594,5 & 5,059 & 6,06 & 949,850 \\
Corte raso & LE3 & 55021,3 & 5,502 & 6,60 & 1291,809 \\
Corte raso & LE3 & 27079,8 & 2,708 & 3,25 & 841,049 \\
Carreadores & LV2 & 2364,5 & 0,236 & 0,28 & 903,217 \\
Corte raso & LV2 & 7594,2 & 0,759 & 0,91 & 478,058 \\
Corte raso & LV2 & 12944,4 & 1,294 & 1,55 & 528,663 \\
Eucalipto & LV2 & 19080,6 & 1,908 & 2,29 & 665,768 \\
Corte raso & LE2 & 12973,5 & 1,297 & 1,55 & 633,093 \\
\hline
\end{tabular}

hidrológico A. Caso esses dois parâmetros fossem espacialmente variáveis, seus mapas correspondentes poderiam ser adicionados aos demais na elaboração do mapa de $\mathrm{CN}$.

A Figura 41 apresenta o mapa de número da curva para a área estudada. A Tabela 13 contém os dados de área, porcentagem e perímetro dos diferentes usos da terra nos diversos solos e, conseqüentemente, do $\mathrm{CN}$. 


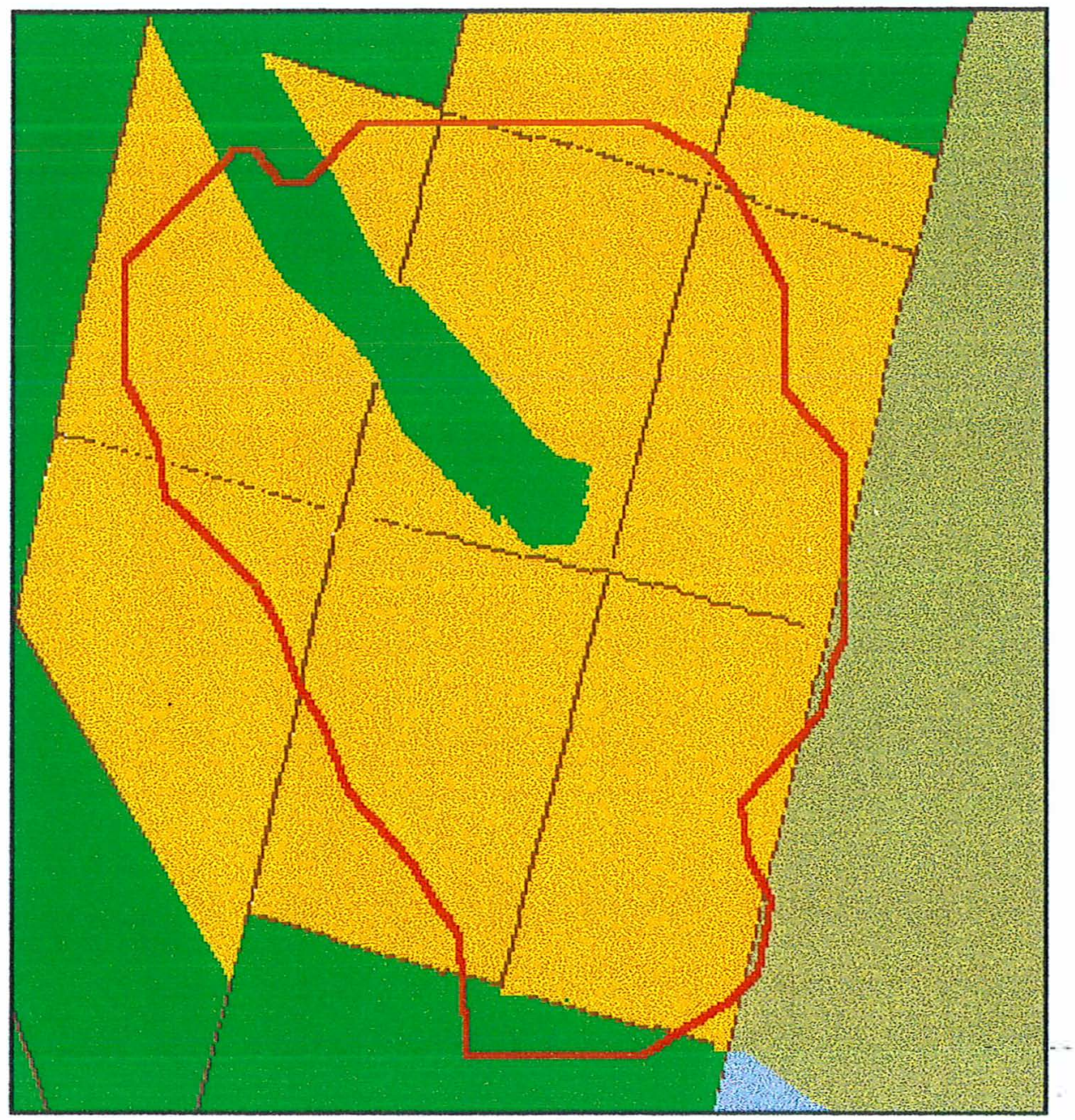

Figura 41 - Número da curva do SCS para a área de estudo e entorno.

Cabe ressaltar que os valores do $\mathrm{CN}$ apresentados correspondem a condição de umidade antecedente II.

Além do uso que foi dado nesse trabalho, um mapa de número da curva espacialmente distribuído é uma informação que pode ser analisada de várias formas. Por exemplo, no SIG ArcView, pode-se facilmente transformar uma precipitação em precipitação efetiva. Também essa precipitação efetiva, para melhor ser estudada, pode ser associada à cada classe de uso do solo. 
Tabela 13 - Tabela de dados de uso da terra, solos, condição hidrológica, grupo hidrológico, $\mathrm{CN}$, área, porcentagem de área e perímetro da Microbacia do Tinga.

\begin{tabular}{|c|c|c|c|c|c|c|c|c|}
\hline Ocupação & Solos & $\begin{array}{l}\text { ondição. } \\
\text { hidrol. }\end{array}$ & $\begin{array}{l}\text { Grupo } \\
\text { hidrol. }\end{array}$ & $\mathrm{CN}$ & $\begin{array}{l}\text { Arrea } \\
\left(\mathrm{m}^{2}\right)\end{array}$ & $\begin{array}{l}\text { Área } \\
\text { (ha) }\end{array}$ & $\begin{array}{c}\text { Area } \\
\%\end{array}$ & $\begin{array}{l}\text { Perímetro } \\
(\mathrm{m})\end{array}$ \\
\hline Carreadores & LE1 & Boa & A & 74 & 12306,0 & 1,23 & 1,5 & 4094,0 \\
\hline Corte raso & LE1 & Boa & A & 25 & 1530,6 & 0,15 & 0,2 & 246,8 \\
\hline Corte raso & LE1 & Boa & A & 25 & 75208,1 & 7,52 & 9,0 & 1184,0 \\
\hline Corte raso & LE1 & Boa & A & 25 & 135232,6 & 13,52 & 16,2 & 2573,6 \\
\hline Mata nativa & LE1 & Boa & A & 20 & 76179,9 & 7,62 & 9,1 & 1596,3 \\
\hline Corte raso & LE1 & Boa & A & 25 & 17445,2 & 1,75 & 2,1 & 590,3 \\
\hline Corte raso & LE1 & Boa & A & 25 & 30104,0 & 3,01 & 3,6 & 1059,6 \\
\hline Corte raso & LE1 & Boa & A & 25 & 129274,7 & 12,93 & 15,5 & 1552,8 \\
\hline Corte raso & LE1 & Boa & A & 25 & 78964,5 & 7,90 & 9,5 & 1385,2 \\
\hline Carreadores & LV1 & Boa & A & 74 & 5168,6 & 0,52 & 0,6 & 1802,4 \\
\hline Pastagem & LV1 & Má & A & 65 & 4834,7 & 0,48 & 0,6 & 772,0 \\
\hline Corte raso & LV1 & Boa & A & 25 & 9580,1 & 0,96 & 1,1 & 484,8 \\
\hline Corte raso & LV1 & Boa & A & 25 & 923,7 & 0,09 & 0,1 & 142,6 \\
\hline Corte raso & LV1 & Boa & A & 25 & 33282,4 & 3,33 & 4,0 & 1327,6 \\
\hline Corte raso & LV1 & Boa & $A$ & 25 & 12287,7 & 1,23 & 1,5 & 520,9 \\
\hline Corte raso & LV1 & Boa & A & 25 & 20689,8 & 2,07 & 2,5 & 1448,4 \\
\hline Eucalipto & LV1 & Boa & A & 20 & 336,3 & 0,03 & 0,0 & 95,1 \\
\hline Carreadores & LE3 & Boa & A & 74 & 3171,1 & 0,32 & 0,4 & 1049,3 \\
\hline Corte raso & LE3 & Boa & A & 25 & 112,9 & 0,01 & 0,0 & 52,6 \\
\hline Corte raso & LE3 & Boa & A & 25 & 50594,5 & 5,06 & 6,1 & 949,9 \\
\hline Corte raso & LE3 & Boa & A & 25 & 55021,3 & 5,50 & 6,6 & 1291,8 \\
\hline Corte raso & LE3 & Boa & A & 25 & 27079,8 & 2,71 & 3,2 & 841,0 \\
\hline Carreadores & LV2 & Boa & A & 74 & 2364,5 & 0,24 & 0,3 & 903,2 \\
\hline Corte raso & LV2 & Boa & A & 25 & 7594,2 & 0,76 & 0,9 & 478,1 \\
\hline Corte raso & LV2 & Boa & A & 25 & 12944,4 & 1,29 & 1,6 & 528,7 \\
\hline Eucalipto & LV2 & Boa & A & 20 & 19080,6 & 1,91 & 2,3 & 665,8 \\
\hline Corte raso & LE2 & Boa & A & 25 & 12973,5 & 1,30 & 1,6 & 633,1 \\
\hline
\end{tabular}

\subsubsection{Cálculo dos parâmetros}

\subsubsection{Cálculo dos parâmetros baseados no MDT}

O mapa de comprimento dos caminhos seguidos pela água na superficie do terreno entre uma saída de bacia e cada célula, de jusante à montante, é apresentado na Figura 42. Na figura, as distâncias foram determinadas para toda a área de entorno 

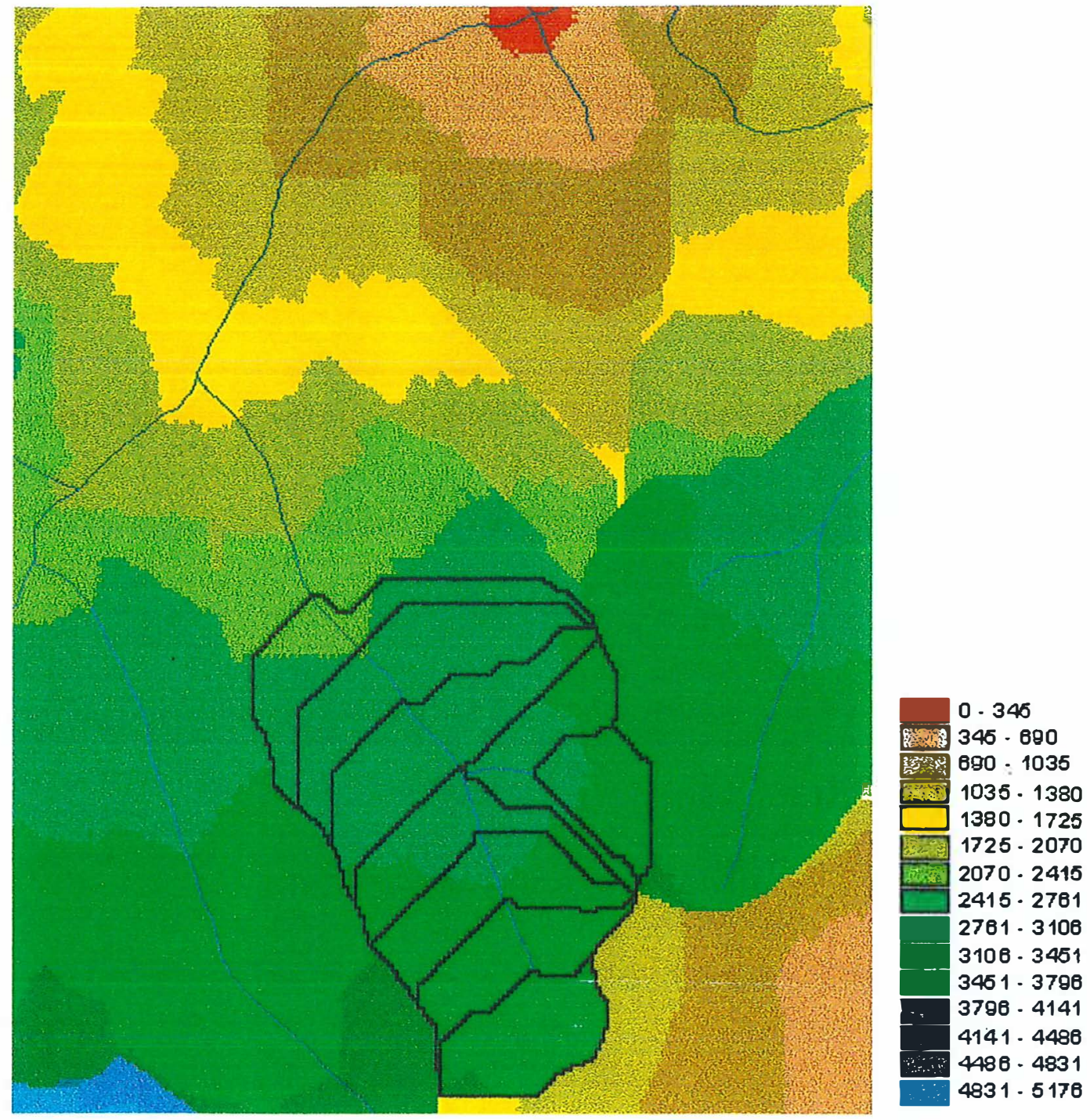

Figura 42 - Comprimento do fluxo de jusante à montante (FLDS) em metros, até o ponto de saída da bacia (comprimento $=0$ ).

da Microbacia do Tinga. Os maiores valores são de 5176 m, representados pela cor azul, até valores próximos ao ponto de saída, com valor zero e cor vermelha. O valor de 5176 $\mathrm{m}$ indica o percurso que a água deve percorrer para atingir o ponto de descarga. Segundo Olivera \& Maidment (1998), essa rota seguida pela água não se restringe aos canais principais, ou seja, são incluídos os trechos sobre a superficie e nos canais. 
As informações contidas nos mapas podem ser utilizadas de várias maneiras. Por exemplo, a partir desse mapa de comprimentos de fluxo e o de velocidades superficiais, pode-se, facilmente, elaborar mapas de isócronas, que servem para determinações de diagramas tempo-área, muito usados na modelagem hidrológica. Nesse sentido, o Método da Hidrógrafa Unitária de Clark, que também é um método de transformação da precipitação efetiva em hidrógrafa, disponivel no HEC-HMS, tem como parâmetro básico o diagrama tempo-área. O mapa de comprimento do fluxo associado com o mapa de velocidades na superfície do terreno também pode ser aplicado para a determinação do tempo de concentração. Porém, na determinação do tempo de concentração de bacias, o caminho de maior comprimento, muitas vezes, não é necessariamente o que apresenta o maior tempo de percurso, pois o seu cálculo depende também da velocidade da água ao longo do percurso.

A Figura 43 é um mapa do caminho seguido pela água de montante à jusante para cada célula (FLUS), com as células do divisor tendendo a zero. Entretanto, tal comportamento não pode ser generalizado, uma vez que existem áreas internas com valores próximos a zero, indicando que são áreas onde as trajetórias de fluxo iniciam, ou seja, não apresentam nenhuma célula drenando para a mesma. Ademais, constata-se pela figura que nas proximidades do divisor de água (cor azul), os comprimentos são menores e aumentam gradativamente à jusante pelos canais principais até o ponto de descarga da microbacia (onde o valor máximo é em torno de 1700). A subdivisão da microbacia em sub-bacias não afetou em nada esses comprimentos, pois, naturalmente, seguiram o seu curso.

Ao passo que a Figura 44 é um mapa de distâncias entre cada uma das células até a saída de cada sub-bacia (FLWO), seguindo o percurso da água na superficie. A distância máxima é de aproximadamente $770 \mathrm{~m}$ (na bacia 16). As distâncias entre 0 e 100 m estão em vermelho, representando áreas próximas da saída de cada sub-bacia. Nesse caso, a subdivisão da área de estudo proporcionou distâncias menores, por causa da adição dos pontos de saída. Como o MDT foi condicionado pelo preenchimento de depressões, não ocorreram áreas internas das sub-bacias com valor zero. 


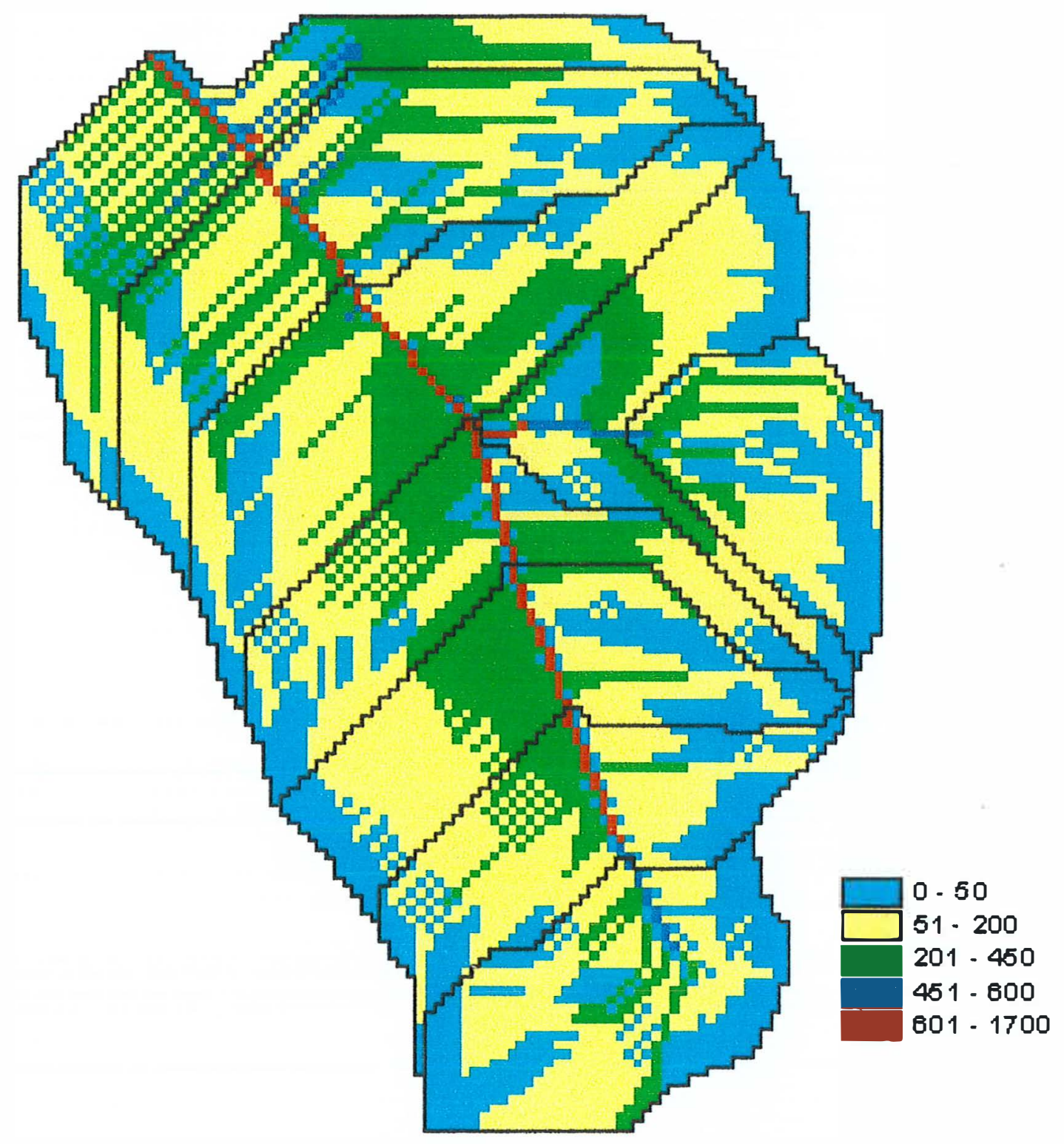

Figura 43 - Comprimento do fluxo de montante à jusante (FLUS) em metros. 


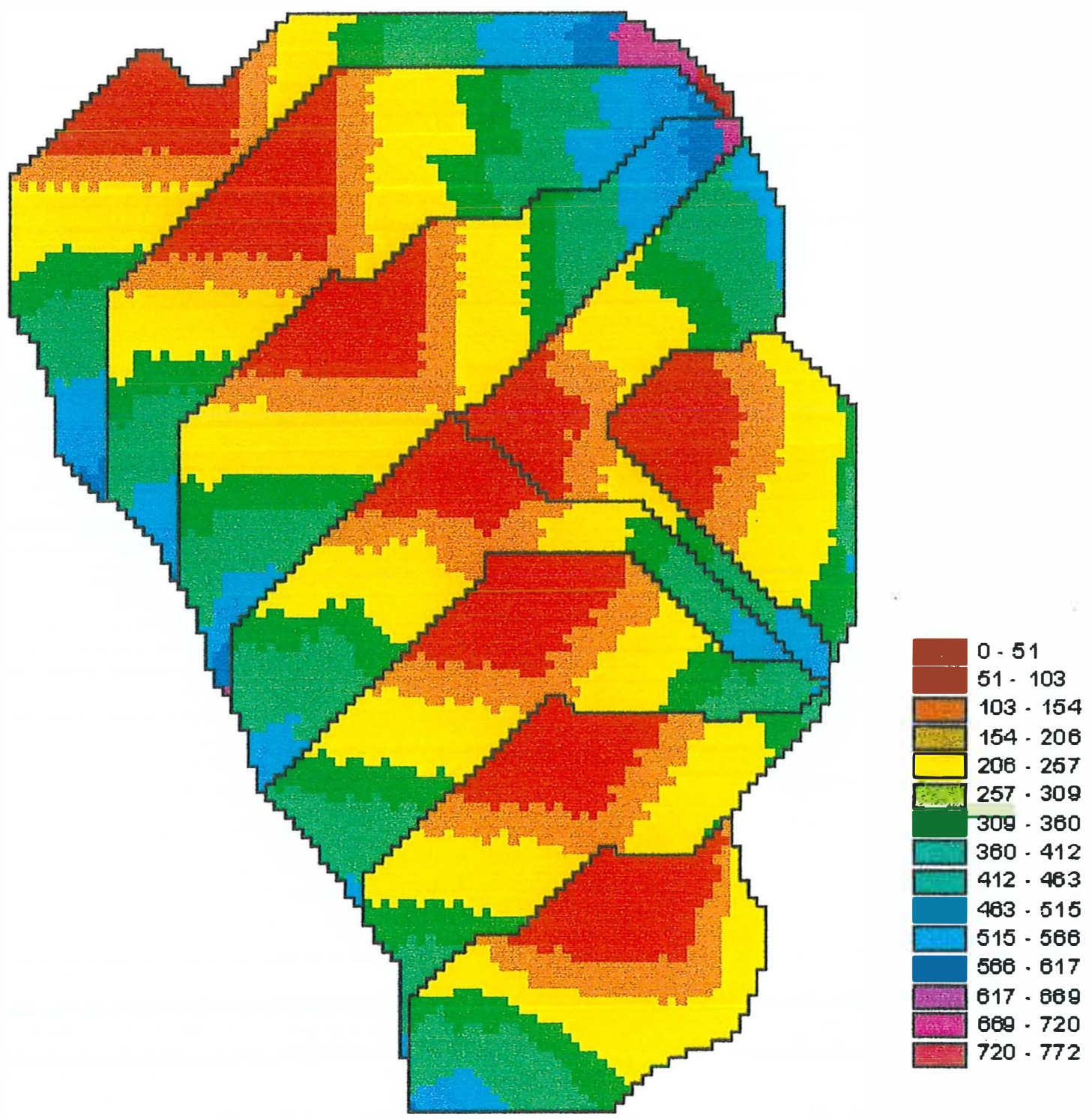

Figura 44 - Comprimento do fluxo de jusarite à montante, desde o ponto de saída de cada sub-bacia (FLWO). O comprimento na saída de cada sub-bacia é igual a 0 .

A distância percorrida pelo fluxo de montante à jusante (FLWB), desde o ponto inicial de acumulação, ou seja, a célula que não apresenta nenhuma contribuição de outras células a montante, até o ponto de saída de cada sub-bacia está ilustrada na Figura 45. Geralmente, o ponto inicial se encontra próximo ao divisor. Os maiores valores giraram em torno de $750 \mathrm{~m}$. 


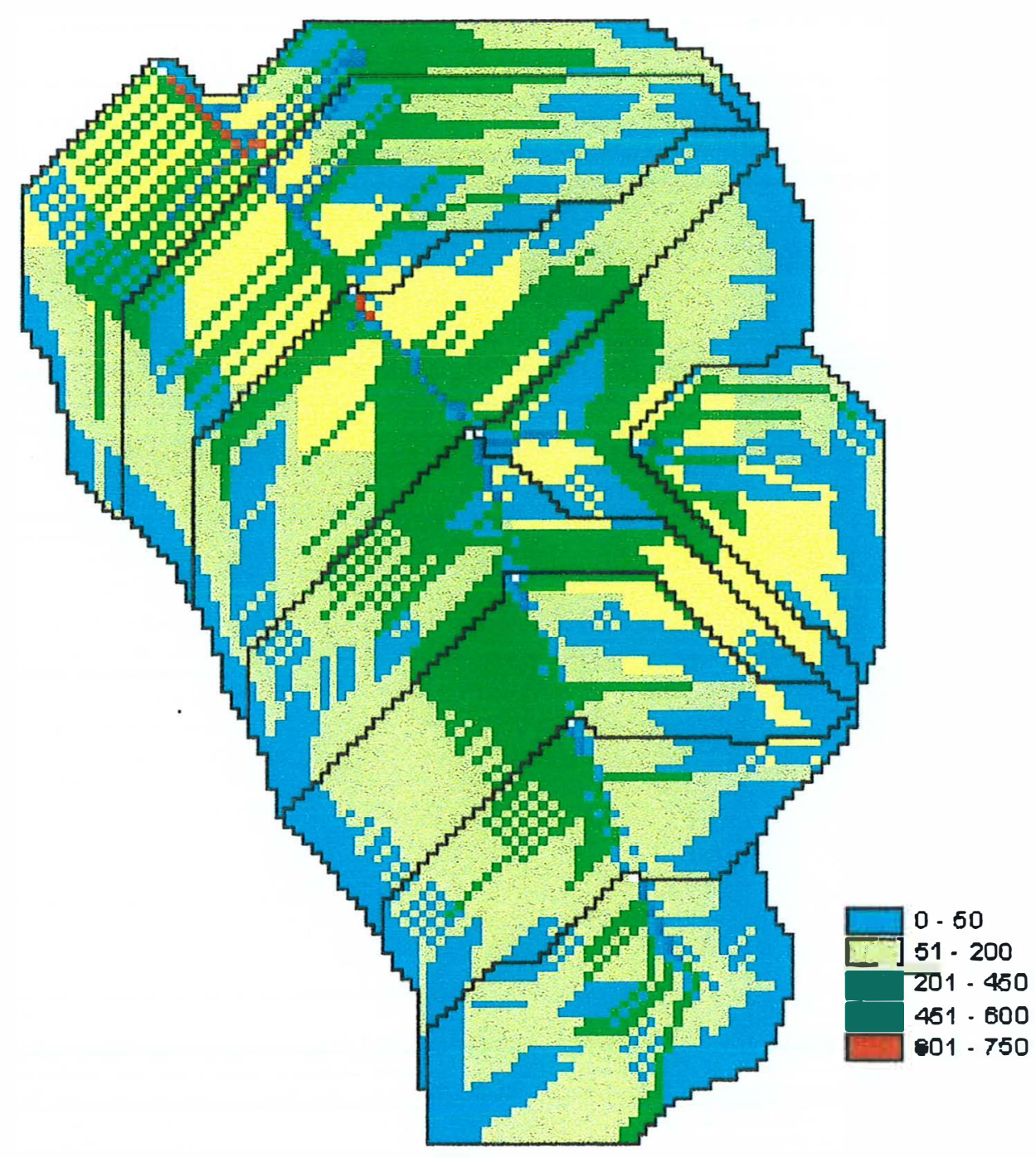

Figura 45 - Comprimento do fluxo de montante à jusante, desde a célula que não apresenta nenhuma contribuição de células acima até o ponto de saída de cada sub-bacia (FLWB), em metros.

Na Figura 46 estão indicados o maior comprimento do caminho seguido pela água para cada sub-bacia. $\mathrm{O}$ maior deles pertence à sub-bacia $16 \mathrm{e}$ o menor à 18 . Nota-se que as bacias alongadas tendem a possuir distâncias mais longas. Já, as com formatos mais arredondados apresentam valores menores. 


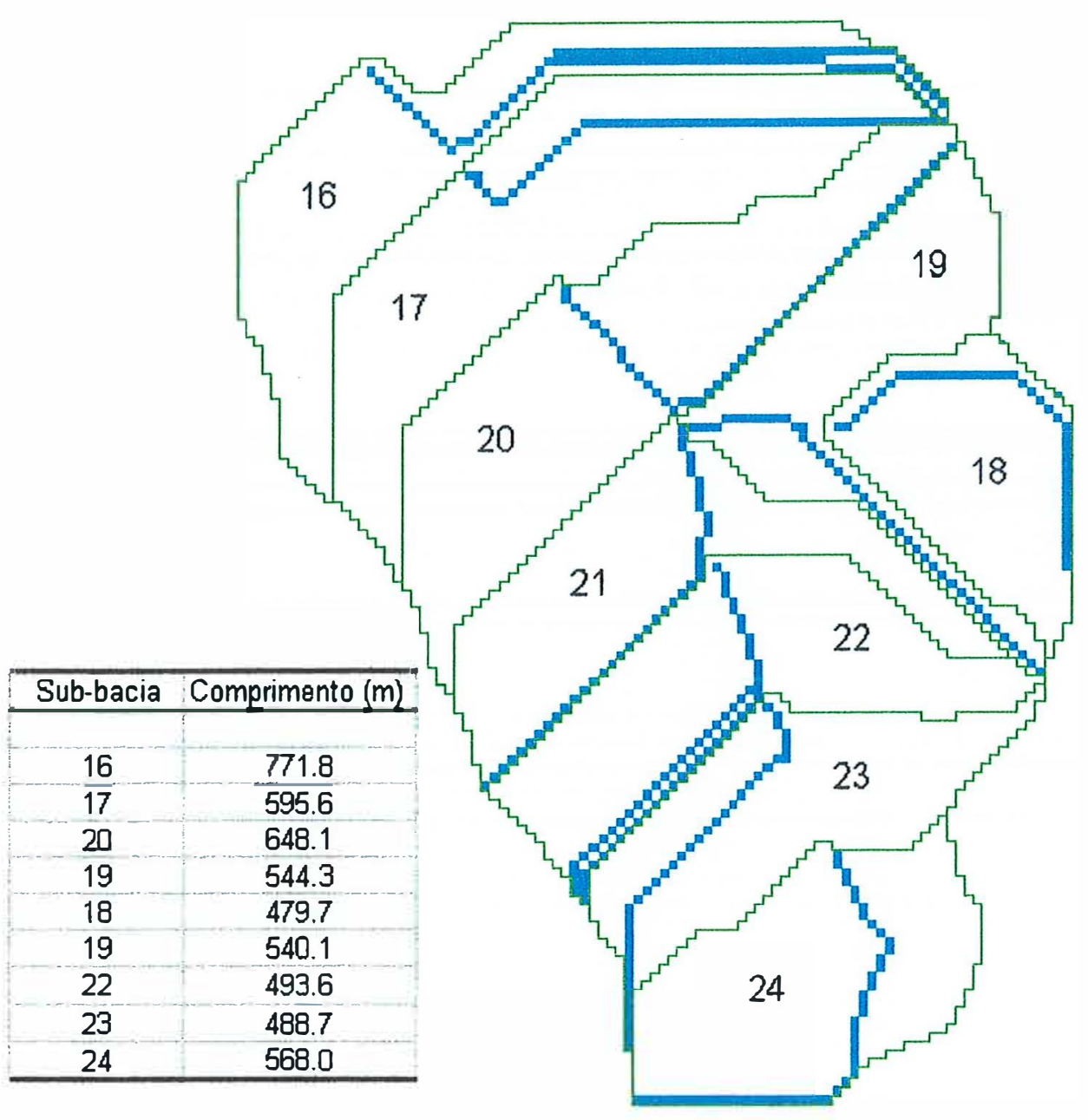

Figura 46 - Maior comprimento do caminho seguido pela água (superficie do terreno e canais) para cada sub-bacia (FLDS +FLUS).

\subsubsection{Cálculo dos parâmetros hidrológicos}

\subsection{Parâmetros de canais}

Os parâmetros de canais foram adicionados automaticamente à tabela de atributos de canais. Na Tabela 14 é apresentado um resumo dessa tabela de atributos. $\mathrm{O}$ campo comprimento refere-se aos comprimentos dos trechos de canais localizados dentro de cada sub-bacia. 
Tabela 14 - Parâmetros de canais retirados da tabela de atributos de canais, com os valores calculados pelo CRWR-PREPRO, com exceção das velocidades, que foram valores fornecidos.

\begin{tabular}{cccccc}
\hline ID & $\begin{array}{c}\text { Comprimento } \\
(\mathrm{m})\end{array}$ & $\begin{array}{c}\mathrm{V} \\
(\mathrm{m} / \mathrm{s})\end{array}$ & $\begin{array}{c}\text { Método de } \\
\text { propagação. }\end{array}$ & $\begin{array}{c}\text { Tempo de } \\
\text { retardamento } \\
(\mathrm{min})\end{array}$ & $\begin{array}{c}\text { Intervalo dos } \\
\text { cálculos } \\
(\mathrm{min})\end{array}$ \\
\hline 9 & 165,6 & 0,53 & Retard. Puro & 5,2 & 10 \\
14 & 177,3 & 0,55 & Retard. Puro & 5,3 & 10 \\
15 & 218,0 & 0,53 & Retard. Puro & 6,8 & 10 \\
10 & 186,6 & 1,20 & Retard. Puro & 2,9 & 10 \\
11 & 180,7 & 0,97 & Retard. Puro & 3,1 & 10 \\
12 & 184,9 & 0,90 & Retard. Puro & 3,4 & 10 \\
13 & 196,0 & 0,89 & Retard. Puro & 3,7 & 10 \\
\hline
\end{tabular}

Os valores contidos nessa Tabela 14 foram utilizados em diversas simulações, independente das ocupações atribuídas para as sub-bacias, uma vez que existiu a suposição de que as mudanças da ocupação das sub-bacias não afetariam, significativamente, as condições de fluxo dos canais.

Cabe comentar que o Método de Muskingum é bastante indicado para o cálculo do tempo de retardamento nos canais, caso a bacia tenha canais com declividade de fundo aproximadamente paralela à superficie da água. Também, eles devem ser longos o suficiente para não apresentarem instabilidades numéricas (Fread, 1993). Como a microbacia é pequena e não produz armazenamentos consideráveis de água em sua rede de drenagem, o Método de Muskingum não pôde ser aplicado. Além disso, os tempos de percurso $(\mathrm{L} / \mathrm{V})$ das sub-bacias são menores do que o $\Delta \mathrm{t}$, sendo, portanto, mais adequado recorrer-se ao Método de Retardamento Puro ( Figura 24A). Assim, o Método de Retardamento Puro foi aplicado com a hidrógrafa sendo atrasada apenas em um determinado tempo, entre a entrada e a saída de cada canal, ou seja, com a translação de todas as suas ordenadas atrasadas em um determinado tempo, sem alteração de sua forma. Na verdade, esse método é um caso especial do Método de Muskingum ou mesmo do Método de Muskingum-Cunge, que levam em consideração, além do atraso, o armazenamento, isto é, efetua-se uma atenuação entre a entrada e a saída de um trecho 
de canal. Dessa forma, o parâmetro tempo de retardamento do método do retardamento puro equivale ao fator $\mathrm{K}$ ou tempo de fluxo do Método de Muskingum, calculado como a razão entre o comprimento e a velocidade $(\mathrm{L} / \mathrm{V})$.

A determinação do tempo de retardamento requisitou o cálculo da velocidade da água nos canais. Os dois métodos aplicados, o Upland Method (USDA, 1972) e o da Fórmula de Manning, proporcionaram resultados praticamente iguais, como é comprovado na Figura 47. Observe-se que a dispersão em torno da reta é baixa e a correlação pode ser considerada alta. Essa boa concordância ocorreu é decorrente do fato do Upland Method ser baseado no nomograma (Figura 6) apresentado pelo USDA (1972). E este nomograma é uma solução da Equação de Manning para diferentes valores de declividades, com a suposição de valores de $\mathrm{n}$ para as ocupações correspondentes.

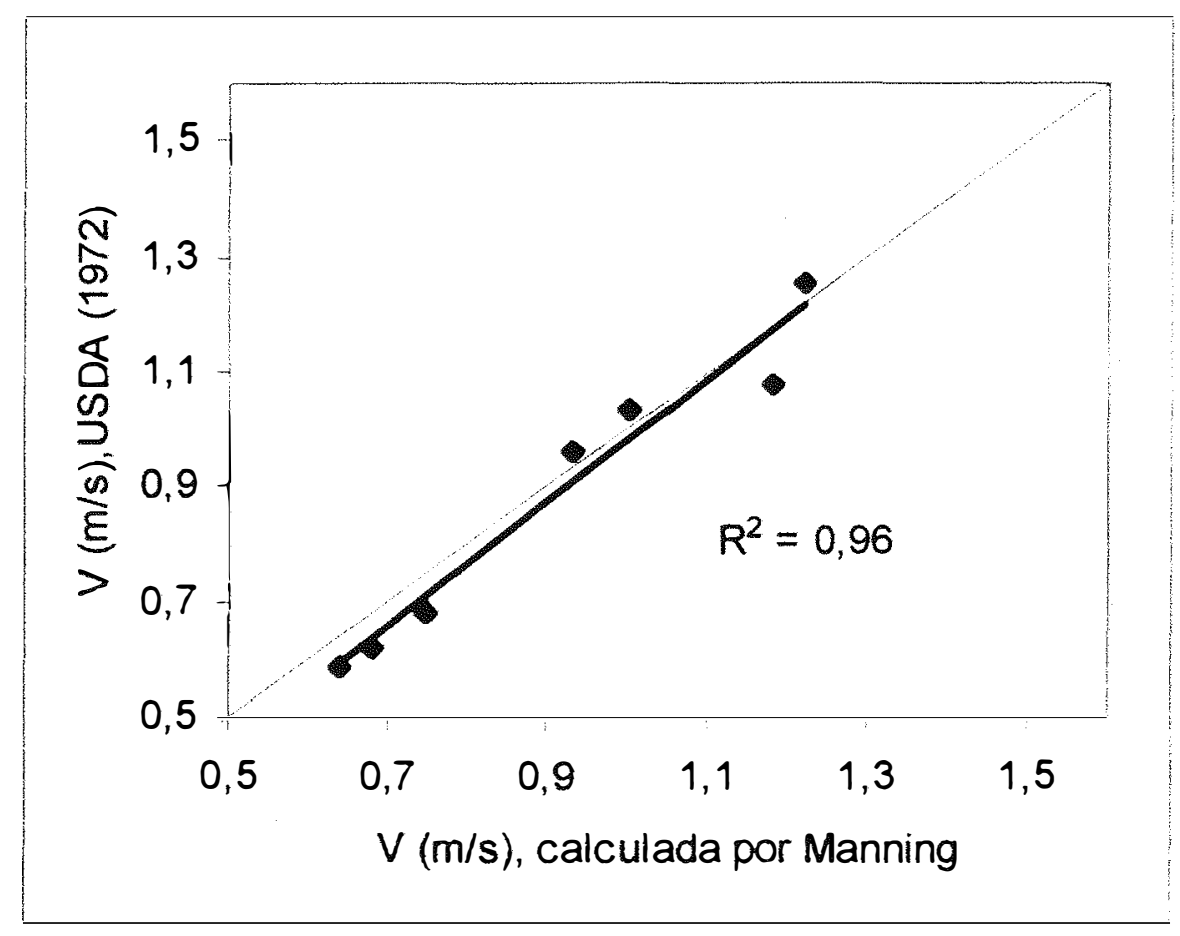

Figura 47 - Estimativa da velocidade da água nos canais pelo Upland Method (USDA, 1972) e pela Equação de Manning. 
A declividade para ambos os métodos e o perfil longitudinal dos canais são mostrados na Figura 48. A declividade média dos dois trechos de canais apresentados é igual a 4,6\%. Existem trechos mais planos na parte mais baixa e trechos mais declivosos na parte intermediária e final. A maior parte do perfil apresenta declividade suficiente para evitar armazenamentos consideráveis nos canais, justificando a aplicação da propagação pelo método do retardamento puro. A altitude média dos canais é de $815 \mathrm{~m}$.

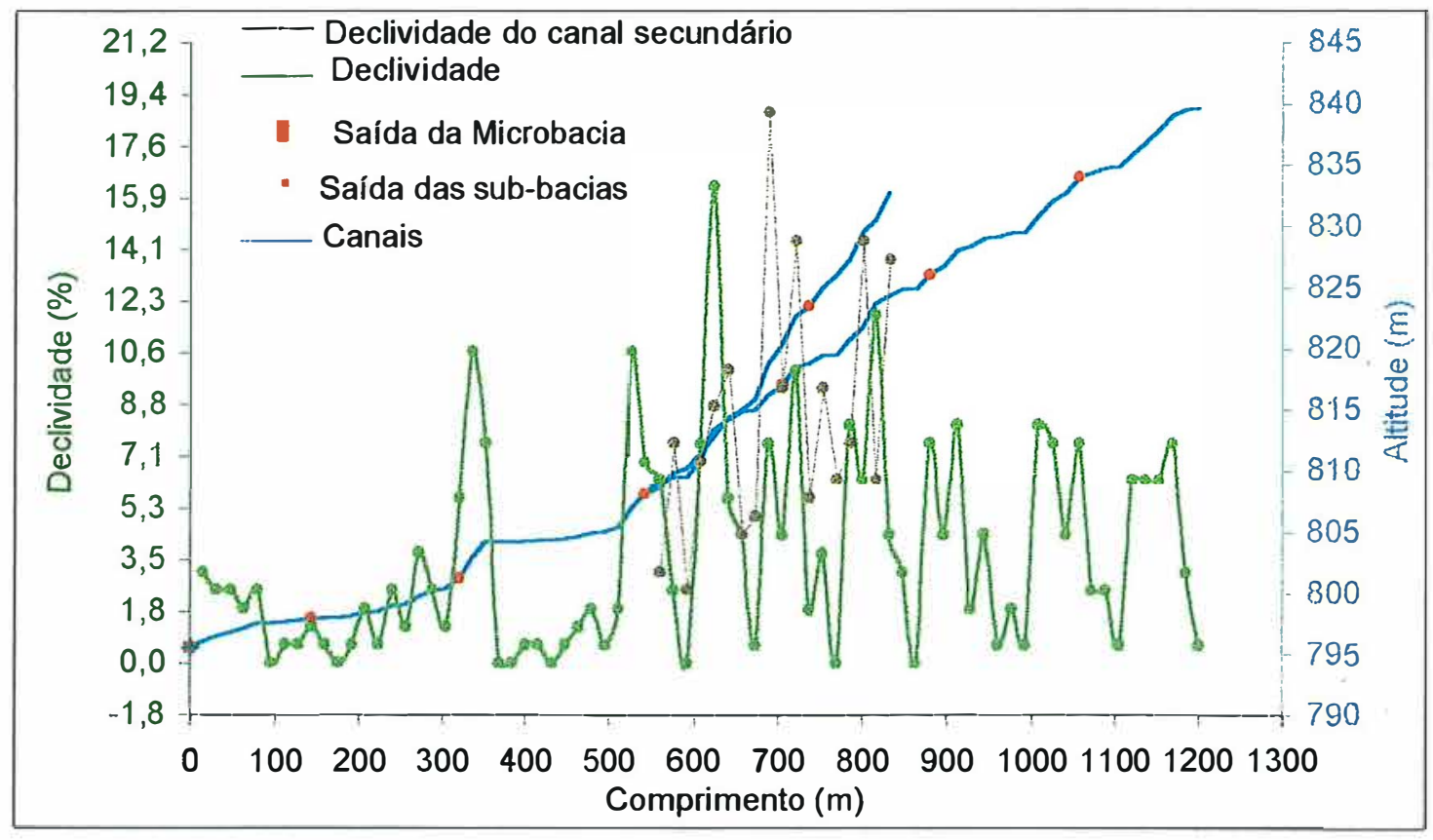

Figura 48 - Perfil longitudinal e declividade dos canais da Microbacia do Tinga.

\subsection{Parâmetros de bacias}

A Tabela 15 apresenta os parâmetros hidrológicos calculados pelo CRWR-PREPRO. Comparando-se essa tabela com a Tabela 14, nota-se que, apesar do número de sub-bacias delimitadas ser 9 , o número de trechos de canais foi 7 . Tal diferença é explicada pela adição de pontos de saída no final superior do trecho de canais nas sub-bacias 24 e 18. Além disso, o somatório das áreas das sub-bacias não 
Tabela 15 - Exemplo de parâmetros de sub-bacias retirados da tabela de atributos de sub-bacias, com os valores calculados pelo CRWR-PREPRO, considerando a Microbacia do Tinga coberta com eucalipto.

\begin{tabular}{ccccccccccc}
\hline ID & $\begin{array}{c}\text { Area } \\
\left(\mathrm{m}^{2}\right)\end{array}$ & $\begin{array}{c}\text { Área } \\
\left(\mathrm{km}^{2}\right)\end{array}$ & $\begin{array}{c}\text { Perim } \\
(\mathrm{m})\end{array}$ & $\begin{array}{c}\text { Maior } \\
\text { trajetória } \\
(\mathrm{m})\end{array}$ & $\begin{array}{c}\text { Declivi- } \\
\text { dade } \\
(\mathrm{m} / \mathrm{m})\end{array}$ & $\begin{array}{c}\text { Mét. de. } \\
\text { transfor } \\
\text { macóes. }\end{array}$ & $\begin{array}{c}\text { Met.de } \\
\text { det das. } \\
\text { perdas }\end{array}$ & CN & $\begin{array}{c}\text { TI } \\
(\mathrm{min})\end{array}$ & $\begin{array}{c}\text { Met.de } \\
\text { det de } \\
\text { TI }\end{array}$ \\
\hline 16 & 97400 & 0,097 & 3160 & 771,8 & 0,055 & SCS & SCS & 20,8 & 91,6 & SCS \\
17 & 128000 & 0,128 & 2560 & 595,5 & 0,069 & SCS & SCS & 21,0 & 65,9 & SCS \\
18 & 60200 & 0,060 & 1300 & 479,7 & 0,051 & SCS & SCS & 24,6 & 56,1 & SCS \\
19 & 71000 & 0,071 & 2460 & 544,2 & 0,074 & SCS & SCS & 22,9 & 54,9 & SCS \\
20 & 124100 & 0,124 & 2580 & 648,1 & 0,055 & SCS & SCS & 20,0 & 82,4 & SCS \\
21 & 81300 & 0,081 & 2360 & 540,1 & 0,069 & SCS & SCS & 21,5 & 59,7 & SCS \\
22 & 91800 & 0,092 & 2120 & 493,5 & 0,059 & SCS & SCS & 24,1 & 54,4 & SCS \\
23 & 77200 & 0,077 & 1960 & 488,7 & 0,050 & SCS & SCS & 24,0 & 58,8 & SCS \\
24 & 86900 & 0,087 & 1480 & 567,9 & 0,030 & SCS & SCS & 29,1 & 71,7 & SCS \\
\hline
\end{tabular}

coincide com a área da Microbacia do Tinga. Essa discrepância decorre, provavelmente, do tamanho reduzido das sub-bacias. Afinal, há uma razão inversa entre o tamanho da sub-bacia e a quantidade de erros. Também, o tamanho de célula $10 \mathrm{~m} \times 10 \mathrm{~m}$ pode ter contribuído para essa diferença de área, uma vez que quanto menor a resolução, maiores os erros.

O campo declividade refere-se as declividades das maiores trajetórias seguida pela água até alcançar a saida das sub-bacias e não a média de declividade das sub-bacias. O valor do número da curva $(\mathrm{CN})$ é a médio para cada sub-bacia. Já, o tempo de retardamento ( $\mathrm{Tl}$ ) foi calculado pelo método do $\mathrm{CN}$.

No ambiente de modelagem do HEC-HMS, o tempo de retardamento é um parâmetro que deve ser fornecido. Cabe recordar que, segundo Ponce (1989), na aplicação do método do SCS, recomenda-se que os valores de $\mathrm{CN}$ não sejam menores que 50 ou maiores que 95 ou que as bacias não sejam menores que $8 \mathrm{~km}^{2}$. Quando o caso estudado não se encaixa nessa recomendação, o método mais indicado para a determinação do tempo de retardamento é o da velocidade. 
Na Figura 49, é apresentada uma comparação entre as estimativas do tempo de retardamento obtidas pelo Método da Velocidade aplicado conforme USDA (1972) e o Método do CN aplicado conforme Chow et al. (1988). Os valores representados nos gráficos de dispersão correspondem a cada uma das sub-bacias. $\mathrm{O}$ Método do $\mathrm{CN}$, aplicado com valores de $\mathrm{CN}$ numa ocupação semelhante à usada no método da velocidade, resultou em valores de tempo de retardamento maiores. Esses resultados são concordantes com o USDA (1972), que recomenda o Método da Velocidade para áreas onde o escoamento superficial é predominante e adverte que sua aplicação pode resultar em tempos de concentração muito curtos em áreas onde os fluxos internos e subterrâneos forem os predominantes, como é o caso da Microbacia do Tinga.
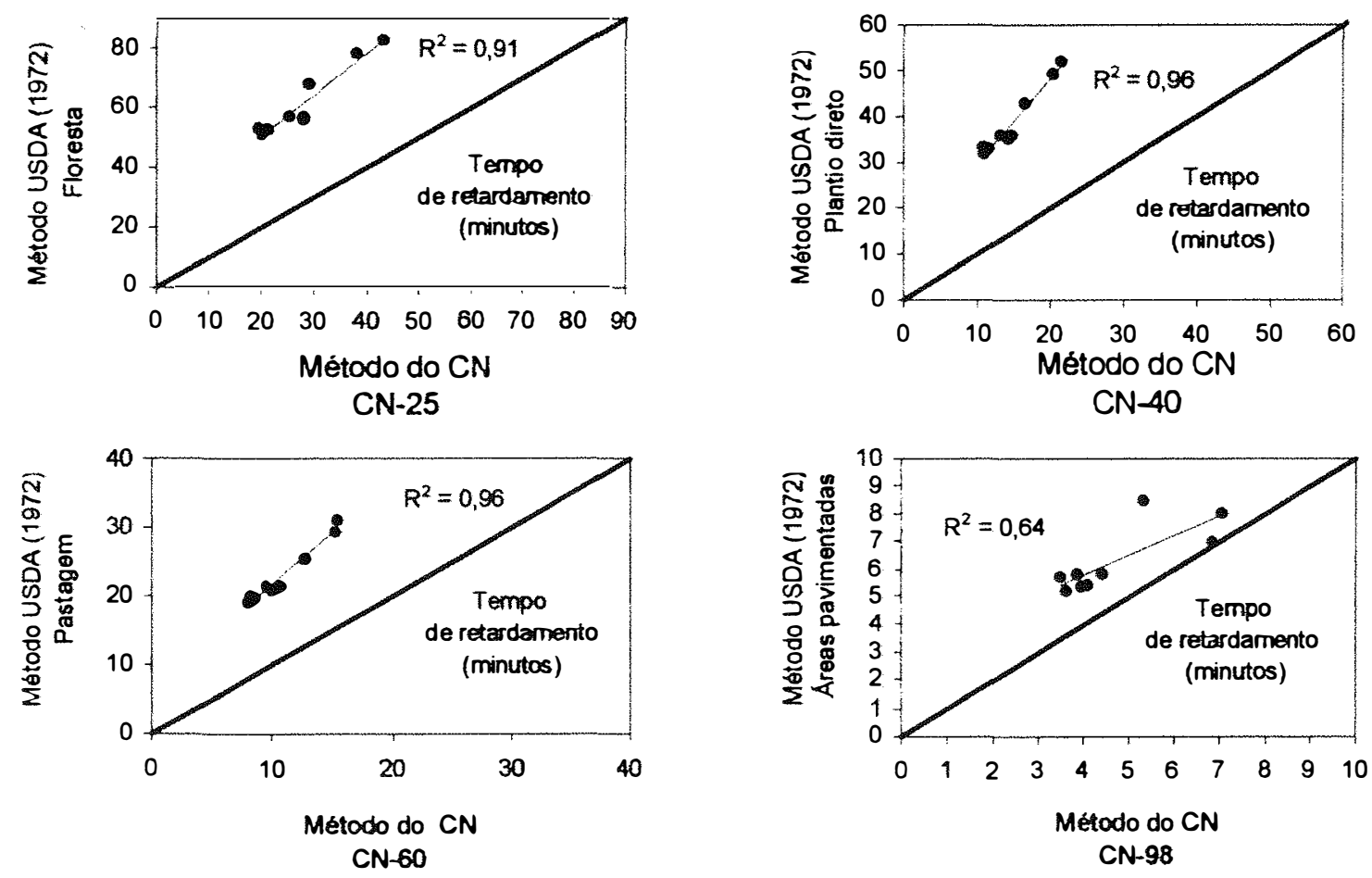

Figura 49 - Gráfico de dispersão entre as estimativas do tempo de retardamento pelo Método do CN (conforme Chow et al., 1988) e pelo Método da Velocidade (USDA, 1972). 
A falta de concordância entre os dois métodos também pode ter sido causada pela inadequada atribuição de valores para as ocupações usadas no Método do USDA e os valores de $\mathrm{CN}$ correspondentes. Um outro ponto importante a ser considerado é que as sub-bacias não apresentam conformação natural, pois foram delimitadas pela inclusão de pontos de saída adicionados. Essa delimitação artificial afetou a forma da bacia.

Vale comentar que, a despeito dos métodos mencionados anteriormente levarem em consideração apenas as características da bacia, ocupação e declividade, outros fatores podem afetar o tempo de retardamento. Por exemplo, a variação de intensidade no tempo e espaço das características das chuvas e, indiretamente, a área e a forma das bacias, umidade antecedente e condições de infiltração (Singh, 1988). Porém, existem controvérsias. Ramser (1927), Ragan \& Duru (1972), Agiralioglu \& Singh (1981) e Singh \& Agiralioglu (1982) não encontraram relação significativa entre a umidade antecedente - representada pelo total de chuva nas 48 horas antecedentes - e o tempo de retardamento, nem entre esse tempo retardamento e a intensidade da chuva. Concluíram que, para a determinação dos tempos de retardamento, devem ser especialmente usados dados de precipitação e vazão provenientes de eventos de chuva maiores. Caso esses dados não existam, observaram que as melhores variáveis preditoras são a largura média da bacia - que é a área da bacia dividida pelo comprimento, a declividade e o coeficiente de armazenamento $S$, usado no método do número da curva do SCS.

Ainda, alguns desses trabalhos mostraram a influência da forma da bacia sobre o tempo de retardamento. No presente trabalho, como as sub-bacias não possuiam conformação natural (eram mais estreitas e com caminhos seguidos pela água mais longos), provavelmente essa característica afetou mais um método do que outro, o que deve ter contribuído para as diferenças constatadas. Por exemplo, como o Método do CN é recomendado para bacias florestadas, que apresentam tempos de recessão maiores, os tempos de retardamento obtidos na sua aplicação foram maiores. 
Cabe ressaltar, mais uma vez, que os valores utilizados para comparação são estimativas e não dados de chuva e vazão observados, que são mais recomendáveis. Para completar, melhores resultados são obtidos quando recorre-se a eventos de chuva maiores. Afinal, nesses tipos, as condições de equilíbrio dinâmico se aproximam e, dessa forma, melhores estimativas podem ser obtidas. Simas (1996) observou que o tempo de retardamento varia consideravelmente entre diversos eventos de chuva, mas são mais estáveis para eventos de chuvas maiores.

Como os dados de vazão estavam disponíveis somente para a saída da bacia, eles servem unicamente para a determinação do tempo de retardamento para a área de estudo como um todo. Portanto, para as sub-bacias, as calibrações foram inviáveis não restando outra opção, apenas estimativas.

ASCE (1996) recomenda o Método do CN para a determinação do tempo de retardamento em bacias com qualquer uma das seguintes condições: densamente florestadas, com canais declivosos, grande fluxo subsuperficial e interno, cobertas por pastagens e com superficies do terreno suaves. Algumas delas estão na Microbacia do Tinga. Considerando isso e também o melhor ajuste entre as hidrógrafas simuladadas e observadas proporcionado pelo Método do $\mathrm{CN}$, esse foi o escolhido tanto para o cálculo do tempo de retardamento como para as simulações. Ademais, como os valores de $\mathrm{CN}$ selecionados foram estudados por Setzer \& Porto (1979) para as condições de São Paulo, esses valores são mais confiáveis.

Com relação ao Método da Velocidade, as relações empíricas, usadas para determinar a velocidade da água, são cercadas por incertezas quanto a sua adequabilidade. No entanto, por ser um método considerado parcialmente fundamentado nos processos físicos (tenta simular o tempo de retardamento baseando-se na representação dos processos físicos envolvidos) seus resultados seriam mais confiáveis, caso fossem obtidas velocidades na superficie do terreno e canais mais adequadas. 


\subsubsection{Elaboração do diagrama esquemático e preparação do arquivo de entrada no HEC-HMS}

O diagrama esquemático pode ser visualizado na Figura 50. Nesse diagrama, os elementos hidrológicos interconectados estão representados na forma de uma cobertura esquemática simbólica da área de estudo. A conectividade entre as subbacias foi determinada em função dos centróides dos polígonos. Já, a conectividade entre canais consubstanciou-se pela união da saída de um trecho superior com a de um outro inferior.

Uma vez que a Microbacia do Tinga é pequena, decidiu-se imprimir e apresentar o arquivo de bacia, ou melhor, o arquivo de entrada do HEC-HMS por completo (Tabela 16). Observa-se que, para as sub-bacias, os parâmetros apresentados estão relacionados ao posicionamento geográfico do centróide, à área, à posição do elemento à jusante (em qual elemento ocorrerá o escoamento), ao método de cálculo para as perdas iniciais, ao número da curva, às abstrações iniciais, ao método de transformação da chuva em escoamento e ao tempo de retardamento. Para os trechos de canais são informados o posicionamento geográfico do nó inicial e final, qual o elemento à jusante onde ocorrerá o escoamento, o método de estimativa do tempo de retardamento nos canais e o seu respectivo valor.

Esse arquivo, por estar no formato ASCII, ocupou pouca memória no computador (6 Kbytes), podendo, por exemplo, em outras situações, armazenar facilmente todo o sistema hidrológico de um município. Cabe destacar que as informações contidas nesse arquivo, podem ser mudadas no HEC-HMS conforme a necessidade do usuário. 


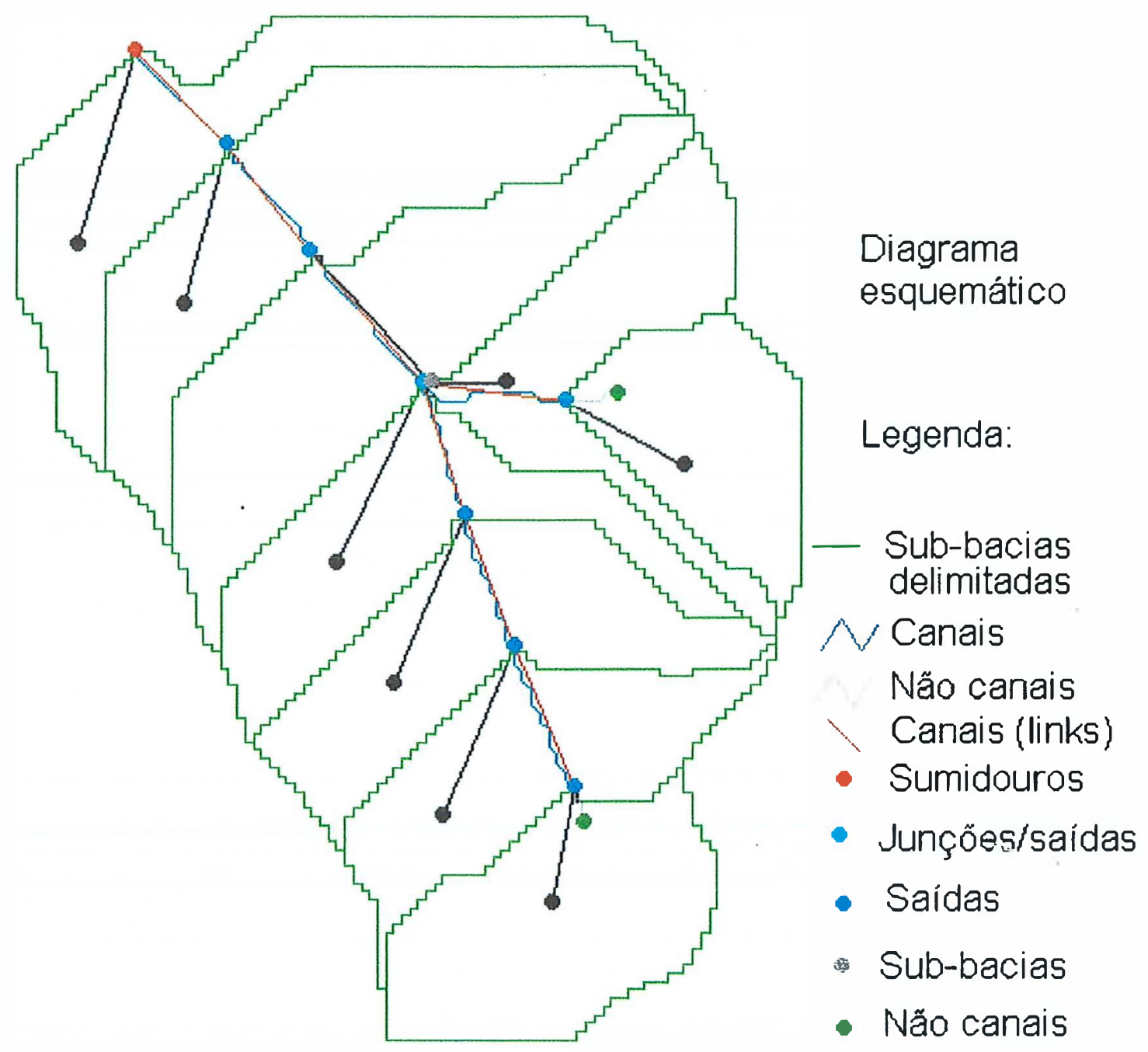

Figura 50 - Diagrama esquemático feito pelo CRWR-PREPRO para a Microbacia do Tinga. 
Tabela 16 - continuação.

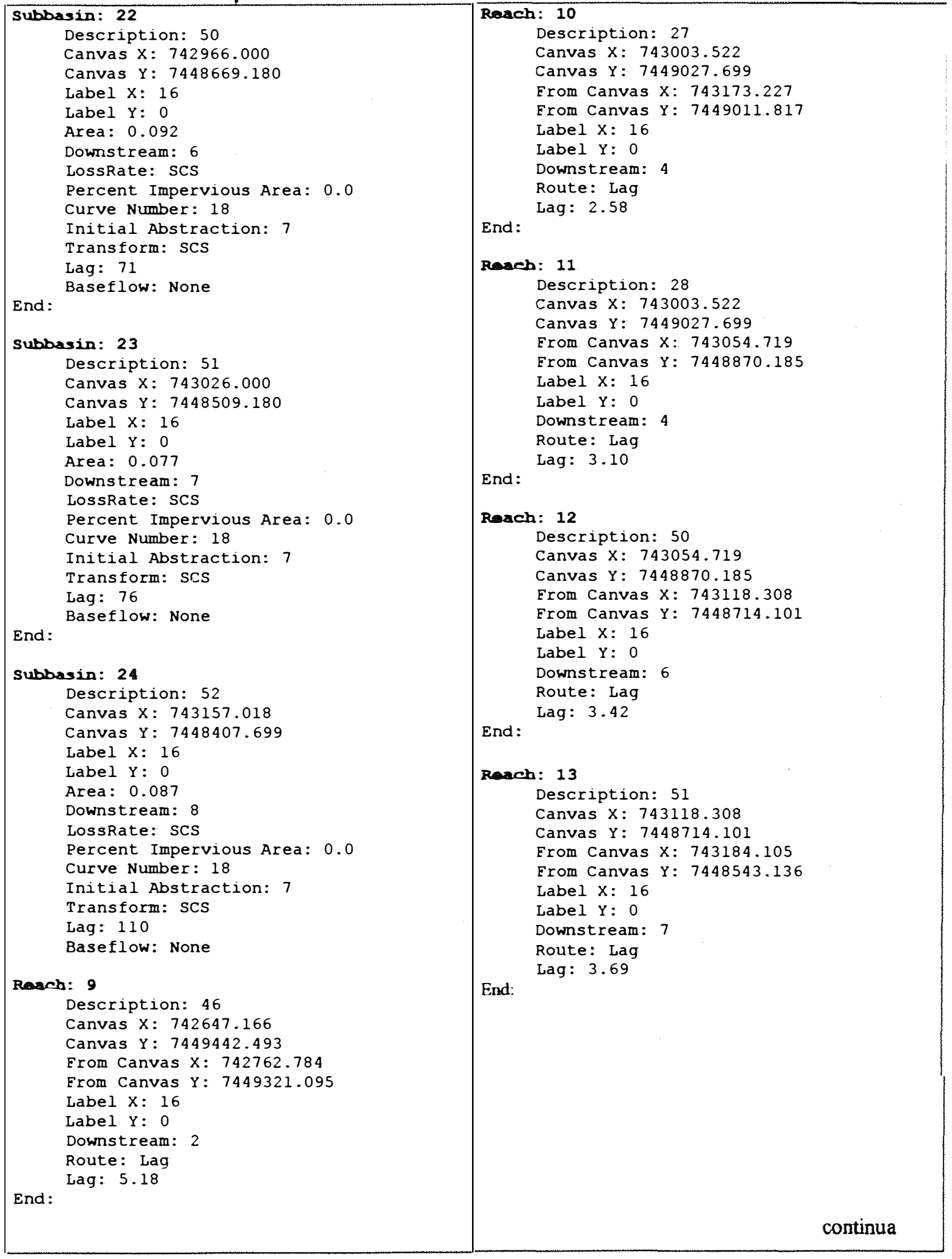


Tabela 16 - continuação.

Raach: 14

Description: 47

Canvas $\mathrm{X}$ : 742762.784

Canvas $Y$ : 7449321.095

Erom Canvas $X: 742863.949$

From Canvas $Y$ : 7449191.025

Label $X: 16$

Label $Y: 0$

Downstream: 1

Route: Lag

Lag: 5.33

End:

Reach: 15

Description: 48

Canvas $X: 742863.949$

Canvas $Y: 7449191.025$

Erom Canvas $X: 743003.522$

From Canvas $Y$ : 7449027.699

Label $X: 16$

Label $Y: 0$

Downstream: 3

Route: Lag

Lag: 6.83

End:

Junction: 1

Canvas $X: 742762.784$

Canvas $Y: 7449321.095$

Label $X: 16$

Label $Y: 0$

Downstream: 9

End:

ranction: 3

Canvas $X: 742863.949$

Canvas $Y$ : 7449191.025

Label $X: 16$

Label $Y$ : 0

End :

Downstream: 14

Junction: 4

Canvas $X: 743003.522$

Canvas $Y: 7449027.699$

Label $X: 16$

Label $Y:-1$

Downstream: 15
Junction: 5

Canvas $\mathrm{X}: 743173.227$

Canvas $Y: 7449011.817$

Label $X: 16$

Label $Y$ : 0

Downstream: 10 End:

ruction: 6

Canvas $\mathrm{X}: 743054.719$

Canvas $Y: 7448870.185$

Label $X: 16$

Label $Y$ : 0

Downstream: 11

End :

runction: 7

Canvas $X: 743118.308$

Canvas $Y$ : 7448714.101

Label X: 16

Label $Y: 0$

Downstream: 12

End :

runction: 8

Canvas $X: 743184.105$

Canvas $Y$ : 7448543.136

Label X: 16

Label $Y: 0$

Downstream: 13

End:

sink: 2

Canvas $X: 742647.166$

Canvas $Y: 7449442.493$

Label $X: 16$

Label $Y$ : 0

End:

End: 


\subsection{Simulação do escoamento com dados observados de chuva, vazão e ocupação atual}

\subsubsection{Reconstrução do arquivo de bacia no HEC-HMS}

O modelo de bacia reconstruído no HEC-HMS, chamado modelo esquemático, é apresentado na Figura 51. Os elementos hidrológicos presentes nesse modelo são: as junções (enumeradas de 1 a 8), os trechos de canais (de 9 a 15) e as subbacias (de 16 a 24). O elemento 2 , apesar de estar especificado como ponto de saída, também é considerado uma junção.

No presente estudo, a divisão da área em sub-bacias, visando a definição de cenários mais discretizados, comprovou ser uma forma adequada para favorecer a determinação de parâmetros espacialmente variáveis. Além disso, a divisão arbitrária da Microbacia do Tinga em sub-bacias merece outras considerações. As principais estão relacionadas às implicações dessa divisão e se os métodos empíricos seriam adequadamente aplicados, uma vez que os mesmos foram desenvolvidos para bacias naturais. É pertinente, então, mencionar que o USDA (1972) recomenda a divisão das bacias em áreas com formas homogêneas. Afinal, muitas variáveis estão integradas na forma da hidrógrafa. Além disso, conforme o USDA (1986), essa divisão viabiliza o uso do Método da Hidrógrafa Tabular. Tal procedimento é indicado para condições de produção de escoamento em bacias não uniformes. Nesse caso, ela é dividida em áreas menores até que o volume produrido nessas subdivisões seja aproximadamente constante e não mude com subdivisões adicionais.

A Hidrógrafa Unitária Adimensional do SCS exige que a bacia seja uniforme, caso contrário proporciona grandes diferenças nos tempos de concentração de cada área. A Hidrógrafa Unitária Adimensional do SCS apresenta um único parâmetro, o tempo de retardamento, que, geralmente, é estimado a partir do tempo de concentração ou também tempo de concentração ponderado. Assim, se esse tempo for determinado em bacias desuniformes, consideráveis diferenças podem ocorrer na forma das hidrógrafas geradas. 


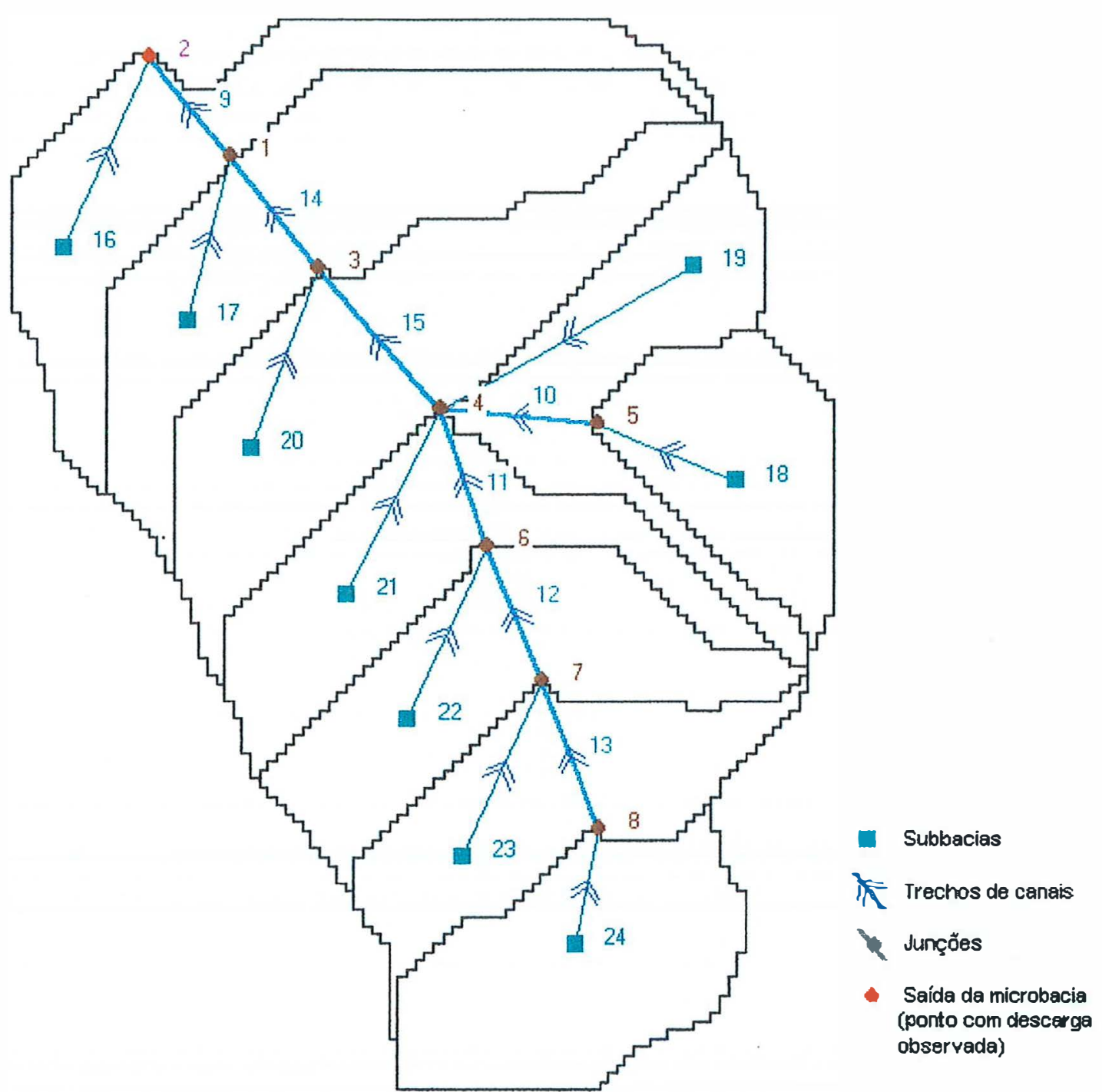

Figura 51 - Modelo esquemático da Microbacia do Tinga reconstruído no HEC-HMS.

De acordo com o USDA (1972), quando não existir homogeneidade quanto à forma das áreas contribuintes de uma bacia, é necessário o desenvolvimento de duas hidrógrafas unitárias, uma para cada área. Posteriormente, as hidrógrafas de cada uma delas são combinadas no ponto comum de descarga para formar uma hidrógrafa composta. 
Especificamente na divisão efetuada na Microbacia do Tinga, as subbacias 18 e 24 apresentam fonmas naturais homogêneas. Entretanto, as outras sub-bacias não são uniformes, pois suas áreas de drenagem poderiam ser consideradas como de duas sub-bacias separadamente. Por outro lado, como o trecho de canal está localizado na parte intermediária das duas sub-áreas (Figura 51), o comprimento e tempo da maior trajetória e, conseqüentemente, o tempo de retardamento são semelhantes para as duas áreas. Com tempos de retardamento semelhantes, ambas as porções das sub-bacias podem ser consideradas globalmente como uma sub-bacia. Cabe lembrar que o tempo de retardamento, juntamente a hidrógrafa unitária adimensional, é responsável pela forma das hidrógrafas geradas. Considerando que as duas áreas das sub-bacias tenham tempos de retardamento semelhantes, as hidrógrafas geradas serão também similares, independentemente de serem computadas de forma composta ou não. Isso não aconteceria caso os tempos de retardamento fossem diferentes. Aí sim, a composição das hidrógrafas seria vantajosa.

\subsubsection{Caracterização dos eventos de chuva e do escoamento direto}

Os eventos de chuva tiveram precipitação média de $37,11 \mathrm{~mm}$ e 54,37 mm de precipitação média nos 5 dias antecedentes aos eventos, conforme a Figura 52. Nesses eventos, o escoamento direto médio foi de $0,82 \mathrm{~mm}$, que representa $2,20 \%$ da precipitação total. Para possibilitar melhores comparações, é apresentada também a quantidade média de precipitação total necessária para gerar $1 \mathrm{~mm}$ de chuva. Esses dados mostram que a área de estudo tem baixo potencial de produção de escoamento direto, o que poderia ser presumido devido às características dos solos e ocupação.

Cabe recordar que a condutividade hidráulica dos solos, com transição difusa, da área de estudo é muito alta, portanto, raramente a capacidade de infiltração é menor do que a intensidade das chuvas. Além disso, as condições de ocupação da Microbacia do Tinga, com intensa regeneração de espécies nativas, favorecem a estabilidade dos agregados do solo, caracteristica fundamental para a não ocorrência de 


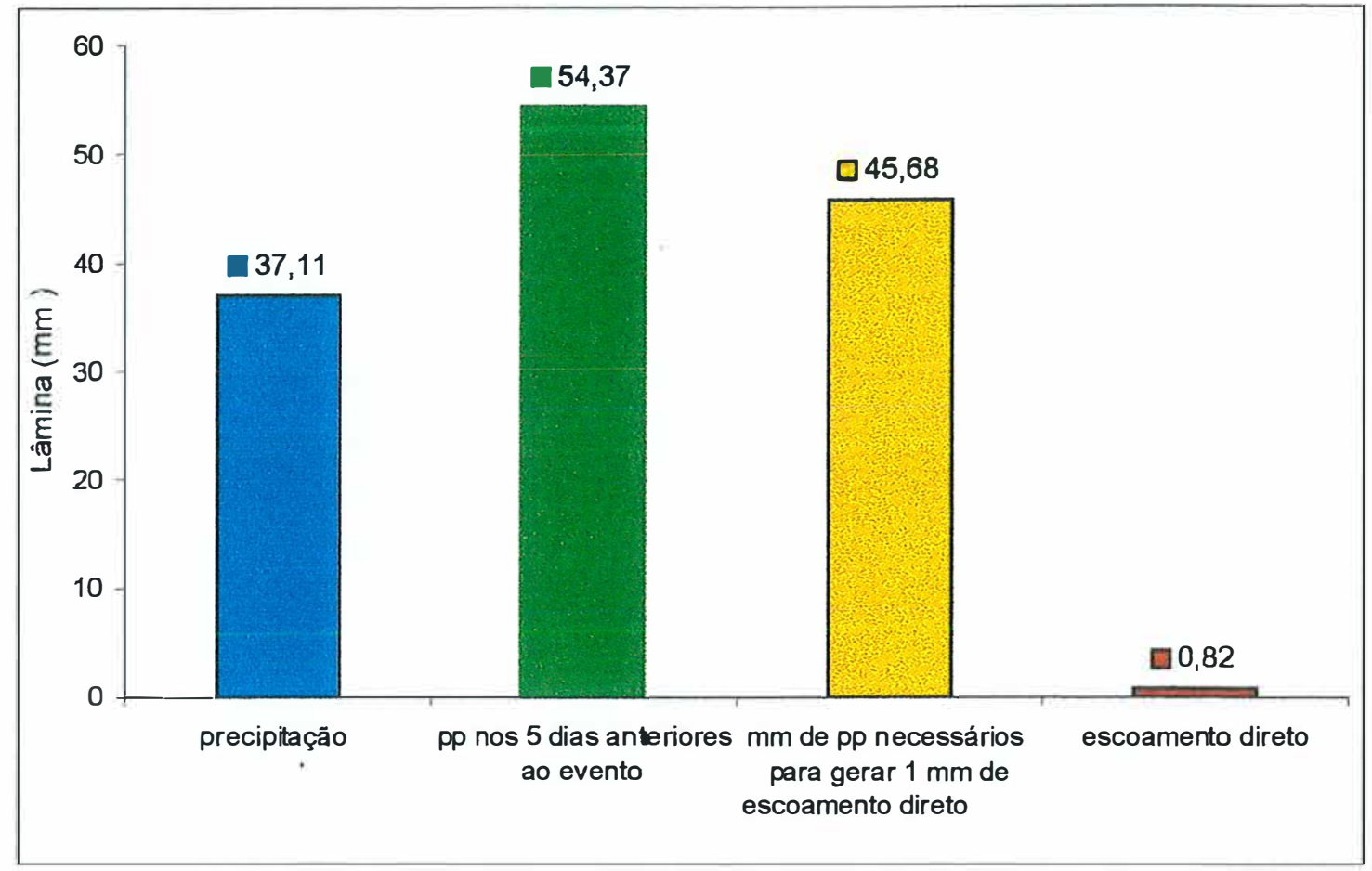

Figura 52 - Algumas características médias dos 14 eventos selecionados no período jan/96 a fev/98.

selamento superficial. Também, a presença de serrapilheira, protegendo contra o impacto direto das gotas, evita a destruição dos agregados e o conseqüente selamento superficial. A rugosidade do terreno em florestas, sendo maior, retarda o escoamento, permitindo maior infiltração. Tudo isso, aliado ao fato de que o eucalipto apresenta altas taxas de transpiração, favorecem o pequeno escoamento da Microbacia do Tinga.

Tal comportamento foi confirmado por Cicco \& Arcova (1998), que compararam o fator de resposta (escoamento direto/precipitação) da Microbacia do Tinga com o de 15 microbacias dos E.U.A. e 4 do Brasil. No estudo, a Microbacia do Tinga foi a que apresentou o menor fator de resposta.

Comparando os dados de transformação de chuva em escoamento direto obtidos por Scardua (1994) na Microbacia do Tinga com os estudados nesse trabalho (Figura 53), é possível notar que houve uma semelhança considerável entre eles. 


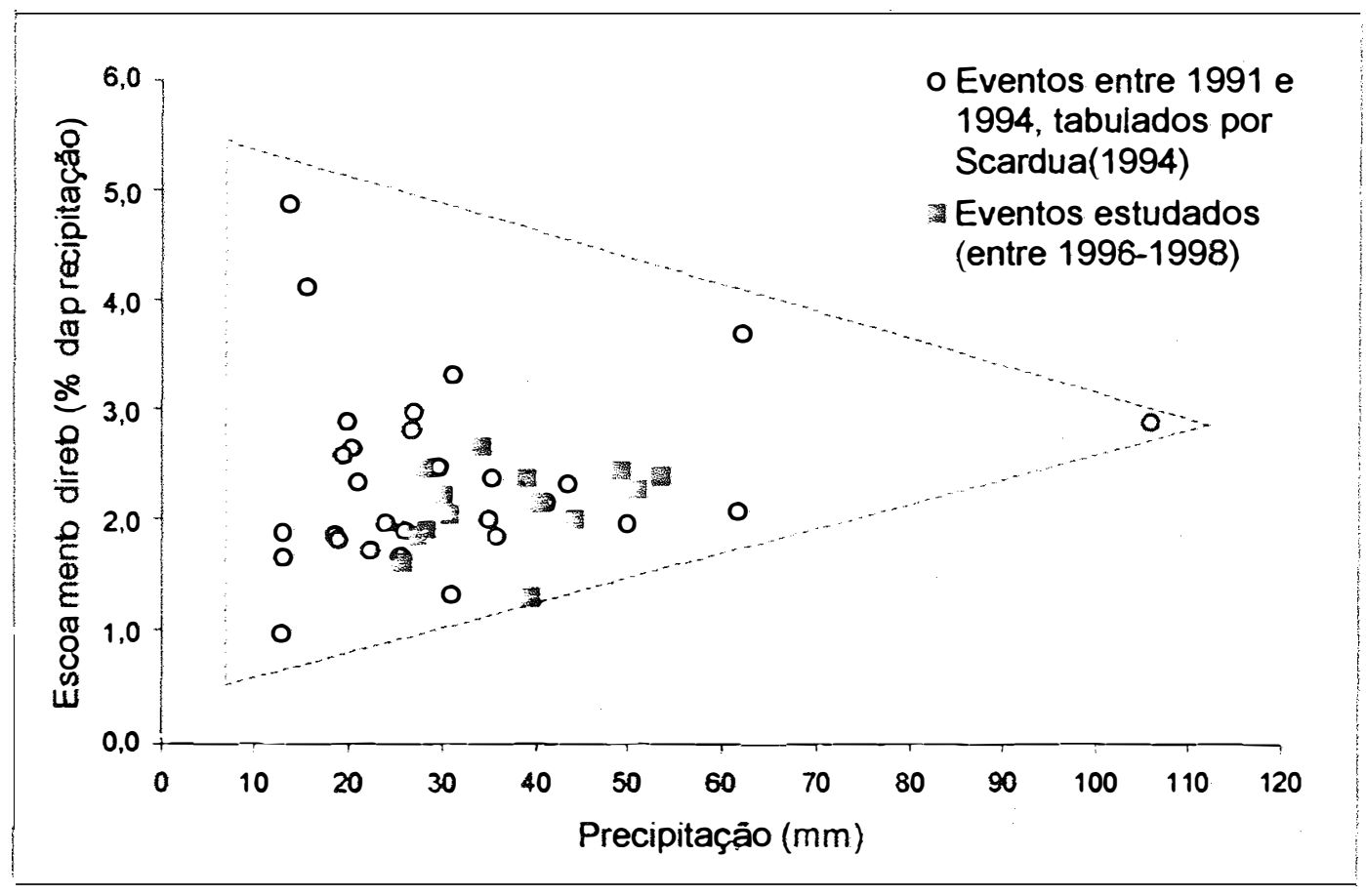

Figura 53 - Porcentagem da precipitação total transformada em escoamento direto.

Scardua (1994) obteve uma média de $2,43 \%$ para 29 eventos, tanto em época seca como úmida e com chuvas antecedentes aos eventos ou não. Ao se considerar apenas os eventos entre 35 e $45 \mathrm{~mm}$, faixa escolhida para o presente estudo, a média calculada pelo autor foi de $2,10 \%$, praticamente igual a $2,20 \%$, encontrada nesse trabalho.

Pela Figura 54, percebe-se que, além do total de precipitação de cada evento, o efeito da precipitação dos 5 dias antecedentes sobre a produção de escoamento direto é dispersa. Ao contrário do que seria o esperado. O gráfico de dispersão e a equação de regressão são apresentados na Figura 55. A equação obtida tem coeficiente angular de 0,0272. Esse valor é praticamente igual a 0,0261, alcançado por Scardua (1994). 


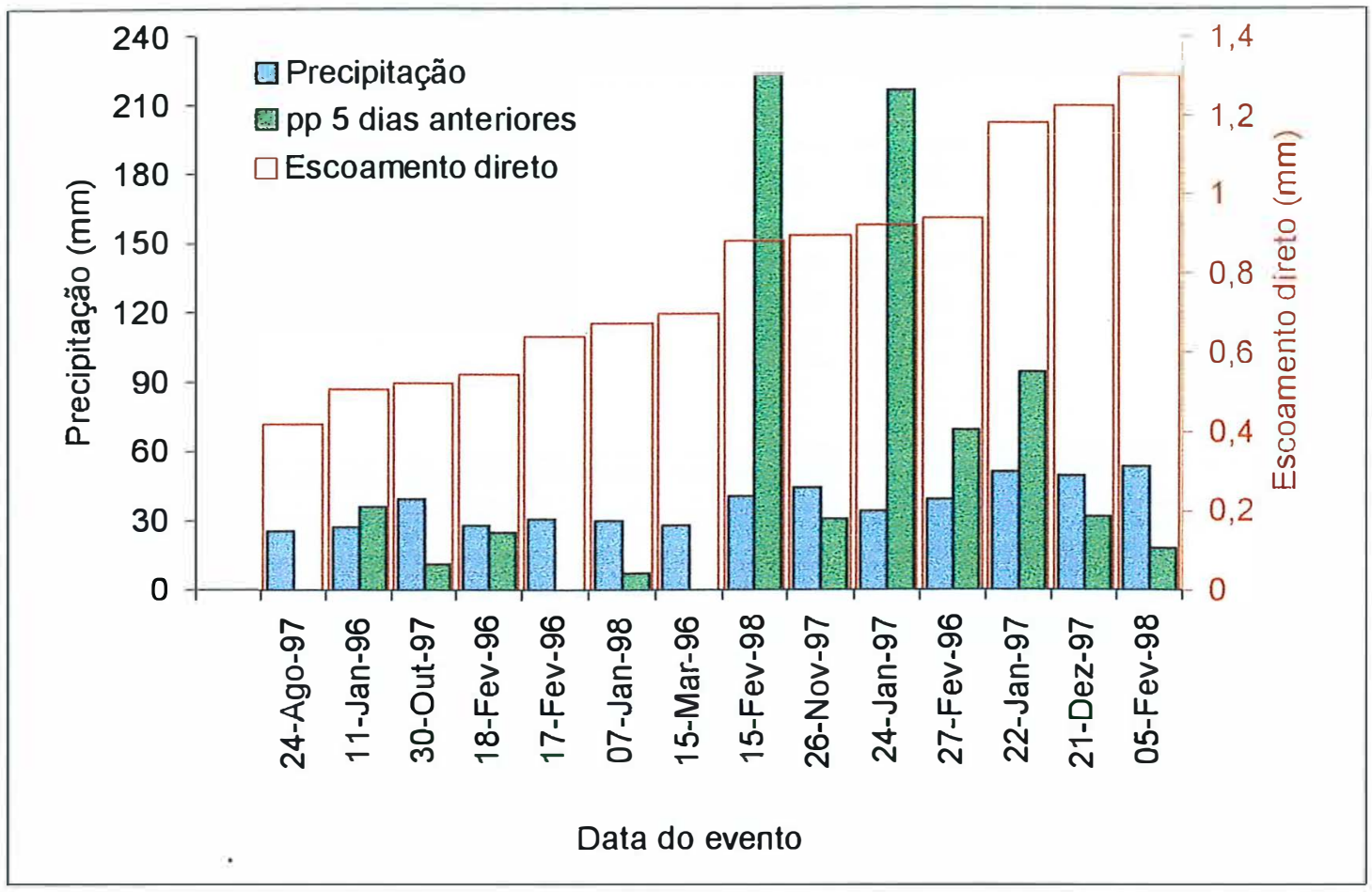

Figura 54 - Caracterização dos eventos de chuva-vazão estudados.

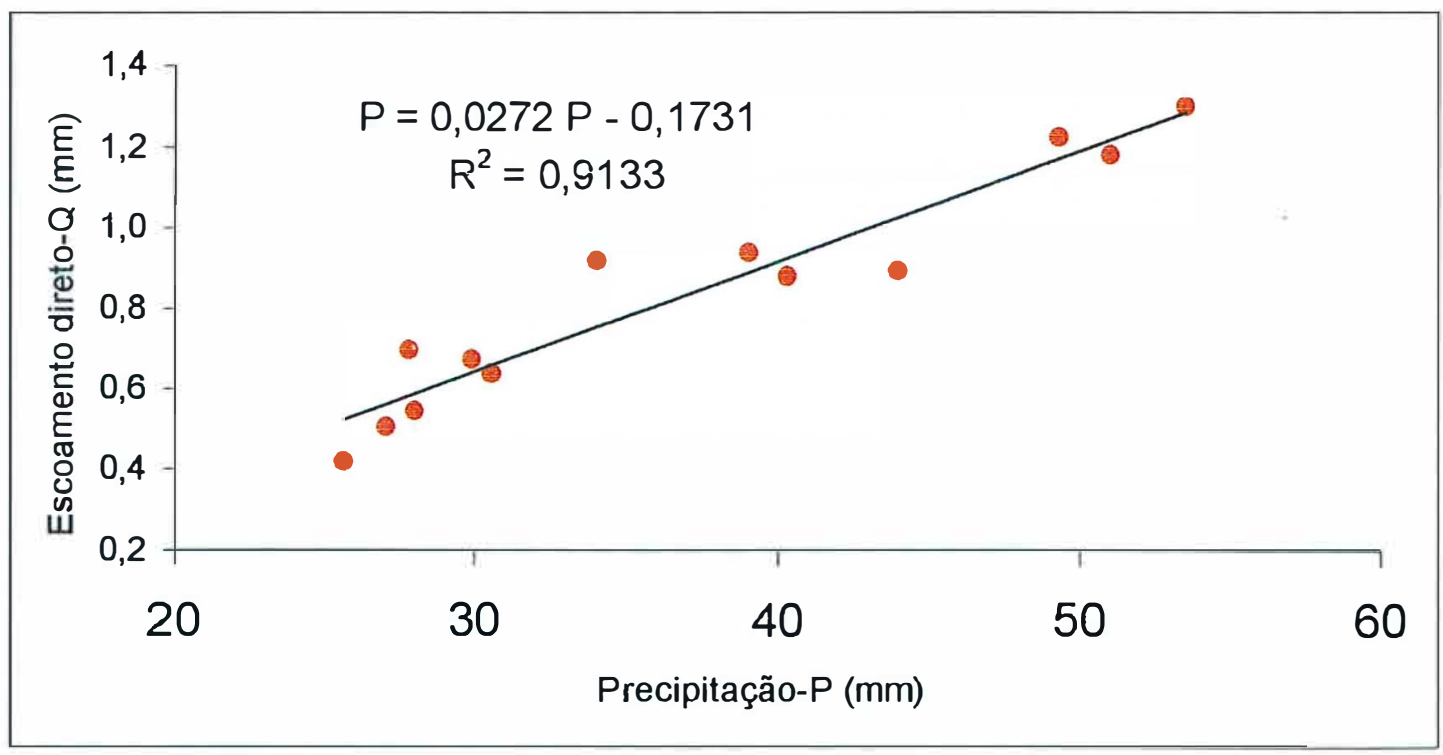

Figura 55 - Regressão entre a precipitação e o escoamento direto, utilizando-se eventos entre jan/96 e fev/98. 
A análise de regressão múltipla efetuada, tendo como variável dependente o escoamento superficial e como variáveis independentes o total de precipitação e a precipitação nos cinco dias antecedentes, mostrou efeito significativo apenas para a variável precipitação total $(\mathrm{P}<0,001)$. Para a precipitação antecedente, o efeito não foi significativo, porém, a probabilidade de 0,37 , indica que, caso fossem utilizados mais eventos, possivelmente, seu efeito teria sido significativo.

Cabe colocar que a precipitação nos 5 dias antecedentes ao evento tenta atribuir importância para a umidade do solo quanto à geração de escoamento. $O$ fato de não haver correlação entre o escoamento direto e a precipitação antecedente reveste-se de importância porque o Método do Número da Curva do SCS considera as condições de precipitação antecedente como uma tentativa de melhorar a estimativa do valor de $\mathrm{CN}$ e das abstrações iniciais, entre um evento e outro.

Para ilustrar os efeitos das condições de precipitação no escoamento direto, é possível citar o seguinte exemplo. Os eventos dos dias 15/02/98 e 26/11/96, respectivamente com $40,3 \mathrm{~mm}$ e $44 \mathrm{~mm}$ de precipitação, resultaram em valores de escoamento direto semelhantes, ou seja, $0,88 \mathrm{~mm}$ e $0,90 \mathrm{~mm}$, apesar das precipitações antecedentes terem sido muito diferentes, $223 \mathrm{~mm}$ e $30,5 \mathrm{~mm}$. Uma possível explicação para isso pode ser a permeabilidade da área de estudo, que transmite a água infiltrada nos eventos anteriores para camadas mais profundas. Com isso, mesmo logo após a ocorrência de chuvas, a capacidade de infiltração se recompõe rapidamente.

Uma outra justificativa plausível, para a falta de relação entre umidade antecedente e a produção de escoamento, é a alta taxa de transpiração do eucalipto. Em cinco dias, que é o intervalo que o método do $\mathrm{CN}$ considera para determinar a condição de umidade antecedente, uma quantidade considerável de água pode ser evapotranspirada. Supondo que a ETP do eucalipto seja $8 \mathrm{~mm} /$ dia, haveria uma evapotranspiração de $40 \mathrm{~mm}$, que é uma porção significativa quando confrontada com o valor médio das precipitações antecedentes aos eventos estudados (54 mm). Esse argumento, no entanto, pode ser refutado por causa das condições da plantação do eucalipto, que utilizam a água de forma conservativa, quando comparada às plantações mais jovens ou florestas naturais (Câmara, 1999). Tais condições da Microbacia do 
Tinga seriam: a idade avançada (tendo ultrapassado as fases de maior acumulação de biomassa) e a baixa densidade da plantação. Após o corte raso do eucalipto, Câmara (1999) constatou que a porcentagem da precipitação média anual evapotranspirada foi de $66 \%$ e antes era de $67 \%$.

As considerações acima são confirmadas por Wood \& Blackburn (1984) que encontraram maiores efeitos, com resultados mais consistentes quando as condições de umidade antecedentes foram avaliadas em solos desnudos ou com vegetação rala.

A falta de correlação entre essas variáveis pode ser confirmada na Figura 54 , onde é perceptível que, com exceção da precipitação, existe pouco efeito da precipitação antecedente. Esse fato tem importância ao se considerar que as simulações foram feitas por meio do Método do Número da Curva do SCS.

Já, a Figura 56 mostra o possível efeito do corte raso sobre o escoamento. Para os eventos estudados, as diferenças parecem decorrer unicamente dos eventos escolhidos. A maior média de escoamento direto para o período após o corte não deve ser considerada como efeito do mesmo, pois, foi conseqüência da maior média de precipitação total. A porcentagem de precipitação transformada em escoamento foi menor $(2,1 \%)$ para o período após o corte, contra $2,29 \%$ para o período anterior ao corte. Por isso, foi necessário maior quantidade de chuva para a geração de $1 \mathrm{~mm}$ de escoamento direto. A menor porcentagem de chuva transformada em escoamento direto decorreu às menores precipitações médias. Ademais, houve uma tendência das porcentagens do escoamento acompanharem o volume de precipitação, isto é, quanto menor a precipitação, menor o escoamento. Conseqüentemente, maior a altura de chuva necessária para a geração de $1 \mathrm{~mm}$ de escoamento. De qualquer forma, se o objeto de estudo fosse avaliar o efeito do corte raso sobre o escoamento direto em eventos individuais, a amostragem deveria ser maior.

Por não terem sido encontradas diferenças antes e depois do corte raso, considerou-se a ocupação da área de estudo como sendo eucalipto em corte raso e não foram feitas distinções na escolha do $\mathrm{CN}$. Ainda, esse parâmetro não tem precisão suficiente para que diferenças tão pequenas sejam consideradas. 


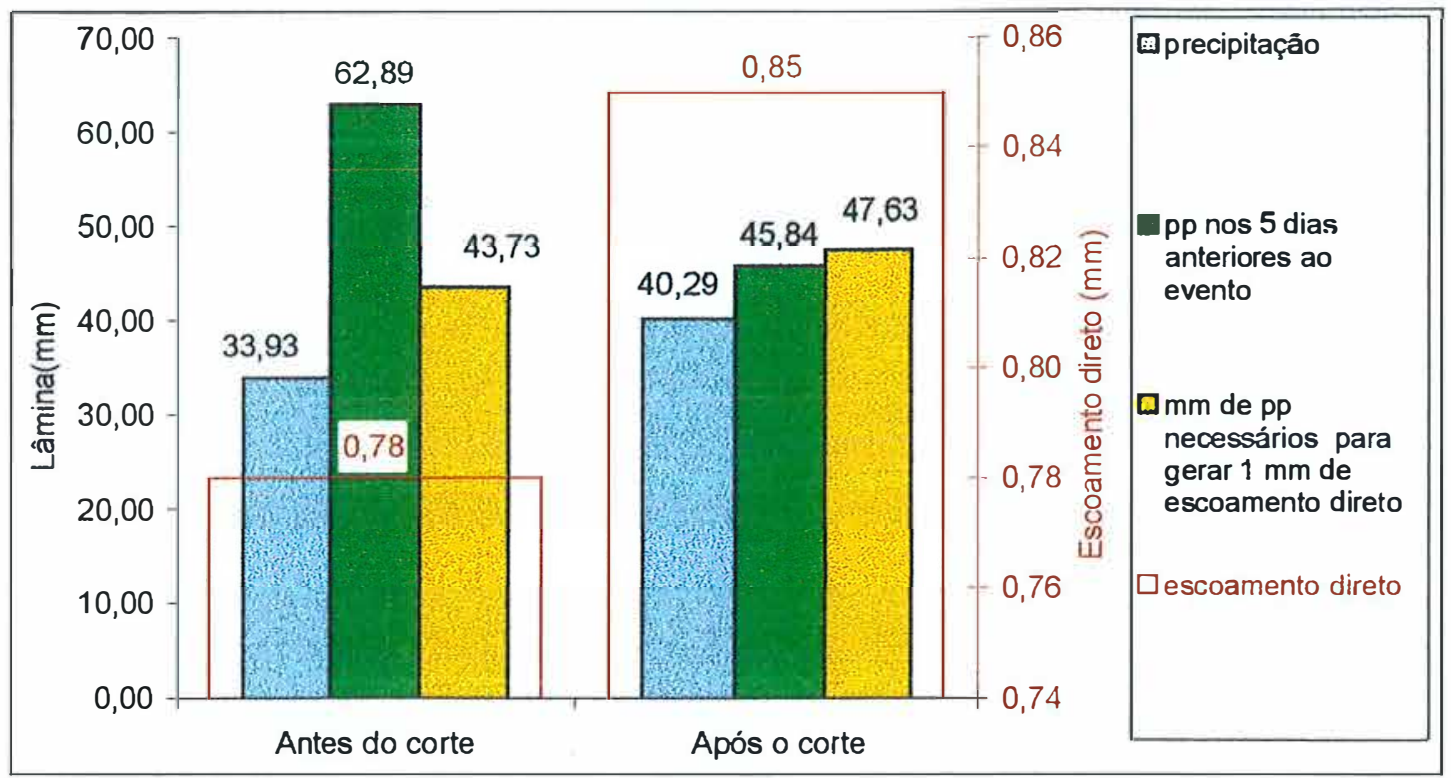

Figura 56 - Médias de precipitação, escoamento direto, precipitação nos 5 dias antecedentes ao evento e $\mathrm{mm}$ de precipitação necessários para gerar $1 \mathrm{~mm}$ de escoamento direto para os eventos estudados, antes e após o corte raso.

\subsubsection{Calibração dos parâmetros hidrológicos usando-se dados de precipitação-} vazão.

Os parâmetros calibrados foram o número da curva e as abstrações iniciais. Os outros parâmetros não foram calibrados, pois a ferramenta utilizada (SIG) para seu cálculo é sofisticada e pressupôs-se que produz resultados suficientemente precisos.

A plotagem dos dados com base na chuva observada e no escoamento direto encontra-se na Figura 57A para a condição da bacia coberta com eucalipto. Utilizou-se 44 eventos, desses, 37 ocorreram antes do corte raso do eucalipto e 7, após. Conforme USDA (1997), essa é a melhor maneira de determinar o número da curva de escoamento, superior à obtenção por meio de tabelas. A maior limitação desse método é exigir dados observados de precipitação e descarga disponíveis. A Figura 57B ilustra uma tentativa de determinação do valor de CN para a bacia aplicando-se a metodologia 


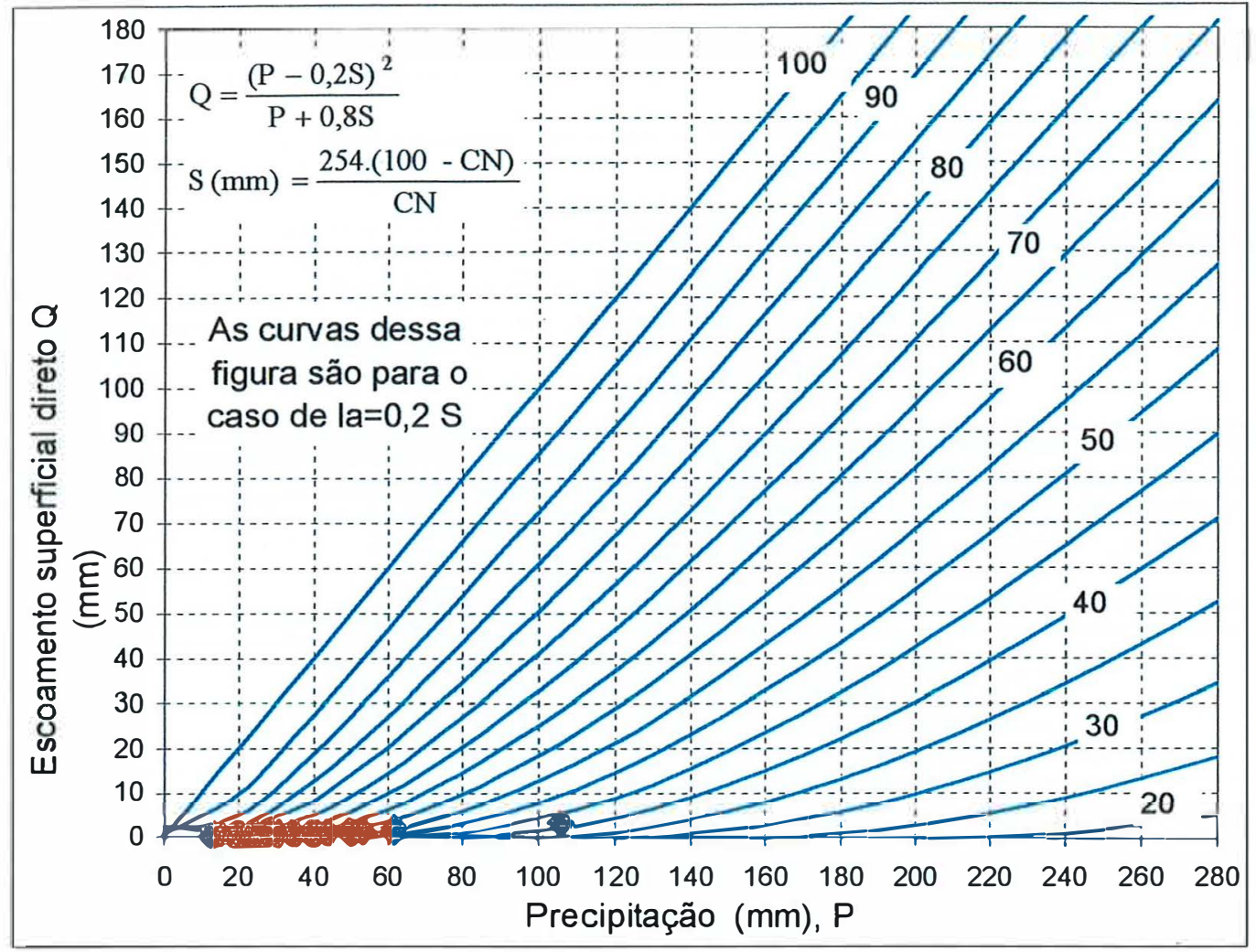

A

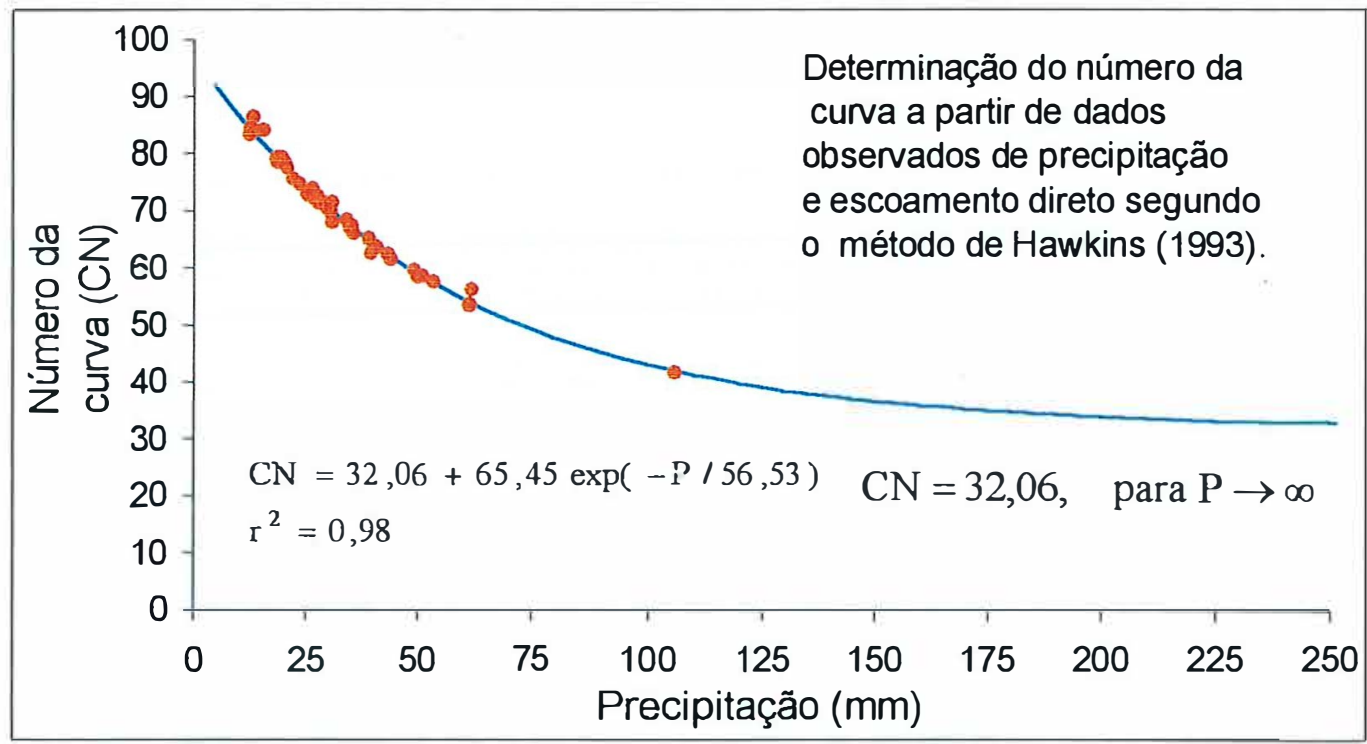

Figura 57 - Soluções da equação do escoamento do SCS e plotagem do escoamento direto contra as precipitações para a Microbacia do Tinga, sendo 37 eventos antes e 7 após o corte raso do eucalipto (A) e aplicação do Método de Hawkins (1993) na tentativa de determinação do $\mathrm{CN}$ a partir de dados de precipitação e escoamento direto. 
de Hawkins (1993). Nesse método, para cada par de precipitação e escoamento direto, determinou-se $\mathrm{S}$ e $\mathrm{CN}$. A partir das relações observadas entre $\mathrm{CN}$ e precipitação, é feito um enquadramento em 3 categorias conforme o comportamento: complacente, padrão e violento.

A despeito das recomendações do USDA (1997), fica claro que a determinação do número da curva por meio do diagrama da Figura 57A foi quase impossivel. Os 44 eventos de chuva-escoamento direto encontram-se numa porção do gráfico onde as curvas estão muito próximas umas das outras, impedindo sua identificação. Apenas o evento de chuva de $105 \mathrm{~mm}$ apresentou maior clareza na definição do número da curva ( $\mathrm{CN} 40)$.

Ademais, percebe-se que com exceção do evento de $105 \mathrm{~mm}$, todos os outros localizaram-se próximos ao eixo $\mathrm{x}$, ou seja, estão abaixo da precipitação crítica (que corresponde a $0,2 . S$ ) e, portanto, teoricamente, produziriam praticamente nenhum escoamento. No entanto, tal fenômeno não ocorre na realidade, pois a série histórica de dados analisada mostrou que mesmo os eventos de $10 \mathrm{~mm}$ ou menores produziram escoamento. Essa constatação foi também observada por Amorim \& Leopoldo (1996). Os autores creditaram a inadequação do Modelo do SCS às características físicas e climáticas, à cobertura vegetal e ao tipo de manejo empregado na bacia, que não são semelhantes àquelas dos E.U.A., onde o modelo e seus coeficientes empíricos foram ajustados.

Quanto aos resultados da aplicação do Método de Hawkins (1993) a Figura 57B, mostra que o comportamento apresentado pela Microbacia do Tinga (complacente) não permite a determinação assintótica do valor do $\mathrm{CN}$, pois o mesmo declina, constantemente, com o aumento das precipitações. Pelo menos dentro da faixa de valores de precipitação analisada não chega a um valor constante. Nesse caso, o escoamento pode, segundo próprio Hawkins (1993), ser modelado mais adequadamente por uma forma linear do tipo $\mathrm{Q}=\mathrm{CP}$, ao invés do Modelo do SCS. Por definição, o comportamento complacente da bacia não responde conforme a Equação do $\mathrm{CN}$ (Equação 8). 
Existe indicação na literatura, conforme Hawkins (1993), de que esse comportamento revela a contribuição de áreas parciais como fontes de escoamento, ou seja, das porcões impermeáveis das bacias.

Apesar das dificuldades para a determinação dos $\mathrm{CN}$ para 0 comportamento complacente, Hawkins (1993) recomenda o ajuste do dados de CN por uma equação exponencial, que neste estudo apresentou um $r^{2}$ de $98,5 \%$, com um valor de $\mathrm{CN}$ assintoticamente constante de 32,06. Esse valor foi conseguido quando considerou-se $\mathrm{P}$ tendendo ao infinito (Figura 57B). Mas, essa determinação é insegura, pois está fora da faixa de valores observados.

Duas questões podem ser levantadas nesse momento. A primeira é que quanto maior o valor de $\mathrm{CN}$, mais estável e segura é sua determinação. A segunda é que deveriam ser escolhidos eventos de chuvas maiores para esse tipo de análise, pois chuvas menores tendem a uma maior instabilidade quanto à produção de escoamento. Isso pode ser constatado na Figura 53, onde aparece a tendência de formação de uma seta, apontando para eventos maiores, sendo que a maior dispersão dos pontos ocorre para os eventos menores. Segundo USDA (1986), o método do SCS é menos preciso quando os valores do escoamento direto forem menores do que $12 \mathrm{~mm}$.

Ultimamente, vários autores têm recomendado o emprego do método do número da curva apenas para valores de $\mathrm{CN}$ maiores que 40. Já, o USDA (1986) indica que esse método pode ser adotado em áreas com valores baixos de $\mathrm{CN}$, ou seja, em áreas florestais e em solos enquadrados dentro do grupo hidrológico A. Para garantia de uma boa determinação do valor do $\mathrm{CN}$, são necessários experiência e um adequado julgamento. Ponce (1989) recomendou a utilização do método $\mathrm{CN}$ mesmo para valores abaixo dos 50 .

Inicialmente, planejava-se calibrar apenas o parâmetro abstração inicial. No entanto, como a determinação do $\mathrm{CN}$ pelo método gráfico (USDA, 1986) gerou dúvidas, ele acabou sendo também definido por calibração.

Apesar de todas as dificuldades, para os objetivos desse estudo, a calibração dos dados foi uma solução adequada. Cabe acrescentar que, para bacias inteiramente florestadas, existe maior instabilidade na determinação do número da 
curva. Já, para os valores maiores, que no presente estudo correspondem às ocupações simuladas, há maior estabilidade. Portanto, sua deterninação é mais segura. Ainda, a calibração dos dados para a condição critica, ou seja, as mais instáveis, conferiu maior confiabilidade nas simulaçôes sob as outras condições. O contrário seria mais desfavorável, isto é, a calibração para uma condição de agricultura ou pastagem e simulação para florestas.

A restrição desse procedimento de calibração reside no fato de que seus valores são aplicados apenas a situações particulares, nas quais os dados foram obtidos. Os resultados das calibraçôes manuais do $\mathrm{CN}$ e abstraçôes iniciais estão na Tabela 17 (página 178). A média encontrada para o $\mathrm{CN}$ foi de 19,6, enquanto que, para as abstraçōes iniciais, foi de 7,4. O valor calibrado médio de 19,6, para área de estudo ocupado com eucalipto, confirma a idéia de que a Microbacia do Tinga apresenta características de floresta natural intocada (Lima et al., 1996). Também, observando-se a Tabela 3 (Setzer \& Porto, 1979), verifica-se que seus autores atribuíram para mata e capoeira velha, em boas condiçôes de infiltração e em solo do grupo A, o valor de 18 . Esse valor é semelhante ao obtido por calibraçôes para a Microbacia do Tinga. Na mesma situação, os mesmos autores atribuíram valores de 25 para reflorestamento. Portanto, pode-se dizer que a Microbacia do Tinga está mais próxima de matas naturais do que de reflorestamentos quanto à produção de escoamento direto.

Segundo USDA (1986), as abstraçôes iniciais são extremamente variáveis, em geral apresentando alta correlação com o solo e a vegetação. É pertinente recordar que a abstração inicial no Modelo do SCS, sob uma perspectiva conceitual, engloba todas as perdas antes do início do escoamento, tais como armazenamento na superfície, interceptação, infiltração antes do escoamento inicial e também perdas por evapotranspiração durante as simulações. Assim, como o eucalipto tem uma alta taxa de evapotranspiração e as simulações sempre duraram mais que 3 horas, seria esperada a ocorrência de perdas variáveis por evapotranspiraçào, conforme o horário, condições atmosféricas e época do ano. 
Já, a atribuição de valores de $\mathrm{CN}$ tão baixos pode ser explicada pelas características morfológicas, pelo tipo de solo e pela ocupação da área de estudo. A Microbacia do Tinga apresenta uma declividade média de 4,6\%, sendo que a parte menos declivosa encontra-se mais à montante, distante dos canais. Nessa região, há mais capacidade de absorção da água, as velocidades do fluxo superficial são menores e, portanto, maior tempo de oportunidade de infiltração do excesso de chuva, antes que ele se concentre nos canais.

\subsubsection{Simulação do escoamento com os parâmetros calibrados}

$\mathrm{Na}$ Tabela 17, encontram-se os resultados das simulações, com os parâmetros calibrados ( $\mathrm{CN}$ e abstrações iniciais) por meio do programa HEC-HMS, para 5 eventos de precipitação e condição de floresta de eucalipto ou após o corte raso do mesmo.

Tabela 17 - Resumo dos resultados das simulações com os parâmetros $\mathrm{CN}$ e abstrações iniciais (Ai) calibrados, considerando a ocupação floresta de eucalipto.

\begin{tabular}{|c|c|c|c|c|c|c|c|c|c|c|c|}
\hline \multirow[b]{2}{*}{ Evento } & \multirow[b]{2}{*}{ Ocupação } & \multirow[b]{2}{*}{$\mathrm{CN}$} & \multirow[b]{2}{*}{$\mathrm{Ai}$} & \multirow[b]{2}{*}{ Precip. } & \multicolumn{2}{|c|}{ Observado } & \multicolumn{2}{|c|}{ Simulado } & \multicolumn{2}{|l|}{ Resíduo } & \multirow[t]{3}{*}{$\mathrm{RM}^{*}$} \\
\hline & & & & & Esc. dir. & Qpico & Esc. dir. & Qpico & Médio & Total & \\
\hline & & & $(\mathrm{mm})$ & $(\mathrm{mm})$ & $(\mathrm{mm})$ & $(\mathrm{m} 3 / \mathrm{s})$ & $(\mathrm{mm})$ & $(\mathrm{m} 3 / \mathrm{s})$ & $(\mathrm{m} 3 / \mathrm{s})$ & $(\mathrm{mm})$ & \\
\hline 11-Jan-96 & Eucalipto & 20 & 5 & 27,0 & 0,51 & 0,069 & 0,50 & 0,068 & 0,004 & 0,000 & 0,99 \\
\hline 27-Fev-96 & Eucalipto & 20 & 8 & 39,0 & 0,94 & 0,123 & 0,90 & 0,119 & 0,015 & 0,000 & 0,95 \\
\hline 22-Jan-97 & Eucalipto & 16 & 10 & 51,0 & 1,18 & 0,132 & 1,20 & 0,122 & 0,018 & 0,000 & 0,98 \\
\hline 24-Jan-97 & Eucalipto & 24 & 7 & 34,1 & 0,92 & 0,108 & 0,84 & 0,116 & 0,018 & 0,100 & 0,87 \\
\hline $15-$ Fev-98 & Corte raso & 18 & 7 & 40,3 & 0,88 & 0,112 & 0,90 & 0,114 & 0,005 & 0,100 & 0,98 \\
\hline Média & & 19,6 & 7,4 & 38,28 & 0,89 & 0,109 & 0,87 & 0,108 & 0,012 & 0,040 & 0,95 \\
\hline
\end{tabular}

* Coeficiente de correlação modificado por MaCuen e Snyder (1975), para comparação de hidrógrafas 
Graças à baixa resolução temporal dos dados, os resultados para variáveis que utilizaram a comparação entre hidrógrafas simuladas e observadas e que dependem do tempo, como por exemplo, o tempo de pico, devem ser considerados com cautela.

Observando-se a tabela, é possível afirmar que os resultados foram satisfatórios, pois os valores do resíduo médio e total foram baixos. Os coeficientes de correlação modificados por MacCuen \& Snyder (1975) variaram entre 0,86 e 0,99. Na maior parte dos eventos, esteve próximo a 1 , indicando um bom ajuste entre os dados simulados e observados. Por sua vez, valores próximos a zero indicariam dissimilaridade. É pertinente elucidar que esse coeficiente de correlação foi desenvolvido para ser aplicado especificamente na comparação entre hidrógrafas simuladas e observadas, levando em consideração o tamanho e a forma do volume abaixo da hidrógrafa.

Os diagramas de dispersão e o coeficiente de correlação (RM) entre as hidrógrafas simuladas e observadas estão nas Figuras 58 e 59.

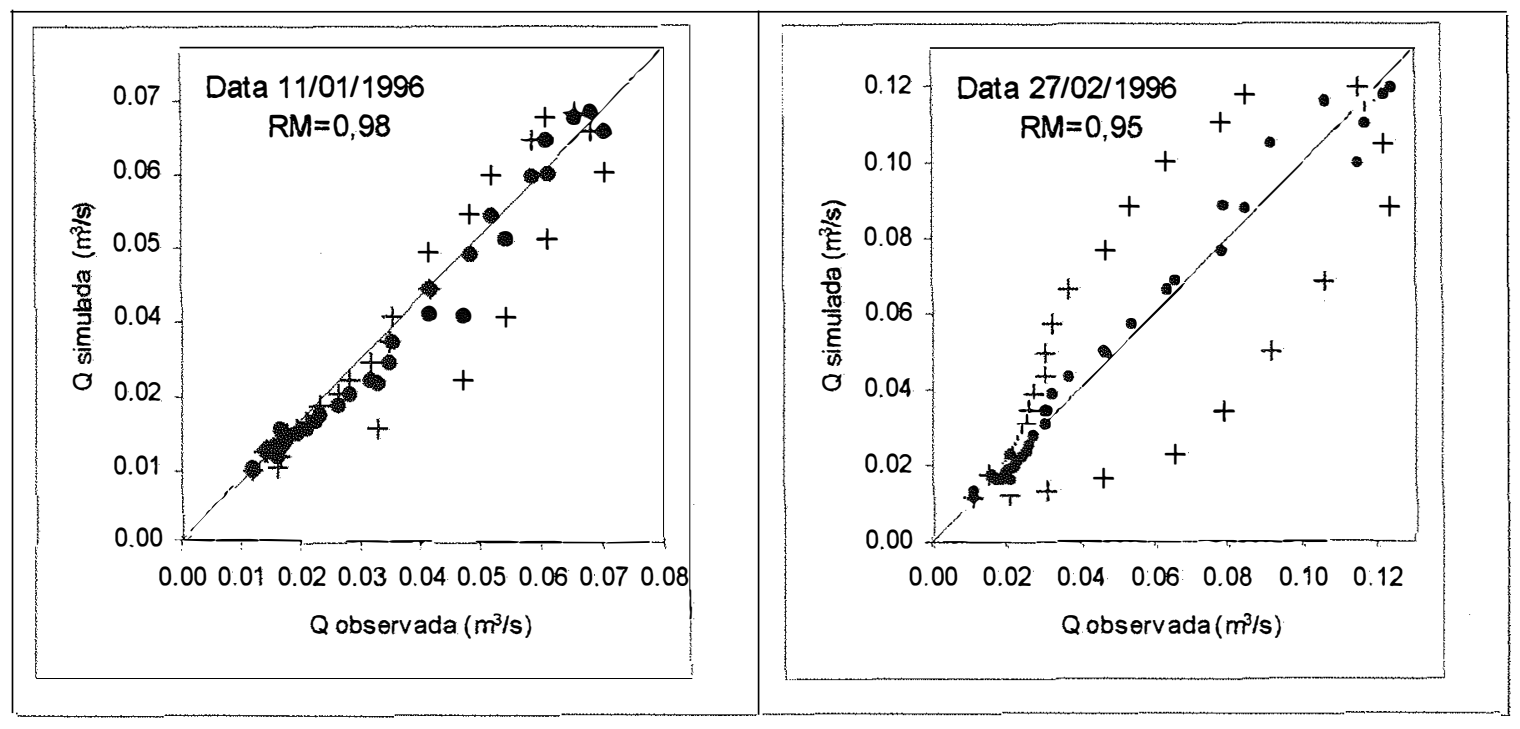

Figura 58 - Diagrama de dispersão e coeficiente de correlação modificado entre hidrógrafas observadas e simuladas, antes $(+)$ e após $(\bullet)$ a correção do tempo. 


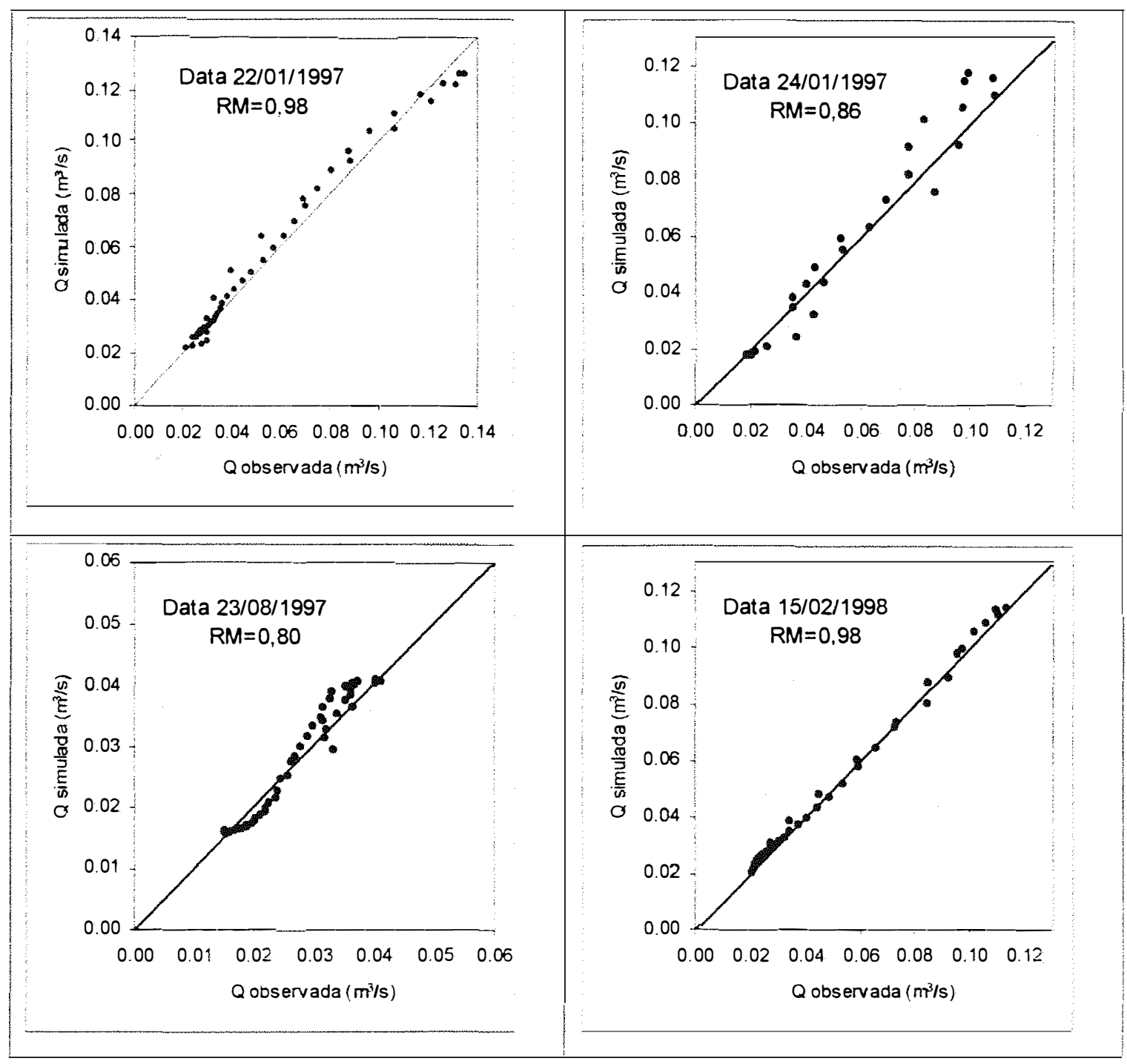

Figura 59 - Diagrama de dispersão entre hidrógrafas observadas e simuladas, com o coeficiente de correlação modificado.

Na Figura 58, algumas particularidades merecem ser consideradas. Como os pluviogramas e os diagramas de linígrafo eram de rotação semanal (Figura 17), e não diária, a resolução temporal dos dados estava aquém das necessidades do trabalho. Além disso, as resoluçòes dos aparelhos eram diferentes. Por exemplo, no diagrama do linigrafo, $3 \mathrm{~cm}$ correspondiam a 1 dia. Um erro de posicionamento de apenas $1 \mathrm{~mm}$ equivale a 48 minutos. Já, para os dados de precipitação, $5,65 \mathrm{~cm}$ no pluviógrafo 
correspondem a 1 dia e $1 \mathrm{~mm}$ de erro corresponde a 25 minutos e 29 segundos. Assim, para alguns eventos, houve discrepância entre as escalas de tempo das hidrógrafas simuladas e as observadas. Afinal, as hidrógrafas simuladas foram obtidas com dados de entrada dos pluviógrafos. Ao passo que as observadas foram obtidas dos diagramas dos linígrafos. Os eventos dos dia 11/01/96 e 27/02/97 tiveram dispersão decorrente da diferença de tempo entre a hidrógrafa simulada e a observada. Portanto, demandaram correção, que produziu resultados mais coerentes.

Já, os diagramas de dispersão, cujos dados não foram corrigidos, encontram-se na Figura 59. Essa figura mostra que bons ajustes para todos os eventos estudados foram obtidos. Particularmente, destaca-se aquele do dia 15/02/98, com coeficiente de correlação de 0,98 . Tal resultado está associado, provavelmente, ao maior volume de chuva, pois chuvas maiores tendem a produzir resultados mais estáveis. Ademais, os dados de chuva para esse evento foram obtidos da estação meteorológica automática, que os coletava a cada 12 minutos. Com isso, a forma do hietograma certamente era mais realista do que a dos outros eventos, retirados dos pluviógrafos com rotação semanal.

Os eventos dos dias 24/01/97 e 23/08/97, por serem menores e mais dificeis de serem simulados para a condições de permeabilidade da bacia, apresentaram menores coeficientes de correlação RM, respectivamente 0,86 e 0,80 . O evento do dia 23/08/97 ocorreu após um período de um mês sem chuva. A duração da precipitação foi longa, com periodo mais intenso no seu início. De qualquer forma, a simulação foi satisfatória, porém, por ser atípico, esse evento não foi incluído na Tabela 17.

As hidrógrafas observadas e simuladas com os parâmetros calibrados para diversos eventos são apresentadas nas Figuras 60 a 65 .

Devido à suposição de que o escoamento é gerado somente após atendidas as abstraçòes iniciais, existiu a tendência de haver diferenças entre a hidrógrafa simulada e a observada para eventos de chuva pouco intensos no início. Nesse tipo de evento, ainda, a hidrógrafa observada apresentou uma ascensão mais rápida. Ao passo que, nos casos de eventos de chuvas intensos no início, essas diferenças diminuíram. 


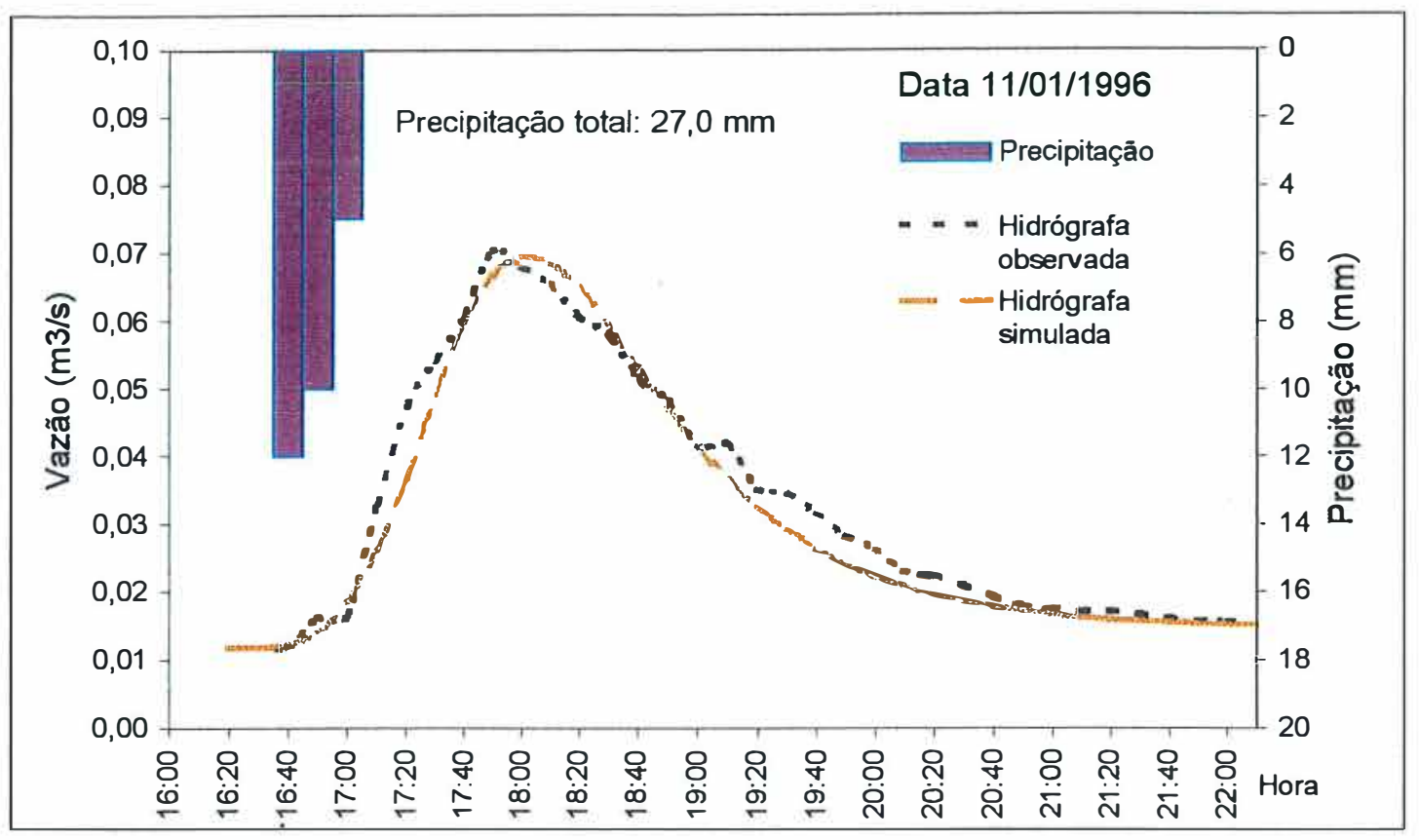

Figura 60 - Hidrógrafas observada e simulada para o evento do dia 11/01/1996.

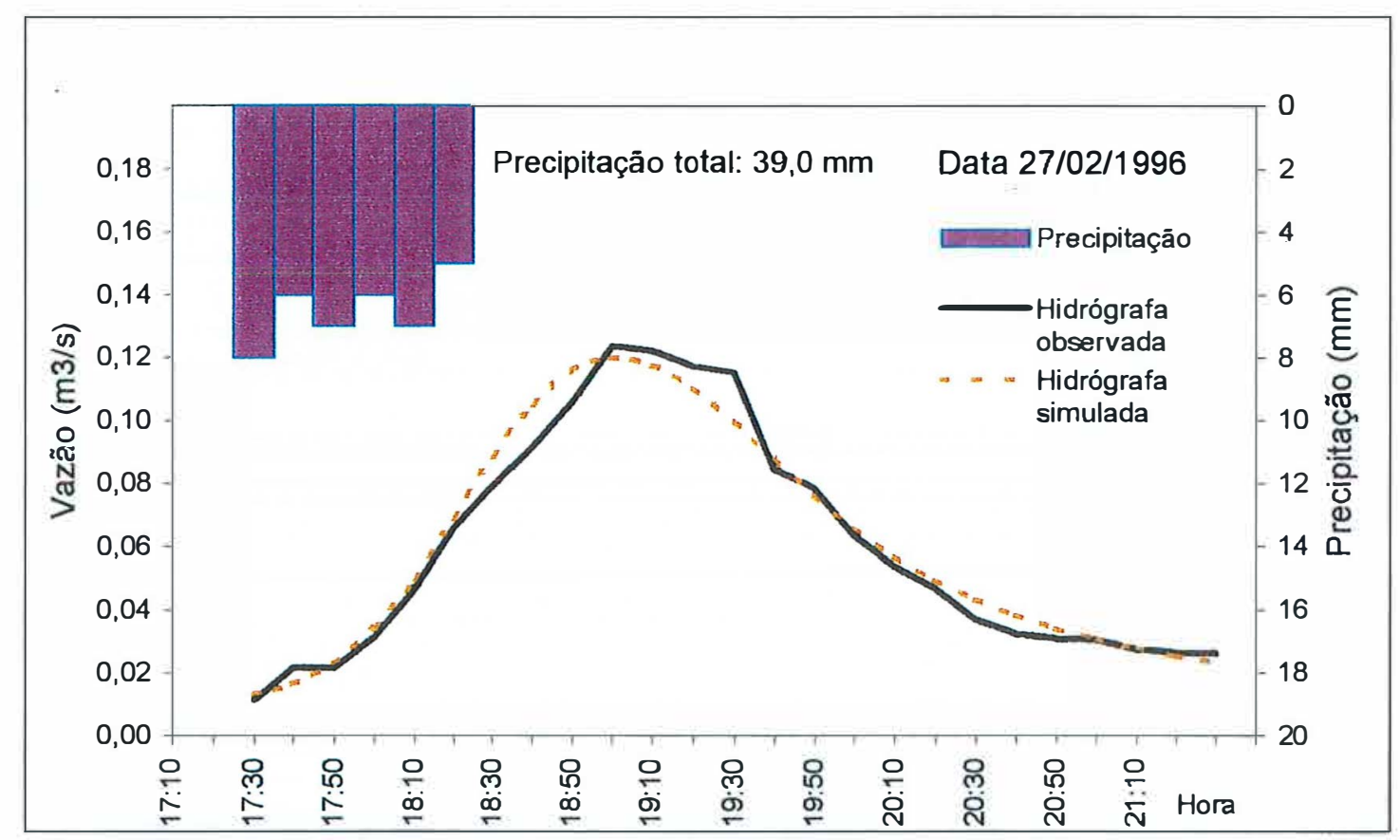

Figura 61 - Hidrógrafas observada e simulada para o evento do dia 27/02/1996. 


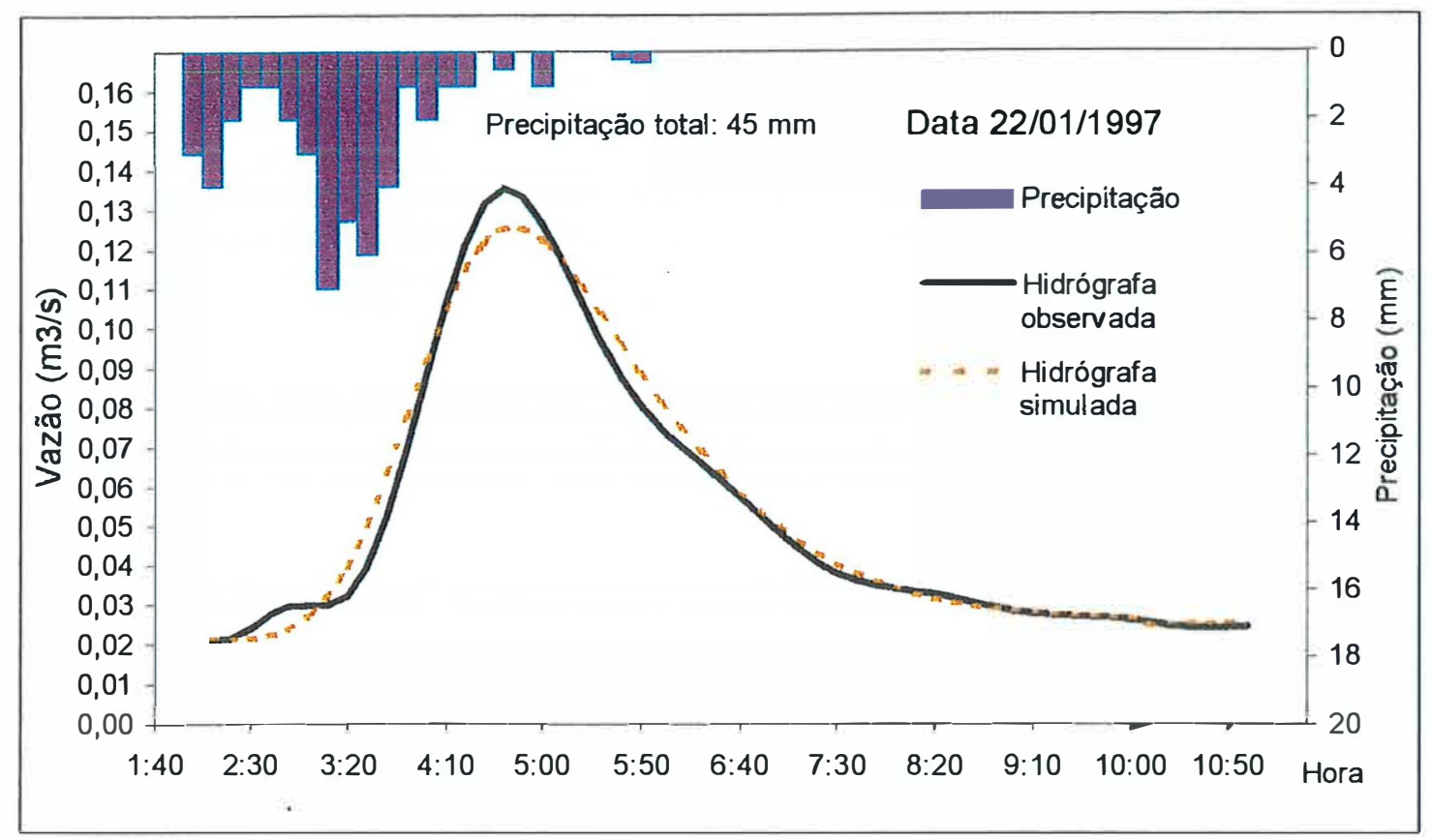

Figura 62 - Hidrógrafas observada e simulada para o evento do dia 22/01/1997.

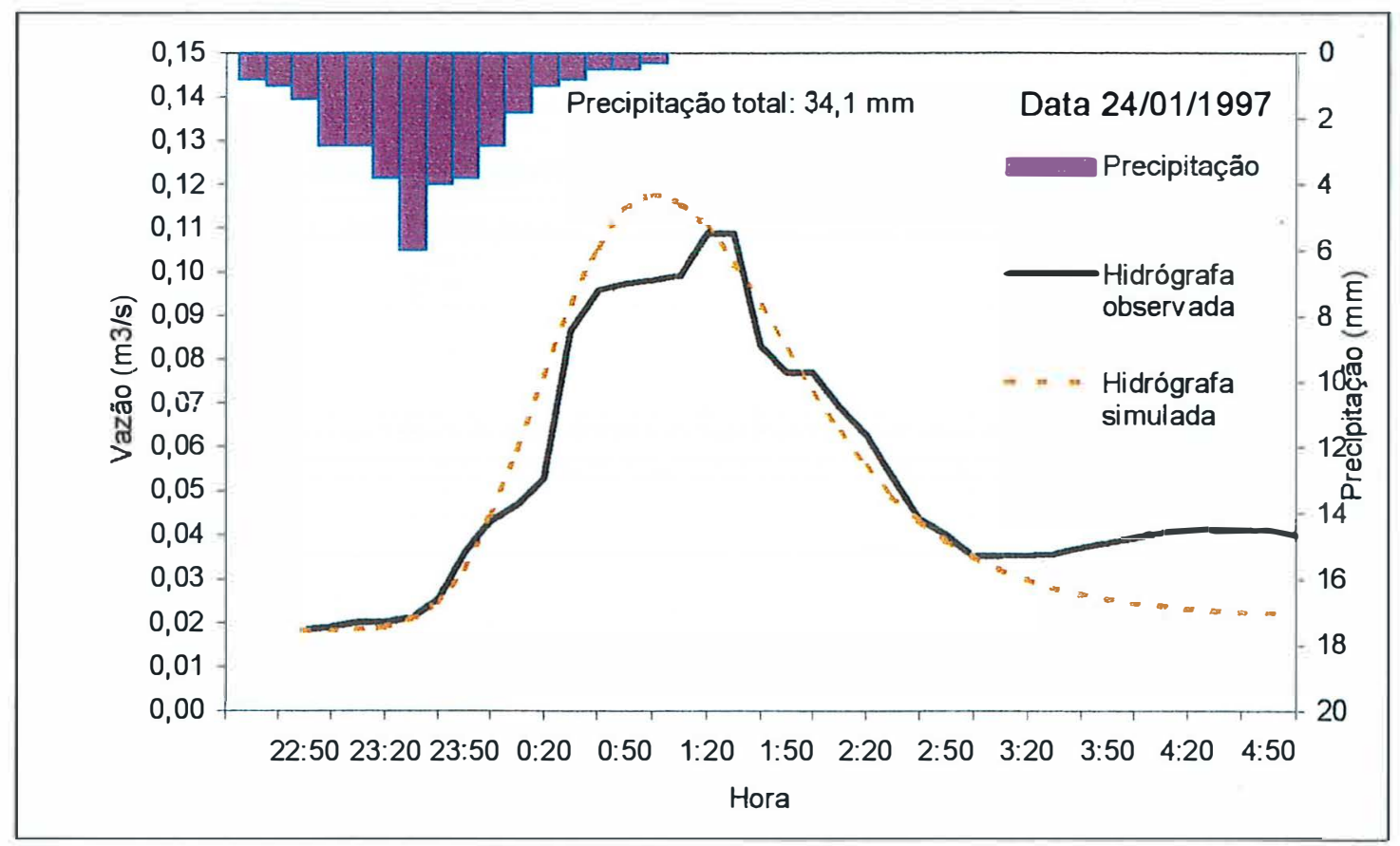

Figura 63 - Hidrógrafas observada e simulada para o evento do dia 24/01/1997. 


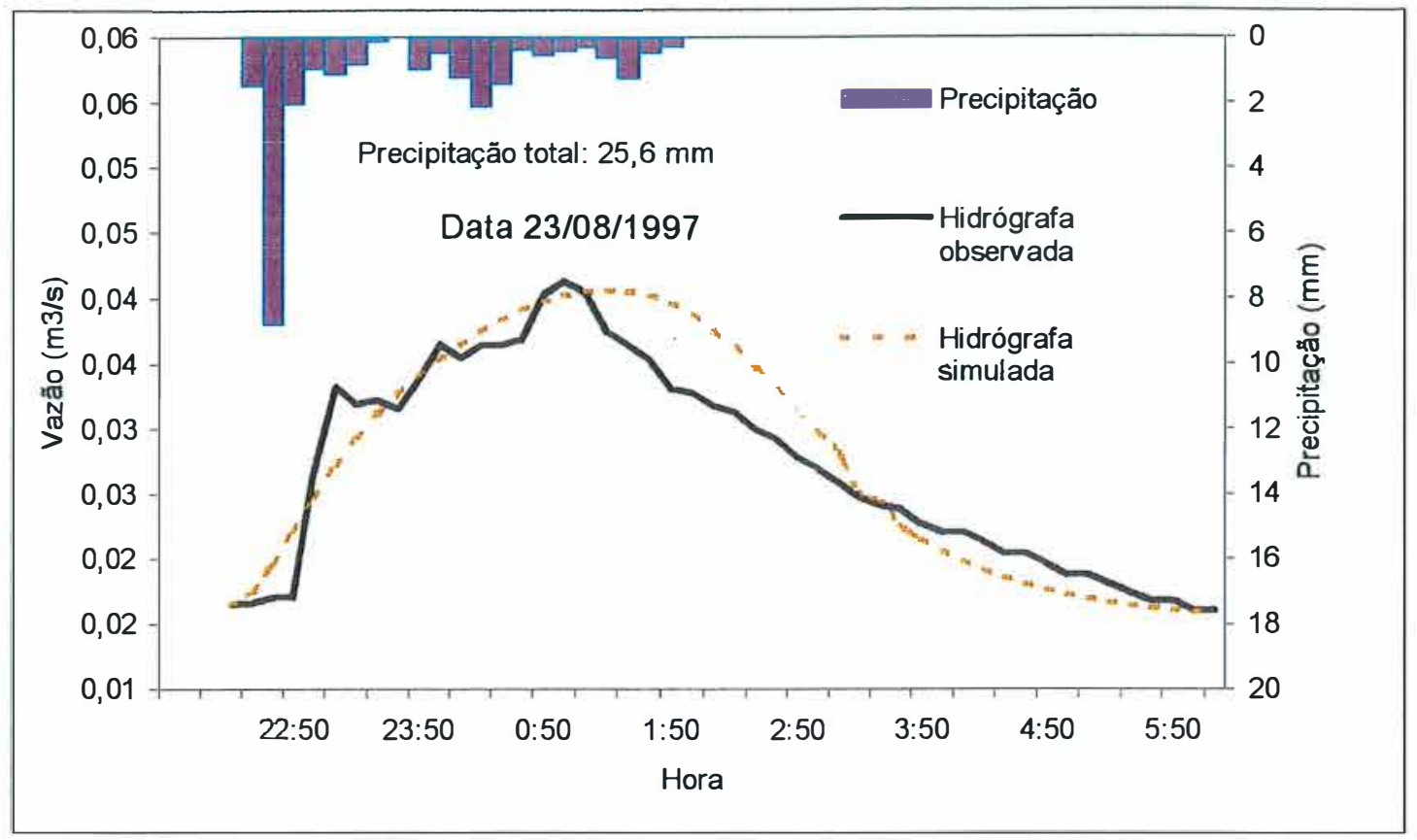

Figura 64 - Hidrógrafas observada e simulada para o evento do dia 23/08/1997.

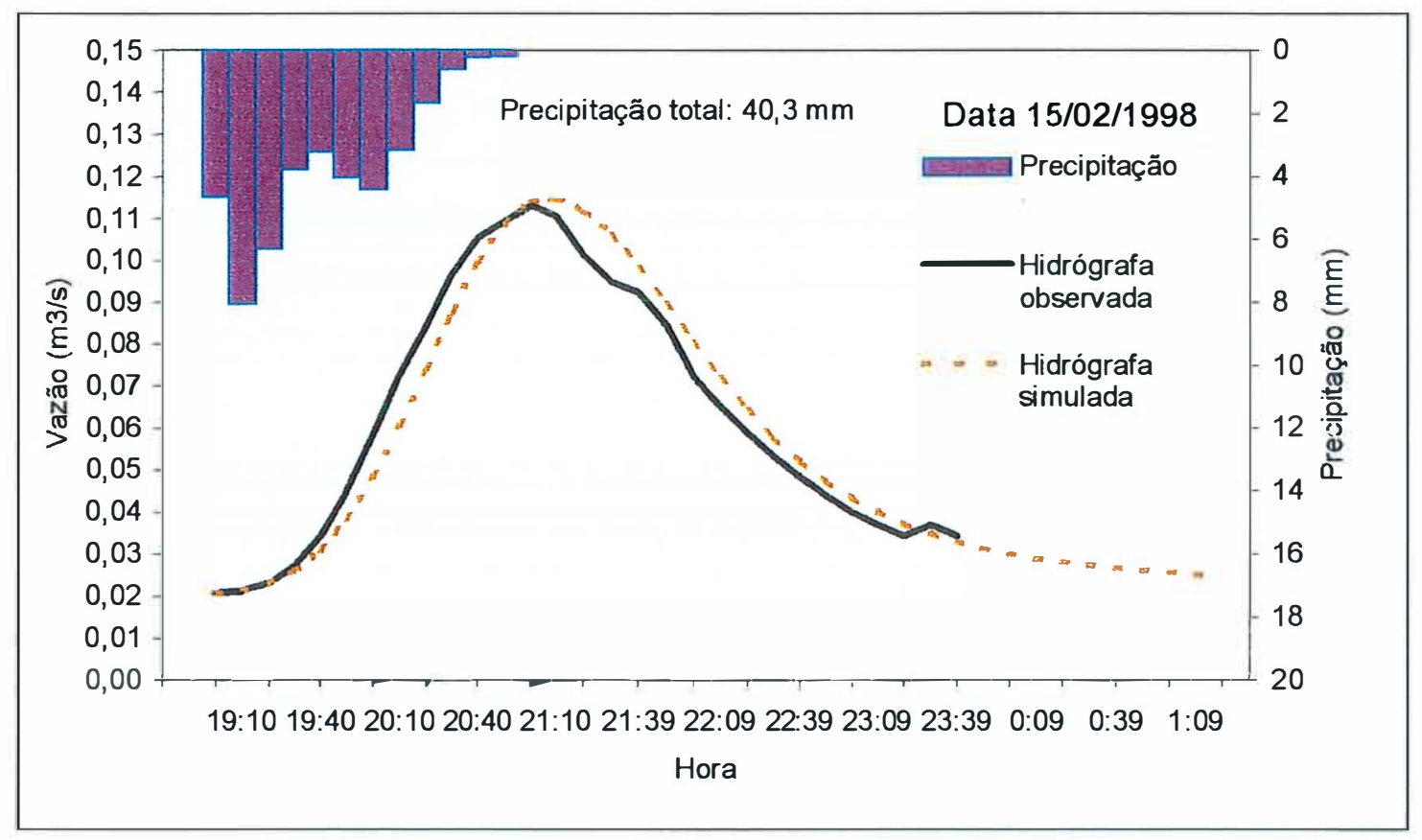

Figura 65 - Hidrógrafas observada e simulada para o evento do dia 15/02/1997. 
A ascensão relativamente rápida da hidrógrafa observada chamou a atenção, uma vez que o esperado seria uma ascensão mais lenta. Afinal, a Microbacia do Tinga apresenta permeabilidade alta e a contribuição do escoamento rápido proveniente da precipitação nos canais não deve ser considerada significativa, pois esses canais ocupam uma pequena porção da área total de estudo. Uma possível explicação para isso vem da contribuição de áreas saturadas, conforme a teoria das áreas variáveis de afluência. Vale recordar que, em áreas florestadas, segundo Hewlett \& Hibbert (1967), Tsukamoto (1963), Weyman (1970), citados por Kobiyama et al. (1998), a água que cai nas partes altas da bacia tende a infiltrar mesmo durante chuvas intensas. A umidade do local aumenta até a saturação, que, posteriormente, é transmitida para as áreas à jusante. Segundo essa teoria, o escoamento direto rápido ocorre unicamente nas áreas saturadas, principalmente à jusante, próximo aos canais que já estão saturados antes do início das chuvas ou saturam-se durante a chuva. Essas áreas saturadas são variáveis, contraindo-se ou expandido-se conforme a precipitação e a contribuição de áreas à montante. Um outro aspecto é que a chuva absorvida pela bacia é transformada em escoamento subterrâneo, que sai da bacia mais lentamente.

Um ponto a ser considerado e que também dá sustentação ao exposto, é que na série de dados estudada, foi observado, que mesmo para eventos menores que 10 mm, ocorria a elevação das hidrógrafas. Essa elevação é causada pela precipitação em canais, que rapidamente é conduzida até a saída da bacia. Porém, a porcentagem da bacia ocupada pelos canais é pequena e outros pontos de geração de escoamento rápido devem existir. Esses pontos podem ser a existência de áreas saturadas, ou mesmo a influência dos carreadores, que na área, não levam em conta a topografia.

Os carreadores (Figura 16), por introduzirem caminhos preferenciais para a água seguir na superficie do terreno e apresentarem menor permeabilidade, certamente influenciaram o volume e a forma das hidrógrafas, levando a ascensòes mais rápidas. Caso a resoluçào temporal dos dados de descarga fosse maior, provavelmente teria sido possivel comprovar os efeitos dos carreadores. Afinal, essa influência dos carreadores poderia ser avaliada nas simulaçòes. 
Por outro lado, a área mais declivosa da Microbacia do Tinga encontra-se na parte mais à jusante, próxima aos canais, e é caracterizada por solos profundos. Conforme a teoria da área variável de afluência, essa conjunção de condições leva a menor formação de escoamento direto por saturação. Um outro fator que desfavorece a formação de áreas saturadas da área de estudo é a inexistência de camadas de impedimento à movimentação da água no solo, uma vez que a mesma não é característica de nenhum dos solos que ocorrem na bacia (Tabela 9). Por outro lado, a existência de áreas planas na parte alta da Microbacia do Tinga (Figura 14) favorece a infiltração de grandes volumes de água, que podem aflorar nas áreas mais baixas das vertentes formando as áreas variáveis saturadas. Quanto a essas áreas que se saturam facilmente, vale comentar, conforme Lima (1989), que devem ser tratadas de forma especial, uma vez que estão diretamente relacionadas à qualidade de água produzida nas bacias e, portanto, ao potencial de poluição e contaminação das águas.

Atualmente, pode-se dizer que já existe suficiente comprovação de que, em áreas úmidas e bem vegetadas, o excesso hortoniano não consegue explicar os padrões de fluxo superficial. Hawkins (1973) encontrou um estranho ajuste empírico entre os valores de $\mathrm{CN}$ observados e o volume de precipitação a partir de dados de bacias florestadas de tamanho pequeno nos E.U.A. Em trabalho posterior o mesmo autor (Hawkins, 1979), testou a hipótese de que tal comportamento poderia decorrer das áreas praticamente impermeáveis devido à saturação. Concluiu que a determinação de um $\mathrm{CN}$ constante e independente do tamanho das chuvas não é adequada para todas as situações. Em alguns eventos, o escoamento pode ser uma porção da precipitação, e isto pode sugerir áreas constantes impermeáveis saturadas, por exemplo, as áreas dos canais, e outras áreas com maior capacidade de infiltração. Entretanto, eventos extremos em intensidade ou condiçòes de umidade da bacia ou ambos invocam outros processos, como por exemplo a contração e expansão das áreas saturadas.

Apesar do Método do Número da Curva do SCS estar baseado no princípio hortoniano de geração de escoamento e, seguindo ele, apresenta capacidade de considerar áreas saturadas ou impermeáveis, Steenhuiss et al. (1995) mostraram que o 
método está diretamente fundamentado nos princípios de áreas parciais e pode prever a área de contribuição com menos transtorno que o método de Boughton (1987), conforme os autores o único para o cálculo desse tipo de áreas.

Em tempo, merece comentário o fato de que existem tabelas de $\mathrm{CN}$ que indicam valores para áreas saturadas e impermeáveis.

As simulações efetuadas com os valores calibrados mostraram que, mesmo sob ocupação de floresta, em área permeável, os resultados foram satisfatórios. O uso do Modelo do SCS para o cálculo do tempo de retardamento em sub-bacias, levando em conta o $\mathrm{CN}$, o comprimento e a declividade do caminho mais longo, além da subdivisão da área de estudo, permitiu que boas concordâncias entre hidrógrafas simuladas e observadas fossem conseguidas, mesmo na fase de recessão.

Cabe mencionar que, no evento de 11/01/1996, as pequenas elevações na fase de recessão são decorrentes do diminuto volume de chuvas e não foram incluídas como parte do evento nas simulações. O mesmo aconteceu nos eventos dos dias 24/01/97 e 15/02/98, a partir das 02:50 e 23:30, respectivamente. Os cálculos dos indices, nesses casos, consideraram apenas o tempo até esses horários.

Um exemplo de sobreposição das hidrógrafas resultantes em cada subbacia é apresentado na Figura 66A. A Figura 66B ilustra a sobreposição das hidrógrafas nas junçòes. No exemplo, utilizou-se o evento do dia 15/02/98, sendo que a soma das hidrógrafas sobrepostas formam a hidrógrafa da microbacia (corresponde à junção 2). No caso da sobreposição das hidrógrafas das sub-bacias, é possível perceber que ocorre dessincronização dos picos e que as formas das hidrógrafas apresentam diferenças, umas mais achatadas e outras menos. Essas diferenças podem ser creditadas exclusivamente às caracterísicas da bacia. Afinal, os outros parâmetros de simulação foram praticamente constantes: o eucalipto ocupava quase toda a bacia e a chuva era a mesma. Como os solos são muito semelhantes em toda a Microbacia do Tinga, a área de contribuição e a geomorfologia sào as responsáveis pelas principais diferenças entre as sub-bacias. Então, é possível afirmar que a obtenção dos parâmetros relacionados à área de 

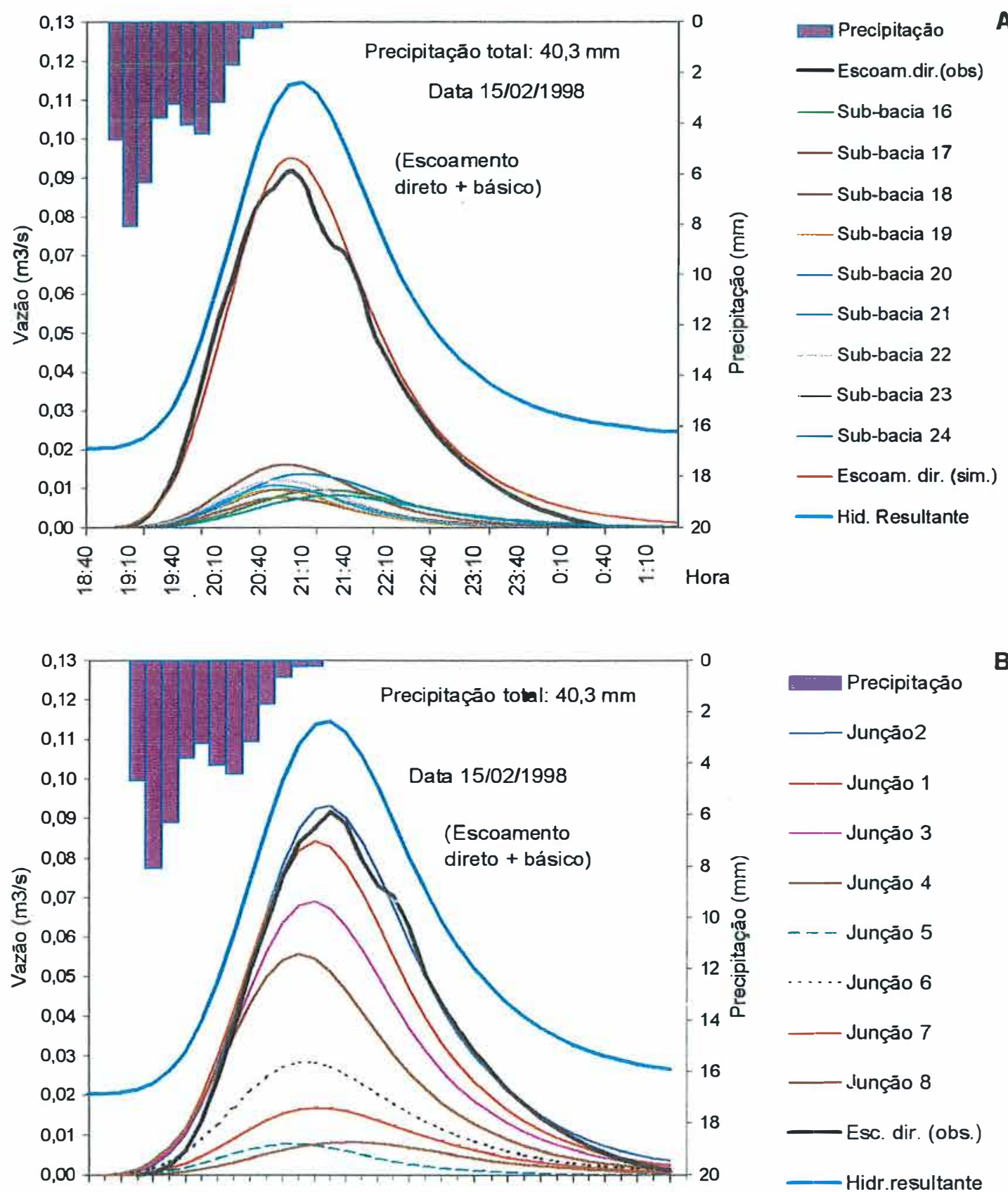

B

Preçipitaçāo

—_ Junção2

—_ Junção 1

—_ Junção 3

— Junção 4

- - Junção 5

.... Junçāo 6

—— Junção 7

—_ Junção 8

Esc. dir. (obs.)

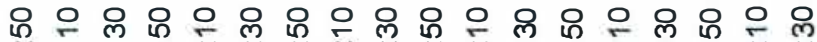

œ চ

Figura 66 - Sobreposição das hidrógrafas de escoamento direto de cada sub-bacia (A) e para cada junção (B), compondo a hidrógrafa de escoamento direto, que, somada ao escoamento básico, forma a hidrógrafa para o evento do dia 15/02/1998 na junção 2. 
contribuição e geomorfologia, a partir do MDT's, colaborou para que as características da área de estudo relacionadas a esses parâmetros fossem levadas em conta de uma maneira mais realista.

Quanto à sobreposição dos pontos de junção, pode-se observar que os picos de vazão aumentaram na medida em que esses pontos localizavam-se mais à jusante. $O$ atraso nos picos, conforme as sobreposições aconteciam, decorreu, principalmente, do tempo de retardamento nos canais.

\subsubsection{Análise de sensibilidade}

Análises de sensibilidade foram efetuadas com a finalidade de verificar as mudanças nos resultados pela alteração de determinados parâmetros. Os escolhidos foram aqueles que demandaram julgamento, ou seja, o valor de $\mathrm{CN}$ e as abstrações iniciais. Nessa parte da análise, características como a declividade e o comprimento do caminho mais longo não foram incluídas, pois foram medidas em SIG.

$\mathrm{O} C \mathrm{~N}$ foi avaliado em funçào do tempo de retardamento para cada uma das sub-bacias. Quando os valores de $\mathrm{CN}$ eram menores que 30, típicos de florestas, ocorreu um aumento mais acentuado no tempo de retardamento. Conseqüentemente, as hidrógrafas geradas foram mais suaves, com tempo de base maior, menores picos de vazão e recessão mais longa. Para valores maiores de $\mathrm{CN}$, ocorreu o inverso.

Ainda, valores inferiores a 50 foram mais sensíveis, isto é, pequenas variações no $\mathrm{CN}$ resultaram em aumentos mais significativos no tempo de retardamento. Esse comportamento viabilizou a simulação para áreas florestais ou mais permeáveis, onde a fase de recessão foi mais suave porque os processos subsuperficiais geraram a maior proporção do fluxo.

Além do $\mathrm{CN}$, os parâmetros que influenciaram a determinação do tempo de retardamento foram: o comprimento do maior caminho seguido pela água e a declividade do mesmo. As declividades maiores reduziram o tempo de retardamento e os maiores comprimentos, o aumentaram. Observando-se os dados tabulares contíguos à Figura 67 , nota-se que a sub-bacia 16 apresenta o maior comprimento e a sub-bacia 24 , 


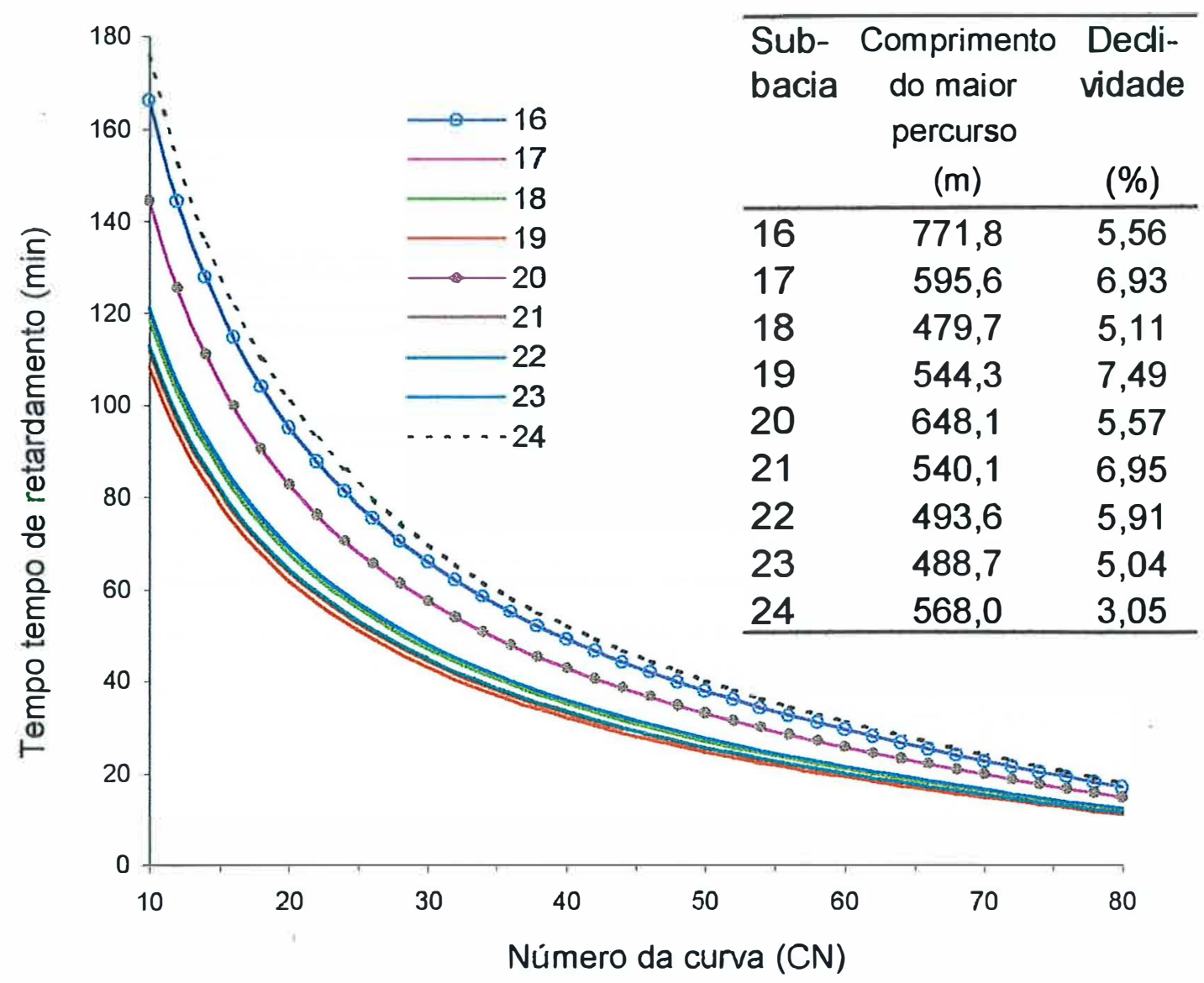

Figura 67 - Tempos de retardamento conforme a variação do número da curva para diversas sub-bacias. Também são apresentados os outros parâmetros usados da determinação, comprimento (L) e declividade do maior caminho seguido pela água, na superfície do terreno e canais.

a menor declividade. Logicamente, ambas possuíram os maiores valores de tempo de retardamento. Por outro lado, como a sub-bacia 19 é a de maior declividade, seu tempo de retardamento foi o menor.

Já, a análise de sensibilidade da variação do pico de vazão e do volume de escoamento em relação às abstrações iniciais e CN é apresentada na Figura 68.

É possível notar que, tanto o pico de vazão como o volume, apresentaram uniformidade quanto à resposta. Quanto maiores os valores de $\mathrm{CN}$, um menor acréscimo 
oldịeono

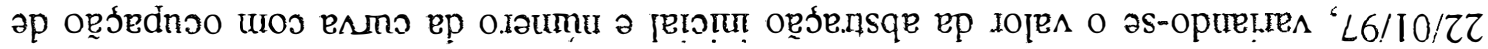

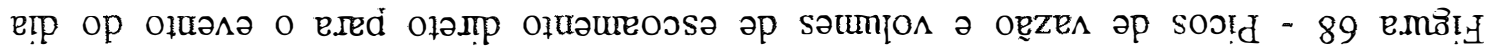

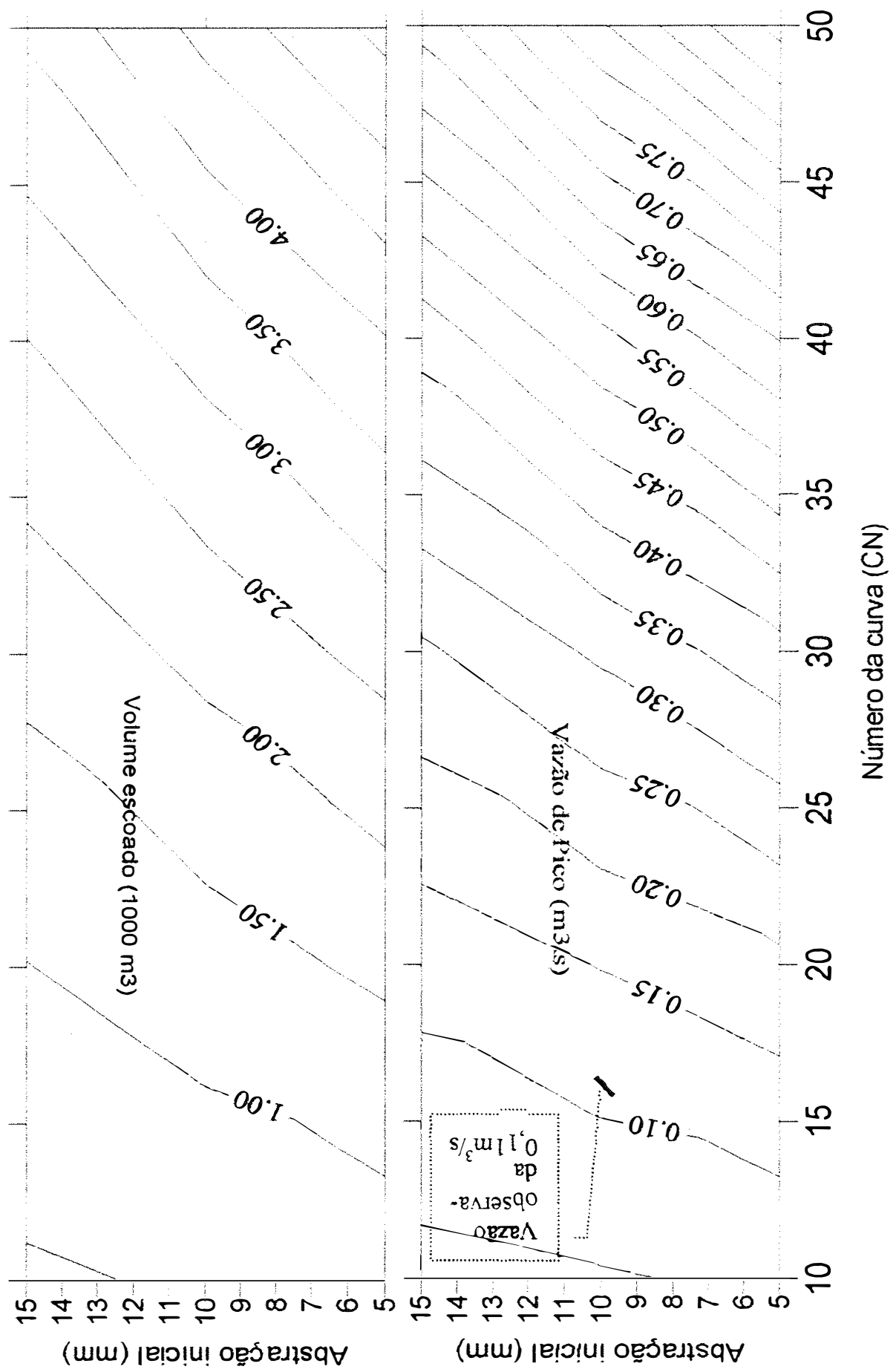


de $\mathrm{CN}$ resulta num maior valor de pico e volume. Abaixo de $\mathrm{CN} 25$, os valores do pico tiveram variações menores e isto era esperado, pois representavam baixos potenciais de produção de escoamento.

Ao considerar um mesmo valor de $\mathrm{CN}$, a abstração inicial apresentou efeitos lineares sobre o pico de vazão e o volume escoado. Afinal, a determinação da precipitação efetiva é feita pelo Modelo do SCS descontando-se, no início de cada evento, as abstraçòes iniciais. Assim, o escoamento superficial era computado somente quando o somatório das precipitações incrementais foi maior que o valor atribuído para as abstrações iniciais. Dessa forma, como seria o esperado, atribuições de valores de abstrações maiores ocasionaram uma redução no pico de vazão e nos volumes escoados.

O volume escoado apresentou o mesmo comportamento do pico de vazão. Para facilitar as comparaçōes, ele pode ser transformado em lâmina (mm) escoada através da Microbacia do Tinga simplesmente pela multiplicaçào do valor do volume por 1,224 . Por exemplo, o volume escoado de $1,5\left(1500 \mathrm{~m}^{3}\right)$ correspondeu a uma lâmina de $1,83 \mathrm{~mm}$.

\subsection{Simulação do escoamento sob cenários alternativos de ocupação}

Os tipos de ocupações utilizados nas simulações merecem alguns comentários. O de eucalipto foi o usado para as calibrações. Conforme descrito no Material e Métodos, a área de estudo era um reflorestamento antigo, apresentando uma abundante regeneração natural e uma série de condiçōes que favoreciam uma boa permeabilidade e baixo escoamento. Provavelmente, essas nào são as condições corriqueiras dos reflorestamentos com eucalipto, especialmente em áreas agrícolas com trânsito de máquinas. Na verdade, as condições da Microbacia do Tinga estão mais próximas às de florestas nativas do que às de reflorestamentos intensivos.

No presente estudo, a ocupação agricola com solo cultivado foi considerada aquela onde o solo está degradado e sem cobertura vegetal, portanto, com grande potencial de geração de escoamento. Cabe comentar que as práticas agrícolas e a cobertura do solo modificam muito a habilidade do solo em absorver água. Por exemplo, 
Selby (1993) argumentou que apenas uma passagem de trator já é suficiente para reduzir pela metade a macroporosidade e a capacidade de infiltração em $80 \%$. A compactação pelas máquinas ou por animais (Schneider et al, 1978) pode ser tão grande que a infiltração tende a apresentar valores muito menores do que em áreas florestadas.

$\mathrm{Na}$ condição intermediária entre uma floresta e um cultivo mal conduzido está o plantio direto, com menor potencial de geração de escoamento graças às diversas condições que facilitam a infiltração e a permeabilidade. Entre elas, é possível citar a presença de cobertura vegetal na superficie, a maior rugosidade da superficie, a maior porosidade, a maior estabilidade dos agregados e o menor selamento superficial. Ainda, a maior capacidade de infiltração e de armazenamento de água no solo reduz o potencial de geração de escoamento, conseqüentemente, o da erosão. Ademais, a quantidade de caminhos preferenciais em macroporos decorrentes da ação da fauna proporciona a redistribuição de água no perfil mais rápida. Portanto, o $\mathrm{CN} 40$ atribuído ao plantio direto para as simulações pôde ser considerado um valor razoável. Indicações das tabelas de $\mathrm{CN}$ e da literatura também nortearam a aplicação do valor de $\mathrm{CN}$ para o plantio direto.

Tanto nas florestas quanto no plantio direto, um fator importante relacionado ao escoamento da água é a presença da cobertura vegetal morta na superfície. No caso das florestas, como mencionado anteriormente, ela é chamada de serrapilheira. Além de proteger o solo contra a erosão e melhorar as características fisicas, tem a importante função de armazenar água.

\subsubsection{Simulação do escoamento sob cenários considerando diferentes zonas de declividade}

Na Microbacia do Tinga, a zona com maior declividade está localizada mais próxima aos canais e a menos declivosa situa-se em regiōes mais distantes dos canais (Figura 25). Na aplicação da Hidrógrafa Unitária Adimensional do SCS, a determinação do tempo de retardamento é um ponto chave. Como já mencionado, ele está relacionado ao tempo de concentração, que, por sua vez, pode ser obtido a partir do 
tempo de percurso, conforme o Método da Velocidade. O tempo de percurso da água em cada sub-bacia, determinado dessa forma, pode ser visualizado na Tabela 18. Nessa tabela, considerando as metades mais e menos declivosas da bacia, conforme divisão apresentada na Figura 26, são também apresentadas as características usadas em sua determinação. A área mais declivosa, próxima aos canais, possui caminhos mais longos com declividade média de 6,6 \%. Já, a menos declivosa apresenta declividade média de $2,4 \%$. Os tempos de percursos calculados para as duas declividades apresentam grandes diferenças e são a principal causa das diferenças nas simulações efetuadas levando em conta as duas zonas de declividades.

Tabela 18 - Declividade do caminho mais longo seguido pela água na superficie do terreno, velocidade e tempos de percurso calculados conforme o Método da Velocidade USDA (1972), para a metade da bacia menos e mais declivosa.

\begin{tabular}{ccccccc}
\hline \multirow{2}{*}{ Sub-bacia } & \multicolumn{3}{c}{ Parte mais declivosa } & \multicolumn{3}{c}{ Parte menos declivosa } \\
\cline { 2 - 7 } & Decliv. (\%) & $\mathrm{V}(\mathrm{m} / \mathrm{s})$ & T.perc.(min) & Decliv. (\%) & $\mathrm{V}(\mathrm{m} / \mathrm{s})$ & T.perc.(min) \\
\hline 16 & 6,7 & 0,19 & 19,5 & 2,6 & 0,12 & 55,3 \\
17 & 7,9 & 0,21 & 17,4 & 2,5 & 0,12 & 44,4 \\
18 & 5,8 & 0,18 & 16,3 & 1,7 & 0,10 & 50,6 \\
19 & 6,3 & 0,19 & 24,4 & 2,1 & 0,11 & 18,1 \\
20 & 7,7 & 0,21 & 12,1 & 2,6 & 0,12 & 41,1 \\
21 & 6,4 & 0,19 & 15,9 & 2,8 & 0,13 & 28,4 \\
22 & 6,7 & 0,19 & 8,5 & 2,3 & 0,11 & 32,8 \\
23 & 6,6 & 0,19 & 8,0 & 2,5 & 0,12 & 45,3 \\
24 & 5,4 & 0,17 & 6,4 & 2,4 & 0,12 & 70,7 \\
\hline Média & 6,6 & 0,19 & 14,27 & 2,4 & 0,12 & 43,0 \\
\hline
\end{tabular}

As simulaçòes realizadas sob cenários estabelecidos a partir da divisào da área de estudo em duas zonas de declividade estão resumidas na Tabela 19 e representadas graficamente nas Figuras 69 a 72 .

Apesar do Método do Número da Curva não considerar a declividade para a determinação do volume escoado (a declividade é considerada em fase posterior, ou seja, na transformaçào da chuva efetiva em hidrógrafas pelo Método da Hidrógrafa Adimensional do SCS), existem evidências fortes de que a declividade, sua posição e 
Tabela 19 - Resumos de simulações considerando a área de estudo ocupada com eucalipto, pastagem, solo cultivado, plantio direto em alternâncias entre parte mais declivosa e menos. Sào apresentados os valores de número da curva $(\mathrm{CN})$ e abstrações iniciais $(\mathrm{Ai})$.

\begin{tabular}{|c|c|c|c|c|c|c|c|c|c|c|c|c|}
\hline \multirow[t]{5}{*}{ Evento } & $\begin{array}{l}\text { Parte mals } \\
\text { dedivosa }\end{array}$ & $\begin{array}{c}\text { Parte menos } \\
\text { declivosa }\end{array}$ & \multirow{2}{*}{$\begin{array}{c}\mathrm{CN} \\
\cdot \\
\end{array}$} & \multirow{2}{*}{$\begin{array}{c}A \\
(\mathrm{~mm})\end{array}$} & \multirow{2}{*}{$\begin{array}{l}\text { Preci- } \\
\text { pitaçåo } \\
(\mathrm{mm})\end{array}$} & \multirow{2}{*}{$\begin{array}{l}\text { Volume } \\
\text { (m3) }\end{array}$} & \multicolumn{2}{|c|}{$\begin{array}{l}\text { Escoamento } \\
\text { direto }\end{array}$} & \multicolumn{2}{|c|}{$\begin{array}{l}\text { Vazão de } \\
\text { pico }\end{array}$} & \multirow{2}{*}{$\begin{array}{l}\text { Pico } \\
\text { (hora) }\end{array}$} & \multirow{2}{*}{$\begin{array}{l}\text { Tempo" } \\
\text { de pico } \\
\text { (horas) }\end{array}$} \\
\hline & $(6.6 \%)$ & $(2,4 \%)$ & & & & & $(\mathrm{mm})$ & $\%^{*}$ & $(\mathrm{~m} 3 / \mathrm{s})$ & $\%^{*}$ & & \\
\hline & \multicolumn{2}{|c|}{ Ocupação } & & & & & & & & & & \\
\hline & Eucalipto & Eucalipto & (Obs.) & & 39,0 & 768 & 0,9 & 100 & 0,123 & 100 & $19: 00$ & $1: 40$ \\
\hline & Eucalipto & Eucalipto & 20 & 8 & Inicio & 736 & 0,9 & 96 & 0,119 & 97 & $19: 00$ & $1: 40$ \\
\hline \multirow[t]{6}{*}{ 27-Fev-96 } & Eucalipto & Cultivo & 42,7 & 8 & $17: 20$ & 2863 & 3,5 & 373 & 0,522 & 426 & 19.00 & $1: 40$ \\
\hline & Cultivo & Eucalipto & 42,3 & 8 & Fim & 2863 & 3,5 & 373 & 0,398 & 325 & $19: 20$ & $2: 00$ \\
\hline & Eucalipto & Pl. direto & 30,1 & 8 & $18: 30$ & 1554 & 1,9 & 202 & 0,230 & 188 & 1910 & $1: 50$ \\
\hline & $\mathrm{PI}$, direto & Eucalipto & 29,9 & 8 & & 1554 & 1,9 & 202 & 0,198 & 162 & 1920 & $2: 00$ \\
\hline & Eucalipto & Eucalipto & (Obs.) & & 51,0 & 966 & 1,2 & 100 & 0,132 & 100 & $4: 40$ & $3: 00$ \\
\hline & Eucalipto & Eucalipto & 16 & 10 & Inicio & 981 & 1,2 & 102 & 0,122 & 92 & $4: 40$ & $3: 00$ \\
\hline \multirow[t]{6}{*}{ 22-Jan-97 } & Eucalipto & Cultivo & 42,7 & 7 & $1: 40$ & 4090 & 5,0 & 423 & 0,604 & 457 & $4: 20$ & $2: 40$ \\
\hline & Cultivo & Eucalipto & 42,3 & 7 & Fim & 4090 & 5,0 & 423 & 0,481 & 364 & 500 & $3: 20$ \\
\hline & Eucalipto & PI. direto & 30,1 & 7 & $6: 00$ & 2454 & 3,0 & 254 & 0,313 & 237 & $4: 40$ & $3: 00$ \\
\hline & PI. direto & Eucalipto & 29,9 & 7 & & 2454 & 3,0 & 254 & 0,276 & 209 & $5: 00$ & $3: 20$ \\
\hline & Eucalipto & Eucalipto & (Obs.) & & 34,1 & 736 & 0,9 & 100 & 0,108 & 100 & $1: 30$ & $3: 10$ \\
\hline & Eucalipto & Eucalipto & 24 & 7 & Inicio & 687 & 0,8 & 93 & 0,116 & 108 & $1: 00$ & $2: 40$ \\
\hline \multirow[t]{6}{*}{ 24-Jan-97 } & Eucalipto & Cultivo & 42,7 & 5 & $22: 20$ & 1799 & 2,2 & 244 & 0,302 & 280 & $0: 50$ & $2: 30$ \\
\hline & Cultivo & Eucalipto & 42,3 & 5 & Fim & 1799 & 2,2 & 244 & 0,243 & 225 & 1.30 & 3.10 \\
\hline & Eucalipto & PI direto & 30,1 & 5 & $1: 10$ & 1063 & 1,3 & 144 & 0,158 & 147 & $1: 10$ & $2: 50$ \\
\hline & PI direto & Eucalipto & 29,9 & 5 & & 1063 & 1,3 & 144 & 0,140 & 130 & $1: 30$ & 310 \\
\hline & Eucalipto & Eucalipto & (Obs.) & & 40,3 & 720 & 0,9 & 100 & 0,112 & 100 & 21:10 & $2: 20$ \\
\hline & Eucalipto & Eucalipto & 18 & 7 & Início & 736 & 0,9 & 102 & 0,114 & 101 & 2100 & 210 \\
\hline \multirow[t]{6}{*}{ 15-Fev-98 } & Eucalipto & Cultivo & 42,7 & 7 & 18:50 & 2372 & 2,9 & 329 & 0.406 & 361 & 2110 & $2: 20$ \\
\hline & Cultivo & Eucalipto & 42,3 & 7 & Fim & 2372 & 2,9 & 329 & 0,323 & 287 & $21: 30$ & $2: 40$ \\
\hline & Eucalipto & PI. direto & 30,1 & 7 & $20: 50$ & 1390 & 1,7 & 193 & 0,210 & 187 & $21: 00$ & $2: 10$ \\
\hline & PI. direto & Eucalipto & 29,9 & 7 & & 1390 & 1,7 & 193 & 0,185 & 165 & $21: 10$ & $2: 20$ \\
\hline & Eucalipto & Eucalipto & (Obs.) & & 41,1 & 798 & 1,0 & 100 & 0,119 & 100 & & $2: 32$ \\
\hline & Eucalipto & Eucalipto & 19,5 & 8,0 & & 785 & 1,0 & 98 & 0.118 & 100 & & $2: 22$ \\
\hline \multirow[t]{4}{*}{ Média } & Eucalipto & Cultivo & 42,7 & 6,8 & & 2781 & 3.4 & 343 & 0.458 & 381 & & $2: 17$ \\
\hline & Cultivo & Eucalipto & 42,3 & 6,8 & & 2781 & 3,4 & 343 & 0,361 & 300 & & $2: 47$ \\
\hline & Eucalipto & Pl. direto & 30,1 & 6,8 & & 1615 & 2,0 & 198 & 0,228 & 189 & & $2: 27$ \\
\hline & PI. direto & Eucalipto & 30,1 & 6,8 & & 1615 & 2,0 & 198 & 0,228 & 189 & & $2: 27$ \\
\hline
\end{tabular}

Obs: As linhas em negrito correspondem aos dados observados.

* percentagem em relação aos dados observados

*aapos o inicio da precipitação 


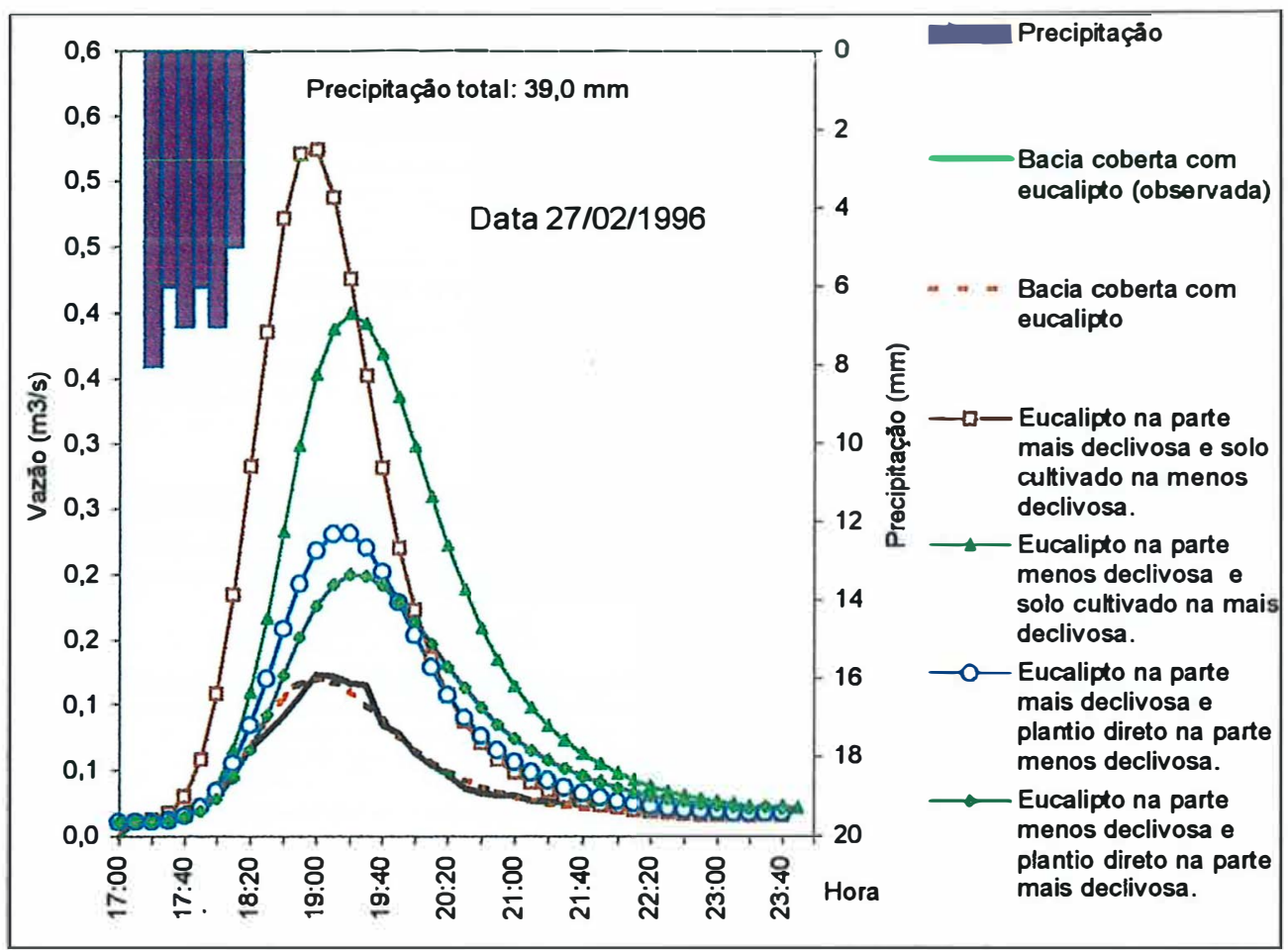

Figura 69 - Hidrógrafas simuladas e observada, para o evento do dia 27/02/1996.

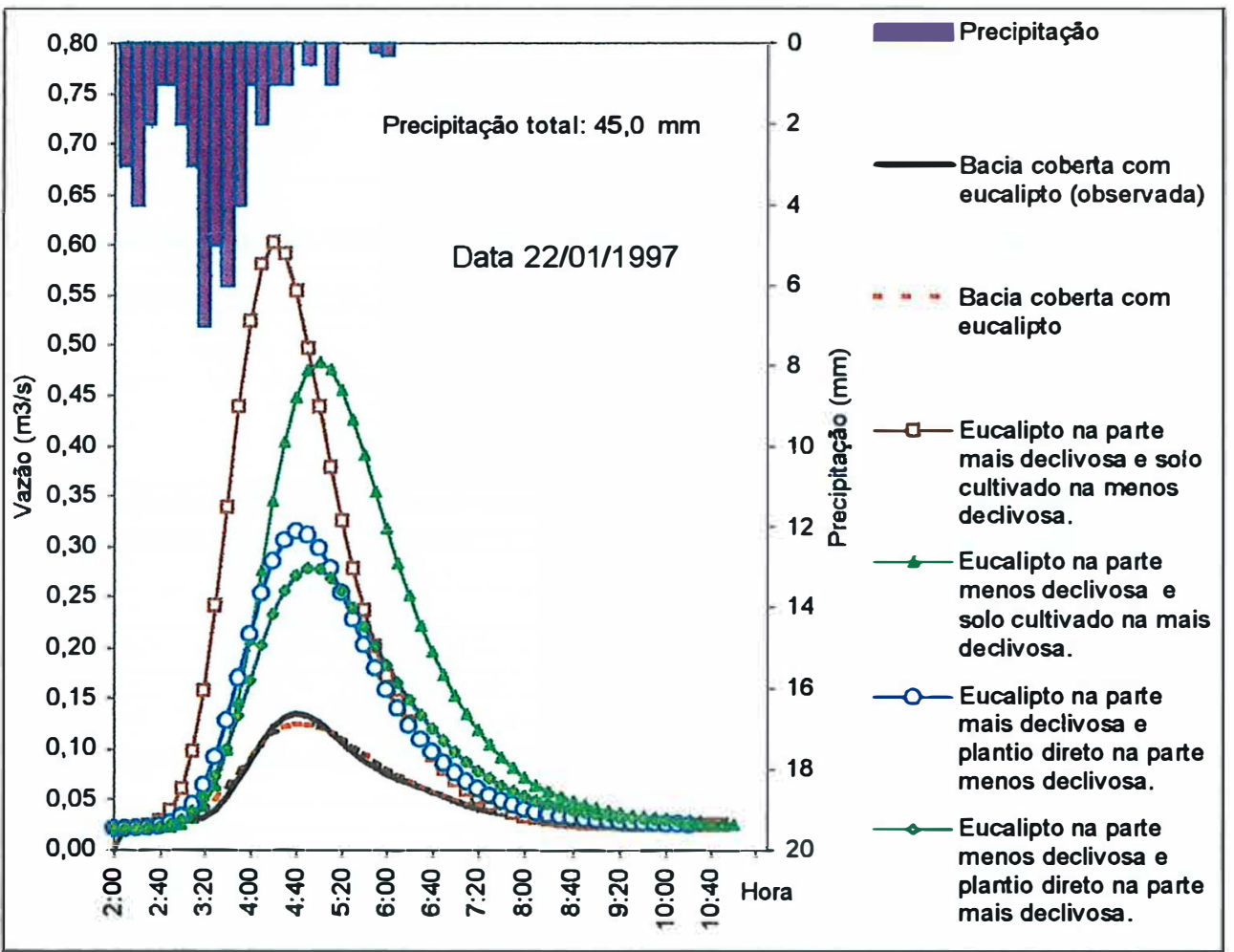

Figura 70 - Hidrógrafas simuladas e observada, para o evento do dia 22/01/1997. 


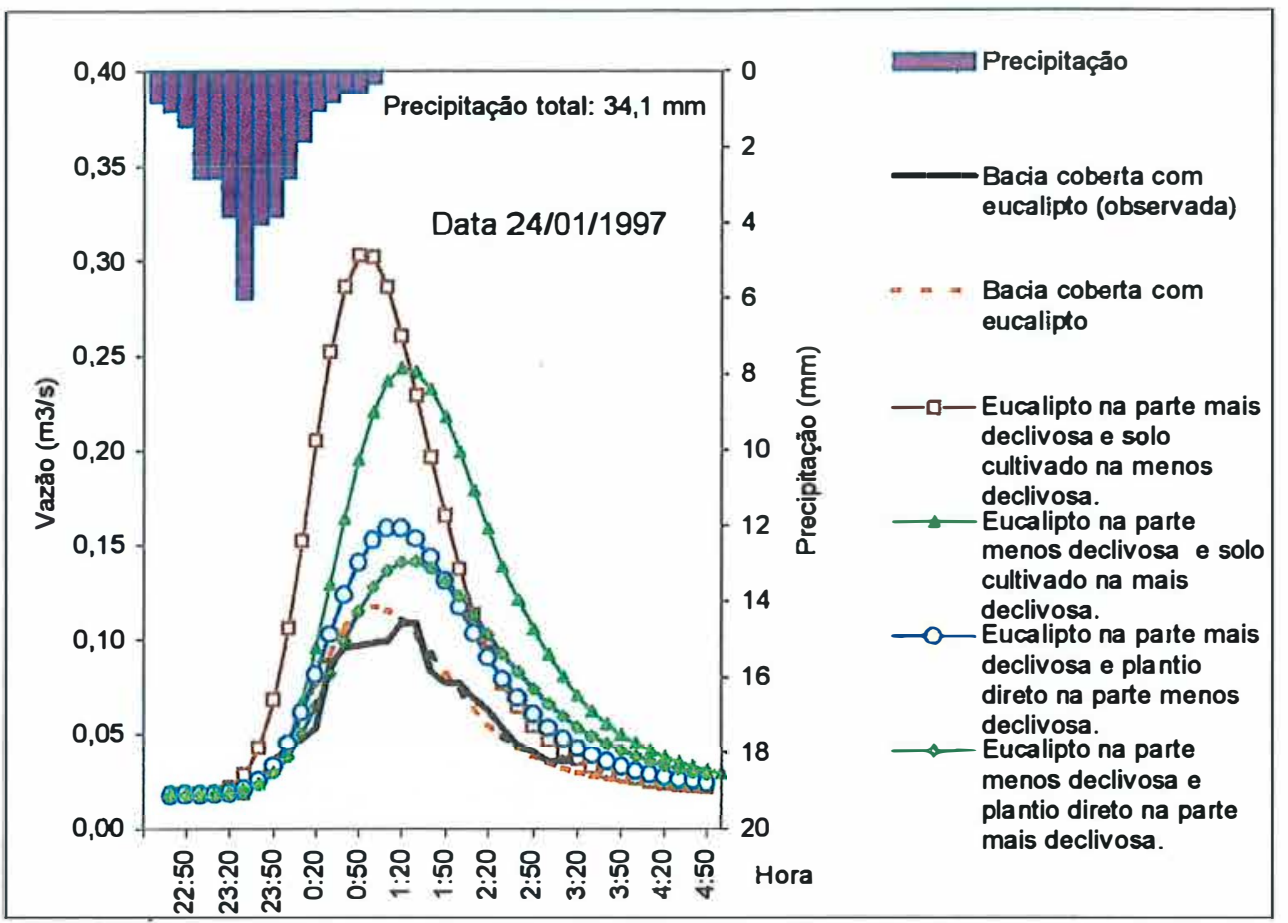

Figura 71 - Hidrógrafas simuladas e observada, para o evento do dia 24/01/1997.

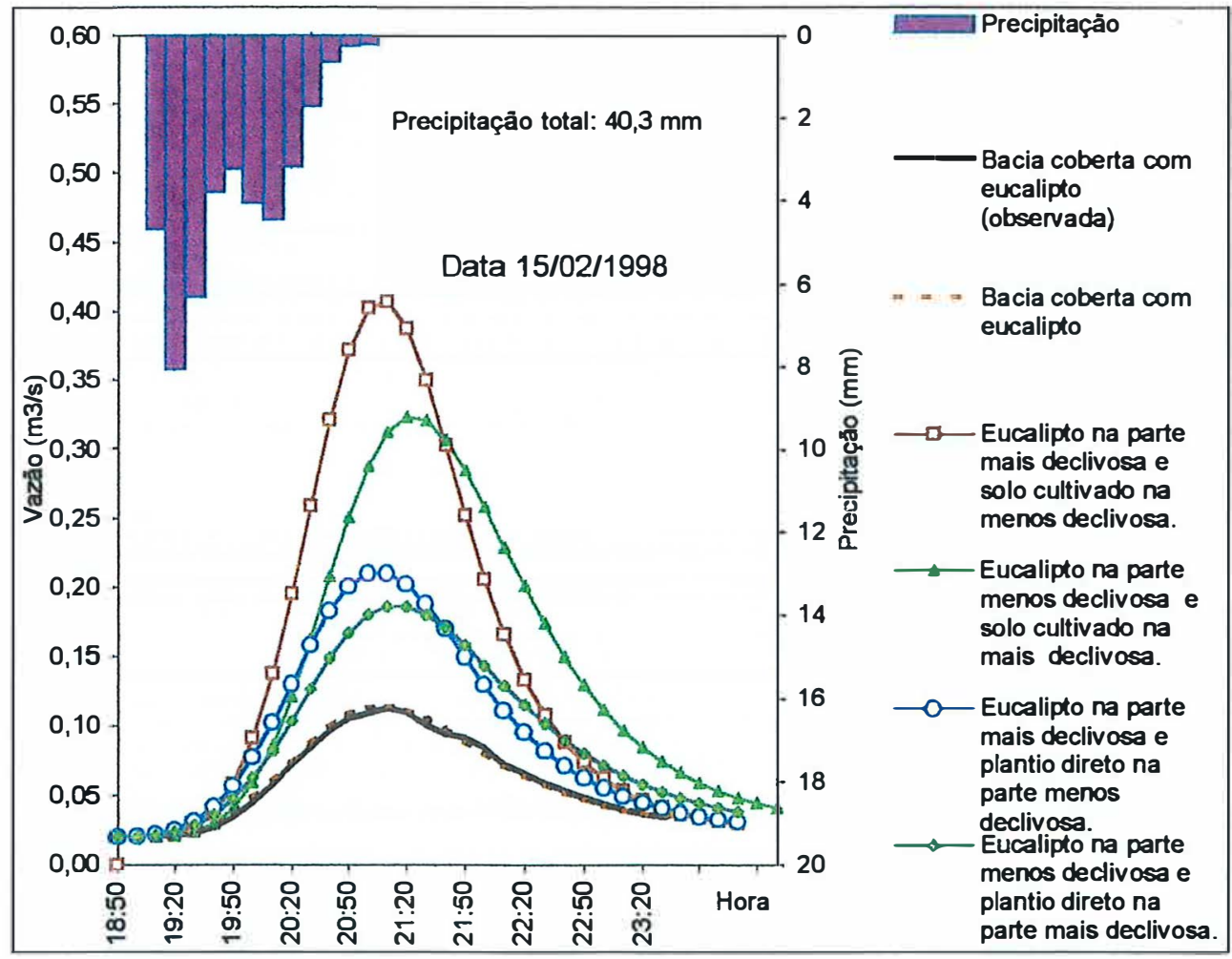

Figura 72 - Hidrógrafas simuladas e observada, para o evento do dia 15/02/1998. 
distribuição dentro de uma bacia apresentam influência tanto sobre os volumes como na forma das hidrógrafas geradas. A esse respeito, Cicco e Arcova (1998), estudando duas bacias montanhosas no Município de Cunha-SP, descobriram que a bacia com maior escoamento ( $18 \%$ a $22 \%$ da precipitação) tinha a parte mais íngreme (acima de $25 \%$ ) concentrada e ocupando até o terço inferior da bacia. Já a outra bacia, com menor escoamento (11\%), apresentava as áreas mais declivosas mais dispersas e localizadas junto aos divisores. Ambas bacias eram ocupadas com Floresta Latifoliada. A topografia, o tamanho e a forma da bacia influenciam o escoamento, especialmente, através do tempo de concentração. Em áreas declivosas, ele é menor do que em áreas planas.

Nos quatro eventos, os resultados das simulações apresentaram comportamento semelhante, destacando-se a combinação eucalipto e solo cultivado com os maiores valores de volume escoado e pico de vazão. Nessa combinação, o cenário eucalipto na parte menos declivosa e cultivo na parte mais declivosa produziu os maiores picos de vazão, apesar de escoar o mesmo volume. Somente com a inversão da posição da ocupação, o comportamento das hidrógrafas mudou, apresentando uma forma mais suave e com menores picos.

Para a combinação floresta e plantio direto, os resultados foram iguais para os quatro eventos, porém com volumes e picos menores, ficando em uma posição intermediária.

Ainda, quando a inversão do tipo de ocupação entre a parte mais declivosa e a menos declivosa (eucalipto na mais declivosa e cultivo na menos e viceversa) foi efetuada, não observou-se alteração no volume do escoamento direto. Apenas o tempo e pico de vazão variaram. O volume escoado permaneceu constante porque os coeficientes CN para cada uma das ocupações não foram mudados, as duas zonas de declividade somavam áreas exatamente iguais e os valores das abstrações iniciais também continuaran os mesmos. Como o Modelo do SCS, no decorrer da chuva, desconta as abstrações iniciais da precipitação os excessos parciais de precipitação transformavam-se em escoamento direto. Portanto, uma cuidadosa determinação das 
abstrações iniciais deve ser feita para que as simulações sejam satisfatórias, uma vez que o volume escoado depende delas. Então, as diferenças nos picos de vazão decorrentes da alternância de ocupações da parte mais declivosa para a menos são conseqüência das variações entre volumes e tempos de retardamento de cada sub-bacia, pois o volume total produzido pela área de estudo não variou.

Os resultados médios para os quatro eventos (Tabela 20) mostram que para um mesmo volume de escoamento, a inversão das ocupações eucalipto e solo cultivado na parte mais declivosa e menos declivosa proporcionou uma diferença de $26,9 \%$ no pico de vazão, maior quando o eucalipto se localizava na parte mais declivosa. Nessa condição, a diferença do tempo de pico foi de $6 \%$ (correspondente a 10 minutos).

Tabela 20 - Resultados médios de quatro eventos simulados com a inversão da ocupação entre a parte mais declivosa e menos declivosa.

\begin{tabular}{|c|c|c|c|c|c|c|}
\hline \multicolumn{2}{|c|}{ Ocupacões } & \multirow{2}{*}{$\begin{array}{c}\text { Escoam direto } \\
(\mathrm{mm})\end{array}$} & \multirow{2}{*}{$\begin{array}{l}\text { Qpico } \\
\text { (m3/s) }\end{array}$} & \multirow{2}{*}{$\begin{array}{c}\text { Aumento } \\
(\%)\end{array}$} & \multirow{2}{*}{$\begin{array}{l}T p^{*} \\
(\min )\end{array}$} & \multirow{2}{*}{$\begin{array}{c}\text { Aumento } \\
(\%)\end{array}$} \\
\hline Parte + decliv. & Parte-decliv & & & & & \\
\hline$(6,6 \%)$ & $(2,4 \%)$ & & & \multicolumn{3}{|c|}{ após início da chuva } \\
\hline Eucalipto & Cultivo & 3.4 & 0.458 & 26.9 & 177 & 6.0 \\
\hline S. cult. & Eucalipto & 3.4 & 0.361 & - & 167 & - \\
\hline Diferença & & - & 0.097 & = & 10 & - \\
\hline Eucalipto & PI. direto & 2.0 & 0.228 & 13.9 & 187 & 15.4 \\
\hline PI. direto & Eucalipto & 2.0 & 0.200 & - & 162 & - \\
\hline Diferença & & - & 0.028 & - & 25 & - \\
\hline
\end{tabular}

Já, a diferença do pico de vazão com a alternância entre eucalipto e plantio direto foi de $13,9 \%$, mais uma vez com o eucalipto na parte mais declivosa. Quanto ao tempo de pico, o aumento foi de $15,4 \%$ (correspondente a 25 minutos).

Cabe ressaltar que, ao se considerar a Microbacia do Tinga como um todo, apenas a forma da hidrógrafa mudou, resultante da alteração do tempo de retardamento. Por outro lado, como cada sub-bacia era coberta por mais de uma ocupação e, consequientemente, possuía mais de um $\mathrm{CN}$, cada uma delas apresentava um volume de escoamento diferente. Já, o somatório dos volumes de uma zona de declividade era igual ao da outra zona de declividade com a mesma ocupação. Afinal, o 
$\mathrm{CN}$ não leva em conta a declividade nem a intensidade da chuva. Portanto, para a mesma ocupação, resultados diferentes decorrem dos parâmetros de entrada relacionados ao tempo, ou seja, tempo de retardamento de bacias, utilizado na transformação da chuva em vazão, e tempo de retardamento de canais, usado na propagação da onda de cheia pelos canais.

Para a combinação eucalipto e solo cultivado, os valores do escoamento direto foram, em média, $345 \%$ superiores ao cenário bacia toda coberta por eucalipto. Já para a ocupação eucalipto e plantio direto, o aumento foi de $198 \%$, por causa dos valores de $\mathrm{CN}$ atribuídos.

Quanto ao pico da vazão, as simulações mostraram que, em média, houve aumentos de $381 \%$ e $300 \%$ para as duas combinações de eucalipto e solo cultivado e $189 \%$ e $166 \%$ para as de eucalipto e plantio direto. A diferença entre os dois primeiros valores e os dois últimos decorreu do menor potencial de geração de escoamento do plantio direto. Ao passo que as diferenças entre os dois valores de cada combinação é conseqüência da interação entre a ocupação e as características da bacia.

As combinações com eucalipto nas áreas mais declivosas promoveram maiores picos de vazão do que o inverso, ou seja, com o eucalipto nas áreas mais planas. Afinal, o eucalipto na parte mais declivosa (mais próxima dos canais) atrasa o fluxo, que chega ao ponto de descarga da área de estudo no mesmo instante que o fluxo da área mais à montante e menos declivosa, porém sob ocupação com alto potencial de geração de escoamento.

Quanto ao tempo de pico, o cenário eucalipto na parte menos declivosa e solo cultivado provocou um atraso em 30 minutos e em 15 minutos quando a outra ocupação era o plantio direto. Os tempos de pico estão distanciados de 10 minutos, por esse ter sido o tempo escolhido como intervalo entre as simulações. Pela Figura 23, é possivel perceber que, nas ocupações que menos favorecem a permeabilidade, os acréscimos na declividade promoveram maiores aumentos nas velocidades do fluxo superficial. Em parte, tal comportamento explica o maior tempo de pico quando a ocupação era eucalipto na parte mais plana. 
Com relação às hidrógrafas simuladas, todas apresentam a forma caracteristica da hidrógrafa adimensional do SCS, comportando-se de maneira semelhante nos quatro eventos.

O evento do dia 27/02/1996 (Figura 69), por ter sido de curta duração, intenso e com interrupção repentina da chuva, produziu hidrógrafas simuladas mais íngremes, com pico maior e rápida recessão. Ele gerou um total de $39 \mathrm{~mm}$ de escoamento. Na Figura 69, as duas hidrógrafas produzidas pela combinação eucalipto e solo cultivado apresentam volumes inferiores às curvas de $2863 \mathrm{~m}^{3}$. Apesar disso, com o eucalipto na parte mais declivosa e solo cultivado na menos, o pico de vazão foi de 0,52 $\mathrm{m}^{3} / \mathrm{s}$ contra $0,39 \mathrm{~m}^{3} / \mathrm{s}$, com a inversão das ocupações. O mesmo comportamento foi encontrado para as combinações de eucalipto com plantio direto, porém em menores intensidades. É evidente que tal comportamento não é constante, podendo ser diferente para outros eventos de chuvas, com volumes e padrões de intensidades diferentes.

$\mathrm{Na}$ Figura 69, bem como nas outras, é possivel constatar que as ocupações com $\mathrm{CN}$ maior apresentam ascensão e recessão mais rápidos. A fase de recessão, por não ter grande volume de fluxo subsuperficial, apresenta um declínio abrupto, com as vazões tendendo rapidamente ao fluxo básico. $\mathrm{O}$ mesmo não acontece com as ocupações floresta em toda a bacia ou plantio direto (mais permeáveis), cujo declínio da fase de recessão é mais lento, com vazões mais altas, em decorrência de um fluxo subsuperficial mais abundante.

$\mathrm{O}$ evento do dia 22/01/97 de $45 \mathrm{~mm}$ (Figura 70) apresentou um comportamento muito semelhante ao anterior. As duas hidrógrafas da combinação eucalipto e solo cultivado produzem volumes de $4090 \mathrm{~m}^{3}$. Para o cenário eucalipto na parte mais declivosa e cultivo na menos, o pico de vazão foi de $0,604 \mathrm{~m}^{3} / \mathrm{s}$ contra 0,481 $\mathrm{m}^{3} / \mathrm{s}$, invertendo-se as posições. Apesar dessa chuva ter maior duração que a anterior, parte considerável dela concentrou-se na posição intermediária do evento, com maior intensidade. Portanto, as características de ascensão e recessão são semelhantes ao evento anterior, com tendência da ascensão ser mais rápida. Afinal, as abstrações iniciais já haviam sido atendidas na fase inicial, onde o evento tinha menor intensidade. Sabe-se que as características das chuvas afetam muito a fase de ascensão da hidrógrafa. 
Já o evento do dia 24/01/1997 de $34 \mathrm{~mm}$ (Figura 71), distribuido em intensidade de padrão médio e com um pico na metade, produziu hidrógrafas com ascensão mais suave, com menores picos de vazão e fase de recessão mais lenta. $O$ efeito das ocupações foi semelhante ao dos eventos anteriores.

Por fim, o evento do dia 15/02/1998 de 40,3 mm, com um padrão de chuva adiantado, pico no inicio e decréscimo gradual da intensidade até o final, produziu hidrógrafas mais achatadas, com tempos de pico maiores, picos de vazão menores e fase de recessão mais longa (Figura 72).

\subsubsection{Simulação do escoamento sob cenários considerando parte alta e parte baixa}

As comparações simuladas entre a manutenção da ocupação atual, a substituição por pastagem em toda a área e a substituição parcial da floresta por pastagem na parte mais baixa ou na parte mais alta da Microbacia do Tinga estão representadas graficamente nas Figuras 73 a 76 e resumidas na Tabela 21. Para cada evento, são apresentadas as hidrógrafas simulada e observada. Os dados de precipitação e de entrada para a ocupação floresta em toda a bacia referem-se aos mesmos eventos utilizados na fase de calibração.

$\mathrm{O} \mathrm{CN}$ atribuido à floresta de eucalipto foi $20 \mathrm{e}$ à pastagem 60. Quanto às abstraçōes iniciais, considerou-se $8 \mathrm{~mm}$ para a floresta e $5,5 \mathrm{~mm}$ para a pastagem. A título de comparação, Crawford \& Linsley (1966) definiram que a interceptação de uma pastagem deveria ser a metade daquela referente à floresta para o Stanford Watershed Model. Em HEC-USACE (2000), existe a sugestão de que as abstraçōes iniciais para áreas florestadas podem ser consideradas como sendo entre $10 \%$ e $20 \%$ da precipitação. Para áreas urbanas, a sugestão é que as abstrações sejam de $2,5 \mathrm{~mm}$ a $5 \mathrm{~mm}$.

Nos quatro eventos, os resultados foram semelhantes. A área de contribuição da parte alta é de 46,8 ha $(57,3 \%)$ e a da parte baixa é de 34,9 ha $(42,7 \%)$. Esse fato não permite que sejam feitas comparações diretas quando foi efetuada a altemância de ocupações eucalipto e pastagem entre a parte alta e baixa (dois últimos cenários de cada evento). 


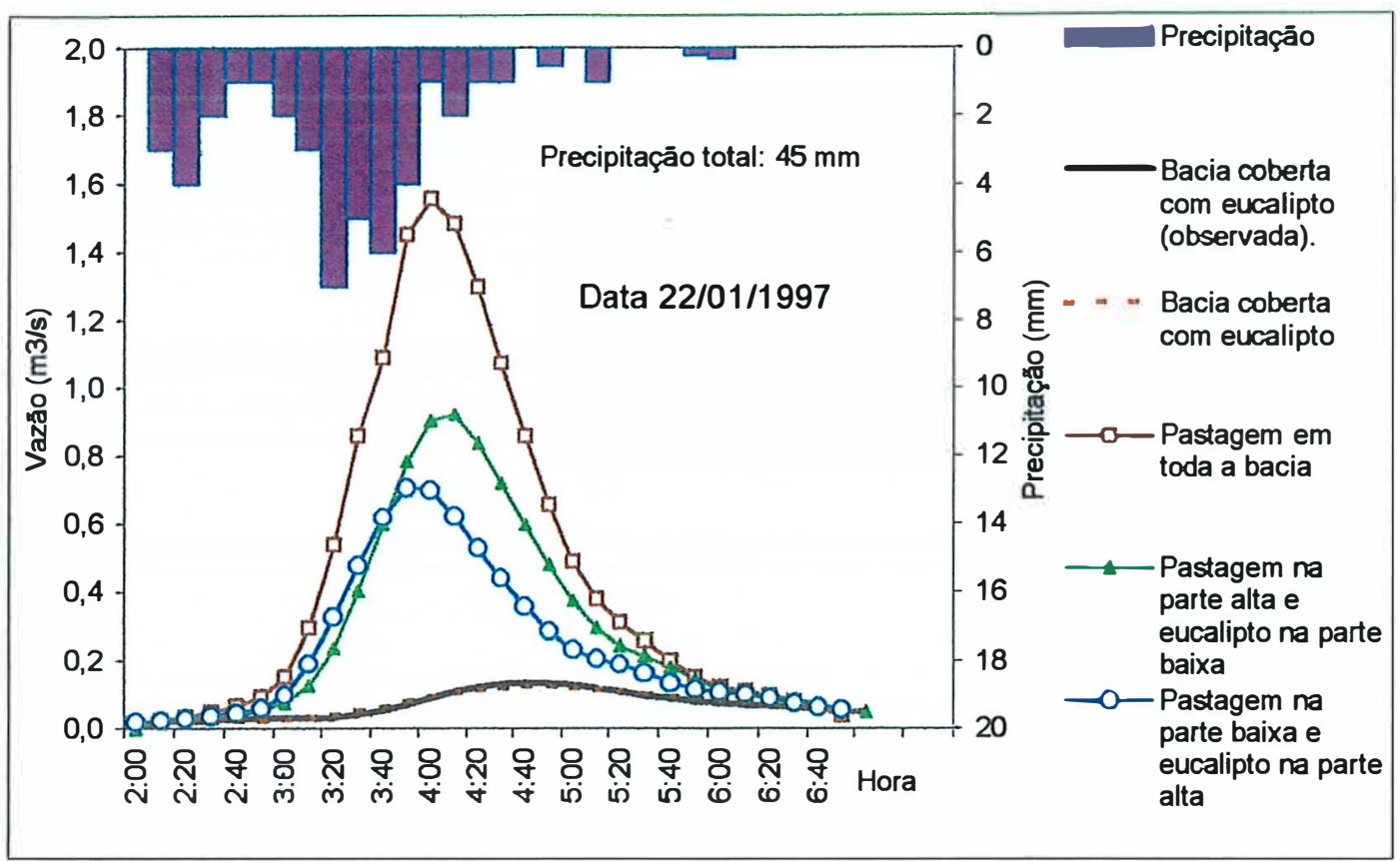

Figura 73 - Hidrógrafas simuladas e observada, para o evento do dia 22/01/1997.

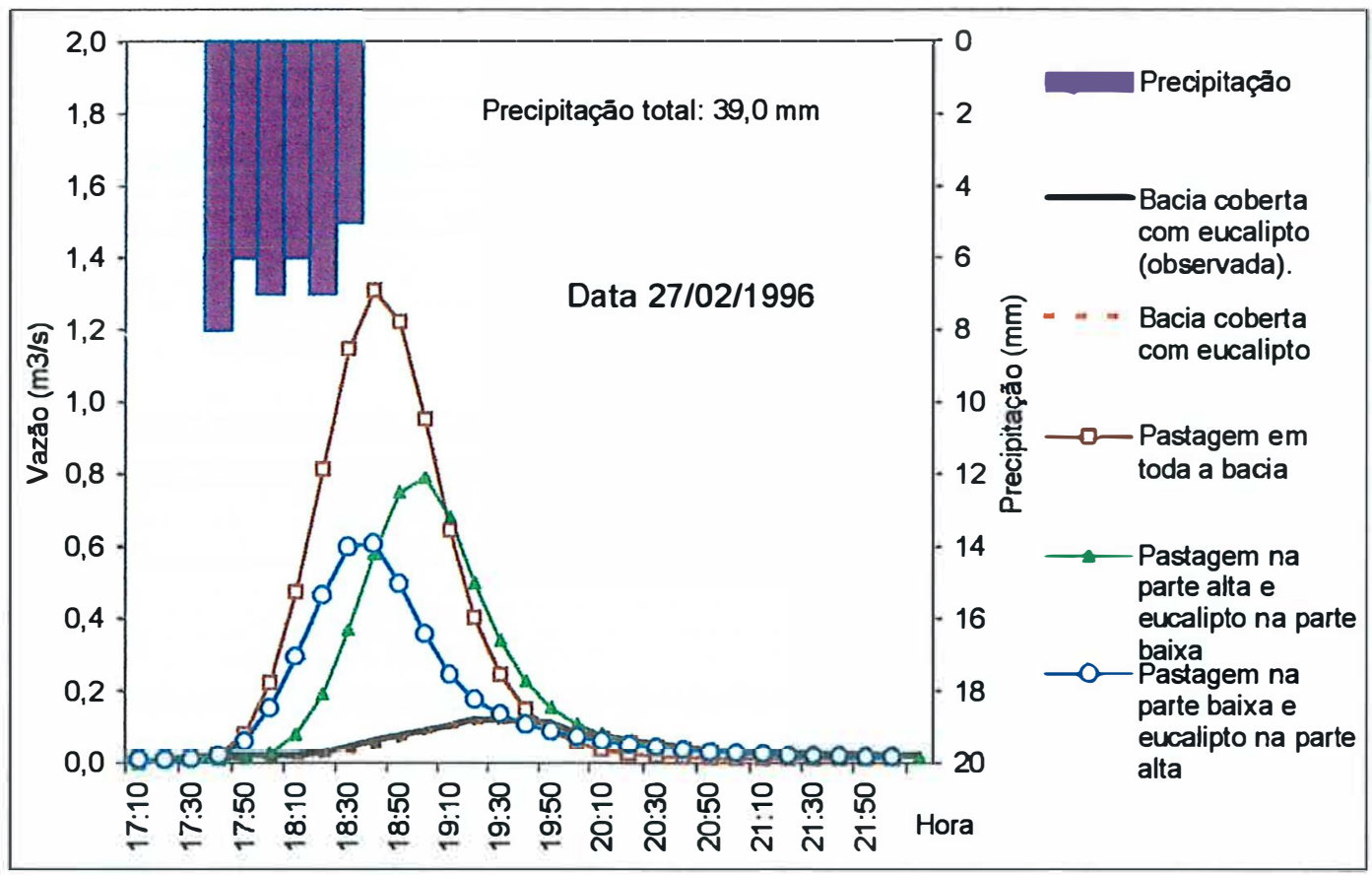

Figura 74 - Hidrógrafas simuladas e observada, para o evento do dia 27/02/1996. 


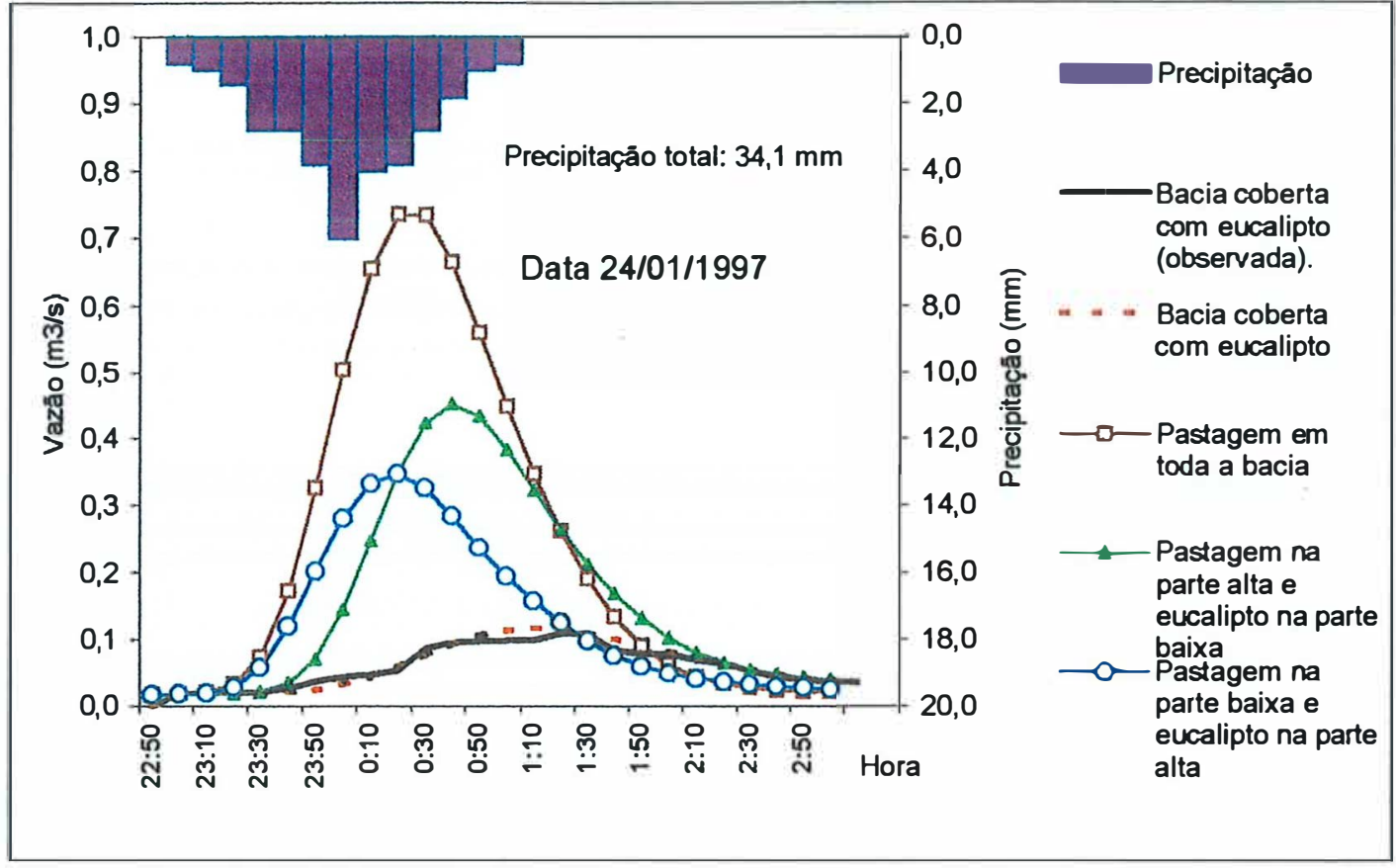

Figura 75 - Hidrógrafas simuladas e observada, para o evento do dia 24/01/1997.

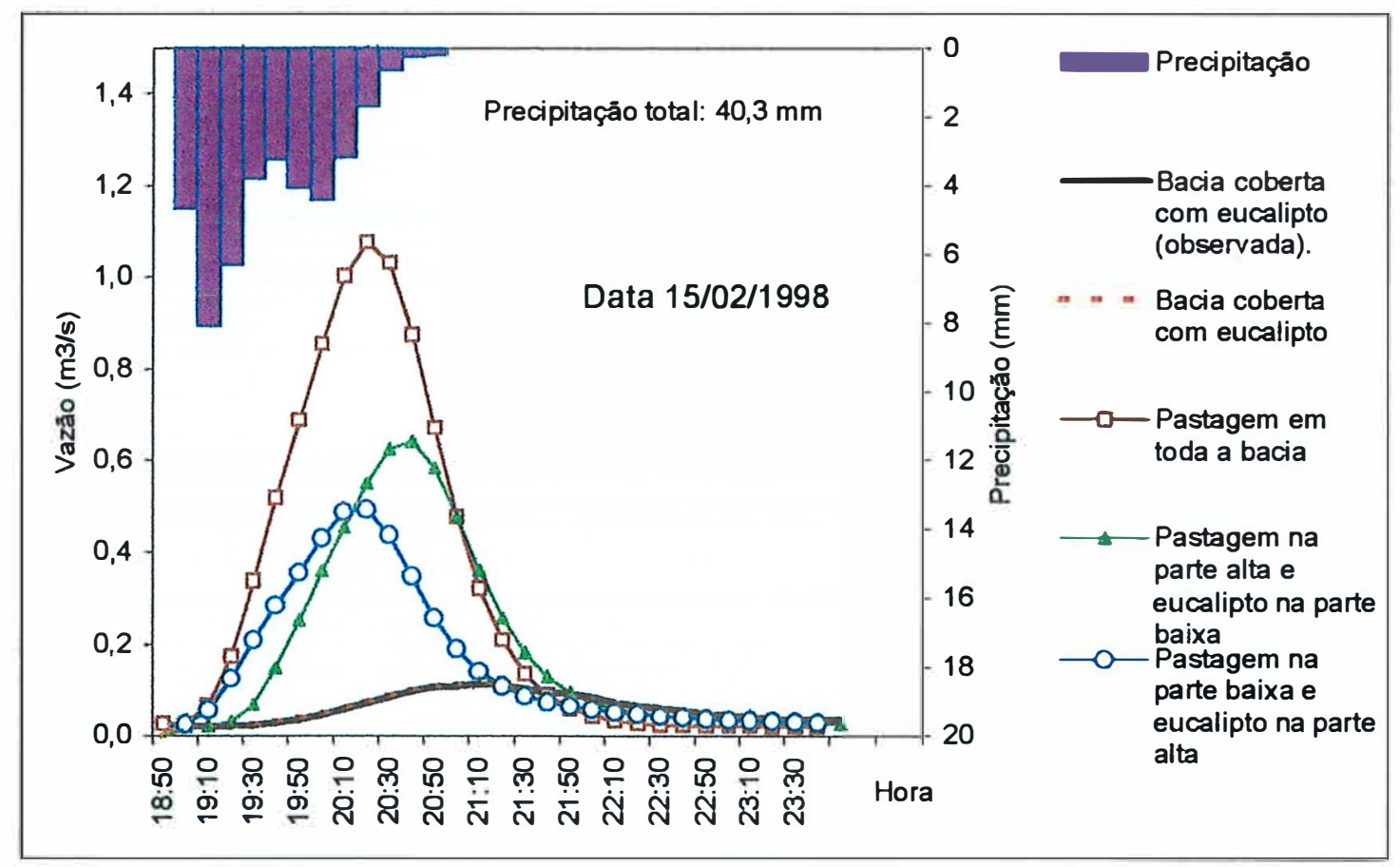

Figura 76 - Hidrógrafas simuladas e observada, para o evento do dia 15/02/1998. 
Tabela 21 - Resumos de simulações considerando a bacia ocupada com eucalipto, pastagem, pastagem na parte baixa e eucalipto na parte alta e eucalipto na parte baixa e pastagem na parte alta.

\begin{tabular}{|c|c|c|c|c|c|c|c|c|c|c|c|c|}
\hline \multirow[t]{2}{*}{ Evento } & \multirow{2}{*}{$\begin{array}{c}\text { Parte alta } \\
46,8 \text { ha } \\
57,30 \%\end{array}$} & \multirow{2}{*}{$\begin{array}{c}\text { Parte baixa } \\
34,9 \text { ha } \\
42,70 \%\end{array}$} & \multirow[t]{2}{*}{$\mathrm{CN}$} & \multirow{2}{*}{$\begin{array}{c}\mathrm{Al} \\
(\mathrm{mm})\end{array}$} & \multirow{2}{*}{$\begin{array}{c}\text { Preci- } \\
\text { pitaçäo } \\
(\mathrm{mm})\end{array}$} & \multicolumn{2}{|c|}{$\begin{array}{c}\text { Escoamento } \\
\text { direto }\end{array}$} & \multirow{2}{*}{$\begin{array}{c}\text { Volume } \\
\text { (m3) }\end{array}$} & \multicolumn{2}{|c|}{$\begin{array}{c}\text { Vazão de } \\
\text { pıco }\end{array}$} & \multirow{2}{*}{$\begin{array}{l}\text { Pico } \\
\text { (hora) }\end{array}$} & \multirow{2}{*}{$\begin{array}{l}\text { Tempo" } \\
\text { de pico } \\
\text { (horas) }\end{array}$} \\
\hline & & & & & & $(\mathrm{mm})$ & $\%$ & & $(\mathrm{~m} 3 / \mathrm{s})$ & $\%$ & & \\
\hline \multicolumn{13}{|c|}{ Ocupaçảo } \\
\hline \multirow{5}{*}{ 27-Fev-96 } & Eucalipto & Eucalipto & Obs. & & 39,0 & 0,94 & 100 & 767,9 & 0,123 & 100 & 19:00 & $1: 40$ \\
\hline & Eucalipto & Eucalipto & 20 & 8 & Inicio & 0,90 & 96 & 736,1 & 0,119 & 97 & $19: 00$ & $1: 40$ \\
\hline & Pastagem & Pastagem & 60 & 5 & $17: 20$ & 5,60 & 596 & 4580,2 & 1,210 & 988 & 1840 & 120 \\
\hline & Pastagem & Eucalipto & 42,9 & 6,3 & Fim & 3,60 & 383 & 2944,4 & 0,793 & 647 & $19: 00$ & $1: 40$ \\
\hline & Eucalipto & Pastagem & 37,1 & 6,7 & $\begin{array}{c}18: 30 \\
?\end{array}$ & 2,90 & 309 & 2371,9 & 0,612 & 500 & $18: 30$ & $1: 10$ \\
\hline \multirow{5}{*}{ 22-Jan-97 } & Eucalipto & Eucallpto & Obs. & & 51,0 & 1,18 & 100 & 965,8 & 0,132 & 100 & $4: 40$ & $3: 00$ \\
\hline & Eucalipto & Eucalipto & 16 & 10 & Inicio & 1,20 & 102 & 981,5 & 0,122 & 92 & 4.40 & $3: 00$ \\
\hline & Pastagem & Pastagem & 60 & 5 & $1: 40$ & 9,60 & 813 & 7851,8 & 1,553 & 1177 & 400 & $2: 20$ \\
\hline & Pastagem & Eucalipto & 41,2 & 7,1 & Fim & 6,00 & 508 & 4907,4 & 0,919 & 696 & $4: 10$ & $2: 30$ \\
\hline & Eucalipto & Pastagem & 34,8 & 7,9 & $6: 00$ & 4,80 & 406 & 3925,9 & 0,706 & 535 & $3: 50$ & $2: 10$ \\
\hline \multirow{5}{*}{ 24-Jan-97 } & Eucallpto & Eucallpto & Obs. & & 34,1 & 0,90 & 100 & 736,1 & 0,108 & 100 & $1: 30$ & $3: 10$ \\
\hline & Eucalipto & Eucalipto & 24 & 7 & Início & 0,84 & 93 & 687,0 & 0,116 & 108 & $1: 00$ & $1: 00$ \\
\hline & Pastagem & Pastagem & 60 & 5 & $22: 20$ & 4,10 & 456 & 3353,4 & 0,735 & 683 & $0: 20$ & $0: 20$ \\
\hline & Pastagem & Eucalipto & 44,6 & 5,9 & Fim & 2,70 & 300 & 2208,3 & 0,451 & 419 & $0: 40$ & $0: 40$ \\
\hline & Eucalipto & Pastagem & 39,4 & 6,1 & $1: 10$ & 2,00 & 222 & 1635,8 & 0,347 & 322 & $0: 20$ & $0: 20$ \\
\hline \multirow{5}{*}{$15-F e v-98$} & Eucallpto & Eucallpto & Obs. & & 40,3 & 0,88 & 100 & 720,2 & 0,112 & 100 & $21: 20$ & $2: 30$ \\
\hline & Eucalipto & Eucalipto & 18 & 7 & Inicio & 0,90 & 102 & 736,1 & 0,114 & 101 & $21: 10$ & $2: 20$ \\
\hline & Pastagem & Pastagem & 60 & 7 & $18: 50$ & 5,9 & 670 & 4825,6 & 1,076 & 957 & $20: 20$ & 130 \\
\hline & Pastagem & Eucalipto & 42,1 & 5,9 & Fim & 3,7 & 420 & 3026,2 & 0.641 & 570 & $20: 40$ & $1: 50$ \\
\hline & Eucalipto & Pastagem & 35,8 & 6,1 & $20: 50$ & 2,9 & 329 & 2371,9 & 0.492 & 438 & $20: 10$ & $1: 20$ \\
\hline \multirow{5}{*}{ Medlas } & Eucallpto & Eucallpto & Obs. & & & 0,98 & 100 & 797,5 & 0,119 & 100 & & $2: 35$ \\
\hline & Eucalipto & Eucalipto & 19,5 & 8.0 & & 0,96 & 98 & 785,2 & 0,118 & 100 & & $2: 00$ \\
\hline & Pastagem & Pastagem & 60,0 & 5,5 & & 6,30 & 634 & 5152,8 & 1,144 & 951 & & $1: 22$ \\
\hline & Pastagem & Eucalipto & 42,7 & 6,3 & & 4,00 & 403 & 3271,6 & 0,701 & 583 & & $1: 40$ \\
\hline & Eucalipto & Pastagem & 36,8 & 6,7 & & 3,15 & 317 & 2576,4 & 0,539 & 449 & & $1: 15$ \\
\hline
\end{tabular}

Obs: As linhas em negrito correspondem aos dados observados.

* percentagem em relação aos dados observados

*após o início da precipitação

A principal diferença ocorreu quando a ocupação da área de estudo foi substituída totalmente de eucalipto bem manejado para pastagem mal manejada. Assim, o aumento médio do escoamento direto entre os quatro eventos simulados foi de $634 \%$. Ao passo que para o pico de vazão, o aumento médio foi de $951 \%$. É importante considerar, em vista desses resultados, que não houve linearidade entre o aumento dos volumes de chuva efetiva e os picos de vazão. Portanto, uma ocupação que promova 
maior retardamento do fluxo em direção aos canais colaboraria para que ocorressem picos menores. Esta informação pode ser, por exemplo, útil em dimensionamentos, se o objetivo principal for a redução do pico.

Esse aumento deve-se aos métodos usados para a determinação do tempo de retardamento de bacias e canais. Mas, deve-se ter cuidado na aplicação do Modelo do SCS, pois a restituição da forma das hidrógrafas depende totalmente do tempo de retardamento. Caso este valor não for bem estimado todo os resultados estarão comprometidos.

Nas simulações, os tempos para atingir o pico de vazão foram, em média, 73 minutos (2:35-1:22=73) mais adiantados na área da área de estudo totalmente coberta por pastagens do que coberta por eucalipto. O curioso é que o cenário pastagem na parte baixa e eucalipto na parte alta apresentou pico de vazão mais adiantado ainda, 80 minutos em média $(2: 35-1: 15=80)$. Afinal, houve uma dessincronização dos picos, pois com pastagem na parte baixa, o tempo de pico menor e com pouca contribuição do eucalipto na parte alta, a vazão foi reduzida. Já com a bacia toda coberta por pasto, o pico de vazão atrasava e ambas as partes contribuiam, resultando no maior pico.

O cenário floresta de eucalipto na parte baixa e pastagem na parte alta proporcionou um tempo de pico, em média, 33 minutos anterior ao tempo de pico da ocupação com eucalipto, portanto, 22 minutos mais atrasado quando comparado ao cenário inverso, ou seja floresta na parte alta e pastagem na parte baixa. Nesse caso, além do caminho mais longo seguido pela água na parte baixa, o eucalipto promoveu maior achatamento da hidrógrafa. Conseqüentemente, o tempo de pico foi atingido somente quando a parte de cima contribuiu com maior área. A subdivisão da área de estudo em sub-bacias fez com que o comprimento dos caminhos mais longos seguidos pelo fluxo apresentassem valores bem maiores para a parte baixa, $152 \mathrm{~m}$ mais longo $(22 \%)$ do que para a parte alta.

A ocupação pastagem proporcionou uma ascensão rápida da hidrógrafa, sendo que a recessão foi curta. Esse comportamento da simulação decorreu da predominância do fluxo hortoniano sob pasto, decorrente da baixa capacidade de infiltração nesse tipo de ocupação. Porém, valores tão altos para as ocupações com 
pastagem também podem ser atribuídos à inadequação dos modelos utilizados ou aos CN's determinados para as ocupações, uma vez que os mesmos foram determinados para condições dos EUA e adaptados ao Brasil por Setzer \& Porto (1979).

As áreas de contribuição da parte alta e parte baixa são diferentes, portanto, não podem ser feitas comparações diretas. Na Tabela 22, os resultados são apresentados em unidades de vazão e escoamento por $\mathrm{km}^{2}$ com a finalidade de estudálas. A junção 4 recebe a contribuição da área de drenagem da parte alta e a junção 2 recebe a drenagem de toda a área da bacia, inclusive da parte alta.

Tabela 22 - Pico de vazão $\left(\mathrm{m}^{3} / \mathrm{s} / \mathrm{km}^{2}\right)$ e volume de escoamento direto $\left(\mathrm{m}^{3} / \mathrm{km}^{2}\right)$, considerando-se a junção 4 (ponto de drenagem da parte alta) e junção 2 (ponto de drenagem de toda a área da microbacia).

\begin{tabular}{|c|c|c|c|c|c|c|}
\hline \multirow[t]{2}{*}{ Evento } & \multicolumn{2}{|c|}{ Ocupação } & \multicolumn{2}{|c|}{ Vazảo Pico $\left(\mathrm{m}^{3} / \mathrm{s} / \mathrm{km}^{2}\right)$} & \multicolumn{2}{|c|}{ Volume $\left(\mathrm{m}^{3} / \mathrm{km}^{2}\right)$} \\
\hline & Parte alta & Parte baixa & $\begin{array}{l}\text { Parte alta } \\
\text { (Juncảo 4) }\end{array}$ & $\begin{array}{l}\text { Parte baixa } \\
\text { (Junçao 2) }\end{array}$ & $\begin{array}{l}\text { Parte alta } \\
\text { (Junção 4) }\end{array}$ & $\begin{array}{l}\text { Parte baixa } \\
\text { (Juncão 2) }\end{array}$ \\
\hline 27-Fev-96 & $\begin{array}{l}\text { Eucalipto } \\
\text { Pastagem } \\
\text { Pastagem } \\
\text { Eucalipto }\end{array}$ & $\begin{array}{l}\text { Eucalipto } \\
\text { Pastagem } \\
\text { Eucalipto } \\
\text { Pastagem }\end{array}$ & $\begin{array}{l}0,149 \\
1,796 \\
1,796 \\
0,149\end{array}$ & $\begin{array}{l}0,143 \\
1,601 \\
0,964 \\
0,743\end{array}$ & $\begin{array}{l}0,913 \\
5,597 \\
5,597 \\
0,913\end{array}$ & $\begin{array}{l}0,913 \\
5,597 \\
3,596 \\
2,914\end{array}$ \\
\hline 22-Jan-97 & $\begin{array}{l}\text { Eucalipto } \\
\text { Pastagem } \\
\text { Pastagem } \\
\text { Eucalipto }\end{array}$ & $\begin{array}{l}\text { Eucalipto } \\
\text { Pastagem } \\
\text { Eucalipto } \\
\text { Pastagem }\end{array}$ & $\begin{array}{l}0,151 \\
2,025 \\
2,025 \\
0,147\end{array}$ & $\begin{array}{l}0,146 \\
1,897 \\
1,120 \\
0,860\end{array}$ & $\begin{array}{l}1,216 \\
9,665 \\
9,665 \\
1,215\end{array}$ & $\begin{array}{l}1,214 \\
9,665 \\
6,055 \\
4,823\end{array}$ \\
\hline 24-Jan-97 & $\begin{array}{l}\text { Eucalipto } \\
\text { Pastagem } \\
\text { Pastagem } \\
\text { Eucalipto }\end{array}$ & $\begin{array}{l}\text { Eucalipto } \\
\text { Pastagem } \\
\text { Eucalipto } \\
\text { Pastagem }\end{array}$ & $\begin{array}{l}0,141 \\
0,955 \\
0,955 \\
0,077\end{array}$ & $\begin{array}{l}0,138 \\
0,896 \\
0,549 \\
0,421\end{array}$ & $\begin{array}{l}0,865 \\
4,129 \\
4,129 \\
0,427\end{array}$ & $\begin{array}{l}0,864 \\
4,129 \\
2,726 \\
2,008\end{array}$ \\
\hline 15-Fev-98 & $\begin{array}{l}\text { Eucalipto } \\
\text { Pastagem } \\
\text { Pastagem } \\
\text { Eucalipto }\end{array}$ & $\begin{array}{l}\text { Eucalipto } \\
\text { Pastagem } \\
\text { Eucalipto } \\
\text { Pastagem }\end{array}$ & $\begin{array}{l}0,139 \\
1,397 \\
1,397 \\
0,099\end{array}$ & $\begin{array}{l}0,134 \\
1,313 \\
0,780 \\
0,598\end{array}$ & $\begin{array}{l}0,920 \\
5,957 \\
5,957 \\
0,665\end{array}$ & $\begin{array}{l}0,917 \\
5,957 \\
3,695 \\
2,923\end{array}$ \\
\hline Médias & $\begin{array}{l}\text { Eucalipto } \\
\text { Pastagem } \\
\text { Pastagem } \\
\text { Eucalipto }\end{array}$ & $\begin{array}{l}\text { Eucalipto } \\
\text { Pastagem } \\
\text { Eucalipto } \\
\text { Pastagem }\end{array}$ & $\begin{array}{l}0,145 \\
1,543 \\
1,543 \\
0,118\end{array}$ & $\begin{array}{l}0,140 \\
1,427 \\
0,853 \\
0,656\end{array}$ & $\begin{array}{l}0,978 \\
6,337 \\
6,337 \\
0,805\end{array}$ & $\begin{array}{l}0,977 \\
6,337 \\
4,018 \\
3,167\end{array}$ \\
\hline
\end{tabular}


Os resultados mostram que os picos de vazão por $\mathrm{km}^{2}$ variam muito pouco entre a junção 2 e 4 , una vez que a área da junção 4 (parte alta) corresponde a $57 \%$ da área total da bacia. Além disso, entre a junção 4 e 2 as distâncias não são grandes, $560 \mathrm{~m}$, e a propagação da onda de cheia foi atrasada pelo Método do Retardamento Puro em apenas 17 minutos (Tabela 14 e Figura 46). Essa grande proporção de área da Microbacia do Tinga, além da proximidade em distância e tempo, colaborou para que a onda de cheia proveniente da junção 2 influencie os picos de vazão na parte inferior

Quanto aos volumes por $\mathrm{km}^{2}$, espera-se que não diferenciem entre a junção 4 e 2 para uma mesma ocupação. Afinal, o método usado para a determinação da chuva efetiva, ou seja, o Método do Número da Curva do SCS, não leva em conta a declividade, que é o principal fator que varia entre a área de drenagem da junção 4 e 2 . O método considera apenas informaçōes sobre o complexo solo, condiçòes da superficie e ocupação, que por sua vez apresentavam uniformidade em toda a bacia. Tanto para 0 pico de vazão por $\mathrm{km}^{2}$, como para o volume por $\mathrm{km}^{2}$, os efeitos são intensos quando ocorre a mudança de ocupação entre eucalipto e pastagem. Quanto ao volume, essas diferenças decorrem dos coeficientes $\mathrm{CN}$ atribuidos para pastagem e eucalipto.

\subsubsection{Considerações complementares}

As simulações mostrararn que as ocupações agricolas mal manejadas geram volumes de escoamento direto muito maiores e com picos de vazào mais altos do que as ocupações eucalipto ou florestas ou mesmo plantio direto. A despeito de tal fato já ser bem difundido, não deixa de ter relevància, pois sabe-se que o aumento do escoamento superficial na superfície do terreno promove a concentração do fluxo e a conseqüente erosão. Isso sem levar em consideração a perda de água da área de estudo, uma vez que a manutenção de um escoamento básico, como o que apresenta a Microbacia do Tinga, durante praticamente o ano todo (Figura 15), somente é conseguido com a manutenção da permeabilidade. E lembrando, a perrneabilidade permite que a maior parte da precipitação infiltre para camadas mais profundas e, 
lentamente, seja transformada em fluxo subterrâneo, fornecendo água com maior regularidade e qualidade.

É evidente que a manutenção de uma floresta com alta taxa de transpiração, como a do eucalipto, proporcione maior perda de água, afinal o processo de evapotranspiração é responsável pelo consumo de grande parte da água que chega na forma de precipitação. De acordo com Câmara (1999), para a Microbacia do Tinga, a quantidade de água evapotranspirada foi de $67 \%$ do total anual de chuvas. No entanto, essa perda atende a um uso produtivo da água, pois ela é necessária ao crescimento vegetal. O problema real reside nos grandes volumes de água que escoam superficialmente e rapidamente, uma vez que, além da perda de água que representam, são dotados de grande potencial destrutivo, causando erosão, assoreamento e transporte de poluentes aos cursos d'água.

Ficou claro que o posicionamento da ocupação dentro da área de estudo pode promover mudanças consideráveis na forma da hidrógrafa, pela dessincronização dos picos de vazão em cada uma das sub-bacias. Ainda, pode-se afirmar que a intensidade e o padrão temporal de distribuição das chuvas em interação com esse posicionamento da ocupação dentro da bacia influenciam a forma da hidrógrafa e, por conseguinte, o pico de escoamento direto produzido.

Como uma consideração geral, levando-se em conta a complexidade dos processos envolvidos na produção de escoamento e as diferentes formas de modelagem física, conceitual e empírica, desenvolvidas até hoje, muitas vezes, em linhas de pesquisas divergentes, talvez seja mais recomendável a abordagem integrada dos processos. Nesse caso, os modelos empíricos, como o do SCS, mostram-se, na prática, adequados, pois simplificam os problemas, caso esses se restrinjam à procura de resultados satisfatórios e não as suas causas. É unanimidade que os modelos de simulação do escoamento, para serem aplicados em planejamento, devem apresentar um equilíbrio entre simplicidade e precisão.

Apesar das críticas da literatura ao Modelo do SCS, as simulações efetuadas nesse trabalho mostraram que o mesmo pode ser uma boa ferramenta para o planejamento de microbacias hidrográficas. A despeito do consenso relacionado à 
dificuldade de atribuir valores de $\mathrm{CN}$ menores que 40 , essa limitação pode ser minimizada por intermédio de calibrações dos parâmetros. Originalmente desenvolvido para ser usado em planejamento de conservação do solo, esse modelo também tem sido adotado para áreas urbanas e florestadas (USDA, 1986).

Seria pertinente sugerir estudos adicionais para verificar os modelos utilizados e os números da curva determinados. Por outro lado, o Método do Número da Curva do SCS já foi extensivamente pesquisado, como pode ser comprovado pela farta literatura disponivel. Aos poucos, está sendo atingida a maturidade quanto a este método e isso inclui, também, o reconhecimento de suas limitações.

O uso de SIG permitiu a incorporação de informações espacializadas na construção do modelo de bacia no HEC-HMS. Não obstante o processamento automatizado do CRWR-PREPRO viabilize a construção de esquemas de bacias para áreas enormes e permita o maior detalhamento de bacias pequenas, constatou-se que a construção do banco de dados foi muito trabalhosa, mesmo considerando o tamanho pequeno da Microbacia do Tinga. Entretanto, uma vez construído o modelo de bacia parametrizado, foram somente necessários mais alguns parâmetros hidrológicos, facilmente disponiveis, para as simulações. 


\section{CONCLUSÕES}

Nas condições do presente trabalho e considerando as caracteristicas da Microbacia do Tinga, as seguintes conclusões puderam ser deduzidas:

O HEC-HMS, associado ao CRWR-PREPRO, constitue uma excelente ferramenta para melhoria de simulações hidrológicas, pois permite criar uma estrutura interconectada de elementos de canais e bacias e determinar automaticamente paràmetros hidrológicos.

Os SIG's ajudam na simulação hidrológica pela incorporação de informações espacializadas, entretanto, para a modelagem de bacias de pequeno tamanho, são necessários dados espaciais e temporais com resolução adequada. A precisão dos resultados depende dessa resolução.

Os SIG's, associados a sistemas de simulação hidrológicos, são recomendáveis para determinação do escoamento em bacias hidrográficas com maior precisão, pois permitem o uso de informações espacializadas facilmente disponiveis, melhorando as simulações e a confiabilidade. Entretanto, a construção do banco de dados requer esforços, especialmente quando se trabalha em microescala. Porém, após esse banco de dados estar pronto, as simulaçòes para diferentes cenários tornam-se fáceis.

As simulações baseadas no Método do Número da Curva, desde que providas de valores criteriosos ou com a devida calibração a partir de eventos observados de chuva e escoamento direto, produzem resultados satisfatórios e confiáveis para orientar uma ocupação adequada da bacia. 
Para uma dada ocupação heterogênea da bacia, a simples troca de posições das parcelas proporciona mudanças consideráveis na forma da hidrógrafa resultante, devido à dessincronização dos picos de vazào.

Observou-se que o padrão da distribuição temporal das chuvas em interação com o posicionamento da ocupação dentro da bacia influenciam a forma da hidrógrafa resultante. Assim, conhecendo-se esse padrão, o planejamento de ocupação da bacia também pode ser orientado por essa característica climática.

Quando a parte mais declivosa da bacia foi ocupada com eucalipto ( $50 \%$ da área), mantendo o restante ocupado com culturas, o pico de vazão resultante foi $26,9 \%$ maior que o do cenário inverso, pois o tempo de retardamento foi menor. 


\section{REFERÊNCIAS BIBLIOGRÁFICAS}

AGIRALIOGLU, N.; SINGH, V.P. Kinematic wave nomographs for time of concentration and lag time. Irrigation and Power, v. 38, n. 4, p.351-358, 1981.

AMORIM, R.F.; LEOPOLDO, P.R. Modelo SCS ajustado para as condições locais da bacia do rio Paraíso. Revista Energia na Agricultura, v.11, n.11, p.1-14, 1996.

ASCE. Hydrology handbook. 2.ed. New York: American Society of Civil Engineers, 1996. 330p.

BAGGIO, A J; SCHREINER, H. G. Análise de um sistema silvipastoril com Pinnus elliotti e gado de corte. Boletim de Pesquisas Florestais, v.16, p.19-29, Jun. 1988.

BAO, J.; MAIDMENT, D.R.; OLIVERA, F. Using GIS for hidrologic datapreprocessing and modeling in Texas. Center for Research in Water Resources, The University of Texas at Austin, 1997. (CRWR Online Report 97-4)

BOSCH, J.M.: HEWLETT, J.D. A review of catchment experiments to determine the effect of vegetation changes on water yield and evapotranspiration. Journal of Hydrology, v.55, p.3-23, 1982.

BOUGHTON, W.C. Evaluation partial areas of wathershed runoff. Journal of Irrigation and Drainage Engineering, v.113, n.3, p.356 - 366, Aug. 1987. 
BRASI. Ministério da Agricultura. Levantamento de reconhecimento dos solos do Estado de São Paulo. Rio de Janeiro, 1960. 634p. (Boletim Técnico, 12)

BROOKS, K. N.; FOLLIOTT, P.F.; GREGERSEN; H. M.; THAMES, J. L. Hydrology and management of watersheds. Iowa: Iowa State University, 1991. $391 \mathrm{p}$.

BRUIJNZEEL, L.A. Predicting the hydrological impacts of tropical forest conversion: The need for integrated research.. In: GASH, J.H.C.; NOBRE, C.A; ROBERTS, J.M.; VICTORIA, R.L. Amazonian deforestation and climate. Chichester: Jonh Wiley \& Co, 1996. cap. 2

BURROUGH, P. A. Principles of geographical information systems for land resources assessment. Oxford: Clarendon, 1986. 193p.

CÂMARA, C.D. Efeitos do corte raso de eucalipto sobre o balanço hídrico e a ciclagem de nutrientes em uma microbacia experimental. Piracicaba, 1999. 87p. Dissertação (M.S.) - Escola Superior de Agricultura "Luiz de Queiroz", Universidade de São Paulo.

CÂMARA, G. Anatomia de sistemas de informaçòes geográficas: visão atual e perspectivas de evolução. In: ASSAD, E. D.; SANO, E. E. Sistemas de informações geográficas: aplicaçòes na Agricultura. Planaltina: Embrapa-CPAC, 1993. cap. 1, p. 15-37.

CARMO, G.F. Efeito de três tipos de cobertura vegetal sobre a velocidade de infiltração básica (VIB) Viçosa, 1976. 32p. Dissertação (M.S.) - Universidade Federal de Viçosa. 
CAZORZI, F.; FONTANA, G.D. Effects of land use changes on flood hazard: a case study. In: ANNUAL SYMPOSIUM ON GEOGRAPHIC INFORMATION SYSTEMS IN FORESTRY, ENVIRONMENTAL AND NATURAL RESOURCES MANAGEMENT, 8., Vancouver, 1994. Proceedings. Ottawa: Suply and Services, 1994. p. 453-461.

CHARLEY, W.; PABST, A.; PETERS, J. The hydrologic modeling system (HECHMS): design and development issues. In: CONGRESS ON COMPUTING IN CIVIL ENGINEERING, 2., Atlanta, 1995. Proceedings. Georgia: ASCE, 1995. p.131-138.

CHAVES, H.M.L. Efeitos do plantio direto sobre o meio ambiente. In: SATURNINO, H.M.; LANDERS, J.N. (Eds.). O meio ambiente e o plantio direto. Brasilia: Embrapa-SPI, 1997. p.57-66.

CHIENG, S.; LUO, J. Application of GIS to peak flow estimation. In: CONFERENCE OF APPLICATION OF ADVANCED INFORMATION TECNOLOGIES: EFFETIVE MANAGEMENT OF NATURAL RESOURCES, Spocane (Washington), 1993. Proceedings. St. Joseph-USA: ASAE, 1993. p.475-484.

CHOW, V. T. Open-channel hydraulics. New York: McGraw-Hill, 1959. 680p

CHOW, V.T.; MAIDMENT, D.R.; MAYS, L.W. Applied hydrology. New York: McGraw-Hill, 1988. 572p.

CICCO, V. de; ARCOVA, F.C.S. Pesquisas em microbacias hidrográficas no laboratório de hidrologia florestal Walter Emmerich, Cunha-SP: quantidade de água. In: FORUM GEO-HIDRO-BIOLOGIA, 1., Curitiba, 1998. Anais. Curitiba: UFPR, 1998. p.30-38. 
CLARK, C.O. Storage and the unit hydrograph transactions of ASCE. American Society Civil Engeneers, v.110, p.1419-1488, 1945.

COELHO NETO, A. L. Hidrologia de encosta na interface com a Geomorfologia. In: GUERRA, J.T.; CUNHA, S.B. Geomorfologia: uma atualizaçào de bases e conceitos. Rio de Janeiro: Bertrand Brasil, 1995. p.93-148.

COELHO NETO, A. L. Overland production in a tropical rainforest catchment: the role of litter cover. Catena, v.14, n.3, p.213-231, 1987.

COELHO NETO, A. L.; SANCHES, M. E.; PEIXOTO, M.N. Precipitação e interceptação florestal em ambiente tropical montanhoso. Revista Brasileira de Engenharia, v.4, n.2, 1986.

CONNOLLY, R.D. Modelling effects of soil structure on the water balance of soil-crop systems: a review. Soil \& Tillage Research, v.48, 1998. p.1-19

CONSULT. Mapa detalhado de solos do Horto Itatinga. Sào Paulo: Consultoria em Solos S/C LTDA, 1994. Escala 1:10.000.

CRAWFORD, M; LINSLEY, T. Digital simulation in hydrology: Stanford Watershed Model IV. Stanford: Stanford University, 1966. 210p. (Technical Report, n.39)

CRUCIANI,.D.E. A drenagem na agricultura. Sào Paulo: Nobel, 1989. 337p

DA ROS, D.; BORGA, M. Use of digital elevation model data for the derivation of the geomorphological instantaneous unit hydrograph. Hydrological Processes, v.11, p.13-33, 1997. 
DERPSCH, R.; ROTH, C.H.; SIDIRAS, N.; KÖPKE, U. Controle de erosão no Paraná, Brasil: sistemas de cobertura do solo, plantio direto e preparo conservacionista do solo. Trad. de I. Popper. Eschborn: GTZ/IAPAR, 1991. 272p.

DEUS, C.E. O papel da formiga saúva (Gênero Atta) na hidrologia e erosão do solo em ambiente tropical montanhoso de Bananal-SP. Rio de Janeiro, 1991. 236p. Dissertação (M.S.) - Universidade Federal do Rio de Janeiro.

DRAYTON, R. S.; WILDE, B.M.; HARRIS, J. H. K. Geographical information system approach to distributed modelling. Hydrological Processes, v.6, n.3, p.361-368, 1992.

DUGGER, A. Linking GIS with the hydrologic modeling system: an investigation of the midwest flood of 1993. Austin 1997. 148p. (Masters Report) University of Texas,

DUNNE, T. Field studies of hillslope flow processes. In: KIRKBY, M.J. (Ed.) Hillslope hydrology. Chichester:Jonh Wiley \& Sons, 1978. p.227-293.

DUNNE, T.; LEOPOLD, L.B. Water in Enviromental planning. San Francisco: Freemann, 1978. 818p.

ELTZ, F.L.F.; PEIXOTO, R.T.G.; JASTER, F. Efeitos de sistemas de preparo do solo nas propriedades físicas e químicas de um Latossolo Bruno álico. Revista Brasileira de Ciência do Solo, v.13, n.2, p.259-267, 1989.

ENGMAN, E. T. Roughness coefficients for routing surface runoff. Journal of Irrigation and Drainage Engineering. v.112, n. 1, 1986. p.39:53 
ESRI. Cell-based modeling with GRID. Redlands: Environmental Systems Research Institute, 1994. lv.

FETTER, C.W. Applied hydrogeology. New Jersey: Prentice Hall, 1994.

FLEEMING, G. Computer simulation techniques in hydrology. New York: Elsevier, 1975. 333p.

FREAD, D.L. Flow Routing. In: MAIDMENT, D.R. (Ed.) Handbook of hydrology. New York: McGraw-Hill, 1993. cap.10. lv.

FREAD, D.L. Channel routing. In: ANDERSON, M.G.; BURT,T.P. (Ed.) Hydrological forecasting. Chichester:Jonh Wiley \& Sons, 1985. p.437-503.

GANDOLFI, C.; BISCHETTI, G.B. Influence of the drainage network identification method on geomorphological properties and hydrological response. Hydrological Processes, v.11, p.353-375, 1997.

GARBRECHT, J.; MARTZ, L. Grid size dependency of parameters extracted from digital elevation models. Computers and Geosciences, v.20, p.85-87, 1994.

GARBRECHT, J.; MARTZ, L. Network and subwatershed parameters extracted from digital elevation models - the Bills Creek experience. Water Resources Bulletin, v.29, p.909-916, 1993.

GENOVEZ, A. B. Avaliação dos métodos de estimação das vazões de enchente para pequenas bacias rurais do estado de São Paulo. Campinas, 1991. 248p. Tese (LivreDocência) - Universidade Estadual de Campinas. 
GROVE, M.; HARBOR, J.; ENGEL, B. Composite vs. Distributed curve numbers: effects on estimates of storm runoff dephts. Journal of the American Water Resources Association, v.34, n.5 p.1015-1023, 1998.

HAWKINS, R. H. Runoff curve numbers from partial area water-sheds. Journal of Irrigation and Drainage Engineering, v.105, n.4, p.375-389, 1979.

HAWKINS, R.H. Asymptotic determination of runoff curve numbers from data. Journal of Irrigation and Drainage Engineering, v.119, n.2, p.334-345, 1993.

HAWKINS, R.H. Improved prediction of storm runoff in mountain watersheds. Journal of Irrigation and Drainage Engineering, v.99, 11.4, p.519-523, Dec. 1973.

HAWKINS, R.H; CATE, A. J. Secondary influences in curve number rainfallrunoff. Jul. 21, 1998. (http://www.wcc.nrcs.usda.gov/water/quality/common/ techpapers/)

HAWKINS, R. H; HJELMFELT, A.T.; ZEVENBERGEN Runoff probability, storm depth, and curve numbers. Journal of Irrigation and Drainage Engineering, v.111, n.4, p.330-340, 1985 .

HEC-USACE. HEC-1 flood hydrograph package: user's Manual. Davis: USACE/HEC, 1998a. 295p.

HEC-USACE. Hydrologic modeling system: HEC-HMS - user's manual, version 1.0. Davis: USACE/HEC, 1998b. Iv.

HEC-USACE. Hydrologic modeling system: HEC-HMS - technical reference manual. Washington: USACE/HEC, 2000. 149p. 
HELLWEGER, F.; MAIDMENT, D. R. Definition and connection of hydrologic elements using geographic data. Journal of Hydrologic Engineering, v.4, n. 1., Jan. 1999.

HELLWEGER, F. MAIDMENT, D.R. HEC-PREPRO a GIS preprocessor for lumped parameter hydrologic modeling programs. Austin-Texas CRWR/University of Texas, 1997. (•CRWR Online Report 97-8) http://www.crwr.utexas.edu/online.html

HELLWEGER, F. MAIDMENT, D.R. HECPREPRO - User's Guide and Reference Manual. (Version 4.0.av). 1997. (http://www.ce.utexas.edu/maidment/gishyd97/)

HEWLETT, J. D. Principles of forest hydrology. Athens: University of Georgia, 1981. 191p.

HEWLETT, J.D.; HIBBERT, A.E. Factors affecting the response of small watersheds to precipitation in humid areas. In: INTERNATIONAL SYMPOSIUM ON FOREST HYDROLOGY. Pennsylvania, 1965. Proceedings. Pennsylvania: Penr jylvania State University, 1967. p.275-290.

HORTON, R.E. The role of infiltration in the hydrologic cycle. Transations of American Geophysics Union, v.12, p.189-202, 1933.

IBGE. Carta do Brasil: Itatinga. São Paulo: IBGE/DAEEE, 1973. Folha SF-22-Z-DII-2, Escala 1:50.000.

JACKSON, T. J. Application and selection of hydrologic models. In : HAAN, C.T.; JOHNSON, H.P.; BRAKENSIEK, D.L. (Eds.). Hydrologic modeling of small watersheds. St. Joseph: ASAE, 1982. cap. 12, p.475-504. 
JENSEN, S.K.; DOMINGUE, J.O. Extracting topographic structure from digital elevation data for geographic information system analysis. Photogrammetric Engineering and Remote Sensing, v.54, n.11, p.1593-1600, 1988.

KARNIELI, A. Stepwise overlay approach for utilizing a GIS with a soil moisture accounting model. ITC-Journal, n.1, p.11-18, 1991.

KOBIYAMA, M. Influência da minhoca louca (Amyntas ssp. Rosa, 1891) sobre o movimento de água no solo, relacionado ao crescimento da Bracatinga (Mimosa scabrela Benth) Curitiba, 1994. 132p. Tese (Doutorado) - Universidade Federal do Paraná.

KOBIYAMA, M; GENZ, F.; MEDIONDO, E.M. Geo-bio-hidrologia In: FORUM GEO-HIDRO-BIOLOGIA, 1., Curitiba, 1998. Anais. Curitiba: UFPR, 1998. p.125.

La BARBERA, P.; LANZA, L.; SICCARDI, F.; NACHNEBEL, H.P. Hydrologically oriented GIS and application to rainfall-runoff distributed modelling: case study of Amo basin. In: Application of geographic information systems in hydrology and water resources management. Wallingford-UK: IAHS, 1993. p.171-179.

LAL, R. Role of mulching techniques in tropical soil and water management. Ibadan: International Institute of Tropical Agriculture, 1974. 37p. (Technical Bulletin, 1)

LIMA, W.P. Princípios de hidrologia florestal para o manejo de bacias hidrográficas. Sào Paulo: ESALQ/USP, 1986. 242p.

LIMA, W.P. Funçào hidrológica da mata ciliar. In: SIMPÓSIO SOBRE MATA CILIAR, Campinas, 1989. Anais. Campinas: Fundação Cargill. p.25-42. 
LIMA, W.P. Impacto ambiental do eucalipto. São Paulo: EDUSP, 1993.301 p.

LIMA, W.P.; MOREIRA, R.M.; SCARDUA, F.P.; MASETTO, A.V. Hidrologia de uma microbacia com cobertura de floresta de eucalipto com 50 anos de idade na Estação Experimental de Itatinga, estado de São Paulo. Scientia Florestalis, n.50, p.11-19, Dez. 1996.

LIMA, W.P.; ZAKIA, M.J.B. Indicadores hidrológicos em áreas florestais. Série Técnica IPEF, n.31, p.53-64, abr., 1998.

LINNARTZ, N.W; HSE, C.Y.; DUVAL, L. Grazing impairs, physical properties of a forest soil in Central Loisiana. Journal of F orestry, v.64, p.239-43, 1966.

LITTLEWOOD, I.G.; JAKEMAN; A.J. A new method of rainfall-runoff modelling and its applications in catchment hydrology. In: ZANNETTI, P. (Ed.) Environmental Modelling. Southampton: Computational Mechanics Publications, 1994. v.2, p.143171.

LITTLEWOOD, I.G.; JAKEMAN, A.J. Characterization of quick and slow streamflow components by unit hydrographs for single - and multi - basin studies. In: ROBINSON, M. Methods of hydrologic basin comparison. New York: Institute of Hydrology, 1992. p.99-111. (Report 120)

LOMBARDI NETO, F.; BELLINAZZI, R.J.; GALETI, P.A.;BERTOLINI.D.; LEPSCH,I.F.; OLIVEIRA, J.B. de Nova abordagem para cálculo de espaçamento entre terraços. In: LOMBARDI NETO,F; BELLINAZZI JUNIOR, F. (Coord) Simpósio sobre terraceamento agrícola. Campinas: Fundação Cargill, 1989. p.99124. 
MAGUIRE, D. J. An overview and definition of GIS. In: MAGUIRE, D. J.; GOODCHILD, M. F.; RHIND, D. W. Geographical information systems: principles. London: Longmann Scientific \& Technical, 1991. v.1 p.9-20.

MAIDMENT, D.R. Developing a spatially distributed unit hydrograph by using GIS. In: KOVAR, K.; NACHTNEBEL, H.P. (Eds.) Application of gegraphic information systems in hydrology and water resources management. Wallingford: IAHS, 1993a. p.181-192. (IAHS, Publication n. 211)

MAIDMENT, D.R. GIS and hydrologic modeling. In: GOODCHILD, M.F.; PARKS, B.O.; STEYAERT, L.T. (Eds.) Environmental modeling with GIS. New York: Oxford University, 1993b. p.147-167.

MAIDMENT, D. R. (Ed.) Handbook of Hydrology. New York:McGraw-Hill, 1993. lv.

MAIDMENT, D.R.; OLIVERA, F.; CALVER, A.; EATHERRAL, A.; FRACZEK, W. A unit hydrograph derived from a spatially distributed velocity field. Hydrologic Processes, v.10, n.6, p.831-844, 1996a.

MAIDMENT, D.R.; OLIVERA, F.; YE, Z.; REED, S.; McKINNEY, D.C. Water balance of the Niger Basin. In: NORTH AMERICAN WATER AND ENVIRONMENT CONGRESS, Anaheim, 1996. Proceedings. Anaheim: ASCE, 1996b.

McCUEN, R. H.; SNYDER, W. M. A proposed index for comparing hydrographs. Water Resources Research, v.11, n. 6, p.1021-1024, 1975.

MEDIONDO, E.M.; TUCCI, C. Escalas hidrológicas. Revista Brasileira de Recursos Hidricos, v.2, n. 1, p.59-122, Jan./Jun. 1997. 
MIRANDA, J.C. Interceptação de chuvas pela vegetação florestal e serrapilheira nas encostas do maciço da Tijuca: Parque Nacional da Tijuca. Rio de Janeiro, 1992. 100p. Dissertação (M.S.) - Universidade Federal do Rio de Janeiro.

MOCKUS, V. Estimation of total (peak rates of) surface runoff for individual storms. Exhibit A of Appendix B, Interim Survey Rep. 1949.

MONTGOMERY, D.R.; FOUFOULA-GEORGEOU, E. Channel network source representation using digital elevation models. Water Resources Research, v.29, n.12, p.3925-3934, 1993.

MOORE I.D.; GRAYSON, R.B. Terrain-based catchment partitioning and runoff prediction using vector elevation data. Water Resources Research, v.27, n.6, p.1177-1191, Jun. 1991.

MUSIK, I. Derivation of unit and flood hydrographs using GIS. Enviromental Monitoring and Assessment, v.23, n.1, p.45-56, 1992.

MUSIK, I. Application of GIS to SCS procedure for design flood hydrographs. In: INTERNATIONAL SYMPOSIUM OF MODELING AGRICULTURAL, FOREST, AND RANGELAND HYDROLOGY, Chicago, 1988. Proceedings. St. Joseph: ASAE, 1988. p.494-500. (ASAE Publication 07-88)

MUSIK, I.; POMEROY, S. J. A geographic information system for prediction of design flood hydrographs. Canadian Journal of Civil Engineering, v.17, p.965-973, 1990.

NASH, J.E. The form of the instantaneous unit hydrograph. IASH Publication, v.3-4, n. 45, p.114-121, 1957. 
OLIVERA, F. Calculation of hydrologic parameters using CRWR-PREPRO. University of Texas: Austin, 1998 (Apresentação em slides http://www.ce.utexas.edu/prof/ olivera/prepro/prepro.htm).

OLIVERA, F. CRWR-PREPRO: A system of GIS tools for HEC-HMS modeling support. In: ANNUAL ESRI INTERNATIONAL USERS CONFERENCE, $19^{\text {th }}$ San Diego, 1999. (Apresentação em slides http://www.ce.utexas.edu/prof/olivera/prepro/ prepro.htm).

OLIVERA, F.; MAIDMENT, D.R. Runoff computation using spatially distributed terrain parameters. In: NORTH AMERICAN WATER AND ENVIRONMENT CONGRESS, Anaheim, 1996. Proceedings. Anaheim: ASCE, 1996.

OLIVERA, F.; REED, S.; MAIDMENT, D.R. HEC-PrePro v. 2.0: an ArcView preprocessor for HEC's hydrologic modelingc system. In: ESRI INTERNATIONAL USERS CONFERENCE, 18., San Diego, 1998. Proceedings. San Diego: ESRI, 1998. (http://www.ce.utexas.edu/prof/olivera/esri98/p400.htm).

OLIVERA, F; MAIDMENT, D.R. Gis Tools for HMS modeling support. In: ANNUAL ESRI INTERNATIONAL USERS CONFERENCE, 19 San Diego, 1999. Proceedings. San Diego: ESRI, 1999. (http://www.ce.utexas.edu/prof/olivera/ esri99/p801.htm).

OLIVERA, F.; MAIDMENT, D.R.; CHARBENEAU, R.J. Spatially distributed modeling of storm runoff and non-point source pollution using geographic information systems, Center for Research in Water Resources, The University of Texas at Austin, 1996.(CRWR Online Report 96-4) http://www.crwr. utexas.edu/online.html. 
PESSOA, M. L. Hidrometeorologia com radar. In: TUCCI, C.E.M. (Org.) Hidrologia: ciência e aplicação. Porto Alegre: UFRGS/ABRH/EDUSP,1993. p.877-914. (Coleção ABRH de Recursos Hídricos, v. 4)

PESSOA, M.C.P.Y; LUCHIARI JUNIOR, A; FERNANDES, E.N.; LIMA, M.A. Principais modelos e simuladores utilizados para análise de impactos ambientais das atividades agrícolas. Jaguariúna, SP:EMBRAPA/CNPMA, 1997. 83p. (Embrapa-CNPMA. Documentos, 8).

PESSOTTI, F.E.S. Levantamento detalhado dos solos do Horto de Itatinga. Piracicaba: ESALQ/Departamento de Ciências Florestais. 1994. 105p. (não publicado)

PETERS, J. The HEC hydrologic modeling system. In: ANNUAL AMERICAN WATER RESOURCES ASSOCIATION CONFERENCE AND SYMPOSIUM, 31 ., Houston, 1995. Proceedings. Houston: HEC, 1995.

PETERS, J.; EASTON, D. Runoff simulation using radar rainfall data. Water Resources Bulletin, v.32, n.4, p.753-760, 1996.

PETERS, J.; FELDMAN, A. Hydrologic modeling system. 1997. (http://www.wrc-hec. usace.army.mil/publications/pubs_distrib/tp-138/tp-138.html)

PILGRIM, D.H. Travel times and nonlinearity of flood runoff from tracer measurements on a small watershed. Water Resources Research, v.12, n.3, p.487496, Jun. 1976.

PILGRIM, D.H.; CORDERY, I. Flood runoff. In: Maidment, D.R. (Ed.) Handbook of Hyd rology. New York: McGraw-Hill, 1993. cap. 9. Iv. 
PILGRIM, D.H.; CORDERY, I; BARON, B.C. Effects of catchment size on runoff relationships. Journal of Hydrology, v.58, p.205-221, 1982.

PONCE, V. M. Engineering hydrology: principles and practices. New Jersey: Prentice-Hall, 1989. 640p.

PONCE, V.M.; HAWKINS R.H. Runoff curve number: has it reached maturity? Journal of Hyd rologic Engineering, v.1, n.1, p.11-19, 1996.

PREVEDELLO, C.L.; BORDIGNON, J.M.T.; MARTINS, K. CAVICHIOLO. Avaliação da influência da minhoca louca (Amynthas spp. Rosa, 1891) sobre a redistribuição da água no solo, através de um modelo de simulação numérica. In: REUNIÃO BRASILEIRA DE MANEJO E CONSERVAÇÃO DO SOLO E DA ÁGUA, 12, Fortaleza, 1998. Resumos. Ceará: SBCS, 1998. p.342-343.

QUINN, P.; BEVEN, K.; CHEVALLIER, P.; PLANCHON, O. The prediction of hillslope flow paths for distributed hydrological modelling using digital terrain models. Hydrological Processes, v.5, p.59-79, 1991.

QUINN, P.; BEVEN, K.; LAMB, R. The ln (a/tanb) index: how to calculate it and how to use it within the TOPMODEL framework. Hydrological Processes, v.9, p.161$182,1995$.

RAGAN, R.M.; DURU, J.O. Kinematic wave nomograph for time of concentration. Journal of the Hydraulics, v.98, n.10, p.1765-1771, 1972.

RAMSER, C.E. Runoff from small agricultural areas. Journal of Agricultural Research, v.34, n.9, p.797-823, 1927. 
RIGHETTO, A M. Hidrologia e recursos hídricos. São Carlos: EESC/USP, 1998. 840 p.

ROTH, C.H. Infiltração de água no solo em relação a sua suscetibilidade à erosão. In: DERPSCH, R.; SIDIRAS, N.; ROTH, C.H. Estudos e desenvolvimento de sistema de rotação de culturas incluindo espécies de cobertura verde e métodos de preparo do solo. Londrina: IAPAR, 1984. p.75-98.

RODRIGUEZ-ITURBE, I.; VALDES, J.B. The geomorphologic structure of hydrologic Response. Water Resources Research, v. 15, n.6, p.1409-1420, Dec. 1979.

RUTTER, A.J. Water consumption by forests. In: KOZLOWSKI, T.T. Water deficits and plant growth. New York:Academic Press, 1968. p.23-84.

SÁ, J. F. de; RISSO, A.; HAERTHEL, V. Uma avaliação das metodologias para extração de informações topográficas utilizando um modelo numérico do terreno e o algoritmo de um modelo hidrológico distribuído. In: SIMPÓSIO BRASILEIRO DE SENSORIAMENTO REMOTO, 7., 1993. Anais. p.252-260

SÃO PAULO (Estado). Plano Cartográfico do Estado de São Paulo. São Paulo: Secretaria de Economia e Planejamento, Coordenadoria de Ação Regional, Divisão de Geografia, $1^{a}$ ed., 1979. Folhas: SF-22-Z-D-II-2-NO-B (Córrego do Lobo), SF22-Z-D-11-2-NE-A (Ribeirão das Pedras), SF-22-Z-D-11-2-NE-C (Fazenda Toca) e SF-22-Z-D-1 1-2-N-D (Córrego Potreirinho); Escala 1:10.000.

SÃO PAULO (Estado). Levantamento topográfico do Projeto de Microbacia. :Piracicaba:Escola Superior de Agricultura "Luiz de Queiroz", ESALQ/USP, Departamento de Engenharia Rural, Seção de Topografia e Geoprocessamento, 1994. Escala 1:4.000. 
SÃO PAULO (Estado). Acervo de imagens digitais da Estação Experimental de Itatinga (compact disc). Piracicaba: Estaçào Experimental de Itatinga/Departamento de Ciências Florestaisl/Escola Superior de Agricultura "Luiz de Queiroz"/USP, 1999.

SCARDUA, F.P. Caracterizaçào hidrológica de uma microbacia hidrográfica experimental da Estação Experimental de Ciências Florestais de Itatinga, ESALQ/USP. Piracicaba, 1994. 93p. Dissertaçào (M.S.) - Escola Superior de Agricultura "Luiz de Queiroz", Universidade de Sào Paulo.

SKAGGS, R.W.; KHALEEL, R. Infiltration, hidrologic modeling of small watershead. St.Joseph: American Society of Agricultural Engineers, 1982.

SCHNEIDER, P.R.; GALVĂO, F.; LONGHI, S.J. Influência do pisoteio de bovinos em áreas florestais. Revista Floresta, v.9, n.1, p.19-23, 1978.

SELBY, M.J. Hillslope materials na processes. New York: Oxford University, 1993. $464 \mathrm{p}$.

SETZER, J.; PORTO, R.L.L. Tentativa de avaliação do escoamento superficial de acordo com o solo e o seu recobrimento vegetal nas condições do estado de Sào Paulo. Boletim Técnico DAEE, v.2, n.2, p.81-104, 1979.

SHERMAN, L. K. The Unit Hydrograph Method. In: MEINZER, O. E. (ed) Physics of the Earth. New York: McGraw-Hill, 1949. IX, lv.: Hydrology.

SIMAS, M.J.C. Lag times characteristics in small watersheds in the United States. Arizona, 1996. 170p. Dissertation (Ph.D.) - University of Arizona. 
SINGH, V.P. Hydrologic systems: rainfall-runoff modeling. New Jersey: Prentice Hall, 1988.

SINGH, V.P.; AGIRALIOGLU, N. Lag time for diverging overland flow. Nordic Hydrology, v.13, p.39-48, 1982.

SMITH, P.N.H. Hydrologic data development system. Austin, 1995. 235p. Thesis (M.Sc.) - University of Texas.

SMITH, M. B.; BRILLY, M. Automated grid element ordering for GIS based overland flow modelling. Photogrammetric Engineering and Remote Sensing, v.58, n.5, p.579-585, 1992.

SNYDER, F.F. Syntetic unit graphs. Americam Geophysical Union Transactions, v.19, p.447-454, 1938.

STEENHUIS, T.S.; WINCHELL, M.; ROSSING, J.; ZOLLWEG, J.; WALTER, M.F. SCS runoff equation revisited for variable-source runoff areas. Journal of Irrigation and Drainage Engineering, v.121, n.3, p. 344-345, 1995.

STEINER, J.L.; KANEMASU, E.T.; CLARCK, R.N. Spray losses and partitioning of water under a center-pivot sprinkler system. Transaction of the ASAE, v.26, n.4, p.1128-1134, 1983.

STOECKELLER, J.H. Trampling by livestock reduces infiltration rate of soil in a oak and pine woods in southwestern Wisconsin. Wisconsin: Lake States Forest Experiment Station, 1959. 2p. (Technical Note, 556)

STRAHLER, A.N. Quantitative analysis of watershed geomorphology. American Geophysical Union Transactions, v.38, p.913-920, 1957. 
STUEBE, M.M.; JOHNSTON, D. M. Runoff volume estimation using GIS techniques. Water Resources Bulletin, v.26, n. 4, p.611-620, 1990.

SUI, D.Z.; MAGGIO, R.C. Integrating GIS with hydrological modeling: pratices, problems and prospects. Computers, Enviromental and Urban Sistems Pergamon, v.23, p.33-51, 1999.

TARBOTON, D.G. A new method for the determination of flow directions and upslope areas in grid digital elevation models. Water Resources Resea rch, v.33, n.2, p.309319, Feb. 1997.

THOMPSON, J.R. Effect of grazing on infiltration in a western watershed. Journal of Soil and Water Conservation, v.23, n.2, p.63-65, 1968.

TROENDLE, C. A. Variable source area models. In: ANDERSON, M.G.; BURT,T.P. (Ed.) Hydrological forecasting. Chichester:Jonh Wiley \& Sons, 1985. p.347-403.

TSUKAMOTO, Y. Storm discharge from an experimental watershead. Journal of Japan Society Forest, v.45, p.186-190, 1963.

TUCCI, C.E.M. Escoamento superficial. In: TUCCI, C.E.M. (Org.) Hid rologia: ciência e aplicação. Porto Alegre: UFRGS/ABRH/EDUSP, 1993. p.391-441. (Coleção ABRH de Recursos Hídricos, v. 4)

TUCCI, C.E.M.; CLARKE, R.T. Impacto das mudanças da cobertura vegetal no escoamento: Revisão In: FORUM GEO-HIDRO-BIOLOGIA, 1., Curitiba, 1998. Anais. Curitiba: UFPR, 1998. p.39-49. 
USDA. Soil Conservation Service. Hydrology. In: ESTADOS UNIDOS. Soil Conservation Service. National Engineering Handbook. Washington: USDA, 1972. Section 4.

USDA. Soil Conservation Service. A method for estimating volume and rate of runoff in small watersheads. Washington: USDA, 1973. 21p. (SCS-TP-149)

USDA. Soil Conservation Service. Hydrology. In: ESTADOS UNIDOS. Soil Conservation Service. National Engineering Handbook. Washington: USDA, 1986. Section 4.

USDA. Natural Resources Conservation Service. Urban hydrology for small watersheads. TR-55. 2 ed. Washington: USDA, 1996. Iv. (Technical Release 55) (http://www.ftw.nrcs.usda.gov)

USDA. Natural Resources Conservation Service. Hydrology. In: ESTADOS UNIDOS. Natural Resources Conservation Service. National Engineering Handbook. Washington: USDA, 1997. Part 630. (http://www.ftw.nrcs.usda.gov)

VALENTE, O P.; CASTRO, P.S.E; VIEIRA, H.. A.; PAULA NETO, F. de. Estudos sobre infiltração de água no solo em povoamentos de Pinus atrobus var. chiapensis E. Bombax. Revista Árvore, v.3, n.1, p.88-93, 1979.

VIEIRA, V. F.; EMERICH, K.H. Importância do geoprocessamento no mapeamento de microbacias hidrográficas. Revista Agropecuária Catarinense, v.5, n.4, Dez. 1992.

VIEUX, B.E. Agregation and smoothing effects on surface runoff modeling. Journal of Computing in Civil Engineering, v.7, n.3, p.310-338, Jul. 1993. 
VIEUX, B.E.; NEEDHAM, S. Nonpoint-polluition model sensitivity to grid-cell size. Journal of Water Resources Planning and Manegment, v. 119, n.2; p.141-157, Mar./Apr. 1993.

VILELLA, M.V.; MATTOS, A. Hidrologia aplicada. São Paulo: McGraw-Hill do Brasil, 1975. 245p.

WANG, X; YIN, Z.Y. A comparison of drainage networks derived from digital elevation models at two scales. Journal of Hydrology, v.210, p.221-241, 1998.

WARD, R.C. Principles of hydrology. London: McGraw-Hill Book Company, 1975.

WEYMAN, D. Throughflow on hillslopes and its relation to the stream hydrograph. Bulletin of International Association of Scientific Hydrology, v.15, n.2, p.25-33, 1970.

WOLOCK, D.M.; McCABE JR., G.J. Comparison of single and multiple flow direction algorithms for computing topographic parameters in topmodel. Water Resources Research, v.31, n.5, p.1315-1324, 1995.

WOOD, M. K; BLACKBURN, W.H. An evaluation of the hydrologic soil groups as used in the SCS runoff method on rangelans. Water Resources Bulletin, v.20, p.379-389, 1984. 
WOOLHISER, D. A.; BRAKENSIEK, D. L. Hydrologic modeling of small watershead. In: HANN, C. T.; JOHNSON, H. P. ; BRAKENSIEK, D. L. (Eds.) Hydrologic modeling of small watersheds. St. Joseph: ASAE, 1982. p.3-16. (ASAE Monograph)

YOUNG, R.A.; ONSTAD, C.A.; BOSH, D.D., ANDERSON, W.P. AGNPS: a nonpoint source pollution model for evaluation agricultural watersheds. Journal of Soil and Water Conservation, p.168-173, Mar./Apr. 1989. 